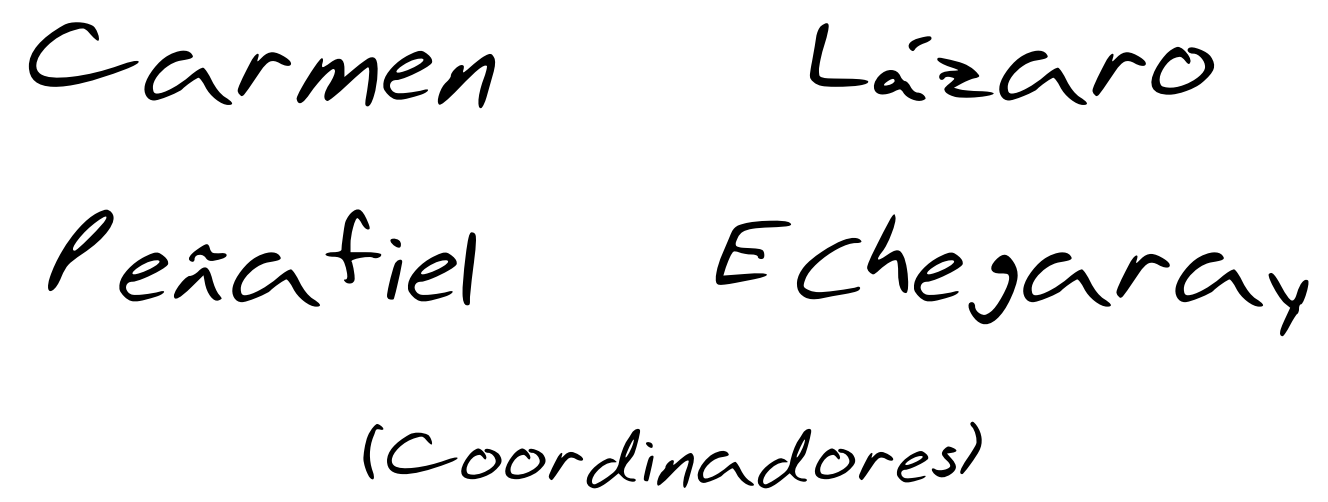

\title{
Estudios de Comunicación y Salud
}

Prólogo de Fermín Apezteguia

José Luis Terrón Blanco, Carlos David Santamaría Ochoa, Blanca Guadalupe Cid de León Bujanos, Flor Micaela Ramírez Leyva, Leticia Castillo Quiñónez, Paloma López Villafranca, Daniel Catalán Matamoros, José Cerdán de las Heras, Pablo Medina Aguerrebere, Elena López Parra, Concepción Álvarez Herrero, Paloma Elviro García, Lázaro Echegaray Eizaguirre, Milagros Ronco López, Idoia Camacho Markina, Carmen Peñafiel Saiz, José Mari Pastor González,

Cuadernos Artesanos de Comunicación, CAC / 63

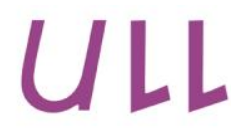

Universidad de La Laguna

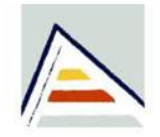

Universitat d'Alacant Universidad de Alicante

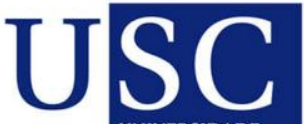

UNIVERSIDADE DE SANTIAGO

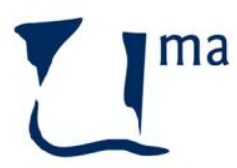

UNIVERSIDAD DE MÁLAGA

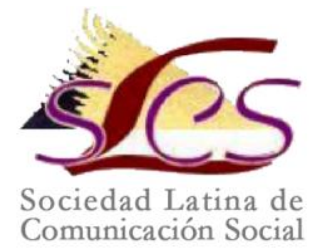




\section{Cuadernos Artesanos de Comunicación \#63 - Comité Científico}

Presidencia: José Luis Piñuel Raigada (UCM)

Secretaría: Concha Mateos (URJC)

- Bernardo Díaz Nosty (Universidad de Málaga, UMA)

- Carlos Elías (Universidad Carlos III de Madrid, UC3M)

- Javier Marzal (Universidad Jaume I, UJI)

- José Luis González Esteban (Universidad Miguel Hernández de Elche, UMH)

- José Luis Terrón (Universidad Autónoma de Barcelona, UAB)

- José Miguel Túñez (Universidad de Santiago, USC)

- Juan José Igartua (Universidad de Salamanca, USAL)

- Julio Montero (Universidad Complutense de Madrid, UCM)

- Marisa Humanes (Universidad Rey Juan Carlos, URJC)

- Miguel Vicente (Universidad de Valladolid, UVA)

- Miquel Rodrigo Alsina (Universidad Pompeu Fabra, UPF)

- Núria Almiron (Universidad Pompeu Fabra, UPF)

- Ramón Reig (Universidad de Sevilla, US)

- Ramón Zallo (Universidad del País Vasco, UPV/EHU)

- Victoria Tur (Universidad de Alicante, UA)

\section{(2) $(1) \Theta(\Theta$}

* Este libro y cada uno de los capítulos que contiene, así como las imágenes incluidas, si no se indica lo contrario, se encuentran bajo una Licencia Creative Commons Atribución-No Comercial-Sin Derivadas 3.0 Unported. Puede ver una copia de esta licencia en http://creativecommons.org/licenses/by-ncnd/3.0/ Esto significa que Ud. es libre de reproducir y distribuir esta obra, siempre que cite la autoría, que no se use con fines comerciales o lucrativos y que no haga ninguna obra derivada. Si quiere hacer alguna de las cosas que aparecen como no permitidas, contacte con los coordinadores del libro o con el autor del capítulo correspondiente.

* Queda expresamente autorizada la reproducción total o parcial de los textos publicados en este libro, en cualquier formato o soporte imaginables, salvo por explícita voluntad en contra del autor o autora o en caso de ediciones con ánimo de lucro. Las publicaciones donde se incluyan textos de esta publicación serán ediciones no comerciales y han de estar igualmente acogidas a Creative Commons. Harán constar esta licencia y el carácter no venal de la publicación.

* La responsabilidad de cada texto es de su autor o autora. 


\section{Carmen Peñafiel y Lázaro Echegaray \\ (Coordinadores)}

Prólogo de Fermín Apezteguia

\section{Estudios de Comunicación y Salud}

José Luis Terrón Blanco, Carlos David Santamaría Ochoa, Blanca Guadalupe Cid de León Bujanos, Flor Micaela Ramírez Leyva, Leticia Castillo Quiñónez, Paloma López Villafranca, Daniel Catalán Matamoros, José Cerdán de las Heras, Pablo Medina Aguerrebere, Elena López Parra, Concepción Álvarez Herrero, Paloma Elviro García, Lázaro Echegaray Eizaguirre, Milagros Ronco López, Idoia Camacho Markina, Carmen Peñafiel Saiz, José Mari Pastor González

Cuadernos Artesanos de Comunicación, CAC /63

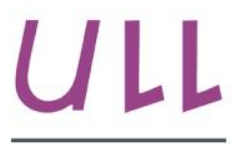

Universidad de La Laguna

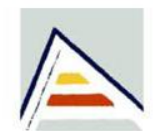

Universitat d'Alacant Universidad de Alicante
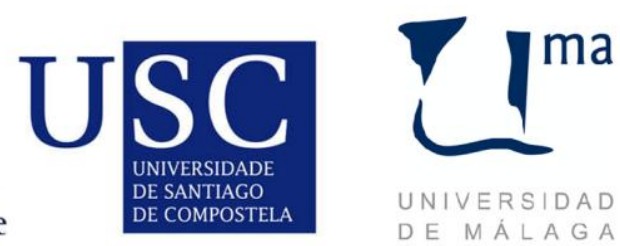

UNIVERSIDAD $D E M A L A G A$

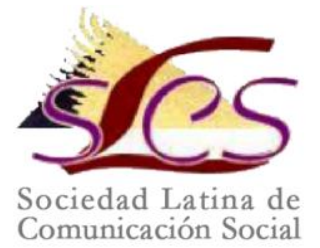




\section{CAC $63^{\circ}$ - Estudios de comunicación y salud}

Carmen Peñafiel Saiz y Lázaro Echegaray Eizaguirre (Coordinadores) José Luis Terrón Blanco, Carlos David Santamaría Ochoa, Blanca Guadalupe Cid de León Bujanos, Flor Micaela Ramírez Leyva, Leticia Castillo Quiñónez, Paloma López Villafranca, Daniel Catalán Matamoros, José Cerdán de las Heras, Pablo Medina Aguerrebere, Elena López Parra, Concepción Álvarez Herrero, Paloma Elviro García, Lázaro Echegaray Eizaguirre, Milagros Ronco López, Idoia Camacho Markina, Carmen Peñafiel Saiz, José Mari Pastor González

\section{Prólogo: Fermín Apezteguia}

Precio social: $8,25 € \mid$ Precio en librería. 10,75€ |

Editores: Javier Herrero, Alberto Ardèvol Abreu y Fernando Sánchez Pita Diseño: F. Drago

Ilustración de portada: Fragmento del cuadro Esta tarde de Sol, de Barca (Buenos Aires, 2003).

Imprime y distribuye: F. Drago. Andocopias S. L. c/ La Hornera, 41. La Laguna. Tenerife. Teléfono: 922250554 | fotocopiasdrago@telefonica.net

Edita: Sociedad Latina de Comunicación Social - edición no venal - La Laguna (Tenerife), 2014 - Creative Commons

(http://www.revistalatinacs.org/09/Sociedad/estatutos.html)

Catálogo $=\underline{\text { http: } / / \text { www. cuadernosartesanos.html }}$

Protocolo de envío de manuscritos con destino a CAC: http://www.cuadernosartesanos/protocolo.html

Descargar el $p d f$ : http://www.cuadernosartesanos.org/\#63

ISBN - 13: 978-84-15698-65-4

DL: TF-412-2014 


\section{Índice}

Prólogo La comunicación entre médicos y sanguijuelas Fermín Apezteguia

1. El tratamiento del VIH y del sida en los medios impresos dominicanos José Luis Terrón Blanco

2. Comunicar la salud: estrategias auxiliares en capacitación para grupos de pacientes con diabetes mellitus Carlos David Santamaría Ochoa y Blanca Guadalupe Cid de León Bujanos ...... 37

3. Representaciones y comunicación en agentes de psicología clínica. Escenarios de exclusión social en salud mental Flor Micaela Ramírez Leyva y Leticia Castillo Quiñónez ................. 55

4. Las asociaciones de pacientes con Enfermedades Raras generan conocimiento en la red Paloma López Villafranca ...... 69

5. Innovación y retos en la comunicación online con los usuarios de un hospital Daniel Catalán Matamoros y José Cerdán de las Heras .................................................. 87

6. Gestión de la comunicación interna en hospitales Pablo Medina Aguerrebere ....................................... 103

7. Comunicación en el ámbito sanitario Elena López Parra, Concepción Álvarez Herrero y Paloma Elviro García ............. 125

8. Metodología para el análisis de webs de salud dirigidas a jóvenes Lázaro Echegaray Eizaguirre, Milagros Ronco López e Idoia Camacho Markina ........................................... 147

9. La información de salud en el universo web dirigida a la juventud: entre profiláctica y educativa Carmen Peñafiel Saiz, José Mari Pastor González e Idoia Camacho Markina .................. 169

Los autores 


\section{Abstract}

Los estudios sobre Comunicación y Salud son cada vez más numerosos y diversos. Los medios de comunicación se convierten en espacios comunicacionales donde interactúan periodistas, médicos y ciudadanos. La información de salud en la sociedad contemporánea está dentro de las políticas sociales y, por ello, debemos de cuidar estos contenidos en los medios ya que el periodismo de salud puede aportar importantes beneficios para el bienestar de una sociedad. La comunicación debe constituir un apoyo fundamental para el logro de los objetivos en la información de salud y atención sanitaria, con la práctica de un periodismo de calidad. Nuestro objetivo en este libro, entre otros, trata de revalorizar esta información especializada.

Las nuevas tecnologías han modificado la forma de entender la salud, tanto desde la perspectiva de los pacientes como de los facultativos y de los profesionales de la información. Internet es una gran fuente de comunicación entre los diferentes sectores implicados en la divulgación y difusión de la información científica porque más del $80 \%$ de los internautas acuden a la web para resolver dudas. Nos encontramos en una nueva dimensión educomunicativa en salud, a la que intentamos adaptarnos y en la que la nueva generación de pacientes, mucho más activos y sobreinformados, demandan información precisa y autorizada también en la Red. Por su parte, el colectivo sanitario está en pleno proceso de aprendizaje para adaptar el sistema de salud a la nueva generación de pacientes. Este interés creciente por la información de salud, tanto en los medios tradicionales como en los medios digitales, se debe en gran parte a un mayor nivel de educación sanitaria de periodistas y lectores. En esta obra se recogen estudios rigurosos sobre prevención de salud, enfermedades, atención sanitaria y salud 2.0. Son síntesis de investigaciones que tienen la finalidad de aportar resultados y en algunos casos de intervención social.

\section{Keywords}

Información, salud, educomunicación, Internet, medicina, enfermedades, pacientes, atención sanitaria, prevención en salud, medios de comunicación social. 


\section{Prólogo}

\section{La comunicación entre médicos y sanguijuelas}

Dor MUCHO que me miro al espejo, no me veo. Remiro, observo, fuerzo la vista, incluso la echo hacia atrás a ver si encuentro algo, pero nada. Ni rastro del buitre, de la sanguijuela, ni mucho menos del 'vendemadres'. Simplemente no lo veo. Da la impresión de que no queda más remedio que apechugar con los tópicos que, a fuerza de repetirse, ejercen su labor de lluvia fina y van calando como certezas. Pero no es así. Reniego y doy un paso al frente: soy periodista, estoy especializado en Salud y me siento orgulloso de mi trabajo y de mi profesión.

Un paciente entra en la consulta de su médico y le dice: «Mire doctor, estoy preocupado porque me ha salido un sarpullido por todo el cuerpo. Me pica horriblemente, pero lo peor de todo es pensar que puede tratarse de algo grave. Me gustaría que me echara un vistazo, pero perdóneme un segundito... Lo tengo en la carpeta... ¡Aquí está! Me va a firmar usted este documento, que es una especie de consentimiento informado, por el que declara que, efectivamente, es cierto que es médico y se compromete a hacerme un diagnóstico certero. El punto tres se refiere al tratamiento, que deberá ajustarlo adecuadamente, sin posibilidad de margen de error; y en el cuarto admite que, efectivamente, me pagará una indemnización, previamente cuantificada, en el caso de que algo falle. Las tarifas se detallan en el punto cinco. ¿Sabe? No es que desconfíe de usted. Lo hago por mí. Me quedo más tranquilo».

Me cuesta imaginar la cara que se le quedaría a un médico si un paciente le abordara de esta manera. De lo que no me cabe duda es de cuál sería su reacción. Le echaría de la consulta directamente. Los periodistas, sin embargo, estamos acostumbrados a que los médicos nos reciban bajo la sombra de la sospecha. «iLos chicos de la Prensa... Me dais un miedo... Si no llega a ser por la gerencia, no te recibo, la 
verdad, que a mí esto de los periódicos no me convence demasiado. Se os cuenta una cosa y luego ponéis lo que os da la gana... Sí me gustaría ver previamente lo que vayas a publicar, porque luego, ¿sabes?, ahí va el nombre de uno y los colegas lo comentan... No es que desconfíe de usted, que lo hago por mí. Me quedo más tranquilo. Bueno, disponemos sólo de cinco minutos, porque tengo que trabajar. Todavía hoy me esperan como veinte pacientes o más. ¿Qué quería?»

Trabajar, sólo quería trabajar... Lamentablemente, esta última es una situación real. No ocurre siempre, pero sí con demasiada frecuencia. Si hay una profesión donde la población crea que, efectivamente, los tópicos son ciertos, ésa es la nuestra. La gente tiende a vernos como calaña, tipos más o menos vagos, vividores, amigos de la noche y la juerga más que de la responsabilidad y el trabajo; y dispuestos prácticamente a lo que sea con tal de conseguir una exclusiva. Ya digo, 'vendemadres'. No importa que la historia sea cierta. Interesa la sangre, el escándalo, la carnaza. Lo que nosotros llamamos la noticia.

La realidad, en cambio -que muchos médicos y científicos desconocen- es otra muy distinta. Nuestro trabajo diario se parece más al de un oficinista que al de los protagonistas de la mayoría de películas y series de televisión sobre periodistas. Es algo que aprendimos en primero de carrera y que, por fortuna y empeño, he comprobado personalmente en los últimos treinta años. Cada historia que contamos debe estar perfectamente contrastada y documentada. Tiene que ser así porque nuestro prestigio como empresa y como autores se juega cada día en los kioscos y a cada minuto en Internet. En el periodismo informativo, no hay espacio para el bulo o el rumor. Si lo que contamos no es cierto, si no damos un buen servicio de comunicación, los lectores dejarán de comprarnos, los anunciantes se irán y, tarde o temprano, nos quedaremos sin empleo. La información es algo muy serio y quizás más si cabe cuando de información científico-sanitaria se trata. De todo esto y mucho más trata el libro que tiene en sus manos.

El problema de científicos y médicos con los periodistas suele ser con frecuencia que pertenecemos a mundos tan distintos, que 
irremediablemente tenemos que chocar. El facultativo, como el científico, es un profesional cuya forma de pensar está condicionada por su trabajo diario. Sus decisiones son consecuencia de una profunda reflexión, que llega después de haber valorado todos los argumentos a favor y en contra de manera pormenorizada. A la hora de escribir elaboran textos largos, muy extensos, que son el resultado de meses, quizás años, de investigación y están invadidos por formas verbales cuyo uso se castiga con la pena máxima en cualquier redacción.

A los periodistas no nos valen los podrían, ni los quizás ni los 'todo apunta a que', porque la noticia es o sino no es noticia. Nuestra forma de trabajar es completamente distinta a la de los profesionales sanitarios. La actividad diaria en una redacción está marcada por la falta de tiempo, la necesidad de síntesis, por la obligación de tener que elaborar una información completa con premura. En muy poco tiempo tenemos la obligación de conseguir una noticia, una historia atractiva, con gancho, contrastarla, escribirla y publicarla. Quizás deba estar lista para su difusión en el plazo de una hora o menos, seguramente para el mismo día pero, como mucho, será para el fin de semana. Somos tan distintos médicos y periodistas como la noche y el día. Y, sin embargo, estamos obligados a entendernos.

Lo estamos porque vivimos en una sociedad envejecida, que está dispuesta a seguir envejeciendo y que demanda cada día más información, especialmente sanitaria. Si dos jóvenes desconocidos coinciden en un ascensor, hablan del tiempo; si son dos jubilados, lo hacen de su salud. «Discúlpeme... ¡Ay estas rodillas, que cada vez pueden menos!». Todo esto, traducido a cifras, supone que el número de personas con 60 años o más se ha duplicado en el mundo desde 1980, que fue ayer, y la Organización Mundial de la Salud prevé que de aquí al año 2050, que es mañana, alcance la cifra de los 2.000 millones. Casi un tercio de la población del planeta. La mayoría de esas personas mayores vive en países occidentales, son pacientes muy informados, cada día más, completamente distintos a lo que fueron sus padres, y demanda de sus gobernantes más y mejores servicios socio-sanitarios. Porque lo que les preocupa, además del futuro de sus hijos y nietos, es la atención de sus propias enfermedades crónicas: 
arterioesclerosis, artrosis, complicaciones respiratorias, cardiacas, cánceres, diabetes...

Como periodista especializado en salud, nunca se me ocurriría meterme en un quirófano para operarle a alguien de apendicitis. ¡Pobrecillo! No quiero ni pensarlo. ¿Por qué los médicos se empeñan entonces en enseñarnos a hacer nuestro trabajo? Y lo que es peor, ¿por qué pretenden revisar nuestros reportajes? Los periodistas podemos equivocarnos $\mathrm{y}$, de hecho, muchas veces lo hacemos; pero intentamos realizar nuestra tarea diaria con la mayor profesionalidad y dignidad posible. Como todo el mundo. ¿Quién no se equivoca también en su trabajo?

La sociedad que viene, la que ya está aquí, demanda una mayor colaboración entre médicos y periodistas, que es posible y necesaria. Los profesionales de la información necesitamos de los de la salud principalmente confianza, la misma confianza que cirujanos y especialistas piden a sus pacientes, que son nuestros lectores. Necesitamos también disponibilidad, la justa para que cuando salte la noticia, - «La UE da el visto bueno al tratamiento más revolucionario contra el cáncer de colon de las últimas décadas»- alguien al otro lado del teléfono nos asesore: «Eso es muy importante», o «no hagas caso, se trata de una estrategia comercial». Puestos a pedir, también queremos que nos hablen con claridad, sin tecnicismos, para que podamos explicar a nuestros pacientes de qué estamos hablando. Sí, señores médicos e investigadores, han leído bien. Trabajo en un periódico que tiene 450.000 pacientes lectores, a los que se suman los pacientes navegantes de la web y los millones de seguidores potenciales del resto de medios que forman el grupo Vocento. ¿Qué les parece si damos un meneo a la consulta?

¡Ah! Y tiempo. Resérvennos a los periodistas tiempo, el que sea necesario. Una buena información no se resuelve en cinco minutos. Serán necesarios veinte o, quizás media hora, que es el tiempo que un médico puede destinar a ver... ¿tres pacientes, cuatro, cinco? Veinte minutos de conversación, un buen reportaje bien presentado, puede convertirse en la mejor campaña de prevención de una enfermedad o, incluso, en la consecución de un nuevo servicio público para los pacientes que abarrotan una consulta. 
En este manual -práctico, ágil, entretenido y de fácil lectura- se analizan las necesidades de comunicación de los médicos y el nuevo protagonismo que los enfermos han alcanzado en la relación médicopaciente. Quizás el temor de los hombres y mujeres de ciencia a los periodistas - no niego que en alguna ocasión fundado- se deba a las habilidades a menudo poco desarrolladas que los facultativos tienen para comunicar, especialmente malas noticias. Pero es un hecho que los pacientes saben hoy de sus dolencias tanto como para llegar a poner en jaque a sus médicos con sus dudas y planteamientos. Según un estudio que se recoge en este libro, un $72 \%$ de ellos, que representan una mayoría abrumadora, da prioridad a la información sobre salud que le ofrecen en los medios, ya sean tradicionales o digitales. Detrás de todos esos artículos, seguramente de los más influyentes, están las manos de un profesional de la comunicación.

Quizás no seamos tan distintos médicos y periodistas. No me cabe duda de que si viajara en coche con un médico y nos encontráramos en la carretera con un accidente y un herido grave, él vería un paciente, y yo una noticia. Aun así, estoy convencido de que los dos, en cualquier caso, sabríamos que estamos ante una persona que sufre y necesita ayuda.

Cada mañana, antes de ir a trabajar, me coloco frente al espejo para anudarme la corbata o acomodarme la chamarra. Y, la verdad, nunca he visto frente a mí el reflejo de un buitre o de una sanguijuela. Más bien veo a un hombre, un marido, un padre, un hijo, un amigo, a tantas personas en una, incluido un periodista que se gana la vida escribiendo sobre la salud humana. Cuando hablo de enfermedades cardiovasculares, tumores y epidemias pienso en el mundo en que vivimos y las personas que amo, que a veces también se ponen malas. Los periodistas no vivimos en una urna de acero y cristal, inmunes al mundo que nos rodea. Recuerdo el ictus que acabó con mi madre, el alzhéimer que mató a mi padre, las veces que he tenido que acudir a Urgencias con mis hijos, los cánceres contra los que luchan algunas de las personas que más quiero. Busco la perfección y la humanidad en mi trabajo y así y todo, a veces, me equivoco. Como cualquiera.

Fermín Apezteguia 



\title{
El tratamiento del VIH y del sida en los medios impresos dominicanos
}

\author{
José Luis Terrón Blanco (Universitat Autònoma de \\ Barcelona)[@ORCID] [ G $\underline{\text { GS }}$ ]
}

\section{Resumen}

El texto que les presentamos a continuación pretende resumir la investigación El tratamiento del VIH/sida en los medios de comunicación escritos dominicanos: Diario Libre, El Caribe, El Dia, Hoy, Listín Diario y El Nacional (octubre 2012- marzo 2013), cuyo objetivo es averiguar qué tratamiento hacen los medios impresos dominicanos del VIH/sida, y si este tratamiento conlleva algún tipo de estigmatización implícita o explícita. Este estudio se enmarca, metodológicamente, en el análisis de contenido, tiene una finalidad de intervención social y forma parte de una serie de investigaciones, con similares características, que venimos realizando periódicamente en España y en México.

Palabras clave: VIH, sida, representación, prensa, República Dominicana, agenda informativa. 


\section{Introducción}

T A INVESTIGACIÓN de la que damos cuenta en estas páginas 1 forma parte de una serie de estudios que venimos realizando desde 2005 en el Observatorio de Comunicación y Salud y el InCom$\mathrm{UAB}$ en colaboración con otras instituciones y universidades $\mathrm{y}$, aunque son independientes en sí mismos, por lo que pueden leerse de manera autónoma, adquieren relieve por su capacidad de generar series e, incluso con la suficiente prudencia, realizar comparaciones.

Hasta la fecha, hemos realizado cuatro investigaciones en España ${ }^{1}$, una en México $^{2}$ y una en República Dominicana, junto a la Fundación Global Democracia y Desarrollo ${ }^{3}$ (FUNGLODE), de cuyos resultados damos cuenta en este capítulo. Obviamente, cada una de ellas se adapta a unos marcos geográficos (los ya reseñados) y temporales (como veremos, aunque sea brevemente, cuando nos refiramos a la metodología) y se configuran a partir del diálogo con la contraparte con la que hacemos cada una de las investigaciones.

En síntesis, podemos apuntar que con las investigaciones pretendemos saber de qué se trata y cómo y cuándo se escribe sobre el VIH o el sida, cuándo y cuánto se informa, de quiénes se habla, qué fuentes se utilizan (¿los miembros de la comunidad VIH/sida se utilizan como fuente?), cómo se informa (haciendo hincapié en la transmisión correcta o incorrecta de los mensajes y la terminología científica), con qué carácter, qué características tienen esas informaciones (género, sección, edición, autoría, etc.), si estigmatizan, si se da un tratamiento de género y que correlación establecen las

${ }^{1}$ Con el Observatorio de Derechos Humanos de la Red2002 (hoy RedVIH). ONG que a su vez es una coordinadora de ONG del ámbito del VIH/sida. ${ }^{2}$ Junto a un equipo de la Texas A\&M International University, liderado por el Dr. José Carlos Lozano.

${ }^{3}$ FUNGLODE es una institución privada sin fines de lucro dedicada a:

a) Formular propuestas innovadoras de naturaleza estratégica y coyuntural sobre temas relevantes para la República Dominicana.

b) Analizar y establecer la influencia de los fenómenos globales en el desarrollo nacional.

c) Contribuir a la elaboración de políticas públicas cruciales para la gobernabilidad democrática y el desarrollo sostenible de la República Dominicana. 
informaciones entre enfermedades oportunistas y VIH o sida, especialmente con la tuberculosis, dada su prevalencia entre los infectados con VIH.

Pero si nuestro objetivo es el saber cómo tratan los medios el VIH y el sida, nuestra finalidad es la de intervención social, y esa es una de las especificidades que diferencian a estas investigaciones de otras próximas en cuanto a los objetivos. Esa finalidad de intervención social, como desarrollaremos en el apartado dos, está presente desde el diseño de las investigaciones y marca el Norte de las mismas. Consideramos que pueden realizarse estudios rigurosos con un propósito que vaya más allá del conocimiento, sin menospreciar, claro está, los que tengan como objetivos y finalidades el conocimiento en sí.

Por todo lo escrito, consideramos que el valor de las investigaciones que venimos realizando se sustenta, de manera breve, en:

- Su continuidad en el tiempo.

- Dicha continuidad nos permite realizar análisis comparativos y, con el tiempo, dibujar un mapa de tendencias que sea algo más que el reflejo de unas impresiones o el resultado de trabajar con una muestra reducida, o el hacerse eco de investigaciones foráneas.

- La cantidad de piezas analizadas.

- Que la investigación, su diseño y su finalidad, resulte del trabajo cooperativo con el demandante de la misma.

- Que su finalidad sea instrumental.

El tratamiento del VIH/sida en los medios de comunicación escritos dominicanos: Diario Libre, El Caribe, El Día, Hoy, Listin Diario y El Nacional (octubre 2012- marzo 2013) ${ }^{4}$, como hemos apuntado, ha sido

\footnotetext{
${ }^{4} \mathrm{La}$ investigación, en su totalidad, la pueden leer como ebook en la siguiente dirección: http://incom.uab.cat/download/201311_vihsida_RD.pdf
} 
realizada en colaboración con FUNGLODE, que es la fundación que la ha financiado ${ }^{5}$.

\section{Metodología}

Esta investigación tiene su precedente en las investigaciones que venimos realizando en España desde 2005 cada dos años. Si bien es cierto que en España ${ }^{6}$ se han hecho investigaciones sobre el tratamiento del VIH/sida en la prensa (véanse, como ejemplo Feijoo Agesta, M. R. (1989), Tuñón, A. (1994), Blanco, J.A., et al (1995), Estébanez, P. (1996), Bueno, J. R.; Madrigal, A. Y. (2000), Martín Llaguno, M. (2000), Garabato González, S (2003), Cantero, B.; García, P. (2005), Lacalle, CH. (2005), Martínez Nicolás, M. (2007), Martín Hernández, R. (2009)), en la actualidad, hasta donde sabemos, son las únicas que pretenden hacer un seguimiento exhaustivo a lo largo del tiempo y, lo que es más importante, que tienen una finalidad de intervención social.

El objeto de estudio son los diarios Abc, El País, El Mundo, El Periódico de Cataluña y $\mathrm{La}$ Vanguardia. Se eligieron los periódicos mencionados por ser los de mayor difusión en España. A su vez, tienen líneas editoriales bien diferenciadas, sus redacciones centrales están en dos ciudades diferentes (Madrid y Barcelona), los cinco periódicos cuentan con periodistas especializados en salud y todos ellos incluían suplementos o páginas específicas dedicadas a este tema. La muestra está compuesta por todas las informaciones que tratan el VIH o el sida entre los meses de octubre y marzo de dos años consecutivos, o sea, durante seis meses consecutivos. En las investigaciones españolas, dada su continuidad, hablamos de oleadas; hasta la fecha hemos realizado cuatro: octubre de 2005 a marzo de 2006, octubre de 2007 a marzo de 2008, octubre de 2009 a marzo de 2010 y octubre de 2010 a marzo de 2012.

\footnotetext{
${ }^{5}$ El equipo de investigación lo compusieron miembros del InCom-UAB y de Funglode: José Luis Terrón (director), Elina María Cruz (coordinadora en República Dominicana), Edel Aguasanta, Jenny Almonte, Leonela Taveras y Ramón García Sedó.

${ }^{6}$ Si hablamos de México, debemos citar a Contreras; Brito; Figueroa (2004), investigación a la que nos referiremos más adelante.
} 
En República Dominicana la muestra la componen las piezas que traten sobre el VIH o el sida de los diarios matutinos Diario Libre, El Caribe, El Día, Hoy y Listín Diario, y el vespertino El Nacional. Se trata de los periódicos con más difusión en la República Dominicana, con líneas editoriales diferenciadas $\mathrm{y}$, además, todos cuentan con buscadores testados, lo que nos permitirá el poder analizar todas las piezas que traten sobre el VIH/sida del periodo escogido.

El objetivo principal que nos propusimos fue averiguar qué tratamiento hacen los medios impresos dominicanos del VIH/sida, y si este tratamiento conlleva algún tipo de estigmatización ${ }^{7}$, implícita o explícita.

El periodo de análisis es de octubre de 2012 a marzo de 2013, ambos meses incluidos. Estos seis meses nos parece tiempo suficiente para obtener una muestra pertinente (en este caso 181 piezas), a la vez que al trabajar con seis meses consecutivos nos permite ver cómo se producen los flujos informativos, si éstos caminan en paralelo en los cinco diarios y la importancia o no de los eventos a la hora de configurar la agenda periodística (de ahí que nos interesara especialmente que el día 1 de diciembre, Día Internacional del Sida, apareciera como una fecha incluida en el periodo de la muestra).

Las piezas periodísticas las buscamos a partir de tres variables: sida, VIH y sida-VIH. En esto seguimos el mismo procedimiento que ya

\footnotetext{
7 “'Entendemos que la estigmatización puede ser el resultado de un uso particular del lenguaje verbal, pero no perdiendo de vista que esa estigmatización también puede derivar de la selección de las informaciones o del tratamiento que se haga de ellas (punto de vista, empleo de fuentes, uso correcto del lenguaje biomédico, etc.). Tales afirmaciones nos obligan, por tanto, a no fijarnos tan sólo en un análisis del contenido de los textos seleccionados, sino también en los procesos productivos de los mencionados textos informativos, considerando que sólo la observación participante nos permitiría responder a algunas de las preguntas que nos planteamos a lo largo de la investigación, pero somos conscientes de que se trata de una metodología que no podemos usar debido a la complejidad y costes que entrañaría. (...) Pensamos que la estigmatización puede estar incorporada a las rutinas de producción y ser el resultado de los procesos de exclusión-inclusión de los textos (agenda o frame), y que las piezas, analizadas como un todo, son susceptibles de aportarnos información de qué y cómo se produce". (Terrón, J.L.; García, R.; Gorozpe, M.J.; Martínez, L., 2006: 6).
} 
venimos haciendo en las investigaciones españolas, sabiendo que con esas tres variables llegaremos a la práctica totalidad del universo que deseamos estudiar. En los buscadores de los diarios hemos usado, en lo posible, un grado de relevancia que nos permitiera excluir las informaciones que pudieran aparecer en las secciones agenda, farmacia, al día, consultorios, cartas al director, etc. En caso de que no se pudiera hacer automáticamente, se han eliminado manualmente. Recordemos que hablamos de piezas periodísticas, por lo que, no se analizan las intervenciones de los lectores, aunque somos conscientes que bien merecería una investigación en sí misma. Sospechamos que de su estudio se puede inferir con bastante aproximación el conocimiento y la percepción que tiene la población del VIH y del sida.

Debemos advertir, y como tendencia global, que cada vez hay mayor diferencia entre lo que un diario publica en su edición en papel y lo que aparece en su edición digital (un mayor volumen informativo); a la vez, que las informaciones digitalizadas pueden no permanecer en el tiempo o, al menos, pierden visibilidad para el lector (aquello que no es leído, desparece del diario electrónico). En esta investigación trabajamos con los buscadores de los diarios, lo que presupone que vamos a trabajar con las piezas digitalizadas; estas, en ocasiones, pueden no ser idénticas a las que aparecen en el soporte papel e, incluso, no haberse insertado. En todo caso, estamos en condiciones de asegurar que con los buscadores llegaremos a un universo de análisis mayor.

El trabajar con las ediciones digitalizadas hace que pierdan sentido ciertas variables que se suelen trabajar en la edición impresa y que derivan de la disposición espacial de la pieza periodística dentro del diario y dentro de la página.

Hablamos de piezas (o de informaciones) y no de noticias para no confundir la unidad de análisis con un tipo de género informativo. Por tanto, piezas será el genérico y noticia el género periodístico noticia.

Para realizar el análisis de contenido, metodología que usamos en estas investigaciones, hemos construido unas bases de datos que hemos ido adaptando a los distintos países y ampliando, según hemos ido avanzando en las investigaciones, siempre en conformidad con la contraparte del estudio cuando no a propuesta suya. 
Así, en el segundo periodo de tiempo investigado en España (octubre 2007- marzo 2008) incorporamos nuevas variables para estudiar desde una perspectiva de género las piezas de la muestra. En su momento justificamos esta decisión al comprobar que expertos y autoridades sanitarias hablaban cada vez más de feminización del sida, lo que nos llevó a plantearnos si los periódicos también lo hacían, y de hacerlo, en qué medida. Este apartado lo basamos en las investigaciones que vienen realizando el Global Media Monitoring Project ${ }^{8}$. Consideramos que dada la prevalencia del VIH entre la población femenina dominicana ${ }^{9}$, este apartado resulta aún más pertinente.

En el tercer periodo (octubre 2009 - marzo 2010) incorporamos variables nuevas para profundizar en el papel de las ONG en las piezas (¿se citan, en qué grado, cuáles, con qué rol,...?). Pensamos que incorporar estas variables podían servir para que las $\mathrm{ONG}$ supieran cómo, cuánto y de qué manera aparecían en las informaciones $\mathrm{y}$, a partir de estos datos, que estas pudieran realizar estrategias que desembocaran en un trabajo colaborativo con los periodistas.

En la presente investigación -y en relación con las anterioresincidimos más en la relación que establecen los medios entre el VIH o el sida y las enfermedades oportunistas y, más específicamente la tuberculosis, con una incidencia grande y grave entre las personas que viven con VIH o que han desarrollado en sida: ¿cómo tratan los diarios esta relación; la tratan?

Junto a la base de datos, y para contextualizar los resultados que podamos obtener, usamos datos epidemiológicos que se extraen de los distintos informes de ONUSIDA y, a la par, empleamos Google Trends $^{10}$ como herramienta que nos sirve para ver y comprobar si ciertas tendencias informativas son propias de la República

${ }^{8}$ www.whomakesthenews.org : ¿Quién figura en las noticias? http://www.whomakesthenews.org/images/stories/website/gmmp_reports/2 010/global/gmmp_global_report_es.pdf

${ }^{9}$ Según ONUSIDA, se estima que en República Dominica hay unos 44.000 adultos infectados por el VIH, de ellos 24.000 son mujeres. La prevalencia entre los jóvenes entre 15 y 24 años es de un 0,4 entre las jóvenes y el de 0,1 entre los jóvenes.

${ }^{10} \mathrm{http}: / /$ www.google.es/trends/ 
Dominicana o si tienen su parangón en el resto del mundo (por ejemplo, comprobar si la agenda viene marcada por el acontecimiento).

En algunos casos, las conclusiones que hemos obtenido en España también nos servirán como elemento contextualizador o explicativo, pero con mucha prudencia, dado que se tratan de realidades diferentes. No obstante, como el funcionamiento de la agenda y de los encuadres y el profesionalismo son transversales a todos los medios del mundo, podemos señalar que muchas de las conclusiones a las que llegamos tanto sirven para España como para la República Dominicana.

Para el apartado dedicado al uso correcto del lenguaje (desde los puntos de vista científico y no estigmatizador) nos hemos basado en tres guías de buenas prácticas: Orientaciones terminológicas de ONUSIDA, CESIDA. Guia de estilo sobre VIH/sida y NIH. InfoSIDA: Vacunas preventivas contra el VIH.

En la investigación se obtienen datos totales y datos segregados por diario, generalmente analizamos únicamente los totales dado que no pretendemos hacer un ranking de buenas prácticas o, dicho con otras palabras, nuestro objetivo no es señalar qué diario lo hace mejor o cuál es el peor. Los lectores de la investigación podrán leer los resultados segregados, pero tenemos que recordarles que para poder establecer comparaciones concluyentes entre periódicos estos deberían contar con condiciones productivas si no iguales al menos muy semejantes -cosa que no ocurre-.

\section{La intervención como finalidad}

Como hemos apuntado con anterioridad, estas investigaciones tienen una finalidad de intervención. Pero hasta llegar a formularla se dio un proceso que cabe explicar esquemáticamente y que hará más comprensible las tareas que hemos venido realizando en República Dominicana y las que en estos momentos están programadas dado que guardan una relación directa con el estudio, su génesis, su diseño, su realización y sus resultados.

La comunidad VIH ha considerado y considera que los medios construyen la realidad, su realidad y que su mediación es lo que 
percibimos el resto de la población. Así, en el editorial del n $n^{\circ} 37$ de la revista Lo+Positivo (2007) -cuyo dossier se dedica a los medios de comunicación-, se nos dice que "hablar, contar, explicar: nos importa, y mucho. No sólo transmitimos ideas, conceptos, valores o sentimientos, sino que también con la expresión lingüística creamos realidad". Esa convicción se apoya en vivencias personales (cómo se han visto relatados) y en la manera en que los medios han ido representando el VIH y el sida desde el inicio de la pandemia ${ }^{11}$. Un tratamiento que han llegado a considerar, a grandes rasgos, episódico, poco riguroso, deshumanizado e, incluso, estigmatizante.

Es a partir de estas convicciones e influidos en gran medida por la investigación Estigma y Discriminación asociado al VIH/sida. El papel de los medios (Contreras; Brito; Figueroa, 2004), que se realizó en México y en la que participaron activistas de la comunidad VIH mexicana que estaban en contacto con activistas españoles, como RedVIH propone que se investigue el tratamiento del $\mathrm{VIH} /$ sida en los medios de comunicación españoles con la finalidad de elaborar una guía de buenas prácticas dirigida a los periodistas y, de esta forma, contribuir a propiciar un cambio en la imagen que ofrecen los medios sobre el $\mathrm{VIH} /$ sida.

En paralelo al análisis de la primea oleada (o sea, la primera investigación) se edita una guía de buenas prácticas dirigida a periodistas (Guia de estilo sobre VIH/ sida, elaborada por CESIDA), por lo que realizar otra pierde todo sentido. Es así, como tras presentar los resultados de la primera investigación a los periodistas y en un diálogo entre ONG, informadores e investigadores RedVIH llega a la paulatina enunciación de otros propósitos:

A)

o Sin renunciar a los medios propios, intentar influir sobre la agenda de los medios y el tratamiento de la información sobre $\mathrm{VIH} /$ sida:

\footnotetext{
${ }^{11}$ Una vez más hay que recomendar la obra de Strazulla para ver cómo trataban los medios la pandemia del sida en sus inicios [Strazulla, 1993: Le sida. Ed. La documentation Française, París]
} 
- Utilizar las investigaciones del OCS como argumento fundamental para incidir en qué y en cómo se trata el VIH/sida.

- Asumir la necesidad de ofrecer información de acorde a unas rutinas de producción y a las características textuales de las piezas periodísticas.

o Institucionalizarse como fuente e invitar a las ONG a que también lo hagan.

- Realizar un trabajo cooperativo con periodistas que beneficie a ambas partes.

○ Crear lazos de confianza con los periodistas.

B)

- Formar a los portavoces y comunicadores de las ONG para que entiendan las rutinas de producción periodística y asuman la elaboración de textos de acuerdo a unas características textuales. Lo que se concreta en una serie de actividades que pasaremos a enunciar rápidamente: elaboración de guías, seminarios y cursos virtuales para el buen informar de las ONG; creación de Mediosysida, sitio online que ofrece a los periodistas fuentes de información, testimonios y documentación para elaborar sus textos informativos $\mathrm{y}$, al mismo tiempo, es una herramienta a disposición de las ONG's para que éstas difundan sus mensajes, actividades y reivindicaciones y puedan entrar en contacto con periodistas y medios, a la par que se formen y se comuniquen entre ellas; organizar seminarios y presentaciones para los estudiantes de periodismo; organizar el Premio Medios y sida para jóvenes periodistas; institucionalizar la relación con los periodistas haciendo que estos participen en las actividades descritas; presentar los resultados de las oleadas en diferentes foros.

La enunciación de esos propósitos, su materialización, hace que reconsideremos para qué sirve el informe que resulta de cada una de las oleadas -investigaciones-. De manera breve:

- Para conocer cómo tratan los medios el VIH/sida, incorporando, como se ha dicho, variables de interés para las ONG en cada una de las oleadas. 
- Para subrayar aquellos aspectos de interés para la intervención de las ONG.

- Como un instrumento argumentativo en el diálogo entre ONG y periodistas.

- Como un instrumento que sirve para evaluar las acciones emprendidas por la propia RedVIH en su relación con los medios o con la comunidad VIH.

Pongamos unos ejemplos: Se comprueba como las ONG se consolidan como fuentes estables y con capacidad de generar agenda. En la última investigación -2012- un 17,5\% del total de fuentes usadas por los periodistas correspondían a ONG y muy mayoritariamente de las ONG de la comunidad VIH. Por otro lado, las ONG son sujetos informativos en más del $20 \%$ de las piezas. Sin embargo, las personas que viven VIH son fuentes en un 3,4\% de las piezas -2010-; su voz quedaba subsumida por las de las ONG y denotaba el miedo (fundamentado) al estigma social a la par que la necesidad de tratar el tema con otros géneros y desde otros marcos que propiciaran la aparición de sus voces.

Con los aprendizajes contextuales obtenidos a partir de nuestras investigaciones en España emprendemos el diseño de la investigación sobre el tratamiento del $\mathrm{VIH} /$ sida de los diarios dominicanos y, para ello, contamos con la colaboración del Consejo Nacional para el VIH y el SIDA (CONAVIHSIDA), el Colegio Dominicano de Periodistas (CDP) y el Círculo de Periodistas de la Salud (CIPESA). Ya en esta fase del diseño de la investigación se empezaron a planificar una serie de acciones que empezaron a realizarse a finales de 2013 y que, en su gran mayoría, se desarrollarán en 2014:

- Conseguir que los resultados de la investigación ocupen un espacio en la agenda de los medios dominicanos.

- Editar la investigación como ebook y ponerlo especialmente a disposición de los periodistas.

- Organizar una serie de seminarios en los que participen ONG, administraciones, periodistas e investigadores para capacitar a los periodistas en $\mathrm{VIH} /$ sida -conducidos por ONG y expertos- y a los activistas de las ONG como comunicadores - conducidos por periodistas-. A la par, se espera que como resultado de esos 
encuentros surjan una serie de acciones colaborativas fruto de los intereses de las partes.

. Y tras la presentación de la investigación (27 de noviembre de 2013) y de sus resultados:

- FUNGLODE plantea el interés por realizar un postgrado especializado en comunicación y salud.

- CONAVIHSIDA se compromete públicamente a primar durante 2014 acciones que refuercen perspectivas de género en relación con el VIH.

\section{Algunos resultados}

Dada la cantidad de datos que se desprenden de nuestra investigación vamos a centrarnos en aquellos que, desde nuestro punto de vista, consideramos capitales para ver cómo tratan los diarios dominicanos el VIH/sida. Este esfuerzo de contención nos obliga a recodarles que el estudio está en línea ${ }^{12}$, por lo que pueden acceder a todos los datos y explicaciones sin restricción alguna.

\section{Tabla 1. Informaciones en torno al VIH/sida en la muestra}

\begin{tabular}{|l|r|r|}
\cline { 2 - 3 } \multicolumn{1}{c|}{} & Piezas & $\%$ \\
\hline Diario Libre & 40 & 22,10 \\
\hline El Caribe & 17 & 9,39 \\
\hline El Dia & 21 & 11,60 \\
\hline El Nacional & 33 & 18,23 \\
\hline Hoy & 38 & 20,99 \\
\hline Listin Diario & 32 & 17,68 \\
\hline Total & 181 & 100,00 \\
\hline
\end{tabular}

No estamos en condiciones de poder decir si los diarios dominicanos informan más o menos sobre $\mathrm{VIH} /$ sida. Carecemos de las series de datos en la que sustentar una conclusión. No obstante, y teniendo en

${ }^{12}$ http://incom.uab.cat/download/201311_vihsida_RD.pdf 
cuenta lo que sucede en otros países y la información que podemos extraer de Google Trends, es plausible que el número de informaciones haya disminuido.

En España, a pesar de que las informaciones biomédicas aumentaban, se pasó de 469 piezas en la primera oleada -2006- a 427 en la tercera de 2010, pero el gran descenso se produjo en 2012, en la que se contabilizaron tan sólo 320 piezas. ¿A qué se debe esta disminución tan marcada? Mantenemos la hipótesis que más que un agotamiento del tema es el resultado de la crisis de los periódicos analizados, que se traduce en un descenso significativo de las informaciones sobre salud.

Eso sí, y sea cual sea la razón, consideramos que en el caso dominicano el uso de nuevas estructuras narrativas a la par que nuevos encuadres podrían revalorizar las informaciones sobre $\mathrm{VIH} /$ sida. Tengamos en cuenta que el $95,6 \%$ de las piezas se corresponden al macrogénero informativo y hay una evidente escasez de piezas interpretativas (3 sobre 181), hasta el extremo que le superan las de opinión (6). La falta de piezas interpretativas supone una construcción del relato más simple, uniforme y previsible. En conformidad con que lo venimos apuntando, el 98\% de las piezas se corresponde con el registro lingüístico informativo.

Ahora bien, los diarios estudiados no le dedican al VIH/sida el mismo espacio, ni lo tratan de idéntica forma, extremo en el que no podemos profundizar en este escrito.

Como en todo el mundo, tal como nos muestra Google Trends ${ }^{13}$, la agenda marca la inclusión o exclusión de las informaciones en torno al VIH/sida. En el caso dominicano el $31 \%$ de las piezas se concentran en la semana que concluye con el 1 de diciembre, Día internacional del sida, tras la cual se produce un agotamiento del tema. Estos repuntes tan marcados en los flujos informativos llevan a la sobresaturación de los medios y de los destinatarios.

\footnotetext{
${ }^{13}$ Para que puedan apreciar con precisión lo que les venimos diciendo, les recomendamos que acudan a la investigación que, como hemos apuntado está en línea. Allí se recogen una serie de pantallas que por cuestión de espacio no podemos incluir en estas páginas.
} 
Google Trends también nos indica que las consultas y las búsquedas son superiores con el tópico sida que con el tópico VIH y que si el descenso en las búsquedas es notorio; este descenso es mucho más acusado en la búsqueda de noticias. Por otro lado, el término de búsqueda que más se repite es sintoma. Consideramos que es una información que debería suscitar más de una reflexión a las autoridades sanitarias y que debería despertar el interés de los periodistas ya que, implícitamente señala deficiencias en las políticas de prevención. Junto a sintoma crece la búsqueda a partir de prueba del VIH.

Cabe destacar que de la muestra analizada el 87,85\% de las piezas tienen como argumento central (eje central) el VIH/sida; en España en 2010 tan sólo se daba en el 49.18\% de las informaciones analizadas, por lo que se trata de un dato muy positivo. Una cosa es escribir sobre el VIH/sida y otra muy distinta que el VIH/sida sea un recurso para escribir de otro tema o un argumento para expresar ciertas opiniones (atraso, pobreza, marginación, prisiones, políticas sanitarias, etc.). También es relativamente positivo que las piezas hagan referencia mayoritariamente al $\mathrm{VIH} /$ sida $(63 \%)$ y no a sida $(6 \%)$-el 31\% restante lo hacen del VIH-. Como venimos repitiendo en nuestras investigaciones, cuando se habla de sida se puede estar hablado de VIH/sida o, simplemente, de VIH; ahora bien, cuando se habla de VIH se hace una diferencia trascendente y clarificadora entre VIH y sida. Y cuando se habla de VIH y de sida en numerosos ocasiones sólo se debería hablar de VIH. Pensemos, por otro lado, que el uso de $\mathrm{VIH} /$ sida también se ha convertido en un comodín lingüístico que puede conllevar el miedo a la incorrección política o el desconocimiento de qué término se debe emplear.

Estos resultados deben complementarse con otros que presentamos a continuación: el uso de la sinécdoque (lo que no deja de ser un error), en definitiva, hasta qué punto se utiliza la parte por el todo, sida por $\mathrm{VIH}$ o por $\mathrm{VIH} /$ sida, lo que ocurre en el 39,6\% de las piezas. Ahora bien, y como ejemplo de esas diferencias entre diarios comentada, mientras que en Diario Libre ocurre en el 52,5\% de las informaciones, en El Día sólo se llega al 23,8\%. Con otras palabras, los resultados no son uniformes. Seamos conscientes de que la sinécdoque no sólo es un error, es también un enfoque (por ejemplo, con el que se amplifica el dramatismo). 
Pero, ¿de qué hablan las piezas de la muestra? Poniendo nuestra atención en las informaciones cuyo argumento central es el VIH/sida y caracterizándolas con palabras clave (un máximo de tres para no abundar en la dispersión de resultados) y tras agruparlas en correlaciones lógicas y así facilitar la lectura ${ }^{14}$ obtuvimos el siguiente resultado:

1.- Eje de la prevención: 176 (palabras clave)

2.- Eje de los tratamientos y de los cuidados médicos: 111

3.- Eje de la investigación: 77

4.- Eje de los derechos de los ciudadanos (y su contraria, la discriminación y la estigmatización): 72

5.- Eje de los recursos económicos: 59

6.- Eje de los niños infectados por VIH (y de la transmisión vertical): 52

7.- Eje de las instituciones: 40

8.- Eje de la epidemiología: 38

9.- Eje de las enfermedades: 30

10.- Eje de las localizaciones espaciales: 29

11.- Eje de la mujer: 26

12.- Eje de la toxicomanía: 11

Resulta significativa la gran relevancia que tienen la prevención y los tratamientos. Acto seguido aparece investigación y derechos (o su conculcación). Debemos explicar que hemos querido diferenciar las palabras clave en torno a la mujer (en República Dominicana el $54,55 \%$ de las personas que viven con VIH son mujeres) de aquellas que guardan una relación con la transmisión vertical -uno de los mayores problemas que perciben las administraciones y la sociedad

\footnotetext{
${ }^{14}$ En el estudio en línea podrán ver además de estas correlaciones el listado completo de palabras clave.
} 
dominicana en relación al $\mathrm{VIH} / \mathrm{sida}^{15}$-, siendo conscientes que en muchos casos también hay una referencia a las mujeres (cuando no es así, se habla de niños o de políticas sanitarias).

Esta tematización es muy semejante a la que se da en España; las diferencias surgen de una realidad específica (transmisión vertical y feminización) (véase Terrón, J.L.; García, R.; Martínez, L. (2010); y Revuelta, G. et al. (2013).

Debemos añadir que sólo en el 9,94\% de las piezas se habla de muerte $^{16}$. O sea, se puede y se debe hablar de VIH/sida sin tener que hablar de muerte, lo que no quita que se deba hacer cuando se considere necesario; o sea, escribir sin caer en la ocultación, por bien intencionada que sea. En España se observa un descenso, así se pasa de un 28,3\%, como se observa en la investigación de 2006 a un 13,8\% -investigación de 2010-. Estos descensos no sólo son fruto de una toma de conciencia por parte de los informadores (VIH no es igual a muerte; destacar a la muerte es comenzar a estigmatizar), son, sobre todo, el resultado de la paulatina universalización de los tratamientos con antirretrovirales, hasta el punto de hablarse, creo que un tanto inconscientemente, de cronificación del sida ${ }^{17}$.

También es oportuno subrayar que en una de cada tres piezas (el $36,5 \%$ ) se habla de prevención, aunque los resultados son muy dispares según los diarios. En este extremo cabe preguntarse si es una proporción adecuada y más ahora que se está dando un repunte de las infecciones y que las políticas públicas, en este aspecto, parecen haber fracasado. Pero profundizar en esto supone preguntarnos por el rol que ha de jugar el periodismo y el medio de comunicación respecto a la salud y respecto a las políticas de las administraciones, cuestión esta poco debatida y que, de manera un tanto simple, se puede resumir en la reivindicación del profesionalismo por los periodistas y la exigencia de que el periodista asuma funciones de agentes de salud por parte de las administraciones e instituciones.

\footnotetext{
${ }^{15}$ Unas 1300 mujeres reciben antirretrovirales para prevenir la transmisión vertical.

${ }^{16}$ Para este año se estiman unas 1.900 muertes provocadas por enfermedades oportunistas.

${ }^{17}$ En 2014 se estima que cerca del 90\% de las PVVS dominicanas tendrán acceso a los antirretrovirales.
} 
Debemos dejar constancia de que el 56,35\% de las piezas incluyen alguna mención a prácticas de riesgo. Esta cifra es superior a la de piezas que tratan de prevención; recordemos que es de un 36,4\%. Evidentemente, se puede escribir de prácticas de riesgo sin escribir sobre prevención, aunque difícilmente se puede escribir sobre prevención sin hacerlo sobre prácticas de riesgo. En muchos casos, se piensa que tratar sobre prácticas de riesgo es hacerlo ya sobre prevención, y no es así. Como hemos podido observar, cuanto más lejano es el origen de una información más probable es que escriba sobre prácticas de riesgo y no, explícita o implícitamente, sobre prevención. Evidentemente, en las piezas analizadas, cuando se habla de riesgos, se habla en la gran mayoría de los casos de 'sexo inseguro'. Eso sí, creemos que en relación a las prácticas sexuales los escritos suelen ser en exceso pacatos, moralistas o alambicados, lo que acaba siendo perjudicial si lo que pretendemos es abundar en la prevención.

En cuanto a de quiénes se habla, los resultados, por citaciones, son los que siguen:

- PVVS: $123(22,82 \%)$

- Mujeres: $68(12,61 \%)$

- Niños: 63 (11,68\%)

- Embarazadas: $49(9,09 \%)$

- Pobres: 29 (5,38\%)

- Jóvenes: $27(5 \%)$

- Adolescentes: $21(3,89 \%)$

- Toxicómanos: $20(3,71 \%)$

- HSH: 19 (3,52\%)

- Prostitutas: 19 (3,52\%)

- Inmigrantes: 11 (2,04\%)

- Presos: 11 (1,48\%)

- Transexuales: 11 (1,48\%)

- Personal sanitario: 3 (0,55\%)

- MSM: 1 (0,37\%) 
El tópico PVVS (o sea, personas que viven VIH) es el que registra un porcentaje más alto. Nos interesa destacar que en segundo lugar aparezca el tópico Mujeres, lo cual nos parece pertinente dado la prevalencia de infectadas dominicanas. Ahora bien, consideramos que no puede desligarse de los tópicos que le siguen en la lista: Embarazadas y Niños. Y es que, en gran medida, subyace una tematización que ya hemos señalado: la transmisión vertical del VIH $\mathrm{y}$, en su caso, el tratamiento con antirretrovirales. Por otro lado, no debemos obviar que cuando se habla de jóvenes y de adolescentes en muchos casos se está haciendo de jóvenes y adolescentes de sexo femenino.

HSH y Trabajadoras del sexo están, hasta cierto punto, invisibilizados (por cierto, a esta variable cabría sumar de facto los resultados de Transexuales, dado que son tratadas en tanto que trabajadoras sexuales), más si tenemos en cuenta que el $5 \%$ de las profesionales del sexo y el $6 \%$ de los homosexuales de República Dominicana viven con VIH. Tengamos presente que en República Dominicana la prevalencia es del 0.8 , por lo que cabría leer esa invisibilidad desde una perspectiva moral, o sea, política. Por otro lado, atendiendo a los determinantes sociales, nos preocupa que el tópico Pobreza no sea muy considerado y nos sorprende que pese a la crisis con Haití, se hable tan poco de inmigrantes.

En cuanto a las zonas geográficas de las que sea habla, decir, en primer lugar, que los resultados son bastante homogéneos en todos los diarios. Y señalar, en segundo, como era de esperar, que la variable República Dominicana es la preponderante, pues aparece en un $64,6 \%$ de las piezas, o sea, prácticamente en dos de cada tres piezas. Ahora bien, quizás ese porcentaje sea excesivo (en España no se llega a una de cada dos piezas) aunque concuerda con los valores noticia del país. Tras República Dominicana aparecen los países occidentales (investigación), países geográficamente próximos y resto del mundo. Nos sorprende, por el contrario, que la zona geográfica más próxima, América Latina y El Caribe, suscite tan poco interés informativo.

En relación a República Dominicana se escribe sobre todo de la Región Norte con 25 entradas -con menciones específicas de 10 provincias-, la Región Este con 14, Santo Domingo con 11 y la 
Región Sur con 5. La provincia de Santiago es la que mayor número de menciones registra, seguida de la provincia de Santo Domingo. En un tercer lugar se sitúa Samaná. Estos resultados no se corresponden con los de prevalencia del VIH por regiones o provincias.

En cuanto a la autoría, y de manera muy sintética, debemos subrayar que sólo el 38,7\% de las informaciones están firmadas. Con otras palabras, existe una gran dependencia del exterior para cubrir este tipo de hecho noticioso y las informaciones que llegan de agencias y otros medios no se trabajan con la suficiente profundidad como para que sean instrumentos para configurar piezas originales. Eso sí, de nuevo constatamos una gran diferencia entre diarios. Por ejemplo, mientras en El Nacional están firmadas el 60,1\% de las piezas, en El Día el 19\%. Y sólo 12 autores (sobre 45) firman más de dos piezas y únicamente 5 periodistas firman 3 o más informaciones. Estos datos denotan una baja especialización.

En otro orden de cosas, los expertos científicos son las fuentes más citadas (41,7\%), seguidos de las agencias gubernamentales, con $22,6 \%$. A partir de estas dos agrupaciones de fuentes ninguna otra llega al 10\%, aunque las organizaciones internacionales lo rozan, el 9,9\%. Le siguen los expertos no científicos $(9,4 \%)$, los Centros de investigación $(7,4 \%)$, las ONG $(5,8 \%)$ y otros $(5 \%)$. Por debajo del $5 \%$ se encuentran los medios de comunicación $(3,7 \%)$, las publicaciones científicas (3\%), los laboratorios $(1,8 \%)$, las asociaciones profesionales $(0,9 \%)$ y afectados $(0,5 \%)$. No tienen ninguna citación como fuente las Agencias y las Asociaciones de pacientes.

Que las Agencias no aparezcan como fuente no debe llevarnos a equívocos, 55 piezas, como mínimo, son totalmente de agencia -en tanto que así aparece la autoría-. No son fuentes porque son proveedores de la información. Deparemos, por otro lado, que los 'afectados' sólo suponen un 0,5\% y que sólo en un 4,4\% de las piezas incluyen como testimonios a personas que viven con VIH (los testimonios suelen usarse cuando el enfoque de la información es pesimista). En definitiva, las personas, sus voces, están ausentes en las 
informaciones y el escaso $5,8 \%$ de las $\mathrm{ONG}^{18}$ no bastan para que estas -las voces- se reflejen indirectamente ni en el tratamiento ni en la agenda de los medios.

Y ya, para finalizar, de manera breve tres cuestiones a considerar:

a) dos de cada tres piezas contiene algún error científico. La mayoría de estos errores se incluyen en las piezas firmadas; con otras palabras: es necesaria una mayor capacitación científica. Los errores que hemos visto se concentran en cuatro de las posibilidades previstas: infectado de sida (43), virus del sida (21), morir de sida (17) y contagio (15). Estos errores los podemos calificar de biomédicos, por lo que nos parece sencillo, con la debida formación, no incurrir en ellos ${ }^{19}$.

b) a pesar que de las 70 piezas firmadas en 41 casos lo hace una mujer (y de que el $52 \%$ de las personas que viven con VIH son mujeres), ni globalmente hay un enfoque de género ni se percibe que este sea mayor cuando la pieza está elaborada por una redactora.

c) la infección por VIH y la TB están tan íntimamente relacionadas que a menudo se habla de "coepidemia", "epidemia dual", TB/VIH o $\mathrm{VIH} / \mathrm{TB}$. Al menos un tercio de los 38,6 millones de personas que hay en el mundo infectadas por el VIH también están infectadas por el bacilo de la TB, y corren un riesgo mucho mayor de padecer TB activa y un $12 \%$ de las muertes mundiales por TB corresponden a personas infectadas por el VIH.

Insertamos estos datos para que se tome conciencia de la importancia de escribir sobre TB cuando se trata el VIH/sida. Sin embargo, sólo una pieza en cada uno de los diarios habla de TB (y en 4 ocasiones es un mismo hecho noticioso, a partir de una denuncia de discriminación sufrida por un paciente) y sólo en un diario, El Nacional, aparece vinculado en un titular: Alertan incremento casos sida y tuberculosis.

${ }^{18}$ Datos que se complementan con los que siguen: en 35 piezas se habla de ONG, lo que suponen un 19,9\% del total; son sujetos informativos secundarios.

${ }^{19}$ Tan sólo a una pieza cabría calificarla como alarmista: "mueren más personas por hepatitis B en un día que por Sida en un año" (Diario Libre, 19 del 10 del 12). 


\section{A modo de conclusiones}

De forma sintética, deseamos destacar algunas de las conclusiones que caben extraerse de esta investigación.

En primer lugar, hacer notar que muchos de los resultados a los que se han llegado son similares a los que han venido obteniendo en los estudios que se realizan en España. Así, podemos hablar de una agenda marcada por el acontecimiento, de una disminución de las piezas dedicadas al VIH/sida, de que no todos los medios hablan de igual forma y con la misma profusión del VIH/sida, de la falta de una perspectiva de género (a pesar de que el $54 \%$ de las personas infectadas en República Dominicana son mujeres), de que el número de denuncias explícitas por discriminación es muy bajo (pero mayor que en España) y de que las personas que viven con VIH no suelen ser ni las fuentes ni los testimonios en las piezas de los diarios analizados (en este caso, en menor proporción en la República Dominicana).

Pensamos que el uso de nuevas estructuras narrativas, a la par que de nuevos encuadres, podrían revalorizar las informaciones sobre $\mathrm{VIH} /$ sida. Sería necesario que las personas que viven con VIH, sus allegados y las organizaciones que los representan ganaran presencia en los medios. Como hemos demostrado en España, el trabajo colaborativo entre periodistas y ONG permite la inclusión de esas voces y la construcción de relatos novedosos y no estigmatizantes.

También cabe destacar que es necesaria una mayor formación de los profesionales en periodismo de salud. De esta manera, disminuirían, por un lado y desde una perspectiva científica, los frecuentes errores detectados y, por otro, la dependencia de los periódicos respecto a las agencias y los medios internacionales, sobre todo al tratar informaciones que requieren una mayor cualificación científica.

A su vez, es necesario que el lenguaje que se utilice no sólo sea inteligible y próximo; ha de rehuir de eufemismos, frases hechas e imágenes moralizantes que esconden la realidad, la edulcoran o la hacen incomprensible; de esta manera la prevención será efectiva y no un simple propósito. También es necesario que ganen visibilidad colectivos de personas con VIH (prostitutas y HSH) que, a pesar de la incidencia de la infección, suelen ser olvidados por los medios 
dominicanos. Por tanto, junto a la capacitación científica debe coexistir una postura moral, o sea una actitud política.

Por último, como ya hemos escrito, esta investigación tiene una finalidad de intervención social. En el momento de redactar estas líneas ya se ha hecho público el estudio en forma de ebook y se han comenzado los primeros talleres de capacitación, en los que están colaborando y participando periodistas, el Consejo Nacional para el VIH y el SIDA (CONAVIHSIDA), el Colegio Dominicano de Periodistas (CDP) y la Red Dominicana de Personas que viven con $\mathrm{VIH} /$ Sida. Los participantes de estos encuentros se han propuesto realizar una guía de buenas prácticas dirigida a los periodistas dominicanos y, por tanto, adaptada a la realidad del VIH/sida en la República Dominicana.

\section{Referencias bibliográficas}

Ampuero, J. (2006): Estudio de Medios: Cómo los medios de comunicación informan sobre el VIH y cómo lo pueden hacer mejor. Lima: Calandria.

Blanco, J.A., et al (1995): La imagen del sida en la prensa española.

Valladolid: Universidad de Valladolid.

Brito, A. (2007): SID A, estigma y discriminación. Guía práctica de manejo de medios. México DF: Letra S, suplemento de La Jornada.

Bueno, J. R.; Madrigal, A. Y. (1998). Presencia y representación del sida en la prensa escrita: acercamiento a un estudio intercultural entre España y Nicaragua. Intervención psicosocial, 7(2), 239-253.

Cantero, B.; García, P. (2005): ¿Qué dice la prensa sobre el sida? Sociedad y contenidos científicos. Enseñanza de las ciencias, $\mathrm{N}^{\circ}$ extraordinario, $6 \mathrm{pp}$.

Contreras; Brito; Figueroa (2004): Estigma y Discriminación asociado al VIH/sida. El papel de los medios. México: Instituto Nacional de Salud Pública.

CESIDA (2011): Guía de estilo sobre VIH/sida. Madrid: CESIDA. Recuperado el 10 de febrero de 2012 de http://www.felgtb.org/rs/343/d112d6ad-54ec-438b-93584483f9e98868/e8a/filename/2011-cesida-guia-estilo-vihsida.pdf 
Estébanez, P. (1996): Mujeres y sida: análisis de la representación que los medios de comunicación hacen de esta relación. Publicación Oficial de la Sociedad Española Interdisciplinaria de Sida, 7(8), 493-494.

Feijóo Agesta, M. R. (1989): Contribución al estudio de los problemas de información sanitaria: el caso singular del SID $A$. Tesis Doctoral, Fac. de Medicina. Universidad de Zaragoza.

Garabato González, S. (2003): La prevención del VIH/sida en los medios de comunicación social escritos: análisis cuantitativo de una muestra de diarios. Trabajo social y salud, 45,139-154.

InfoSIDA (2006): Vacunas preventivas contra el VIH. Washington: Departamento de Salud. Recuperado el 10 de febrero de 2012 de

http://infosida.nih.gov/contentfiles/Vacunaspreventivascontra VIH FS sp.pdf

Lacalle, Ch. (2005): Educar a través de la televisión: la representación del enfermo de sida en los formatos televisivos de ficción. DeSignis, 7-8, 31-39.

Martín Hernández, R. (2009): El sida ante la opinión pública: el papel de la prensa y de las campañas de prevención estatales en la representación social del sida en España. STIDIUM. Revista de Humanidades, 15, 237-268.

Martín Llaguno, M. (2000): De la detección al recuerdo: una historia periodística del sida. Zer, 8. Recuperado el 8 de junio de 2010 de http://www.ehu.es/zer/zer8/8martin3.html

Martínez Nicolás, M. (1994): La información periodística en la crisis del Sida. Algunos temas de interés para la investigación comunicativa. Anàlisi, 16, 89-105.

Martínez Nicolás, M. (2007): Epidemia y media. La construcción simbólica del SIDA en el discurso periodístico. En J. R. Bueno Abad y M. Estellés (eds.). Actas sobre el Encuentro FIPSE de Investigación de la Perspectiva Social del VIH/SIDA. Valencia: Universidad de Valencia (CD-ROM).

ONUSIDA (2011): Orientaciones terminológicas de ONUSIDA. Ginebra: ONUSIDA. Recuperado el 10 de febrero de 2012 de 
http://www.unaids.org/en/media/unaids/contentassets/docu ments/unaidspublication/2011/JC2118_terminologyguidelines_es.pdf

Revuelta, G et al (2013): La comunicación pública en torno al sida y el VIH. Informe Quiral2012. Barcelona: Fundació Vila Casas; Universitat Pompeu Fabra. Observatorio de la Comunicación Científica. Recuperado el 9 de octubre de 2013 de http://www.occ.upf.edu/img/imatges cms/Informequiral2012.pdf

Strazulla, J. (1993): Le sida. París: La documentation Française.

Terrón, J.L.; Martínez, L, García, R. (2010): El tratamiento del $V I H /$ sida en los medios de comunicación escritos españoles: $A B C, E l$ Mundo, El País, El Periódico, La Vanguardia (Octubre 2009-Marzo 2010). Bellaterra: Incom-UAB Recuperado el 10 de diciembre de 2012 de http://www.portalcomunicacion.com/ocs/entrega/informe vi hsida 2010 ok.pdf

Terrón, J.L.; García, R.; Gorozpe, M.J.; Martínez, L. (2006): El tratamiento del VIH/SIDA en los medios de comunicación escritos españoles: Abc, El Mundo, El País, El Periódico y La Vanguardia (octubre 2005-marzo 2006). Barcelona: InCom.

http://www.portalcomunicacion.com/ocs/down/20061110_in ves_VIHsida.pdf

Terrón, J.L. (2012): El tratamiento del VIH/sida en los medios españoles, investigar para propiciar nuevos relatos periodísticos, Comunicação e Sociedade, Número Especial, 57-67

Tuñón, A. (1994): "El sida, como factor noticiable, en la construcción del acontecimiento cultural en cuatro diarios de calidad: El País, La Vanguardia, Le Monde y The Times". Anàlisi, 16, 57-87. 


\section{Comunicar la salud: estrategias auxiliares en capacitación para grupos de pacientes con diabetes mellitus}

Carlos David Santamaría Ochoa [DORCID] [ ${ }^{\mathrm{GGS}}$ ] (Universidad Autónoma de Tamaulipas, UAT, México)

Blanca Guadalupe Cid de León Bujanos [DORCID] [CGS] (Universidad Autónoma de Tamaulipas, México)

\section{Resumen}

Por su alta prevalencia en el mundo, la diabetes mellitus se ha convertido en un problema de salud pública de magnitudes inalcanzables; en México, 14 de cada cien fallecimientos son atribuibles a esta enfermedad crónico degenerativa. Las autoridades han instrumentado una serie de estrategias para tratar de revertir los casos y lograr un control de la misma. La Secretaría de Salud instrumentó un programa denominado "Grupos de Ayuda Mutua", en el que se proporciona la capacitación tanto a pacientes como familiares; su base es el compartir experiencias e información. El éxito en programas de capacitación a pacientes depende de la forma en que se pueda ofrecer un mensaje claro, conciso y que pueda ser comprensible para los asistentes, tanto pacientes como familiares que, por lo general, tienen escasa instrucción formal, además de ser personas de edades que superan el medio siglo de existencia (mexicomaxico.org, 2012). Por lo anterior resulta prioritario el ofrecer un programa de capacitación que en forma clara pueda apoyar a los asistentes a entender los alcances de la diabetes en su organismo. La 
falta de comprensión propicia deserción y, por consiguiente, falta de control glicémico. Considerando que deben mejorarse las técnicas de comunicación en los Grupos de ayuda Mutua, el presente trabajo analiza las formas de capacitación de éstos, y la importancia de incorporar a un comunicador en el equipo multidisciplinario, a fin de lograr los resultados deseados. El presente trabajo busca ubicar al paciente en su rol, así como a sus familiares y personal sanitario: mejorar estrategias comunicativas para impactar positivamente en el estado de salud de la población en general y, específicamente, en el grupo de pacientes con diabetes mellitus.

Palabras clave: Diabetes mellitus, grupos de ayuda mutua, capacitación.

\section{Introducción}

— S LA DIABETES mellitus una de las enfermedades que más se ha propagado en el mundo moderno, por razones que tienen diversos orígenes; la nueva forma de vida propicia que existan factores propicios para su aparición. En el mundo entero ha habido un incremento alarmante según la Organización Mundial de la Salud y los datos estadísticos de países del orbe.

Siendo una enfermedad incurable, se puede controlar en su totalidad, para lo que se requiere de un adecuado autocuidado, mismo que requiere de una capacitación básica.

Es en el ámbito sanitario donde existen barreras comunicativas para que tanto pacientes como sus familiares tengan la información adecuada y ésta propicie un adecuado cuidado y control de la misma, lo que podría evitar la aparición de complicaciones crónicas tales como ceguera, amputaciones y daños renales, entre muchos otros problemas de salud.

Es la comunicación eficaz la principal herramienta que debe privilegiarse en este sentido, para lograr un cambio en la comunidad de cada entidad y, por consiguiente, una mejora en la calidad de vida del individuo. 


\section{Objetivos, Hipótesis y Metodología}

\section{- Objetivos}

El objetivo principal del presente trabajo es contar con las herramientas que permitan evaluar el impacto de las estrategias comunicativas utilizadas en los grupos de ayuda mutua por el personal de salud, en el caso de los pacientes con diabetes.

Asimismo, se busca lograr que los instructores -médicos, trabajadores sociales, psicólogos, enfermeras y otros profesionales de la salud- puedan utilizar diversas y nuevas estrategias para informar y convencer al paciente sobre la necesidad de un cuidado más intenso, de manera que pueda tener un mejor control glucémico y evitar un gran número de complicaciones.

\section{- Hipótesis}

Deben mejorar las estrategias de comunicación entre pacientes y personal sanitario, a fin de contar con resultados positivos en cuanto a control y seguimiento de enfermedades crónico degenerativas.

- Debe incluirse la figura del comunicador en los grupos de ayuda de los programas de capacitación a pacientes y personal sanitario en instituciones de salud.

\section{- Metodología}

El diseño del estudio es de tipo cuantitativo, transversal, considerando además algunas entrevistas no estructuradas, para conocer la opinión de pacientes adheridos al Grupo de Ayuda Mutua del Hospital Civil de Ciudad Victoria, Tamaulipas, México, con respecto a la influencia que tiene la información recibida en sus actividades y su impacto en el control glucémico.

Se utilizó un instrumento de recolección de datos, incluyendo diversas variables como: aspectos socioeconómicos, de comunicación intergrupal, control glucémico y sobre estrategias empleadas en la capacitación que se otorga. 


\section{Reflexiones teóricas}

Dado su carácter de incurable y el crecimiento que ha registrado en los últimos años, la diabetes mellitus se ha convertido en un problema de salud pública para el mundo, cuya magnitud crece año tras año.

Esta enfermedad crónico-degenerativa tiene características que surgen del daño que se provoca en las células beta de los islotes del Langerhans, en el páncreas; al generar este órgano insuficiente cantidad de insulina que le permita cubrir las necesidades del organismo, surgen complicaciones que incluyen daño inicial a severo en el organismo, y que puede incluir la muerte.

La diabetes provoca que se genere insuficiente cantidad de insulina para cubrir los requerimientos humanos, o que la generada no tenga la calidad necesaria para hacer frente a las demandas del organismo, provocando que los niveles de glucosa en la sangre se eleven considerablemente fuera de los rangos establecidos como adecuados, mismos que oscilan entre los 70 y $100 \mathrm{mg} / \mathrm{dl}$., según la clasificación de la American Diabetes Association (ADA), avalada por la IDF $(2006)^{20}$.

$\mathrm{Al}$ experimentar el organismo una elevación considerable de estos niveles de glucosa en sangre, se propicia el que haya desórdenes en el mismo, principalmente, en vasos sanguíneos, lo que provoca complicaciones que van desde las más conocidas como retinopatía (daño en la retina), nefropatía (daño en el riñón) y neuropatía (daño en las terminales nerviosas), así como también daño en el sistema circulatorio, lo que lleva a una alta prevalencia de infartos, enfermedades cerebro-vasculares y otras, elevando los riesgos de mortalidad en quien la padece o ha sido diagnosticado (Cabezas Serrato, Touriño Peralba, Cabezas Agrícola, 2004) ${ }^{21}$.

El Atlas de la IDF la define de esta manera: 'La diabetes es una enfermedad crónica que aparece cuando el páncreas no produce insulina suficiente o cuando el organismo no utiliza eficazmente la insulina que produce. La insulina es una hormona que regula el azúcar en la sangre. El efecto de la diabetes no controlada es la hiperglucemia (aumento del azúcar en la sangre), que con el tiempo

${ }^{20} \mathrm{http}: / / \mathrm{www} . \mathrm{idf} .0 \mathrm{grg} / \mathrm{sites} / \mathrm{default} /$ files/attachments/article 450 es.pdf p.18

${ }^{21}$ http://dialnet.unirioja.es/servlet/articulo? $\operatorname{codigo}=1288876$ 
daña gravemente muchos órganos y sistemas, especialmente los nervios y los vasos sanguíneos".

El objetivo del presente trabajo no pretende hacer una explicación detallada de la diabetes mellitus, sin embargo, resulta fundamental para su comprensión el tener claros algunos conceptos; la International Diabetes Federation -IDF- reconoce tres tipos básicos de diabetes:

Diabetes mellitus tipo 1, conocida también como insulinodependiente, juvenil o infantil; se caracteriza por una deficiente $-\mathrm{O}$ nula- producción de insulina, $\mathrm{y}$ requiere la administración diaria de esta hormona por vía intramuscular. A la fecha, se desconocen las causas que la provocan, por lo que no se puede prevenir en la actualidad.

Sus principales síntomas son, entre otros: poliuria o excreción excesiva de orina; polidipsia o sed frecuente, polifagia o hambre desmedida, pérdida de peso, cansancio y trastornos visuales; todos estos síntomas pueden presentarse en forma aleatoria o conjunta y suelen aparecer en forma súbita.

Diabetes mellitus tipo 2, conocida como no insulinodependiente o de inicio en la edad adulta; caracterizada por una utilización inadecuada de la insulina por parte del organismo, por su poca producción o mala calidad de la misma. Se presenta en un 90 por ciento de los casos en el mundo, y aparece, en gran medida, cuando el paciente tiene un peso corporal excesivo y vida sedentaria, es decir, inactividad física.

Los síntomas son similares a la diabetes tipo 1, aunque menos intensos, y por lo general se diagnostica cuando tiene varios años de evolución y hay complicaciones manifiestas. Algunos estudios aseguran que puede permanecer asintomática hasta por cinco años.

Aunque era conocida como la diabetes del adulto, hoy en día se ha manifestado en niños, jóvenes y adultos de todas las edades, debido al incremento de casos de obesidad y sedentarismo, así como el estrés, propios de la vida moderna, principalmente en las grandes ciudades.

Diabetes Gestacional, que se presenta durante el embarazo, con síntomas similares a la diabetes tipo 2 , y se diagnostica en un importante porcentaje durante las pruebas prenatales; pocas veces la 
paciente refiere síntomas. Por lo general desaparece cuando concluye la etapa de embarazo, aunque se considera que el 50 por ciento de las mujeres que fueron diagnosticadas, en un período breve de tiempo desarrollarán diabetes tipo 2 .

La diabetes mellitus es una enfermedad crónico-degenerativa con alcances alarmantes para los sistemas sanitarios: en el mundo, según estadísticas de la OMS -Organización Mundial de la Salud- existen, según registros de 2004, más de 346 millones de personas que han sido diagnosticadas con esta enfermedad, y se calcula que a partir de esa fecha, y hasta el año 2025, los casos se dupliquen.

Se considera, según la Federación Internacional de Diabetes, que hay poco más de 183 millones de personas con diabetes que no han sido diagnosticadas.

En ese mismo año -2004- se registraron 3.4 millones de fallecimientos de personas, todos relacionados directamente con la diabetes mellitus, de los cuales, más del 80 por ciento se registró en países de ingresos bajos y medios; casi la mitad eran menores de 70 años y el 55 por ciento del sexo femenino. Para 2011, la cifra subió a 4.6 millones (OMS, 2012).

La IDF -International Diabetes Federation- asegura en su Atlas 2011 que ya los casos superan los 366 millones, es decir, el 8.3 por ciento de la población adulta mundial, y para el año 2030 serán 552 millones, lo que constituye el 9.1 por ciento de la población, y que significa que cada 10 segundos hay 3 casos nuevos en el orbe.

Con 10.3 millones de casos, México ocupa el séptimo mundial en este rubro, debajo de naciones como China, India, Estados Unidos de América, Rusia, Brasil y Japón.

Para hacer frente a esta problemática, la Secretaría de Salud instrumentó un programa denominado "Clubes de Autoayuda", ahora "Grupos de Ayuda Mutua" (GAM); de acuerdo a la guía técnica para su funcionamiento, de la Secretaría de Salud en México, se concibe como "La organización de los propios pacientes que bajo la supervisión médica y con el apoyo de los servicios de salud, sirve de escenario para la capacitación necesaria para el control de la diabetes". 
El objetivo de estos grupos es propiciar que la intervención médica sea más efectiva, y que se pueda reforzar la adherencia o apego al tratamiento correspondiente, así como lograr que la labor de los miembros del equipo sanitario sea más efectiva. Para tal efecto, se orienta y capacita a los miembros del grupo que acuden a los centros de salud u hospitales, con el objetivo principal de que, en base al conocimiento básico de la enfermedad se logre reforzar el autocuidado de cada paciente que le permita controlar su diabetes y, por ende, evitar complicaciones crónicas y agudas.

En estos grupos, el paciente recurre, mediante técnicas basadas en la dinámica de grupos (Cirigliano, 1982), a la aplicación de estrategias de comunicación interpersonal entre personas igualmente diagnosticadas con esta enfermedad, coordinados, por lo general, por un profesional sanitario, que puede ser un trabajador social, psicólogo, enfermera o médico.

En la mayoría de los casos, se coordina a través de una persona y se ofrece capacitación acerca de aspectos propios de la enfermedad, por lo general, impartidos en conferencias o charlas que ofrecen médicos, aunque en un porcentaje importante, participan otros profesionales de la salud tales como psicólogos, nutricionistas, trabajadores sociales, enfermeros y otros, ofreciendo capacitación o información de acuerdo a sus áreas de estudio e influencia.

Los grupos de Ayuda Mutua buscan que el paciente logre el manejo de su enfermedad, lo que se conoce como "empoderamiento", es decir, que tome el control de la misma, para lo que se le ofrece la información necesaria, tanto de la diabetes como de las formas de control. La decisión de tomar los cuidados necesarios dependerá del paciente, apoyado por lo aprendido en los grupos de ayuda mutua, con la premisa de que, si tiene la información necesaria puede tomar las decisiones adecuadas, logrando establecer una retroalimentación con los demás miembros de esa pequeña comunidad creada para atender un fin común.

Sobre el aumento de casos de diabetes en el mundo hay muchas opiniones: se puede atribuir el mismo a la aplicación inadecuada de las medidas preventivas de parte de las autoridades sanitarias o la falta de atención a las políticas instrumentadas; cuando el paciente es diagnosticado se requiere que tome él mismo el control de esta 
enfermedad, logrando evitar las consecuencias que implica, entre las que destacan de manera importante las llamadas complicaciones crónicas (Cabezas Serrato, Touriño Peralba, Cabezas Agrícola, 2004), que se refieren al daño en riñones, ojos y nervios, principalmente.

Para la Organización Mundial de la Salud, los daños son importantes cuando no se tiene un verdadero control de los niveles de glucosa en sangre: la diabetes aumenta el riesgo de cardiopatía y accidente vascular cerebral. Un 50 por ciento de los pacientes diabéticos mueren por enfermedades cardiovasculares, y la neuropatía en los pies, combinada con la reducción del flujo sanguíneo, incrementa el riesgo de úlceras en las extremidades inferiores, lo que lleva al incremento de amputaciones. Cabezas-Cerrato, Touriño, Cabezas (2004).

Para la Asociación Latinoamericana de Diabetes, según establece en su documento titulado "Guías ALAD de diagnóstico, control y tratamiento de la Diabetes Mellitus tipo 2", las complicaciones crónicas son: retinopatía diabética, que al cabo de 15 años de evolución de la diabetes en promedio ocasiona ceguera en un 2 por ciento de los pacientes, aunque también se sabe que un 10 por ciento de éstos sufre deterioros graves. También se sabe que es de las principales causas de insuficiencia renal, considerando que del 10 al 20 por ciento de pacientes con diabetes mueren por esta situación.

La neuropatía diabética se define como lesión en los nervios y pérdida de sensibilidad en los mismos; puede afectar al 50 por ciento de los pacientes, y ocasionar problemas diversos que van desde hormigueo, dolor muy intenso, entumecimiento o debilidad en pies y manos, lo que lleva también a tener al menos dos veces más riesgo de fallecimiento.

En materia de economía se considera que la diabetes causa grandes pérdidas a los sistemas sanitarios, como ejemplo, la OMS calcula que entre los años 2006 y 2015, China dejaría de percibir alrededor de 550 mil millones de dólares por causa de las cardiopatías, accidentes vasculares y diabetes mellitus (OMS, 2012).

Las estrategias son variadas y tienen una gran relación con las medidas que se llevan a cabo en el ámbito de la medicina, sin embargo, ante la prevalencia mostrada a nivel mundial surge la 
interrogante acerca de si se están llevando a cabo las medidas indicadas.

Ante el panorama de esta enfermedad que sigue creciendo en el mundo, cabe preguntarse si existe la posibilidad de mejorar ese sistema de interacción entre personal sanitario, pacientes y familiares de éstos para que las decisiones sobre la diabetes impacten en la salud $y$, por consiguiente, en las estadísticas mundiales.

Se entiende que la medicina preventiva es la herramienta más adecuada en materia de salud, dado su bajo coste y viabilidad para su instrumentación; aunque puede suceder que no se tenga una idea definida de lo que se busca, o no se haya logrado convencer al paciente diagnosticado de la necesidad de establecer medidas adecuadas de autocuidado, lo que se ve reflejado en el incremento de problemas sanitarios como el sobrepeso y la obesidad, que se han incrementado en forma alarmante en el mundo entero (Dorantes, 2010). Al respecto, los expertos consideran que estos dos aspectos, convertidos en foco de atención mundial en salud pública propician enfermedades como hipertensión arterial, diabetes mellitus y problemas cardiovasculares, entre muchos otros.

Ante tal panorama sanitario, se sugiere un proyecto que tiene como objetivo el hacer llegar la información de causas y formas de desarrollo y control de la diabetes mellitus en forma tal que cualquier persona pueda entender lo que se dice, y obtener, por consiguiente, una mejor respuesta a las acciones de prevención y conservación de la salud.

Para lograr lo anterior, se busca que los instructores -médicos, trabajadores sociales, psicólogos, enfermeras y otros profesionales de la salud- puedan utilizar otras estrategias y formas para informar y convencer al paciente de la necesidad de un cuidado más intenso, de manera que se pueda evitar un gran número de padecimientos, entre ellos, la diabetes mellitus.

La OMS sugiere que las medidas necesarias básicas son el atender una dieta saludable, así como realizar actividad física regular, mantener un peso corporal normal y evitar el consumo de tabaco, como base para prevenir este tipo de problemas de salud. 
El ritmo actual de la vida en las grandes ciudades obliga a muchos hogares al consumo de productos alimenticios no balanceados, ricos en carbohidratos, que tienen repercusión directa en el peso corporal y por consiguiente, en el riesgo de ser diagnosticado con diabetes.

En ese sentido, habrá que establecer estrategias que convenzan al paciente y al ciudadano en general de cuidar su alimentación y su peso corporal.

Es aquí donde surge el proyecto de llevar, mediante distintas técnicas de comunicación, la información al paciente diabético, con el objetivo de que pueda entender el mensaje que se requiere, y que éste tenga un impacto positivo en su estado de salud.

En sus distintas formas, la teoría de la comunicación, según lo explica Berlo (2003) en su obra El proceso de la comunicación, se fundamenta en una rutina en la que interviene un emisor y un receptor: se envía un mensaje a través de un código y canal común, para lograr la retroalimentación. Cuando ésta última no se hace presente, se considera que el proceso comunicativo está incompleto, es decir, no es válido. En ese sentido coinciden los modelos que comenta Berlo, atribuidos a distintos estudiosos de la comunicación.

Prácticamente todos los modelos de comunicación consideran que la retroalimentación es el principal justificante de la eficiencia en el proceso comunicativo, inclusive en el modelo de Schram ${ }^{22}$, que utiliza el "campo de la experiencia" como base para transmitir el mensaje adecuado. En este caso, y ubicando las necesidades de los grupos de pacientes con diabetes mellitus, suele considerarse el empleo de este modelo, dado que la experiencia de uno y otro paciente puede ayudar a que los demás entiendan los términos que se emplean y manejan en la reunión, propiciando un mayor entendimiento $y$, por consiguiente, logrando un apego a las indicaciones fundamentales que debe tomar cada paciente.

Sobre las estrategias que se emplean en la capacitación a pacientes con diabetes mellitus, podemos afirmar que, si el mensaje de control no es recibido adecuadamente, supone que la comunicación presenta algunos ruidos o berreras que deben atenderse para que pueda existir la retroalimentación adecuada que, en este caso, se debe reflejar en el

${ }^{22}$ Citado por Berlo, 2003, en su obra Teoría de la Comunicación 
estado de salud de cada individuo. Es necesario señalar que lo que en el ámbito comunicativo se conoce como ruido se refiere a las barreras que se pueden presentar y que evitan que se complete adecuadamente el proceso comunicativo.

Buscando que la función de capacitación tenga éxito, se sugiere inicialmente la incorporación en el equipo multidisciplinario de las instituciones a un profesional de la comunicación, quien deberá asumir la función de dar forma a los mensajes de medicina preventiva y control dirigidos a los pacientes, así como la elaboración de material didáctico -trípticos, carteles, mensajes, correos, etcétera- para reforzar esta acción y obtener resultados positivos.

Integrado al equipo multidisciplinario, el comunicador deberá incorporar las técnicas de transmisión de información y capacitación necesarias, tales como "pequeños grupos”, “discusión”, “juegos tradicionales" o capacitación en general, a fin de que los pacientes entiendan el mensaje del sector sanitario y puedan tomar la decisión adecuada respecto a la conservación de su salud.

Dentro de los objetivos del grupo será importante considerar la capacitación de quienes tienen a su cargo la instrucción, así como los pacientes y familiares, propiciando el que se conviertan en monitores para los pacientes, otorgando la información necesaria de forma clara y sencilla, para que los resultados se vean reflejados en su estado de salud.

Para Gibb (1982), los grupos tienen sus dinámicas de acuerdo a cada integrante, pero, en el aspecto interno, consideran el tamaño, atmósfera grupal, identificación, homogeneidad, comunicación, participación, objetivos, normas, actividades y evaluación grupal, entre otros aspectos.

Considerando los dos tipos básicos de grupo en cuanto a pertenencia, y que son: por adscripción, es decir, cuando se pertenece por defecto, como puede ser la familia, y por adquisición, que considera la elección propia del mismo. Los pacientes y familiares se ajustan al segundo tipo, dado que se requiere de su consentimiento para que participen en las actividades. Deben ser funcionales, es decir, enfocados al objetivo común que es el control de la diabetes mellitus. 
Gibb (1982) propone, para lograr un buen funcionamiento del grupo, el atender 8 principios fundamentales para lograr un adecuado aprendizaje en los miembros del grupo, y que son:

1. Ambiente,

2. Reducción de la intimidación,

3. Liderazgo,

4. Formulación del objetivo,

5. Flexibilidad,

6. Consenso,

7. Comprensión del proceso y

8. Evaluación continua.

Para Cirigliano y Villaverde (1982), las técnicas grupales son "maneras, procedimientos o medios sistematizados de organizar y desarrollar la actividad de grupo, sobre la base de conocimientos suministrados por la teoría de la 'dinámica de grupo'; son el más valioso recurso para el logro de los objetivos que se ha propuesto el mismo grupo".

Resulta fundamental la elección de las técnicas grupales de acuerdo a los objetivos que se persiguen y que en este sentido son muy claras; la madurez y entrenamiento de los elementos que participan son importantes, así como el tamaño del mismo, el ambiente físico, las características del medio externo y de los miembros, así como la capacitación del conductor, dirigente o líder.

El líder o cabeza del grupo se convierte en el coordinador de este proceso de aprendizaje: su papel es orientar la información, facilitar su adquisición y despertar el interés para que ésta sea ampliada y confrontada, fortalecida y reafirmada en cada uno de los miembros del grupo.

Respecto a los miembros del grupo, Chehabayar y Kuri (1989) sugiere que el sujeto de aprendizaje o el integrante del grupo "necesita saber qué aprende, sentirse productivo y aportar él mismo de su propia experiencia. Que no sea suficiente entender la información, sino tener la posibilidad de utilizarla”.

Ya conformado el grupo de pacientes y familiares, el líder o cabeza del grupo, que en el caso de las instituciones públicas es el 
coordinador, determinará las acciones a seguir para lograr un aprendizaje adecuado; lo anterior se llevará a cabo de acuerdo a las características de cada uno de los elementos participantes y las necesidades de todos.

\section{Resultados}

La edad de los pacientes oscila entre los 30 y 75 años; 100\% forma parte del grupo de ayuda mutua; 70\% tiene más de tres años como miembro; 50\% tiene más de cinco años diagnosticado. El 67\% son viudos, quienes dependen económicamente del apoyo que les proporcionan sus hijos y el 33\% son casados, recibiendo una pequeña pensión por parte del Estado. El 100\% son personas de nivel socioeconómico bajo, sus viviendas están construidas con materiales de baja calidad, ubicadas en colonias de la periferia de la ciudad. En cuanto a la alimentación, se observó que en la mayoría, su dieta está compuesta por alimentos altos en carbohidratos, sin incluir la ingesta de verduras, lo que repercute en sus altos índices glucémicos, ya que reportan cifras superiores a los $170 \mathrm{mg} / \mathrm{dl}$.

Respecto a su asistencia al grupo de ayuda mutua, expresaron que hacen lo posible por cumplir con las sesiones programadas, pero que ocasionalmente no asisten debido a que tienen problemas para trasladarse desde su domicilio, además de no tener el apoyo de su familia, ya que acuden solos.

Manifestaron no saber qué hacer en caso de una emergencia y consideran que sus familiares no están capacitados para responder ante una situación de crisis y atenderlos de una manera adecuada. La comunicación que tienen entre los miembros del grupo les permite compartir con otras personas situaciones difíciles en el control de su padecimiento o en su vida personal y familiar, pero sólo se establece dentro de la institución.

El 60\% manifestó no conocer las complicaciones de la diabetes y sólo 30\% reconoce que el personal de salud le ha informado sobre algunas de ellas, pero no las identifican como tales.

En cuanto a las estrategias utilizadas por el personal de salud, el $100 \%$ comenta que en la mayor parte de las ocasiones han recibido la información a través de charlas o pláticas con algunos de los médicos 
$\mathrm{u}$ otros profesionistas, pero que en ocasiones no les queda claro el mensaje o no entienden las palabras que utilizan; mencionan que el personal de trabajo social les hace llegar información a través de folletos que les han entregado en algunas de las sesiones, donde les hablan de aspectos relacionados con su enfermedad, así como a través de mamparas con temática alusiva, que se colocan en diferentes áreas del hospital.

Los pacientes expresaron interés por conocer más acerca de la enfermedad, aprender de otra forma a mejorar su control glucémico y tener una comunicación más estrecha con sus familiares y el personal de salud.

Reiteraron no tener contacto con otros miembros del Grupo de Ayuda Mutua fuera de las sesiones, aunque confirmaron que la interacción entre ellos les permite conocer diversos aspectos sobre el desarrollo de su diabetes.

\section{Conclusiones}

Existe una barrera entre el profesional de la medicina y el paciente, provocada por la falta de claridad en los mensajes, de ahí que se requiera buscar otro tipo de estrategias de comunicación adecuadas, que permitan a unos y otros interactuar de forma positiva, logrando que el paciente tenga las herramientas necesarias para tomar las decisiones adecuadas respecto a su tratamiento, considerando como resultado la mejora de su salud en general.

El lenguaje que emplean los profesionales de la salud muchas veces se torna incomprensible porque utilizan términos propios de su profesión. Será determinante para la comprensión de los miembros del grupo que se les explique cada uno de éstos. Resulta más claro indicar a un paciente recién diagnosticado que puede tener los niveles de glucosa elevados en lugar de decirle que puede tener una hiperglucemia, o que la nefropatía diabética se refiere al daño que se ocasiona en los riñones, y así, uno a uno, los términos deben ser explicados con la claridad que requiere el grupo de acuerdo a su nivel cultural.

Se necesita cambiar estrategias en los Grupos de Ayuda Mutua, mediante las que se pueda fortalecer la comunicación entre los 
miembros del grupo de ayuda mutua, así como los lazos de unión, para crear verdaderas redes de apoyo que, con una adecuada comunicación, faciliten la atención y el buen control del padecimiento.

Se percibe claramente que no se ha logrado el impacto deseado sobre los índices glucémicos de los pacientes, lo que compromete aún más a los profesionales de la salud para buscar nuevas estrategias, que tengan la influencia directa sobre la comprensión de la información otorgada. Asimismo, la corresponsabilidad de los pacientes para ejercer de manera real los conocimientos adquiridos para un cuidado con mayor intensidad.

Se propone la participación del comunicador en el equipo multidisciplinario de salud, para que pueda colaborar en el establecimiento y manejo de técnicas, que la transmisión de la información no sólo sea a través de charlas; incluir además la participación de los pacientes en dinámicas grupales, juegos de mesa y de actividad física, en los que el comunicador pueda hacer llegar el mensaje de forma clara y concisa, para que el paciente logre una mayor comprensión de los temas tratados y, por consiguiente, un mejor estado de salud.

De la misma manera, se propone la instrumentación de un proyecto como programa piloto de salud pública en las instituciones de salud oficiales del Estado de Tamaulipas, para lo que se ha establecido ya el contacto con la Secretaría de Salud en Tamaulipas. Se llevará a cabo en los hospitales ubicados en la capital del Estado, donde se cuenta con grupos de pacientes diagnosticados con diabetes conformados con antelación, y que tienen un programa de capacitación continua.

\section{Referencias bibliográficas}

Baden Powell, R. (2010): Escultismo para muchachos, México, CEAC.

Berlo, D.K. (2003): El proceso de la comunicación, Introducción a la teoría y a la práctica, México, Ateneo.

Cirigliano, G. y Villaverde, A. (1982): Dinámica de Grupos y Educación, Buenos Aires, Argentina, Humanitas. 
Chehayabar y Kuri, E. (1989): Técnicas para el Aprendizaje Grupal.

Universidad Nacional Autónoma de México, México.

Dirección de Desarrollo Académico (1993): Taller de Dinámica de Grupos, Universidad Autónoma de Tamaulipas, México.

Dorantes, M. (2010): México, primer lugar en obesidad infantil, consultado en:

http://www.amnu.org.mx/index.php?option=com content\&view 三article\&id=31:articulo-2\&catid=10:articulos el 5 de octubre, 2012).

Federación Internacional de Diabetes (2011): Atlas Mundial de la Diabetes, (versión en español), Federación Internacional de Diabetes, Bélgica.

Fernández, C. (2001): La Comunicación Humana en el Mundo contemporáneo. Mc Graw Hill, México.

Gibb, J. R. (1982): Manual de Dinámica de Grupos, Buenos Aires, Argentina: Humanitas.

Trevithick, P. (2010): Habilidades de Comunicación en intervención social, Madrid, España, Narcea.

Villanueva, V. (2003): "Enfoque práctico de las complicaciones crónicas de la diabetes mellitus", Revista de posgrado de la Via Cátedra de medicina, UNNE, Buenos Aires, Argentina, (130) 34-39

\section{Páginas web consultadas}

http://www.who.int/mediacentre/factsheets/fs312/es/index.htl

(Consultada el 21 de junio, 2012).

http://www.idf.org/diabetesatlas/5e/es/prologo?language $=\mathrm{es}$

(Consultada el 21 de junio de 2012).

http://www.mexicomaxico.org/Voto/MortalidadCausas.htm

(Consultada el 3 de octubre, 2012).

http://www.inegi.org. $\mathrm{mx} /$ sistemas/olap/proyectos/bd/consulta.asp?

$\mathrm{p}=11094 \& \mathrm{c}=15273 \& \mathrm{~s}=$ est\&cl=4\# (Consultado el 3 de octubre, 2012).

http://vivecondiabetes.com/basicos-de-diabetes/estadisticas

(Consulta: 5 de octubre, 2012). 
http://www.idf.org/sites/default/files/attachments/article 450 es.p

df (Consultado 5 de octubre, 2012).

http://dialnet.unirioja.es/servlet/articulo?codigo=1288876, $\mathrm{J}$.

Cabezas-Cerrato, R. Touriño Peralba, J.M. Cabezas Agrícola

(2004): Complicaciones crónicas de la diabetes mellitus,

publicado en Medicine, ISSN 0304-5412, Serie 9, No. 16, 2004

(Ejemplar dedicado a: Enfermedades endocrinas y metabólicas

(IV). Diabetes mellitus y otros trastornos del metabolismo de la glucosa y fosfocálcico), págs. 990-999.

http://www.inegi.org.mx

http://www.alad-

latinoamerica.org/phocadownload/guias\%20alad.pdf Guías

ALAD de diagnóstico, control y tratamiento de la diabetes mellitus tipo 2 (consultado, Octubre 20, 2012).

http://med.unne.edu.ar/revista/revista130/enfoque.pdf Revista de

posgrado de la Vía Cátedra de medicina, UNNE, Buenos Aires,

Argentina, No. 130, (2003) Consultada, octubre 21, 2012.

http://ensanut.insp.mx/doctos/analiticos/DiabetesMellitus.pdf

(Consultada, enero 14, 2014). 



\section{Representaciones y comunicación en agentes de psicología clínica. Escenarios de exclusión social en salud mental}

Flor Micaela Ramírez Leyva (Centro Universitario de la Costa Universidad de Guadalajara, México) [DoRCID] [GGS]

Leticia Castillo Quiñónez (Universidad Autónoma de Ciudad Juárez, México) [DORCID] [GGS]

\section{Resumen}

Este trabajo aborda la exclusión e inclusión social desde el campo de la salud mental en Puerto Vallarta, México, a partir de las narrativas que sobre su trabajo construyen quienes ejercen la psicología clínica. Se toman como referencias la noción bourdiana de campo y las interacciones de comunicación, orientadas a legitimar la posición de sus agentes. Se considera que los aspectos de diferenciación y agrupación inciden en diversas dimensiones de la salud; a nivel global, en los sistemas económico, sociocultural y político, y, en escalas grupales e individuales, en sus procesos de comunicación, vínculo afectivo, desarrollo personal y profesional. Identificar las relaciones entre los profesionales de la salud y con sus pacientes y alumnos, en ese contexto, puede favorecer la promoción, formación e investigación en el campo sanitario.

Palabras clave: Campo social, exclusión social, interacción, narrativas, psicología. 


\section{Introducción}

L

AS DINÁMICAS de distanciamiento o de integración entre personas y grupos de diversa índole, suelen resultar fenómenos de exclusión/inclusión social, produciendo un círculo, cuyas inercias se sostienen por los conflictos y/o luchas de intereses en pugna, aunados a la falta de conciencia social, acceso/uso indiscriminado o excesivamente limitado de recursos/ capitales (económicos, sociales y culturales -de información-) de los involucrados, entre otros. En el campo académico y terapéutico de la psicología en Puerto Vallarta, México, se produce un proceso similar, de acuerdo con información recabada con representantes del mismo y de la cual se da cuenta en la presente colaboración, que a su vez pretende enfatizar la dimensión de la comunicación en esas relaciones.

Bel (2002) ha señalado que en una sociedad donde el progreso y la competitividad son valores centrales, los mecanismos de exclusión constituyen una regla de juego elemental. La naturaleza de la competitividad es excluyente, por lo tanto, niños, ancianos, mendigos, inmigrantes, indígenas, o personas con algunos grados de discapacidad, entre otros, constituyen una población muy vulnerable a ser excluida. Hay otros estudios (Rubio, 2006) sobre aspectos relativos a los estereotipos y al género, donde se sugiere cierta 'feminización' de la pobreza y de la exclusión, o una especial susceptibilidad por parte de las mujeres, lo cual también está presente en las afirmaciones de las personas entrevistadas, cuando éstas refieren que en la familia la situación más complicada sigue siendo la de las mujeres.

La dimensión simbólica del lenguaje/narrativas y la noción de campo de Bourdieu ha sido una herramienta útil para abordar este campo de relaciones de comunicación y sus implicaciones en la exclusión e inclusión en el área de Psicología. Se identifican dichas concepciones y dinámicas en las construcciones narrativas elaboradas por profesoras que ejercen en el campo de la salud mental, en relación con su conocimiento relativo a ciertos rubros significativos de su trabajo y su propia percepción del fenómeno de inclusión y exclusión social. 
La pregunta inicial de investigación fue ¿cuál es la posible relación de las narrativas y concepciones de persona, salud y trabajo en Psicología Clínica con el binomio exclusión/inclusión social? A partir de ella se formularon otros cuestionamientos, que fueron planteados a las personas entrevistadas, incluyendo los siguientes: particularmente, en el ámbito de la psicología clínica y desde una perspectiva de comunicación: ¿Qué aspectos provocan la exclusión e inclusión social?, ¿Quiénes y de qué modo participan en ellas?, ¿Con qué finalidades o propósitos lo hacen y desde dónde?, ¿Cuáles son sus implicaciones y consecuencias? y ¿Cuáles son las propuestas para revertir la exclusión y promover escenarios de inclusión?

\section{Lo simbólico: incidencia del campo y el lenguaje en el desorden social}

Una de las claves indiscutibles de la determinación y reproducción de lo social, hacia lo que de cierta forma apuntan los procesos de exclusión e inclusión, se encuentra en lo simbólico. Su estudio resulta pertinente para el análisis de cualquier hecho social, puesto que éstos se reconfiguran y establecen a partir de lo simbólico, que establece conceptual o físicamente diferenciaciones en diversos órdenes, sea económico, político, sociocultural.

De acuerdo con Bourdieu (2011) lo simbólico es el lugar donde se esconde la dominación; ello supone la expresión extrema de los efectos de ciertos tipos de exclusión social. Quien aspire a la conservación o la trasformación (de un orden social), siguiendo a Bourdieu, deberá comprender los mecanismos básicos de las relaciones simbólicas, sus posibilidades y sus límites. Dentro de estos aspectos se contemplan las prácticas de consumo y las simbólicas, las cuales funcionan como principios de selección o de exclusión reales que el sujeto contemporáneo vive y sufre.

La violencia simbólica, como todo lo simbólico en el ser, se encuentra en cualquier lado de lo social. Tanto los excluidos como los aspirantes a competir por los bienes de determinado campo están obligados a reconocer los medios dominantes. Un campo sólo funciona si encuentra individuos socialmente predispuestos a comportarse como agentes responsables que luchen por ganar y por conseguir los beneficios que éste les propone. 
Conviene señalar la importancia de las percepciones de los sujetos involucrados en un campo. Al respecto, Jiménez (2011: 16) sostiene que "la objetividad y realidad de lo que sucede en una situación, depende de cómo los miembros la observan como una ocasión localizada y que presenta un orden social objetivo."

Se debe destacar otra situación que tiene su correspondencia con los procesos de comunicación y de exclusión e inclusión de la propia psicología, a saber: la relacional, en el sentido de que la persona solo existe en la medida en que está en compañía de otros; la razón última se encuentra en el 'ser-con' o el 'ser-hacia' y no solo en el 'ser', es decir, se estudia cómo la relación de los individuos afecta o influye en los elementos del sistema. Más que de sociedad Bourdieu habla de campo o espacio social, donde los agentes y las instituciones luchan permanentemente por apropiarse de productos específicos que se encuentran en disputa. Jiménez puntualiza que aun siendo un universo de antagonismos, todo campo está constituido por un consenso en el disenso y también funcionan a la manera de mercados $^{23}$.

Una de las implicaciones del campo es la agrupación de individuos, a los que se permite o no un acceso, se otorga o no cierta visibilidad o reconocimiento, estableciendo pautas diferentes para las acciones e interacciones, según las lógicas e intereses de cada sistema o grupo. Los procesos de inclusión y exclusión coinciden con los elementos característicos del campo -deducidos por Satién (Jiménez: 2010) ${ }^{24}$-, en tres órdenes: primero, ser un espacio de lucha limitado, una competencia que deja fuera los profanos o legos, o incapaces y en la que la distribución de fuerzas es desigual; quien domina el juego

\footnotetext{
${ }^{23}$ Los agentes y sus obras no se definen solo en relación con los demás productores sino también en relación con su demanda. En tanto mercado, el campo es un lugar de competencia entre los productores y entre los consumidores, pero los intereses que en él se tratan de satisfacer no son puramente económicos, como los implicados en el tráfico de mercancías, sino de orden simbólico, y varían según el campo considerado. Hay tantas formas de interés y de capital cultural -en su forma simbólica- como campos.

${ }^{24}$ Satién Ravina, citado por Jiménez p 31. Bourdieu Pierre. La fuerza del Derecho. Estudio Preliminar de Carlos Morales de Nuevo Pensamiento Jurídico. Universidad de los Andes. Instituto Pensar. Siglo del Hombre Editores. Bogotá D. C., 2000: 62.
} 
impone sus condiciones, buscando extender en el tiempo y al máximo sus privilegios; segundo, ser un espacio definido mediante regularidades de conducta y reglas aceptadas; y tercero, presentar momentos de crisis coyunturales.

Después de campo, la segunda categoría conceptual de Bourdieu es la de capital, que se refiere al conjunto de recursos circulantes, objeto de luchas y consensos al interior de los distintos campos. La sociedad humana es como "una competencia feroz cuyo premio es la posición social. Poseer capital económico (bienes), social (redes de relaciones) y cultural (conocimientos especializados y diploma de una universidad prestigiosa) es una ayuda". (Jiménez, 2010: 21) Por lo tanto, hay una lucha entre estilos de vida, que es, al mismo tiempo, una lucha por el poder, específicamente por el capital simbólico.

En ese sentido, surge la cuestión de si el vínculo social se constituye en la lucha por el reconocimiento, el cual puede observar diferentes niveles, desde los lazos filiales, de consanguinidad e incluso conyugales. Es necesario recordar que excluido significa justamente no ser reconocido, no ser tenido en cuenta, en suma, definitivamente 'no ser' para otros. Esto manifiesta nuevamente uno de los matices o intenciones de las dinámicas de exclusión e inclusión: la lucha por el reconocimiento, que procura alcanzar el plano jurídico.

En esas interacciones inventamos tramas, para ayudarnos a configurar nuestra experiencia temporal confusa, informe y, en última instancia, muda (Ricoeur, 2005). Estos procesos de configuración de realidades se orientan algunas veces a establecer demarcaciones simbólicas que se traducen en distinciones, reglas de juego o intenciones, que pueden o no llegar a concretarse en escenarios y acciones para promover la exclusión e inclusión de las personas. Al designar al individuo como hombre capaz, pero también que padece, subrayando así la vulnerabilidad de la condición humana, Ricoeur defiende que la identidad personal está marcada por una temporalidad constitutiva; la persona es, de algún modo, su historia.

En la tipología propuesta por Ricoeur se considera la capacidad de decir, la de actuar y la de contar. En este vasto panorama de las capacidades afirmadas y asumidas, por 'poder decir' se comprende una capacidad más específica que el don general del lenguaje. 'Poder decir' es producir espontáneamente un discurso sensato. En el 
discurso alguien dice algo a otra persona de acuerdo con reglas comunes. En el mismo sentido, por 'poder actuar', Ricoeur alude a la capacidad de producir acontecimientos (no son sólo lo que pasa) en la sociedad y en la naturaleza. Introduce la contingencia humana, la incertidumbre, y lo imprevisible en el curso de las cosas. El 'poder contar' ocupa un lugar eminente entre las capacidades del ser en la medida en que los acontecimientos de cualquier origen sólo se vuelven legibles e inteligibles cuando se cuentan dentro de una historia.

Dado el valor y utilidad de las nociones anteriores aplicadas al fenómeno de exclusión/inclusión y a la función de lo simbólico en las relaciones y espacios sociales en un campo, en la siguiente selección se presenta y examina parte de las expresiones elaboradas por las profesionales que trabajan en Psicología Clínica, que fueron entrevistadas sobre las representaciones, relaciones interpersonales, $y$ acciones, en su trabajo, sus áreas temáticas, en contextos de educación, terapia e investigación.

En la sección se pretende enfatizar la importancia de las interacciones de comunicación de los agentes del campo de Psicología clínica en Vallarta: la capacidad de decir de la persona, su expresión como producto simbólico y vehículo del discurso que representa, cuya resonancia alcanza la configuración de espacios y el ejercicio del poder, relacionados con las estrategias y modalidades del fenómeno de la exclusión e inclusión social.

\section{Narraciones y discurso en Psicología Clínica}

Procurando integrar y representar en expresiones específicas y significativas algunos de los supuestos y nociones referidas en los párrafos anteriores enseguida se exponen fragmentos de las narrativas -construidas en el contexto de entrevistas personales- de cuatro profesionales de género femenino integradas al ámbito de Psicología Clínica. En primer término, se reúnen sus expresiones acerca de las concepciones de persona, salud, aspectos del trabajo en general y del poder. En segundo lugar, se incorporan sus ideas sobre modalidades y propuestas respecto a los procesos de exclusión e inclusión social. Así, desde estos escenarios es posible observar la importancia de la 
comunicación y de la propia lógica de estos fenómenos sociales en relación con los campos (académico y terapéutico) que lo configuran.

Cabe aclarar que no se pretende hacer un comparativo de las diferentes posiciones o fragmentos del discurso entre las 4 personas consultadas -a las que aquí nombraremos Silvia, Josefina, Patricia y Angélica-, por lo cual la presentación y cantidad de información contenida en cada aspecto varía, en algunos casos sólo se muestra una idea, en la que se encuentran contenidas otras apreciaciones o hay coincidencias.

Hay comentarios que abonan a diferentes elementos o circuitos vinculados con las interacciones de comunicación, así como a las problemáticas sobre exclusión e inclusión social, por lo cual también es difícil "separarlas" o ubicarlas en determinados "cajones" o categorías empíricas. Para favorecer el análisis se optó por organizarlas y colocarlas bajo aspectos concretos, pero como el lector podrá identificar, se asocian también a otras dimensiones o rasgos, pues tanto el lenguaje como la realidad son polisémicos e indisolubles, por lo que se encuentran conectados de varias maneras y en diferentes niveles.

Iniciemos con las concepciones de la propia persona, del psicólogo y de la salud. Sobre la primera, Silvia señala: "Para definir a la persona es fundamental esa unidad que tiene esos componentes biológicos, físicos, psicológicos individuales, intra-psíquicos... La relación entre cada una de esas partes de nosotros es esencial para la salud del cuerpo, del alma y de los grupos de los que somos parte, nuestras relaciones, la pareja, la familia, la comunidad, el país, la comunidad mundial".

De acuerdo con Josefina, la persona es el ser que se construye social y culturalmente porque vive en procesos sociales y se desarrolla a partir de la potencialidad que el sistema o la sociedad hace de él mismo y le proporciona. Así -dice- podemos ver diferentes personas con ambiciones, con propósitos, con sentidos de vida distintos, algunas casadas, pobres, ricas, creativas, ociosas, en diferentes condiciones. Agrega que el psicólogo es un profesional capacitado en una universidad, especializado en el área clínica; su función no queda en una posición curativa. Además previene que la enfermedad, el caos o el problema no lleguen. Dentro de su proceso de aportación a la 
sociedad también está el investigar y proveer a la sociedad con plataformas saludables para que en la medida de lo posible los problemas sean menores, así como participar en el ámbito de la formación.

Estas concepciones de persona y de la propia figura del psicólogo muestran las condiciones de este campo, en cuanto a cómo sitúa a los individuos en un espacio determinado, aunque éste siga siendo motivo de disputas por su legitimación, por hacer valer su posición, su visión y su forma de nombrar la realidad. Ningún campo es permanente, sino se encuentra en continua transformación y consolidación. La categoría de sociedad es desde esta perspectiva un campo de relaciones sociales, algunas devienen en procesos de exclusión e inclusión.

En relación con la noción de salud, Silvia la concibe como "un proceso, un caminar entre mayor o menor bienestar; el estado de completo bienestar biopsicosocial es una categoría ideal y cerrada; no es tan categórico ni tan excluyente, pues varía dependiendo quién lo defina, situación, grado de desarrollo, entorno, género, herencia, ambiente, educación, crecimiento, las redes sociales, la ecología del planeta. Van intrínsecamente unidos a tu nivel de bienestar y salud, el de tu comunidad, tu familia, tus relaciones".

Para Josefina, la salud es "la apreciación personal y subjetiva de cómo yo me siento ante lo que está a mi alrededor, tiene que ver con la autoestima. En la cuestión social hacer algo relevante, que tenga sentido como proyecto de vida, que abarque aspectos más amplios que la familia, que haya una retroalimentación positiva, un círculo creativo". Angélica sintetiza la idea de salud, retomando lo señalado por Freud, "es la capacidad del ser humano de amar, trabajar y gozar, de manera integral y balanceada".

Estas afirmaciones, sobre la relación que tiene la salud con los vínculos y procesos interpersonales, de redes sociales, comunidad y familia, es decir con el ambiente y las personas a nuestro alrededor, así como con la propia interpretación o expresión de los actores o sujetos al respecto, evidencian la importancia de la interacción de comunicación -entre personas, grupos o comunidades-, a la vez que en su calidad de fragmentos de un discurso -en el sentido de Ricoeur (Ricoeur, 2005; Peña y Tarrés, 2008)- tienen un carácter temporal, 
poseen un significado; se dirige a alguien capaz de responder, de cuestionar, de iniciar una conversación y un diálogo. La acción, específicamente la de comunicación en el campo de la salud, se hace con otros agentes, que pueden ayudar o estorbar; el relato reúne a múltiples protagonistas en una entrega única; una historia de vida se compone de una multitud de otras historias de vida.

Respecto a las concepciones sobre la exclusión e inclusión social, Josefina sostiene que "la exclusión tiene dos formas: una por parte de los otros y la segunda es a nivel personal, cuando ocurre la autoexclusión". La exclusión sería que las posibilidades terapéuticas, educativas o de investigación, no estén al alcance de las poblaciones o su acceso no sea posible por limitaciones económicas, políticas, o de credo. También incluye que la posición de los profesionales no sea tomada en cuenta.

En esa misma línea, Silvia explica: "Todos nos movemos hacia un polo con mayor plenitud de derechos y ciudadanía o más lejos de eso, hacia un estado con menos acceso a su participación, a todos los beneficios y responsabilidades, lo cual dependerá de muchas situaciones sociales, económicas".

En relación a las formas específicas de inclusión Patricia subraya: "No es pensar que el gobierno proporcione o no opciones y recursos para incluirnos, sino qué tanto por nosotros mismos podemos ser autosuficientes y con apertura para acceder a los beneficios y posibilidades de desarrollo social".

Este escenario de las formas concretas de inclusión, considerando las cuestiones personales, laborales o civiles, se asocia con los principales factores de exclusión en el ámbito relacional indicados por Rubio (2006): el deterioro de las redes familiares (conflictos o violencia intrafamiliar); escasez o debilidad de redes familiares (monoparentalidad, soledad, entre otros) y de las redes sociales (dificultades para relacionarse, crear y/o mantener su red social) y, finalmente, el rechazo o estigmatización social. Los condicionantes en la inclusión y la exclusión social también son de orden histórico y varían según espacio y tiempo, de acuerdo a cuestiones estructurales.

Particularmente, en cuanto a los procesos de inclusión en la formación del psicólogo, Josefina aclara que estos contemplarían acceder a los niveles educativos más elevados, independientemente 
del origen, la situación económica, el status migratorio, el credo, etcétera, así como educarse en medios alternativos a la escuela, tener esa posibilidad de acuerdo a sus intereses y sus cualidades cognitivas, y ocupar un lugar en el mundo. Agrega: "no hay una capacitación continua, no hay una formación de posgrado, no están adheridos a un colegio donde estén vigilados, donde esté supervisada su práctica. No hay controles para saber qué se hace, en muchos de estos casos no hay una acción voluntaria o premeditada y la exclusión es circunstancial".

Patricia lo expresa en los siguientes términos: "en la cuestión educativa hay quien fácilmente se integra y puede entrar a un proceso de cognición, de utilizar ese conocimiento para fortalecerse y tener mejor desempeño. Pero también hay una gran mayoría que tiene todos esos medios pero no los aprovecha; en área social, de investigación y clínica pasa lo mismo". Para Angélica, la exclusión se refiere a la interacción de la persona con paradigmas accesibles, es decir "si no pueden entender toda la teoría que son lenguajes muy complejos, se van por algo que intelectualmente sea más accesible para ellos y, además, también formativamente más a su alcance". Estas últimas cuestiones evidencian uno de los elementos señalados por Satién (Jiménez, 2010) que caracterizan al campo, como espacio de lucha limitado, donde se compite y se deja fuera a los profanos o legos, o incapaces y donde la distribución de fuerzas es desigual.

En las anteriores expresiones sobre las condiciones e interacciones de sujetos que desean formarse (integrarse) en el campo de la psicología, puede destacarse la importancia de las decisiones tomadas por personas en contextos de comunicación y relación con otros, donde influye su propia situación y estructura, es decir su babitus. ${ }^{25}$

\footnotetext{
${ }^{25}$ En palabras de Bourdieu, el habitus es una "estructura estructurante, que organiza las prácticas y la percepción de las prácticas [...] también estructura estructurada: el principio del mundo social es a su vez producto de la incorporación de la división de clases sociales. [...] Sistema de esquemas generadores de prácticas que expresa de forma sistémica la necesidad y las libertades inherentes a la condición de clase y la diferencia constitutiva de la posición, el babitus aprehende las diferencias de condición, que retiene bajo la forma de diferencias entre unas prácticas enclasadas y enclasantes (como productos del habitus), según unos principios de diferenciación que, al ser a su vez producto de estas diferencias, son objetivamente atribuidos a éstas y
} 
Este concepto central en la obra de Bourdieu, es muy ilustrativo para comprender los procesos de exclusión e inclusión social, por ser -el habitus - un conjunto unitario de elección de personas, de bienes y de prácticas, que continuamente excluye y obviamente acepta. Dicha elección también tiene la capacidad de producir prácticas y obras, construyendo el mundo social representado, el espacio de los estilos de vida. Cuando ello es puesto en acción, se vuelve una diferencia simbólica y constituye, en palabras de Bourdieu, un verdadero lenguaje.

En contextos terapéuticos, Silvia subraya que la inclusión se expresa también en brindar al otro toda la atención. Patricia defiende que la inclusión implica el grado en que la persona que acude se quiere integrar, relacionar, que se adapta al mismo cambio evolutivo que hay en el propio medio o sistema donde vive.

Sobre la relación con colegas (gremio), Josefina indica que existe un apoyo, una retroalimentación de su trabajo en la academia y eso es importante porque están en constante capacitación. Sin embargo, agrega: "Se abren muchos consultorios, no hay restricciones de acuerdo al área de competencia, según el conocimiento que se tenga de las propias limitaciones, ese es un problema. Hay charlatanes... Hay competencia, hay rivalidad en el sentido disciplinar, cada uno de los grupos se cierra y no comparte o no cree en posibilidades de éxito de otros paradigmas. Ese es el conflicto que veo en la psicología, desde luego se traduce en que los conductistas se juntan con los conductistas, los psicoanalistas con los psicoanalistas. En ese sentido, hay un problema de desacreditación de los métodos y las formas de acción que los otros hacen que no coinciden con su formación".

Silvia y Angélica coinciden al referir que hay muchas voces pero no hay concierto. Algunas personas disienten con el punto de vista biológico, médico o neurobiológico, o con el psicoanálisis. Angélica señala que hay quienes casi satanizan al psicoanálisis y aceptan "críticas que son muy válidas, pero se nos ha hecho muy difícil hacer consenso. En lo que estamos todos de acuerdo es que buscamos

tienden por consiguiente a percibirlas como naturales (1988, p. 170-171). La distinción. Madrid. Taurus. 
cambios para favorecer el bienestar, la salud, la calidad de vida y el desarrollo de esa persona".

Sobre las interacciones comunicativas en el gremio de psicólogos clínicos vale la pena recordar las palabras de Ricoeur sobre lo que se considera adecuado o no, y la incidencia que ello tiene en el grupo (campo) al que se aspira ingresar, o en el cuál se desea permanecer. El autor sostiene que el desdén y la humillación impactan al vínculo social en un plano superior, a saber, el de la estima social dirigida al valor personal y a la capacidad de buscar la felicidad de acuerdo con la propia concepción de la vida buena.

Desde la dimensión personal y educativa, estas representantes del campo de la Psicología Clínica sugieren para promover mayor inclusión social, el crecer en términos de conocimiento; estar informados, desarrollar sus propias condiciones, supervisar y reflexionar continuamente sobre el quehacer; dejar entrar la voz de los otros hacia nuestros espacios, ser solidarios, no esperar a que "los otros hagan para podernos mover, o que le diga de qué se trata o qué tiene que hacer o dónde ser incluido, sino que él mismo descubra lo que eso significa", según Patricia.

En cuanto al trabajo terapéutico, se apuesta por promover la inclusión y el empoderamiento desde el principio. Pensar en situaciones concretas, preguntar a quién y por qué se le excluye, pero en general que exista claridad sobre cuáles son las reglas del juego.

Patricia enfatiza que tomar conciencia sería el primer paso, difundir el punto de vista o la necesidad de cambios en ese sentido. Silvia especifica que sería útil participar en movimientos ciudadanos que favorezcan la inclusión y a través de esto aportar a reformas estructurales, legales y demás. "La ciudadanía debe promover inclusión, hablarle al vecino rarito, darle chance de empleo a alguien morenito, chaparrito, o tratar de moderar el impulso de rechazar mejor ese no por gordo o amanerado; como personas empezar por abrir los ojos, porque son situaciones que se nos plantean en lo cotidiano. Organizarnos para que haya apoyo a las mujeres que sufren violencia, son indígenas o tienen trastorno mental. Creo en el poder del cambio a nivel de cada uno; preocuparse por el otro, por la gente que queda en situación de calle, situaciones entrelazadas unas con otras". 
Para complementar dichas propuestas respecto a promover la inclusión y reducir los efectos de la exclusión, cabría considerar el concepto de 'nosotrificación' en todos los espacios o escenarios sociales posibles interpersonales (cotidianos y terapéuticos), familiares, institucionales (educativos y laborales), que es una palabra cuyo sentido es eliminar la individualización y pensar en términos de comunidad o grupo, en un 'nosotros' (González, 2007).

\section{Comentarios finales}

En estas expresiones sobre los diversos sub-grupos del campo de la salud mental se pueden observar las luchas por la legitimación de posiciones, donde entra en juego la 'identidad' de las personas que los conforman. También se ha dado cuenta del profundo impacto del lenguaje para la exclusión e inclusión de lo que se considera o no aceptable sea en un espacio terapéutico o entre colegas. El marco de esta disputa por la estima son los diferentes escenarios de la vida cotidiana: las universidades, el trabajo, la vía pública y cualquier otro espacio/campo social en el que se encuentre el sujeto, pero independientemente de su naturaleza, a su interior/exterior se generan interacciones de comunicación y pugnas por legitimarse como tal, sea a nivel grupal o personal.

Es necesario reflexionar permanentemente sobre las cuestiones implicadas en la inclusión/exclusión social desde el campo sanitario y de la comunicación, que entre otras incluyen las concepciones de quiénes somos, qué hacemos, cuál es nuestra función y cuál su sentido en el contexto propiamente de la salud y del trabajo. Se requiere también revisar las formas específicas de nombrar las realidades y las problemáticas que los agentes identifican y, por supuesto, las correlaciones entre quienes integran los grupos (reconocidos o de poder) en la Psicología y en el resto de las áreas sanitarias, o de los que son apartados de ellos, desprovistos de privilegios o beneficios.

Este conocimiento se obtendría mediante la investigación de las representaciones sociales (en plataformas mediáticas), prácticas, procesos (comunicativos, laborales y formativos), y las propias narrativas/interpretaciones de los sujetos involucrados o excluidos de diferentes campos de la salud. Así se podrían obtener importantes 
claves para comprender no sólo qué está pasando, o cómo cambian las visiones e interacciones -según el contexto histórico o geográficosino además, hacia dónde podremos reorientar los esfuerzos y recursos, si deseamos promover mejores opciones para la salud pública integral, compartida e incluyente.

\section{Referencias biblográficas}

Bourdieu, P. (2011): Las estrategias de la reproducción social. México: Siglo XXI.

Bourdieu, P. (1988): La distinción. Madrid: Taurus.

González, J. (2007): Entre cultura(s)y cibercultur@(s) Incursiones y otros derroteros no lineales. Argentina: Editorial de la Universidad Nacional de La Plata.

Jiménez Gil, W. (2010): Pierre Bourdieu y la racionalidad jurídica como instrumento de subyugación. Análisis de la crisis de los deudores individuales de créditos hipotecarios en UPAC a la luz de la teorética del campo jurídico. Colombia: Universidad La Gran Colombia.

Peña, J. y González, O. (2008): "La representación social. Teoría, método y técnica” en Tarrés, M. (Coord): Observar, escuchar y comprender. Sobre la tradición cualitativa en investigación social. México, Flacso/Colmex.

Ricoeur (2005): Volverse capaz, ser reconocido * Texto escrito con motivo de la recepción del Premio Kluge, otorgado por la Biblioteca del Congreso de Estados Unidos en Revue des revues de l'adpf, sélection de décembre.

Rubio Arribas, F. (2006): "La exclusión socio-laboral de colectivos con dificultades en su acceso al mercado laboral". En Nómadas. Revista Crítica de Ciencias Sociales y Jurídicas Núm. 14 Publicación electrónica de la Universidad Complutense. 


\section{Las asociaciones de pacientes con Enfermedades Raras generan conocimiento en la Red}

\section{Paloma López Villafranca [ORCID] [ G $\underline{\text { ORS }}$ ] (Universidad de Málaga)}

Resumen: Las asociaciones de pacientes se han convertido en actores principales en el impulso de la investigación, en la recopilación de información sobre los distintos diagnósticos y tratamientos. La red es el espacio en el que realizan intercambios de información, comparten experiencias, realizan reivindicaciones y muestran solidaridad con quienes padecen las mismas afecciones. Estos colectivos están demostrando en los últimos años un gran esfuerzo, empeño y utilización de Internet con objeto de mantenerse en contacto y generar e intercambiar conocimiento.

La aparición de la web 2.0, las redes sociales y las nuevas tecnologías, incluidas aplicaciones como WhatsApp, permiten a estos usuarios estar constantemente conectados y avanzar en el conocimiento de su propia enfermedad de forma acelerada. Incluso estos pacientes llegan a tener más información sobre estas patologías que ciertos sectores de la comunidad científica.

En un momento en el que estas personas necesitan más apoyo que nunca, mayor visibilidad en la sociedad y más información sobre sus enfermedades, la red es el espacio adecuado para conseguir sus objetivos. Teniendo en cuenta la baja prevalencia de estas enfermedades, 5 casos por cada 10.000 en la Comunidad Europea, 
Internet es la vía por la que estos pacientes obtienen e intercambian la mayoría de la información. La red supera los obstáculos que suponen la distancia geográfica, cultural e incluso idiomática. Una fuente de conocimiento que generan los propios pacientes y que comparten con otros afectados, la sociedad e incluso las administraciones y comunidad científica.

Palabras clave: asociación de pacientes, enfermedades raras, e-salud, web 2.0, conocimiento.

\section{Introducción}

EGÚN LA Agencia Europea de Medicamentos ${ }^{26}$, hay entre 5.000 $\mathcal{O}_{\text {y }} 8.000$ enfermedades raras distintas en la Unión Europa, que afectan a entre 27 y 36 millones de personas. Los pacientes de Enfermedades Raras en España son aproximadamente 3 millones. Feder, la Federación Española de Enfermedades Raras, se ha convertido en la portavoz de estos pacientes, que se agrupan además en más de 200 asociaciones localizadas geográficamente por toda España. Estas entidades cuentan con sede en las capitales de las comunidades autónomas. De cualquier manera, la mayoría de estas asociaciones tienen muchas limitaciones e intentan ofrecer información y ayuda a otros pacientes con un mínimo número de miembros.

Esta participación activa de las asociaciones se ha visto favorecida por la utilización cada vez más habitual de Internet, sobre todo por el uso de webs propias y redes sociales como herramientas para establecer una comunicación efectiva.

Potts (2008) afirma que los usuarios de la sociedad del conocimiento, en particular los usuarios de salud en la red, evolucionan de forma más rápida que los propios investigadores o proveedores de servicios. El autor hace alusión al caso de Estados Unidos, donde más de diez millones de personas forman parte de grupos de apoyo online que comparten recursos.

Los pacientes son proactivos y una pieza clave en los avances de la

${ }^{26}$ Datos obtenidos en la página web de la Agencia Europea de Medicamentos: http://www.ema.europa.eu/ema/ (visto por última vez en febrero de 2014) 
investigación médica. Las personas con enfermedades poco frecuentes y sus allegados están realizando una labor vital para conseguir la recopilación de la información sobre estas patologías, compartirlas con otros afectados e incluso con la comunidad científica.

\section{Marco teórico}

\subsection{Las asociaciones de pacientes de Enfermedades Raras en la red}

En Europa se produce la consideración de enfermedad o desorden raro cuando afecta a 1 de entre 2.000 personas. La red Europea de Asociaciones de Enfermedades Raras (EURORDIS) afirma que existen más de 6.000 enfermedades raras, que afectan a 30 millones de ciudadanos europeos. El 80\% de las enfermedades raras son de origen genético y muchas veces son crónicas y ponen en riesgo la vida.

La mejora asistencial y la investigación sobre estas patologías ha avanzado en la última década gracias al movimiento asociativo. A través de organizaciones independientes y después mediante federaciones, estas entidades han logrado mejorar la difusión de conocimientos.

Rabeharisoa y Callon (2002) destacan el papel de estas asociaciones que fomentan la creación de "grupos de ayuda mutua, la reivindicación creciente de los usuarios y una participación más activa en la concepción de los servicios que les están destinando".

En España existe la Federación Española de Enfermedades Raras, FEDER, que agrupa a este movimiento asociativo. Feder nace en 1999 con un objetivo primordial: la unión de los pacientes para buscar soluciones a sus problemas y difundir información. Agrupa a unas 200 asociaciones en España. A nivel nacional y con carácter representativo de estos colectivos, existen 124 asociaciones con presencia en Internet, ya sea en la web o redes sociales.

Los usuarios de estas redes sociales, los miembros de estas asociaciones realizan la labor de crossumer. Un término que se refiere a una nueva generación de consumidores que desean hacerse oír y que establece una relación con los productores más igualitarios. En el 
caso de los pacientes, en la red actúan como esos usuarios que también producen y consumen información sobre las enfermedades que les afectan. Han jugado un papel muy importante mejorando el conocimiento de esas patologías poco frecuentes, sobre todo teniendo en cuenta que la mayoría de estos pacientes se encuentran aislados, sin información y con muy pocos recursos y desconocimiento de posibles tratamientos, terapias o medicación.

Internet, en concreto las redes sociales, están sirviendo para que estas asociaciones además se hagan más fuertes, se consolide el apoyo solidario y la información al resto de los ciudadanos. En la Unión Europea, EURORDIS ${ }^{27}$ (European Organization for Rare Diseases) es una alianza no gubernamental de organizaciones de pacientes dirigida por ellos mismos que representa a 606 organizaciones de afectados por enfermedades raras en 56 países. A nivel internacional los pacientes con Enfermedades Raras se decantan también por utilizar la red RareConnect ${ }^{28}$.

Además de sus propias webs, blog y su inclusión en las redes sociales habituales como Facebook o Twitter, existen otras redes sociales especializadas en pacientes con Enfermedades Raras en España, como por ejemplo; redpacientes.com, personasque.com, somospacientes.com, patientslikeme.com, kronikoensarea.net, ayudacancer.com o guiametabolica.org, entre otras.

\subsection{La evolución de la e-Salud}

Hay dos términos claves a tener en cuenta para profundizar en la generación de conocimiento a través de la red. Por una parte, nace un nuevo concepto con el avance de las nuevas tecnologías y el desarrollo de las herramientas de la web, es el término de Salud 2.0. Salud 2.0 es según Guillén Barrionuevo y Basagoiti (2009) ese aspecto clave en la revolución en la red, que se refiere sobre todo a cuestiones como accesibilidad a la información y otros recursos que rompe las

\footnotetext{
${ }^{27}$ Eurordis es una red que presta sus servicios en la red en español en la página web: <http://www.eurordis.org/es > (visto por última vez en febrero de 2014) ${ }^{28}$ Esta red está sirviendo de nexo de unión y comunicación para todos los pacientes con estas patologías. La página es: < $\underline{\text { https://www.rareconnect.org/es }}>$ (visto por última vez en febrero de 2014).
} 
barreras geográficas, culturales y las propias de la organización.

Por otra parte, hay que citar el concepto de eSalud, que según la Organización Mundial de la Salud (OMS), ) consiste en "el apoyo que la utilización eficaz y segura de las tecnologías de la información y las comunicaciones ofrece a la salud y a los ámbitos relacionados con ella, con inclusión de los servicios de atención de salud, la vigilancia y la documentación sanitarias, así como la educación, los conocimientos y las investigaciones en materia de salud".

Estos dos conceptos están muy relacionados con el nuevo perfil de paciente, que según el Libro blanco sobre la oncología médica en España, es el de un usuario con mayor nivel educativo, con cultura de derechos del consumidor y acceso a mayor información sobre salud mediante Internet y los medios de comunicación. (Muñiz y varios, 2007: 53).

Bañón y Fornieles (2011) en su libro "Desafíos y estrategias comunicativa de las enfermedades raras: la investigación médica como referente" ${ }^{29}$ resalta el papel que juega Internet en el campo de la salud. La red se presenta como medio fundamental para divulgar información sobre estas patologías y compartir experiencias e información. Aunque ambos consideran que resulta insuficiente, "ya que la población en general desconoce la existencia de las Enfermedades Raras".

Sánchez Castillo (2012) cuando alude a la representación de las Enfermedades Raras en la prensa, sostiene que son los medios los que contribuyen a concienciar a la sociedad de las necesidades de las personas afectadas. La información, la que los pacientes obtienen de del médico, de las asociaciones y de los medios de comunicación es clave para que se llegue a la opinión pública. De esta forma, mediante la obtención y difusión de esta información se logra un objetivo primordial; obtener esa visibilidad que necesitan estos pacientes en la sociedad. Para que el conocimiento o la concienciación de la opinión pública sobre estas patologías sea mayor, es necesario que exista una mayor presencia en los medios de comunicación generalistas.

\footnotetext{
${ }^{29}$ Editado por CIBERER, en colaboración con la Universidad de Almería y la Universidad CEU-Cardenal Herrera de Valencia que analiza discursiva y cuantitativamente el tratamiento en prensa de las Enfermedades Raras de 2009 a 2010.
} 
Las asociaciones gestionan, difunden y controlan mediante estas herramientas la información que obtienen y que comparten con otros afectados. La presencia en las redes sociales de las asociaciones de Enfermedades Raras es cada vez más habitual. Mediante estas redes los afectados se mantienen en contacto y se relacionan con otros sectores de interés.

"Los nuevos medios de comunicación no han servido sólo para la generación de mensajes por parte de los colectivos implicados, sino también para mostrar el interés de los propios medios". (Bañón y Fornieles, 2009: 31 y 32).

Las asociaciones cuentan cada vez con mayor asiduidad con herramientas 2.0 en la web. Armayones y Hernández (2007) incluso se refieren a la web 3.0, como medio más eficaz en la búsqueda y difusión de información sobre enfermedades, con el papel de "figura de apoyo" que necesitan personas tras ser diagnosticadas y que no encuentran en el mundo físico o como forma de experimentar sensaciones en un futuro no muy lejano como un aspecto más de la eSalud.

Un hecho a tener en cuenta en España ya que según Nielsen ${ }^{30}$, este país con más de 25 millones de internautas, es el segundo país del mundo que más las utiliza. De cada cuatro internautas españoles, tres las visitan y, además, los españoles le dedican 5’3 horas al mes, dato que supera Rusia, Brasil, Canadá y Puerto Rico.

Facebook continúa siendo la red social más popular en España, el $96 \%$ de los internautas entre 18 y 55 años la utilizan. Y en 2013, según Nielsen las redes con más crecimiento desde 2011 son Linkedin, Google + y Twitter. Pero como demostraremos en el análisis las redes sociales más utilizadas son las más comunes Facebook y Twitter, a pesar de que ya existen redes especializadas en las ER como RareConnect, RareShare, y otras asociaciones de

\footnotetext{
30 The Nielsen Company es una empresa de información y medios a nivel global, y es una de las fuentes líderes en información de mercado de medios de comunicación y audiencias de televisión, información on-line, móviles y publicaciones de negocio y entretenimiento. Más datos de este informe en $<$ http://es.nielsen.com/site/index.shtml $>$ (visto por última vez 31 de mayo de 2013).
} 
pacientes como SomosPacientes, RedPacientes, Patientslikeme, kronikoensarea, Ayudacancer.

\subsection{La generación del conocimiento}

Una iniciativa pionera en la generación de conocimiento es la que ha llevado a cabo la asociación de Lowe. LoweResearchProject, es un proyecto dirigido por los doctores Serrano, del Hospital Materno Infantil de San Juan de Dios, y Armayones, de la Universidad Abierta de Cataluña y de la UOCEI. Está basado en el modelo ePacibard, pacientes que generan inteligencia colectiva en Investigación Biomédica, trata de mostrar los esfuerzos realizados de forma colaborativa entre médicos, psicólogos de la UOC, investigadores y asociaciones de pacientes para generar conocimiento mediante el trabajo colaborativo en redes sociales.

Armayones afirma que con este proyecto se ha conseguido reunir más información y ponerla a disposición de los investigadores que en 60 años en los que se ha descubierto la enfermedad de Lowe, una enfermedad considerada ultra-rara. Según Armayones, los e-pacientes son potencial de enormes posibilidades; colaboración técnica, recaudación de fondos, divulgación, colaboración directa en investigación, que no está siendo utilizado.

\section{Objetivos}

Entre los objetivos principales de este estudios se encuentran los siguientes;

1. Analizar la presencia en la red de las asociaciones más proactivas.

2. Comprobar qué tipo de herramientas de comunicación utilizan y el contenido que generan a través de ellas.

3. Relacionar el uso que hacen de estas herramientas con la generación de contenido.

\section{Hipótesis}

La hipótesis se basa en demostrar que la utilización de las 
herramientas y posibilidades que otorga la red contribuye a que estas asociaciones generen, recopilen y compartan información que puede ser vital para que se avance en la investigación de estas patologías.

\section{Metodología. Variables y codificación}

La metodología utilizada es el análisis de contenido de los espacios en la red de las asociaciones de Enfermedades Raras que se basan en el trabajo colaborativo en Internet para generar conocimiento, tanto webs, blogs como redes sociales.

Se realiza un análisis de las herramientas de comunicación de la web teniendo en cuenta variables relacionadas con la comunicación 2.0 por lo que se elabora una plantilla de análisis semejante a la utilizada por el profesor Castillo (2008) en el análisis de las salas de prensa de las diez empresas más grandes de España. Se tendrán en cuenta aspectos que conformarán unos códigos específicos como: la utilización de recursos de salas de prensa (notas, comunicados, dossier de prensa, revistas, entrevistas), utilización recursos audiovisuales (fotos, videos, recursos sonoros, canales de youtube), presencia en redes sociales enlazadas con la web, (redes sociales generales o especializadas en pacientes) y sindicación de contenidos (rss). Además se comprueba en qué redes sociales están presentes, si cuentan con foros enlazados o independientes, blogs independientes o enlazados con las webs analizadas.

\subsection{Objeto de estudio}

Las herramientas 2.0 de las asociaciones españolas de Enfermedades con presencia en la red, que muestran una actividad más intensa en Internet.

\subsection{Universo}

El universo lo componen las más de 200 asociaciones españolas de Enfermedades Raras, entre las que encontramos 124 nacionales con presencia en Internet. 


\subsection{Muestra}

Este estudio procede de un análisis previo de estas 124 asociaciones. Elegimos una muestra significativa, las asociaciones que apreciamos que registran mayor actividad y un mayor número de seguidores en las redes sociales. La muestra está compuesta por las siguientes 32 entidades, incluida la Federación Española de Enfermedades Raras (Feder):

1. Feder, la Federación Española de Enfermedades Raras.

2. Asociación de Lowe España, la asociación pionera en el modelo ePacibard, pacientes que generan inteligencia colectiva en Investigación Biomédica.

3. Fundación Isabel Gemio.

4. Asociación de Víctimas de Talidomida en España.

5. Asociación de Charge España.

6. Asociación de Afectados por Displasia Ectodérmica.

7. Asociación de Afectados de Neurofibromatosis.

8. Asociación de Duchen Project.

9. Asociación de Corazones Púrpuras.

10. Asociación Hipofam.

11. Asociación Nacional de Hipertensión Pulmonar.

12. Asociación Síndrome Stickler.

13. Federación Fibrosis Quística.

14. Asociación Española contra la Leucodistrofia, ELA.

15. Fundación Atrofia Muscular.

16. Asimaga, Asociación Sindrome del Maullido del Gato.

17. Asociación Nacional de Amigos de Arnold Chiari.

18. Asociación Stop Sanfilippo.

19. Asociación Rubinstein Taybi.

20. Asociación de afectados por el Síndrome de Moebius.

21. Fundación Menudos Corazones.

22. Federación Española Enfermedades Neuromusculares (ASEM).

23. Asociación Síndrome de Angelman.

24. Asociación Española para el Síndrome Prader Willi.

25. Asociación Síndrome de Williams.

26. Asociación Española de Esclerosis Lateral Amiotrófica, Adela.

27. Asociación Corea de Huttington. 
28. Alianza Española de Familias de Von Hippel Lindau, VHI.

29. Asociación Síndrome de Marfan.

30. Asociación Española de Déficits Inmunitarios Primarios.

31. Asociación del Síndrome de Lesch-Nyhan España.

32. Asociación Española para la Investigación y Ayuda al Síndrome de Wolfram.

\section{Resultados}

De forma previa, hemos comprobado que el $80 \%$ del total de las asociaciones, de las 124 existentes, utilizan la red para intercambiar información. Al analizar la muestra, las 32 asociaciones, comprobamos que la mayoría utilizan las herramientas 2.0. Son webs 2.0 las que utilizan el $88 \%$ de las entidades analizadas. El resto, 12\% aún comparten conocimientos a través de una web 1.0.

Gráfico 1. Webs de las asociaciones analizadas

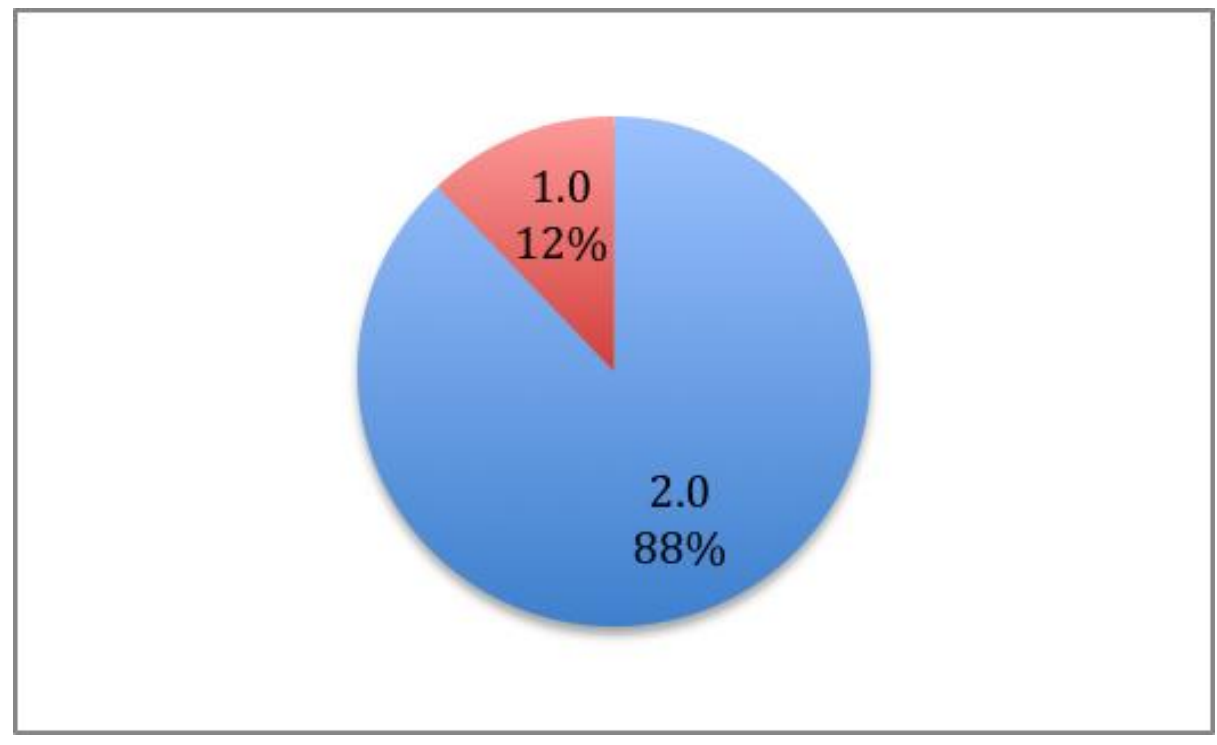

Fuente: elaboración propia

Con referencia a los recursos de la que podría ser sala de prensa de la web de la asociación, utilizan los siguientes recursos:

- Noticias: el 72\% de las asociaciones genera noticias sobre la entidad o la propia enfermedad. Noticias de interés para los pacientes.

- Comunicados: el 41\% elabora comunicados, a veces en forma de circular dirigida a los propios afectados, pero en 
definitva son comunicados sobre la asociación.

- Dossier de prensa: el 47\% elabora dossiers de prensa, en los que incluyen folletos, carteles y otros elementos que sirven para realizar divulgación sobre las patologías que tratan.

- Revistas: el 38\% cuenta con revistas, de la propia asociación o de otras entidades que resultan de interés para el usuario.

- Entrevistas: el 19\% tiene en este espacio entrevistas, las mayoría procedentes de medios de comunicación que cuelgan para que estén disponibles a todos los navegantes.

Gráfico 2. Herramientas de comunicación

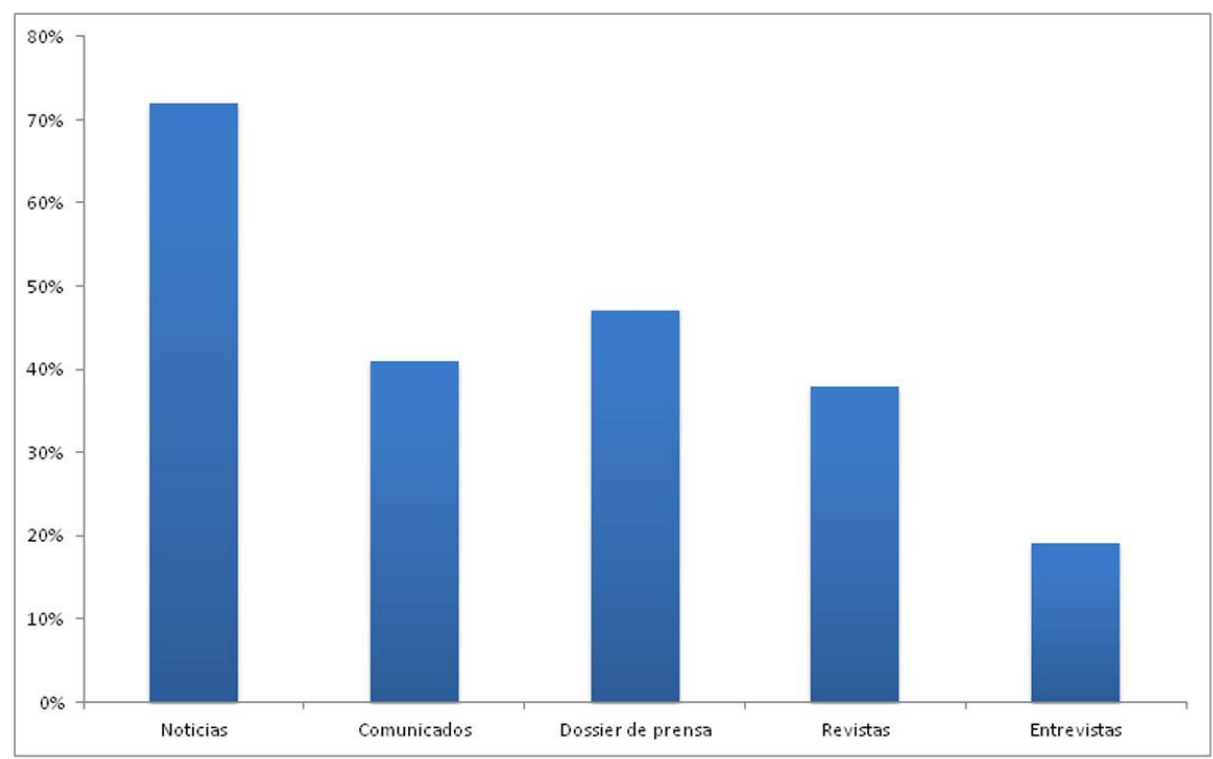

Fuente: elaboración propia

En relación a los recursos audiovisuales, utilizan:

- Fotos: 50\% dispone de fotogalería en la web.

- Vídeos: 60\% tiene un espacio donde se pueden reproducir vídeos relacionados con la enfermedad.

- Recursos Sonoros: el 16\% de estas webs disponen de recursos sonoros.

- Canales de Youtube: 34\% dan la posibilidad a suscribirse en canal de youtube. 
Gráfico 3. Recursos andiovisuales

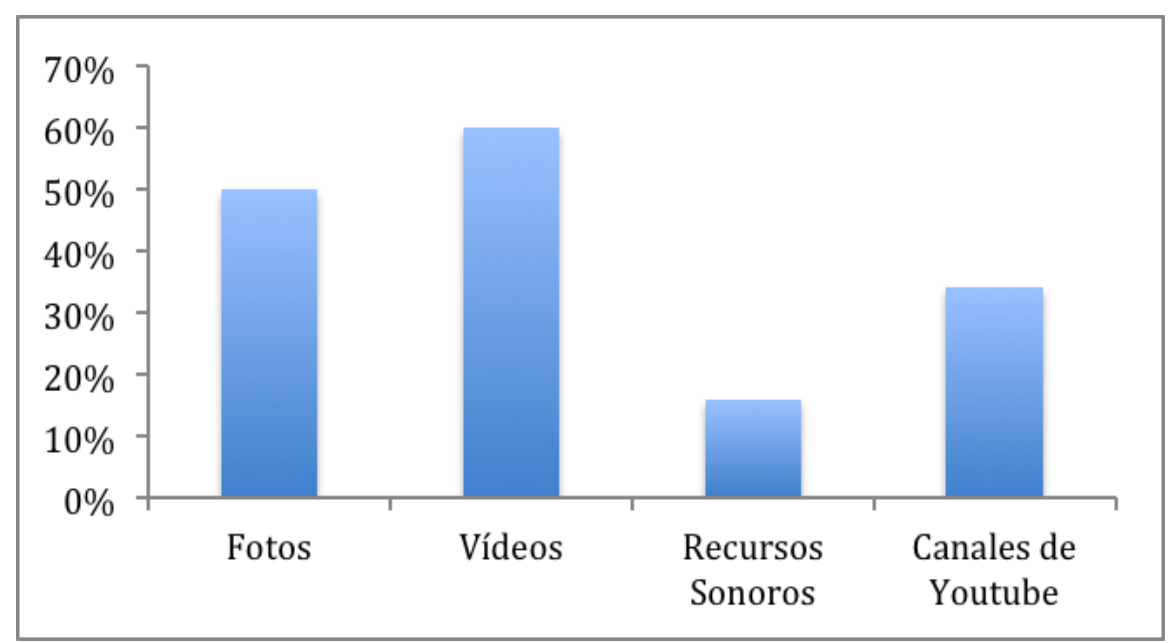

Fuente: elaboración propia

El 12\% de las asociaciones te ofrece la posibilidad de sindicación de contenidos, RSS.

El 91\% cuentan con presencia en las redes sociales y un número de seguidores entre 500 y 1.000 , que ha sido uno de los factores por los que se ha tenido en cuenta la elección de estos espacios como muestra del análisis. Por regla general, las dos redes sociales en las que está presente son Facebook, la utilizan el 78\%, y Twitter, el 69\%. Sólo el 6\% hace uso de redes sociales especializadas en pacientes o al menos, así lo indica en la página web.

Gráfico 4. Presencia en redes sociales

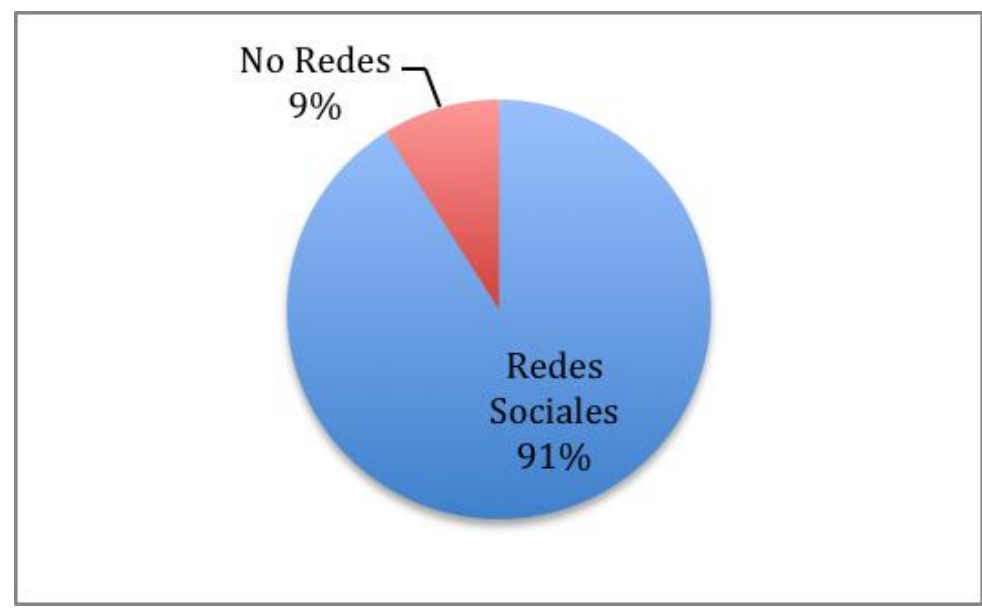

Fuente: elaboración propia

El 44\% cuenta con un blog enlazado a la web de la asociación, se puede acceder desde la misma página web. 
Gráfico 5. Blogs enlazados a la web de la asociación

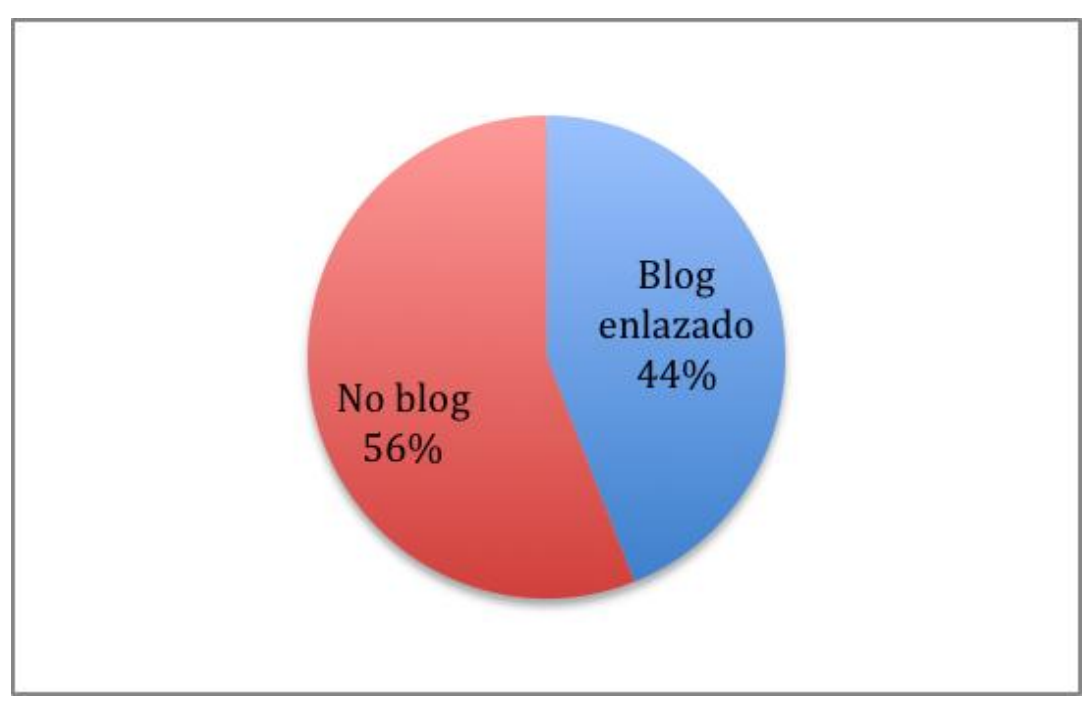

Fuente: elaboración propia

Por último, el $35 \%$ de las asociaciones cuenta con un foro, que normalmente requiere de un registro previo para comentar aspectos más delicados relacionados con la enfermedad.

\section{Conclusiones y discusiones}

Mediante el análisis de esta muestra, queda patente que el uso de las nuevas tecnologías y de la web 2.0 se extiende cada vez más entre estos pacientes, que necesitan del contacto y la información que en muchas ocasiones no obtienen por otros canales.

El hecho de que el $80 \%$ del total de las asociaciones tenga presencia en la red y de que casi el 90\% de las asociaciones analizadas cuente con una web 2.0, pone de manifiesto que a través de Internet se está cubriendo una necesidad básica para estos enfermos. No sólo hay una comunicación e intercambio de información entre pacientes, además se establece una conexión con la sociedad mediante la divulgación de información.

El 72\% de estas asociaciones da prioridad a las noticias, ya sea a la recopilación de las que se generan en los medios o las que ellos mismos producen. Por lo tanto, están ofreciendo la posibilidad a otros afectados, a sus familiares o a los ciudadanos de tener una visión más cercana sobre una dolencia poco común y de la que existe 
escasa literatura. Este tipo de textos siempre será más comprensible que los artículos científicos o la información con terminología médica, que es una de las trabas con las que se encuentra el usuario a la hora de entender las propias patologías.

La utilización del dossier de prensa, que elaboran el 47\% de estas asociaciones, es muy útil para el profesional de comunicación, que puede ejercer la función de portavoz y también resulta un elemento de divulgación muy interesante. La aportación además de anexos como carteles, folletos y otros elementos, contribuyen a hacer más cercana la enfermedad y a ofrecer de forma sintética la información básica.

Los comunicados que elaboran los miembros de estas asociaciones sustituyen a las antiguas circulares, aunque también tienen la utilidad de servir como instrumento para convocar a los medios o socios interesados a acudir a los actos de las entidades. Utilizan los comunicados en la web el $41 \%$ de las asociaciones y el 38\% realizan revistas $\mathrm{O}$ las distribuyen procedentes de otras entidades $\mathrm{O}$ federaciones, por falta de medios económicos o recursos humanos. El esfuerzo de estas asociaciones, que cuentan en ocasiones con un escaso número de miembros, es loable. Los pacientes con enfermedades raras son un colectivo de 3 millones de personas que se sienten desamparados por las administraciones y que las iniciativas que llevan a cabo parten del afán por avanzar y conseguir metas por parte de familiares, enfermos y voluntarios.

Lo audiovisual se impone en las webs como elemento atractivo y como una pieza clave en la generación de conocimiento. En el 50\% de estas webs analizadas existen fotogalerías y el 60\% tiene algún vídeo colgado. Incluso el 34\% tiene canal de Youtube. La imagen prima en la sociedad y el conocimiento se comparte en Youtube. La difusión de campañas de información sobre las patologías, los posibles tratamientos o las experiencias tienen cabida en este canal, donde se muestra una realidad difícil de explicar sin estos recursos audiovisuales, más cercanos al ciudadano.

Prima la imagen sobre el sonido, que sólo utilizan el 16\% de las asociaciones.

Estos colectivos tienen una presencia casi obligada en las redes sociales. Las utilizan más del $90 \%$, y las dos redes sociales generalistas 
Facebook y Twitter se convierten en un canal accesible a todos los ciudadanos, económico y un medio idóneo para compartir y generar información. De hecho, la mayoría de las asociaciones de la muestra cuentan con un número significativo de seguidores, que llega más allá del paciente y afectados y cumple el objetivo de conexión con la sociedad y la divulgación de información de interés para el ciudadano.

El hecho de que el 6\% de las entidades pertenezca o participe en redes de pacientes es significativo, ya que estas asociaciones prefieren abrirse más a la sociedad y participar en ella a través de otras redes tradicionales, antes que centrarse en redes especializadas, más aisladas socialmente, aunque también importantes fuentes de conocimiento.

Los foros tienen una función específica, y quizás entren más en la privacidad y otros aspectos necesarios, pero que tienen una función distinta a la de compartir conocimiento con la sociedad, aunque sí se cumple el objetivo de compartir entre los propios pacientes o con la comunidad científica.

Por último, los blogs son espacios personales, más basados en experiencias, aunque también muy funcionales desde el punto de vista del paciente que puede sentirse identificado o comprender ciertos aspectos de estas patologías mediante las experiencias de otros navegantes.

\section{Futuras líneas de investigación}

Puede ampliarse esta investigación de forma pormenorizada mediante el estudio del contenido publicado por estas asociaciones en las redes sociales. De esta forma se podría conocer en profundidad cuál es el conocimiento que se genera sobre las distintas enfermedades y su repercusión en los usuarios de estas redes sociales. Se podría ampliar la investigación al análisis de contenido específico destinado a mantener conexión con la comunidad científica y comprobar la repercusión en el avance de la investigación. 


\section{Referencias bibliográficas}

Areosa, L. A. (2009): “Asociaciones de pacientes". Enfermería Dermatológica, 3(6), 36-38.

Aguilar, M. G. (2013): "De la hiperinformación a la desinformación 2.0." Paradigma: revista universitaria de cultura, (15), 7-10.

Avellaneda, A., Izquierdo, M., Torrent-Farnell, J. Ramón, J. R. (2007): "Enfermedades raras: enfermedades crónicas que requieren un nuevo enfoque sociosanitario". En Anales del Sistema Sanitario de Navarra (Vol. 30, No. 2, pp. 177-190), 2007, August. Gobierno de Navarra. Departamento de Salud.

Armayones, M y Hernández Encuentra, E. (2007): “Las características psicológicas de los usuarios en la eSalud: nuevas oportunidades a través de la web 3.0." RevistaeSalud.com, 3 (11).

Bañón, A. M. (2011): “Comunicación, discurso y salud”. En J. Fornieles et al. (eds). Lenguaje, Comunicación y Salud. Sevilla, Arcibel Editores, pp. 13-57.

Bañón, A. M. Et Al. (2011): Desafíos y estrategias comunicativas de las enfermedades raras: la investigación médica como referente. Valencia, CIBERER.

Bañón, A.M. y Fornieles, J. (2011): “Comunicación y enfermedades raras: contextualización”. En A.M. Bañón et al. (eds.). Desafíos y estrategias comunicativas de las enfermedades raras: la investigación médica como referente. Valencia: CIBERER, pp. 11- 40.

Bañón, A.M., Fornieles, J. (2011): 'Comunicación y enfermedades raras: contextualización’ en A. M. Bañón, J. Fornieles, A. Solves e Inmaculada Rius (coords.) (2011), Desafíos y estrategias comunicativas de las enfermedades raras: la investigación médica como referente, Valencia, CIBERER. ISBN: 978-84-694-0596-3, págs. $11-41$.

Basagoiti, I., Fernández-Luque, L. (2011): “Compartir información sanitaria: ePacientes: comunicación e interacción”, en V. Traver Salcedo, L. Fernández-Luque (coords.), El ePaciente y las redes sociales, Valencia, Publidisa, págs. 47-68. 
Castillo Esparcia, A. (2012): "La comunicación empresarial en Internet". Icono14. Revista cientifica de Comunicación y Tecnologías emergentes, 6 (2), 1-18.

Jadad, A., \& Lorca Gómez, J. (2006): "La eSalud: una Fuerza que debe multiplicar Recursos, no dividirlos". Revista eSalud. com, 2 (7).

Monteagudo Peña, J. L., Hernández Salvador, C., y García-López, F. (2004): "Metodología de introducción de servicios e-salud para el seguimiento y control de pacientes crónicos". Revista española de salud pública, 78 (5), 571-581.

Potts, H. W. (2008): “¿Progresa la eSalud más rápido que sus propios investigadores?”. Revista eSalud. com, 4 (15).

Rabeharisoa, V., \& Callon, M. (2002): "La participación de las asociaciones de pacientes en la investigación". Revista Internacional. 



\title{
Innovación y retos en la comunicación online con los usuarios de un hospital
}

\author{
Daniel Catalán Matamoros [๑ㅈID] [GGS] (Universidad \\ Carlos III de Madrid) \\ José Cerdán de las Heras [으CID] [GGS] (Hospital Hvidovre, \\ Copenhague, Dinamarca)
}

\section{Resumen}

$\mathrm{El}$ auge de Internet 2.0 ha hecho que la comunicación online sea una realidad en la que se han invertido los papeles tradicionales. Hoy, la comunicación online en la web 2.0 es un espacio abierto y democrático cada vez más utilizado por las organizaciones e instituciones para ofrecer más servicios y relacionarse más y mejor con sus usuarios. Estas nuevas herramientas online han cambiado el paradigma de la comunicación en salud, y la importancia de la red como sistema de difusión de la información viene ratificada por su crecimiento exponencial en la última década. Inicialmente, los centros hospitalarios se centraron en la automatización de los procesos sanitarios y en sus trámites administrativos de atención a usuarios. En la actualidad, los portales web están generando nuevas y diversas formas de comunicación entre los hospitales y sus usuarios. Los foros de pacientes, la tele-consulta con los profesionales sanitarios, las secciones temáticas con información dirigida a grupos de pacientes son algunas de las herramientas de comunicación que incluyen estos portales web. Este capítulo presenta un análisis de las herramientas online puestas en marcha en los hospitales, la usabilidad por sus 
usuarios, así como los retos que este tipo de comunicación presentan en la actualidad.

Palabras clave: comunicación en salud, comunicación 2.0, portal web, hospital.

\section{Introducción}

— $\mathrm{N}$ LOS INICIOS de la era de la comunicación 2.0, las organizaciones fueron en su mayoría reacias a asumir este gigantesco cambio y las nuevas reglas del juego de la web 2.0. Y muchas lo hicieron sólo cuando comprobaron que al teclear su nombre en los buscadores de Internet, los resultados no eran los que les gustaría que fueran. En la actualidad, la gran mayoría de las organizaciones presumen de contar, al menos, con una página web ofreciendo información sobre sus servicios y formas de contacto con sus clientes. Sin embargo, la comunicación 2.0 ofrece muchas más posibilidades en las relaciones que las organizaciones mantienen con sus usuarios.

En el campo de la salud, un hecho que ha revolucionado la relación entre los profesionales de la salud con sus pacientes es la posibilidad de obtener información sobre salud en la red, pues la presencia de portales de salud ha crecido de manera exponencial en los últimos años. De hecho, Internet se está posicionando como la primera fuente de información sanitaria, incluso por delante del profesional sanitario. Según el estudio Pfizer (2010), cada vez que el internauta tiene dudas sobre cuestiones de salud, en un $65 \%$ de los casos, acude a Internet, mientras que sólo el $21 \%$ consulta directamente con un profesional de la salud, resultados que se derivan por la mayor accesibilidad, comodidad y rapidez que ofrece el canal web por sí solo, sobre todo en el caso de molestias o dudas, no cuando se trata de una enfermedad propiamente dicha o un asunto grave. Este hecho ha motivado que hospitales, sociedades científicas, asociaciones de pacientes y profesionales de la salud sientan cada vez más la necesidad de estar presentes en la red.

Los hospitales, como proveedores de la atención especializada en salud, constituyen uno de los ejes centrales de los sistemas de salud 
actuales. Al mismo tiempo, Internet ofrece a sus usuarios un punto de encuentro y de interrelación personal y profesional en cualquiera de sus dimensiones: científica, comercial, lúdica, etc. Esto ha provocado que los formatos y los medios por los que se transmite la información en los hospitales cambien de forma vertiginosa. Ejemplo de ello es que los portales web se consideran actualmente la puerta de entrada de los hospitales ya que los usuarios acceden a ellos para pedir citas, gestionarlas, buscar información, consultar resultados de pruebas clínicas, participar en foros, etc. Además, existe la creencia de que el hospital que no tenga un portal web no existe o es poco importante, por lo que actualmente, todos los hospitales han creado su propio portal.

Como consecuencia de este crecimiento, al mismo tiempo anárquico, hay una enorme variedad en la calidad, la orientación e incluso en la propia finalidad de la información disponible de los portales de salud. De hecho, un 43\% de los usuarios considera que es una información sin calidad y un $32 \%$ no se fía de la información obtenida (Pfizer, 2010). Para paliar este problema en el ámbito sanitario, en los últimos años se han publicado algunas evaluaciones sistemáticas de estos contenidos analizando la calidad de la información (Arencibia-Jiménez, 2007). Estas investigaciones coinciden en que existe una clara necesidad de vigilar la calidad de estos portales web ya que un contenido con errores podría producir daños en la salud de los internautas que lo lean.

De una manera u otra, la era Internet es una realidad que ha llegado o está llegando a todo el Sistema Sanitario Español. La informatización de la sanidad pública ha sido uno de los objetivos del Plan 2006-2010 para el Desarrollo de la Sociedad de la Información y de Convergencia con Europa y entre Comunidades Autónomas, conocido como Plan Avanza. Éste quiere lograr una Administración Electrónica enteramente desarrollada, más eficiente y próxima a los ciudadanos en el ámbito local y en las áreas de la educación, sanidad y justicia.

Este capítulo presenta un análisis de las estrategias de comunicación online puestas en marcha por los hospitales, un análisis de la calidad de sus contenidos, así como la usabilidad y barreras percibidas por los usuarios/pacientes. 


\section{La comunicación online de los hospitales}

Los hospitales han tenido siempre audiencia desde mucho tiempo antes de la era de Internet. Antiguamente el contacto con el hospital se hacía con cita previa a través de teléfono o carta remitida por el médico de familia o a través de servicios de urgencia. Cada hospital ha realizado su propio proceso de atención adecuándolo a las necesidades de los usuarios y utilizando los medios actuales de la época que se poseían para informar a sus pacientes de la experiencia que iban a experimentar desde la llegada a la salida del hospital. Antes de la llegada de Internet, el paciente recibía una carta "tipo padrón" con información previa a su llegada y a partir de entonces se podría decir que el usuario estaba informado. Para cualquier duda, el paciente siempre tendría la opción de llamar por teléfono a un sitio específico. Hoy en día se sigue utilizando este tipo de canal de comunicación que es complementado con otros canales de información como panfletos o Internet.

\section{Figura 1. Página web un hospital comarcal}

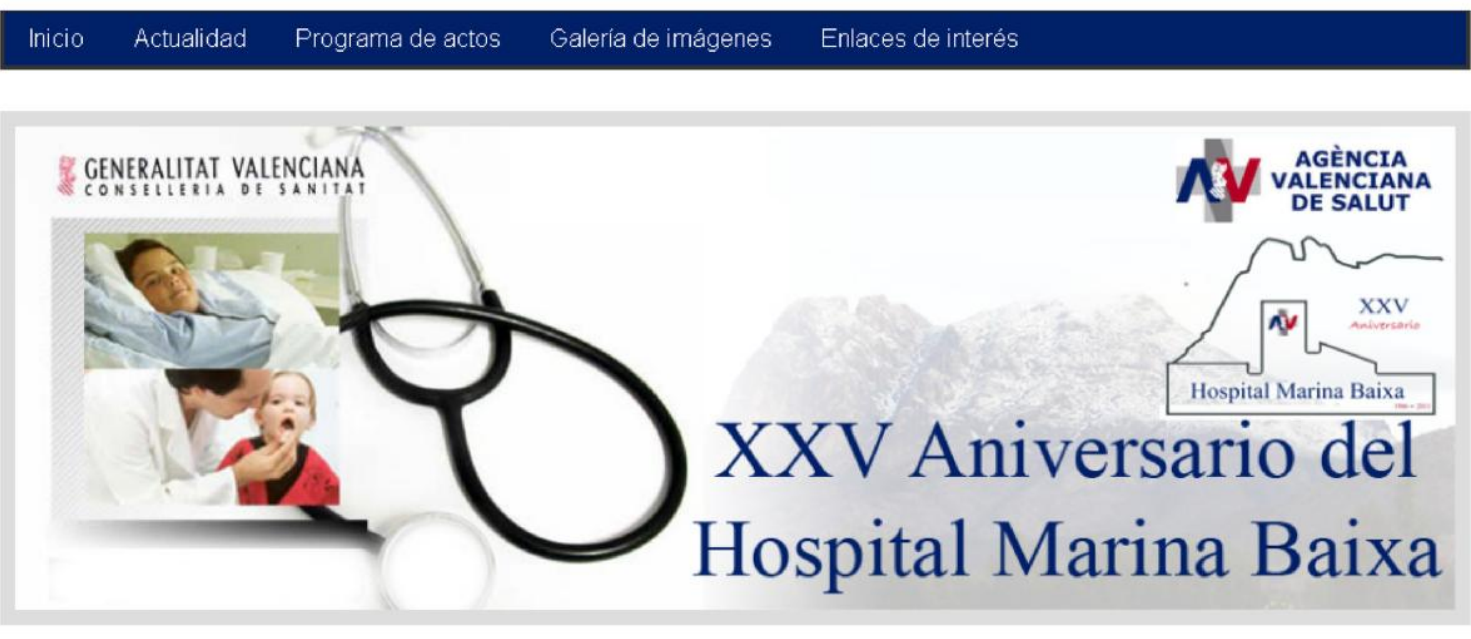

Fuente: Hospital de Villa Joyosa de la Marina Baixa en Alicante

A comienzos de la era de Internet, los departamentos de comunicación de los hospitales vieron una gran oportunidad de utilizar la red como un canal de comunicación más para llegar fácilmente a una audiencia masiva. En estos comienzos, las páginas web que se creaban eran de uso exclusivamente informativo y fijo. El objetivo era entre otros de informar de la situación geográfica, 
teléfonos de contacto y enlaces de interés sin entrar en necesidades más específicas de los distintos usuarios del propio hospital. Hoy en día los hospitales comarcales en España siguen utilizando este tipo de página web como en el ejemplo de la figura1, quizás debido a no tener un departamento de comunicación propiamente dicho que pueda trabajar todas las posibilidades que la red puede ofrecer en la comunicación y relaciones con los usuarios.

Cualquier hospital con presencia en Internet tiene el objetivo de mejorar los canales de comunicación a una audiencia masiva. En este caso, las páginas web suelen actuar como portales vivos de contenido actualizado y renovado que se dirigen especialmente a usuarios y especialistas de la salud. Sin embargo, actualmente estos portales web no ofrecen únicamente información, sino que ofrecen aplicaciones y servicios telemáticos de comunicación que facilitan las relaciones y los procesos sanitarios con sus usuarios.

Ejemplo de esto son las nuevas tele-consultas para que pacientes con movilidad limitada no se trasladen al hospital, o la telerehabilitación para que usuarios con procesos crónicos no tengan que acudir diariamente al centro hospitalario. Estas nuevas formas de comunicación con los usuarios, además de facilitar el acceso a la salud a gran parte de la población, pueden producir un ahorro en las arcas públicas debido a la disminución de costes en los desplazamientos y listas de espera en los centros sanitarios. Actualmente, muchos hospitales con un departamento de comunicación propiamente dicho han apostado por crear una variedad de servicios online entre el hospital y el usuario, así como también simplificar el proceso de comunicación.

La web del hospital en la figura 2 es un claro ejemplo de esta nueva era donde se abren distintos canales de comunicación centrados primeramente en informar al paciente desde los distintos departamentos y áreas de salud, sus derechos y deberes, guía de usuario, visita guiada virtual, etc. Al mismo tiempo, este tipo de hospitales muestran un área específica para los propios especialistas y profesionales de la salud donde incluyen entre otros bolsas de trabajo, investigación y docencia, órganos de representación de los trabajadores, al igual que un servicio de intranet donde compartir 
información específica para los empleados del centro accediéndose desde el portal web del propio hospital.

Figura 2: Pagina web de un hospital general

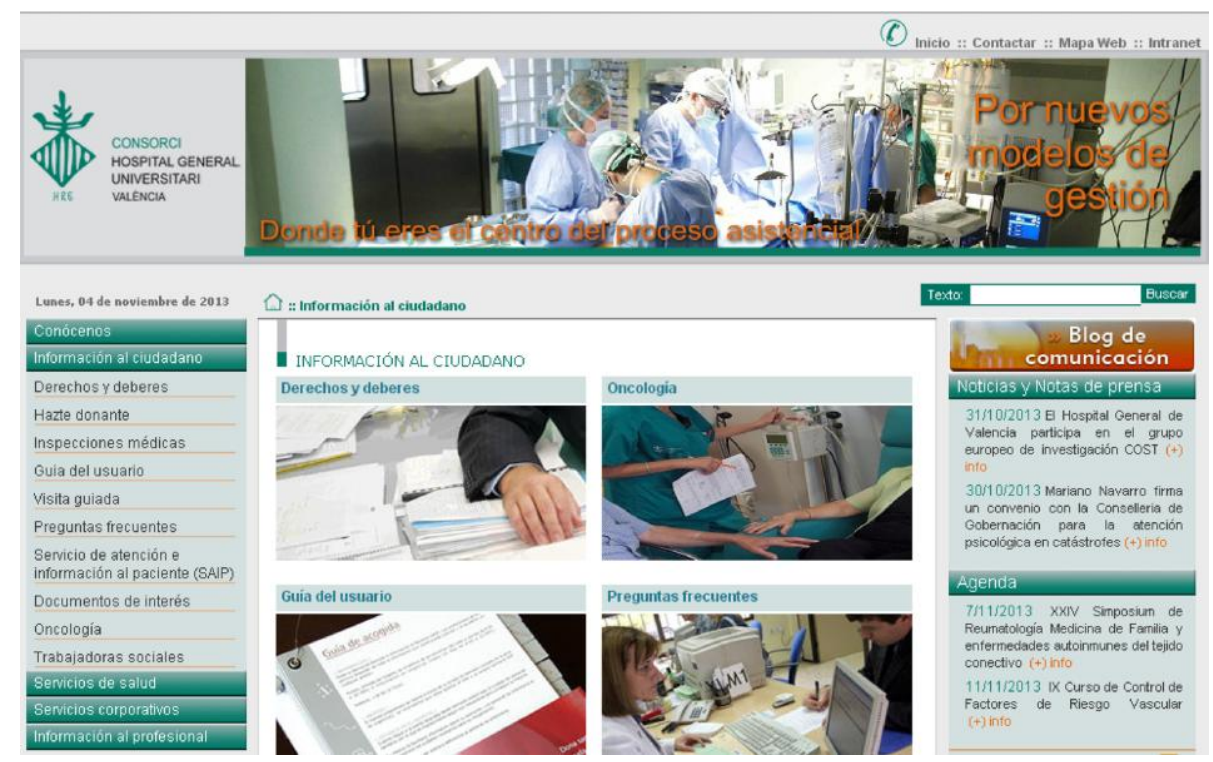

Fuente: Hospital General Universitario de Valencia

Los hospitales de financiación privada van todavía más allá e intentan introducir herramientas de interacción con el propio usuario como por ejemplo pedir cita con cualquiera de los especialistas de sus centros (ver figura 3).

Figura 3: Página web de un hospital privado

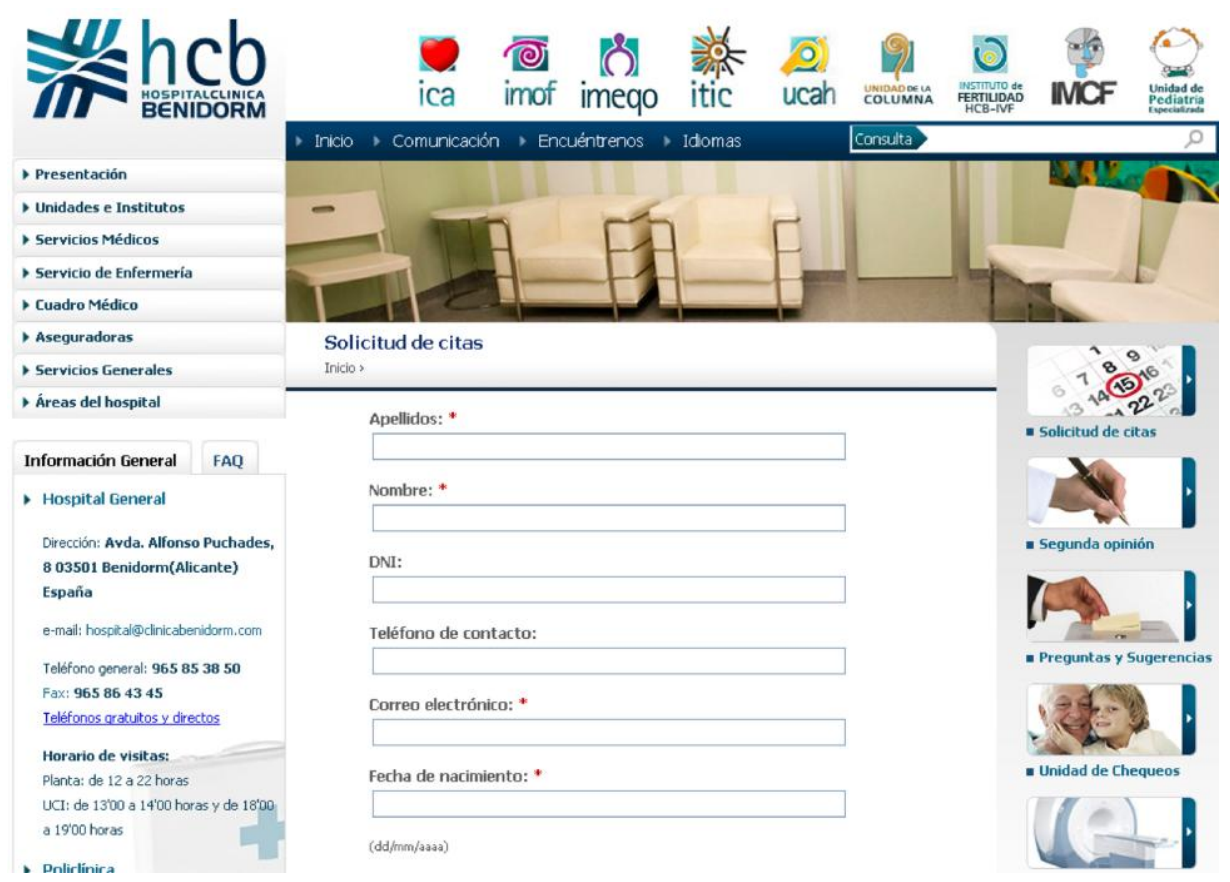

Fuente. Hospital privado Clinica Benidorm con opción a solicitud de cita previa 


\section{Innovaciones en la comunicación online de hospitales}

Hospitales preocupados en interactuar con sus usuarios a través de sus portales web han desarrollado una gran variedad de servicios satélite con el objetivo de profundizar en ciertas patologías y facilitar un servicio previo a la visita, durante la estancia en hospital y después en el centro de salud. Estas iniciativas surgen en primer lugar con pacientes crónicos y con el objetivo de mejorar su independencia a la hora de facilitarles el día a día con su estado crónico.

Un ejemplo lo podemos encontrar en un hospital universitario de Dinamarca, el Hospital de Hvidovre (figura 4), donde han llevado a cabo el desarrollo de un portal satélite que asiste al paciente en temas de rehabilitación. El objetivo fue crear una herramienta de fisioterapia interactiva que indujera al paciente a ser más independiente en sus actividades de la vida diaria, que tuviera un rol más activo en relación a su proceso de recuperación y, finalmente, mejorar la adherencia al tratamiento previniendo exacerbaciones en su estado de salud.

Figura 4: Página web de un hospital universitario

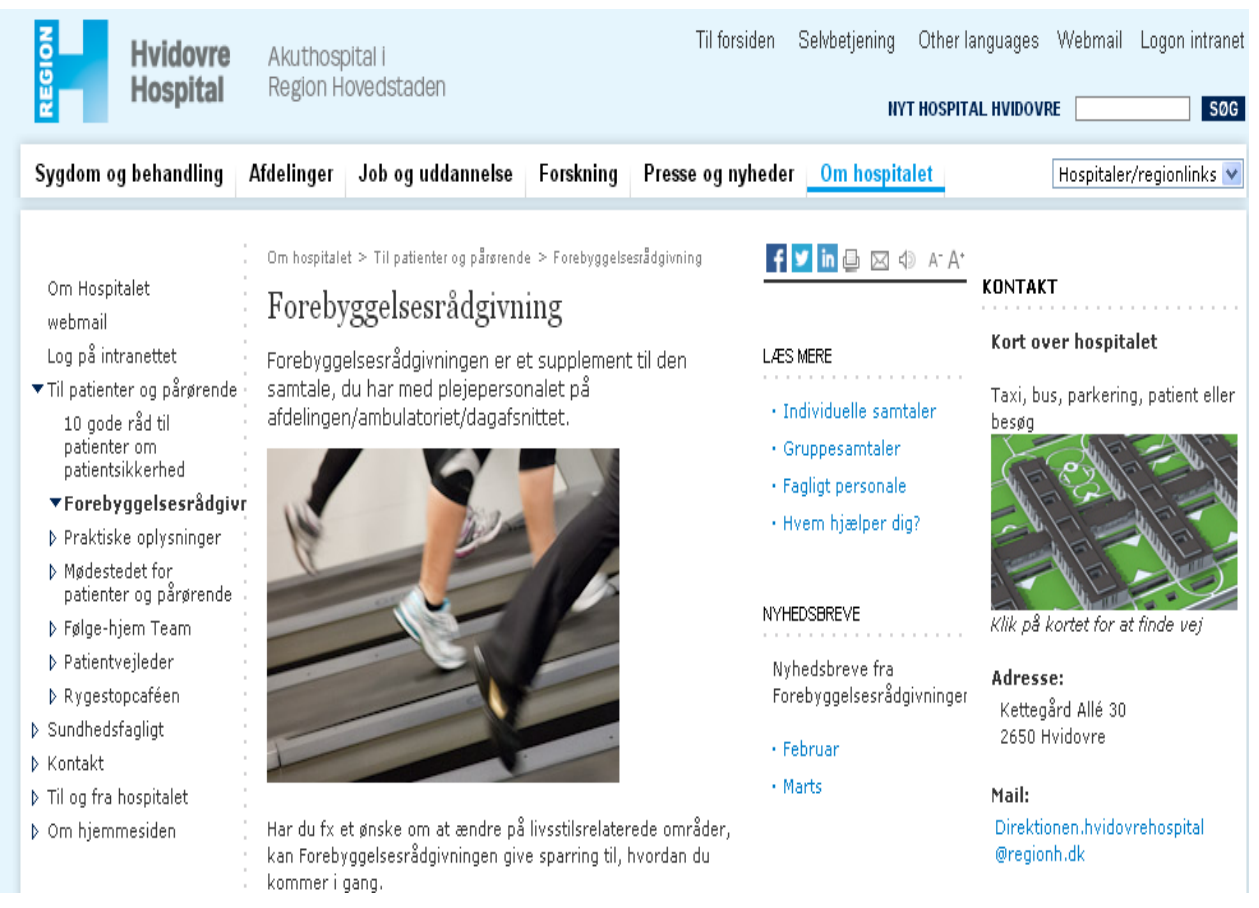

Fuente: Hospital Universitario de Hvidovre en Dinamarca 
Este portal (figura 5) fue lanzado en primer lugar para tres grupos de pacientes crónicos: pacientes con EPOC (Enfermedad Pulmonar Obstructiva Crónica), pacientes con enfermedades cardiacas y, por último, pacientes con edema linfático. Más tarde se amplió a otros tipos de pacientes no crónicos con necesidades similares de comunicación con el hospital. Por ejemplo a pacientes con ruptura del ligamento de Aquiles que llegaban directamente a urgencias y precisaban información sobre cómo utilizar unas simples muletas, información para padres de recién nacidos sobre cómo estimular a sus bebés de una manera óptima en sus primeros 6 meses de vida, etc.

Figura 5: Portal satélite para pacientes de un hospital

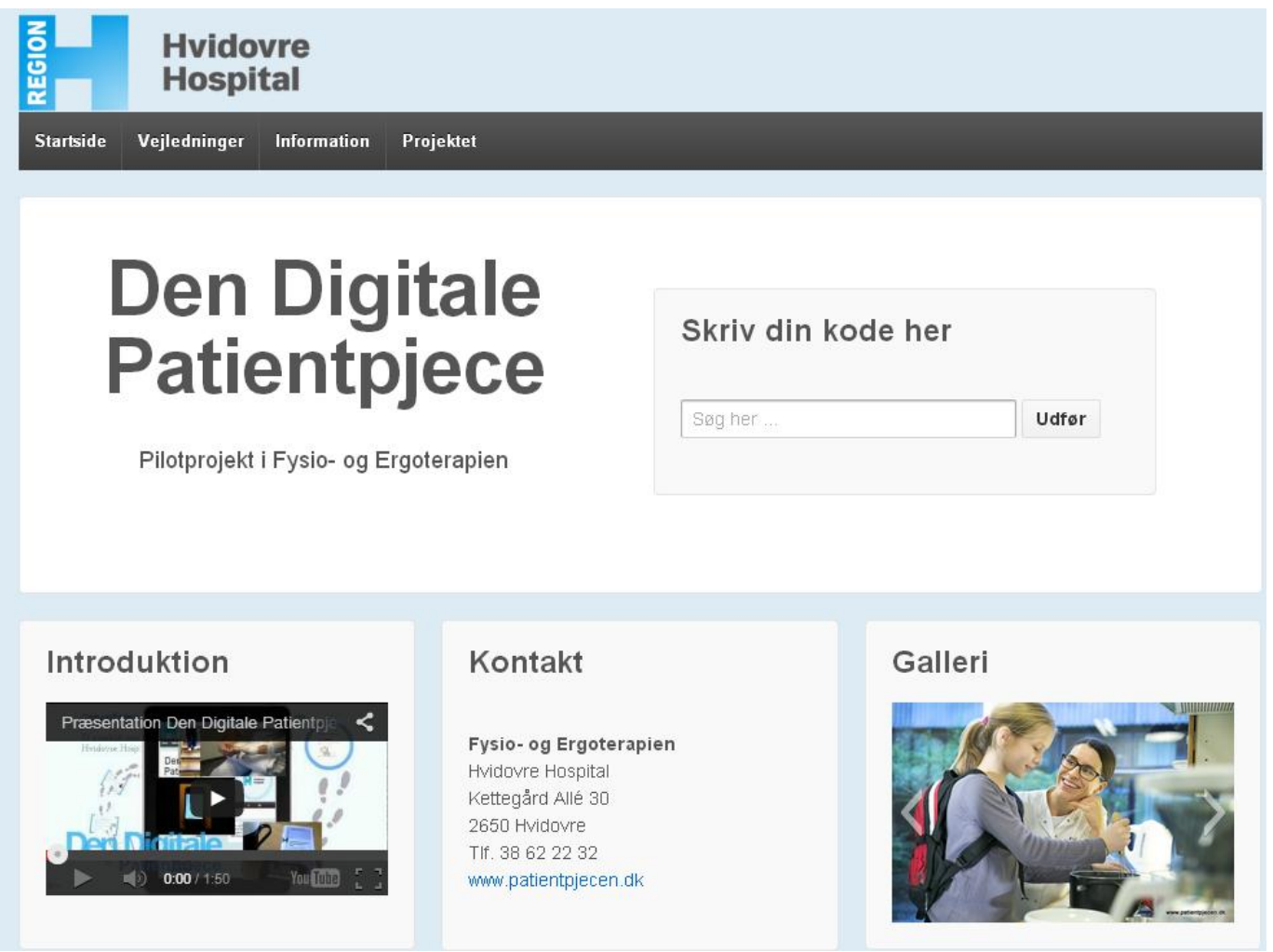

Fuente: Hospital Universitario de Hvidovre en Dinamarca

El portal funciona con un simple folleto (figura 6) que redirecciona al paciente (a través de un link o QR-code) a una zona específica del portal donde se encuentra contenido específico para su estado de salud o proceso de rehabilitación. 
El contenido que el paciente encuentra en este portal se concentra en tres áreas temáticas: información específica sobre el proceso de rehabilitación en el hospital, programas de ejercicios específicos en 3D adaptados a distintos niveles de salud del paciente, y paquetes de E-learning (enseñanza virtual) sobre temas a tener en cuenta cuando se tienen estas enfermedades.

Figura 6: Folleto redireccionable a portal satélite para pacientes de un hospital
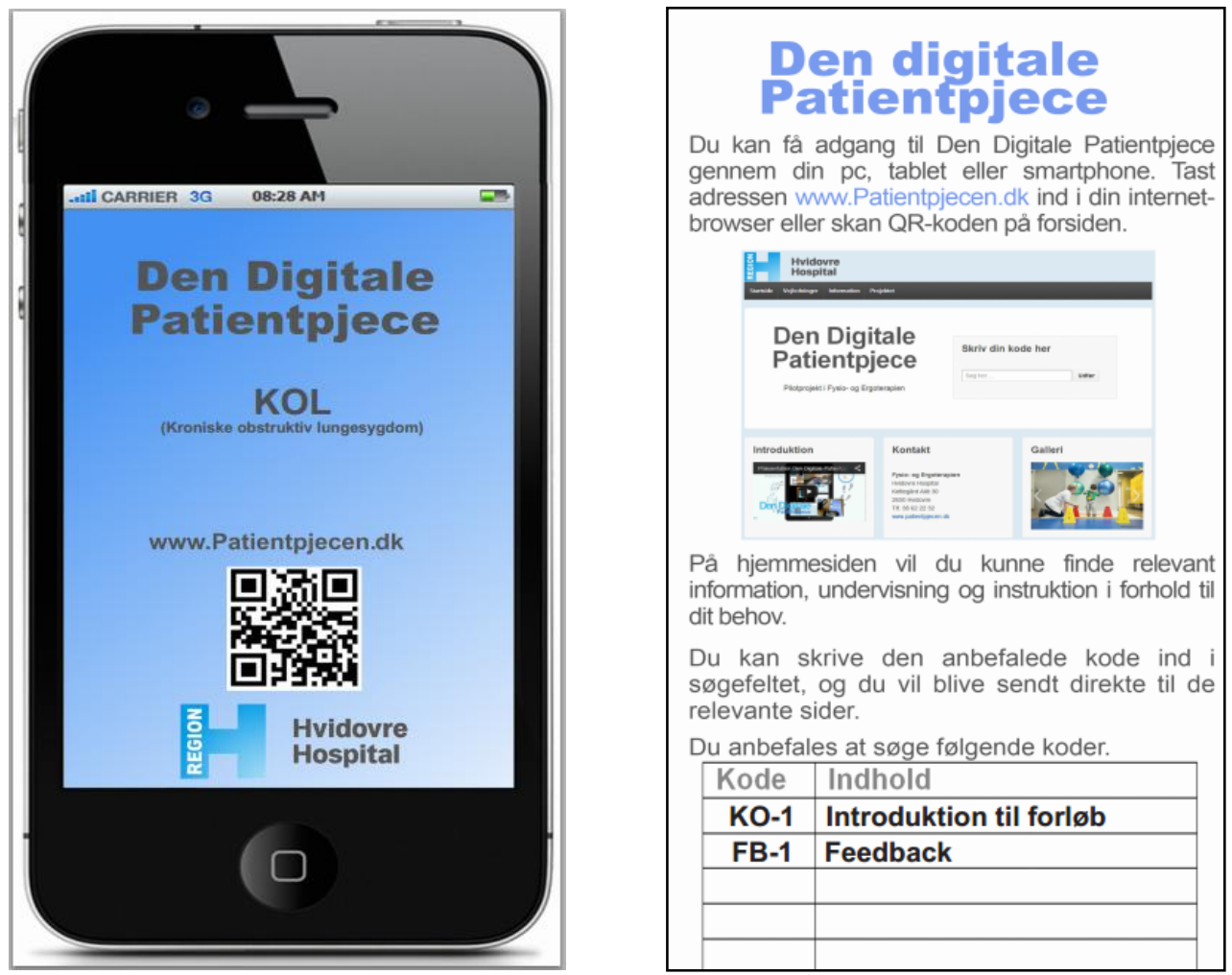

Fuente: Hospital Universitario de Hvidovre en Dinamarca

\subsection{Información específica sobre el proceso de rehabilitación en el hospital}

Este contenido se basa en cortos vídeos informativos acompañados de texto que explica el proceso de rehabilitación que el paciente puede esperar durante un periodo de fisioterapia intensiva $y$ ambulatoria en el hospital. Un ejemplo se puede ver en este vídeo (http://www.youtube.com/watch?v=2kiDprzMMm8) que se centra en el proceso de rehabilitación de los pacientes con edema linfático. 


\subsection{Programas de ejercicios específicos en 3D adaptados a distintos niveles de salud del paciente (figura 7)}

Figura 7: Interfaz del tipo de programa de ejercicios en 3D creados en la plataforma de rehabilitación Optimov y colgados en un portal satélite para

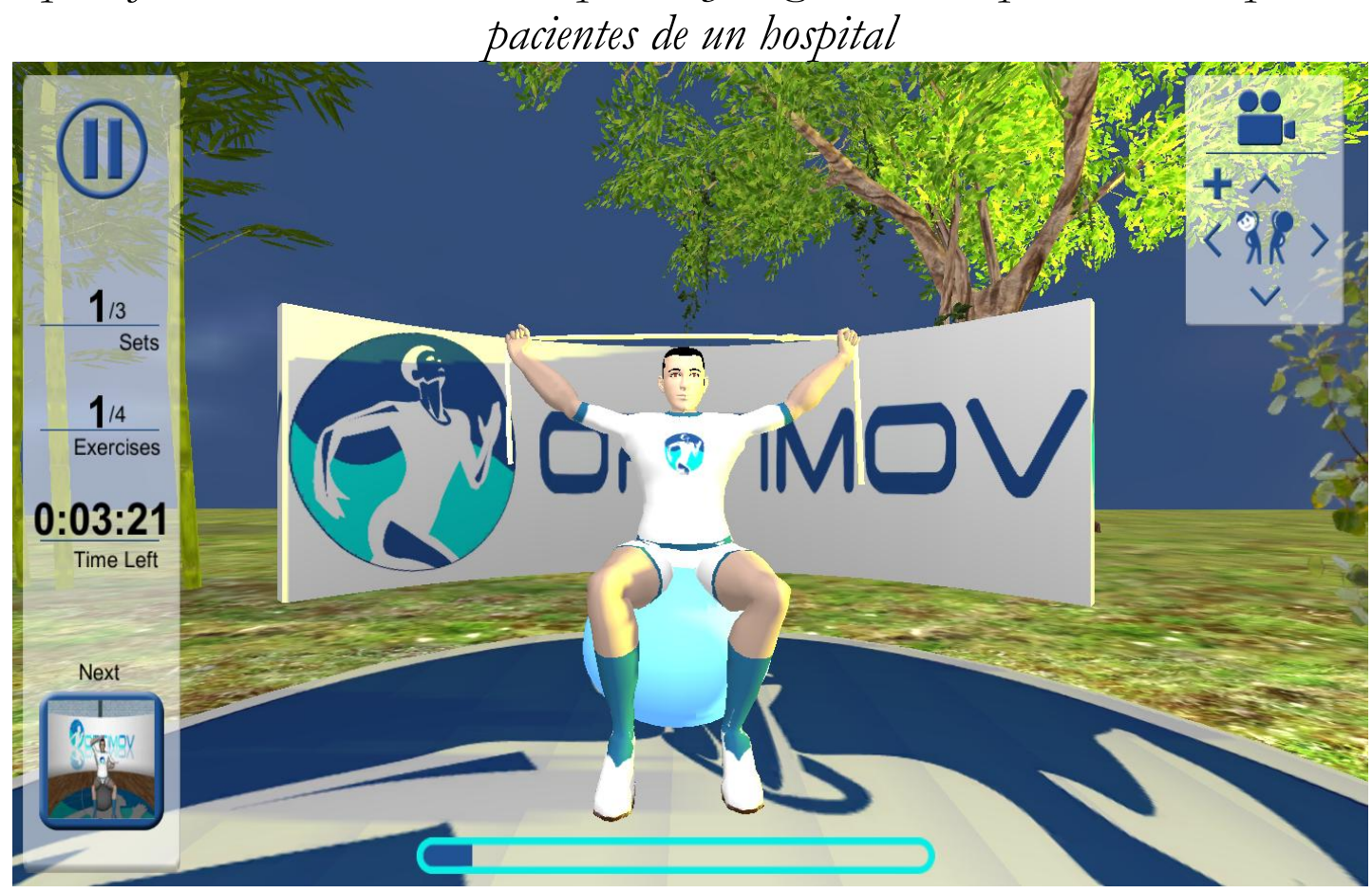

Fuente: Hospital Universitario de Hvidovre en Dinamarca

Este contenido se basa en programas de ejercicios desarrollados en una simbiosis entre el conocimiento de los distintos especialistas del hospital, los pacientes específicos a tratar y la herramienta de telerehabilitación virtual Optimov (www.optimov.com). Ejemplos de programas de ejercicios publicados, testeados y en pleno funcionamiento se pueden encontrar en estos enlaces dirigidos a pacientes con EPOC:

- Programa de condición física nivel bajo: http://patientpjecen.dk/kol/interaktivovelsesprogram/let-kol-ovelses-program/

- Programa de condición física nivel moderado: http://patientpjecen.dk/kol/interaktivovelsesprogram/moderat-kol-ovelses-program/

- Programa de condición física nivel alto: http://patientpjecen.dk/kol/interaktivovelsesprogram/hardt-kol-ovelses-program/ 
- Programa para ejercitar la musculatura: http://patientpjecen.dk/kol/interaktivovelsesprogram/styrke-for-kol/

- Programa de relajación del cuello espalda y brazos: http://patientpjecen.dk/kol/interaktivovelsesprogram/smidighed-for-kol/

\subsection{Paquetes de E-learning (enseñanza virtual)}

Estos contenidos se basan en pequeños vídeos de corta duración que intentan informar al paciente sobre ciertos temas relevantes para llevar el día a día de su enfermedad y mantener una salud estable. Estos vídeos son seguidos de preguntas con múltiples respuestas que ayudan al paciente a asegurarse que ha entendido el mensaje. Ejemplos se pueden encontrar de nuevo para pacientes con EPOC en el siguiente paquete de E-learning cuyo objetivo es enseñar al paciente a utilizar la flauta-PEP (http://patientpjecen.dk/kol/informationvideos/pep-flojte/) (Figura 8).

Figura 8: Paquete de E-learning tipo de un portal satélite para pacientes de un hospital

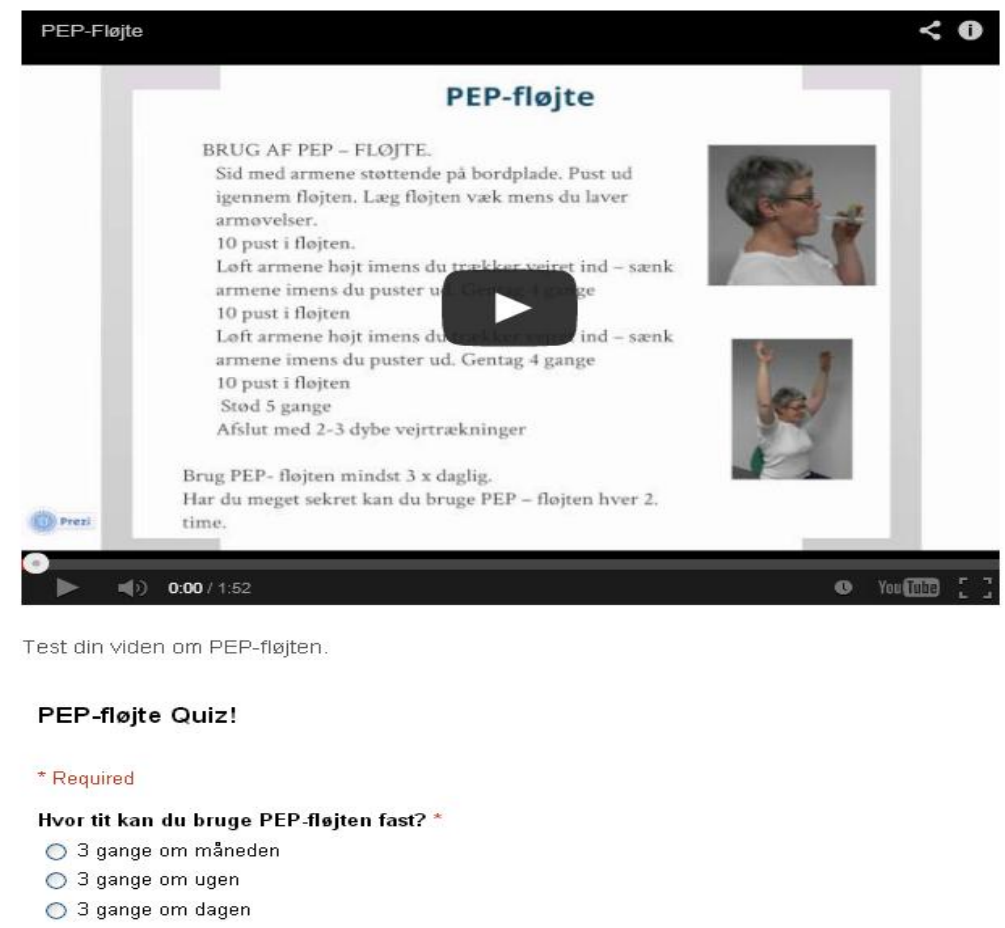

Fuente: Hospital Universitario de Hvidovre en Dinamarca 


\section{Análisis de la calidad informativa en la comunicación online de hospitales}

Numerosos investigadores han propuesto diversos indicadores para analizar la calidad informativa de los portales web. Arencibia-Jiménez hizo la siguiente propuesta para evaluar la calidad de los portales web de los hospitales (2007):

- Accesibilidad: la facilidad de acceder a la página web del hospital. Por ejemplo, cuanto más links tenga en otras páginas web informando sobre su existencia, o los formatos diferentes desde los que se puede acceder a esta información (teléfono móvil, tablet, ordenador, etc.).

- Usabilidad: se refiere a la facilidad del manejo y la navegación por la página web. Por ejemplo, que los links que aparezcan en el portal funcionen correctamente, o que se tenga que realizar pocos clicks para llegar a la información.

- Interactividad: que exista o no relación "virtual" entre el hospital y los usuarios a través de la web.

- Información presentada: si la información contiene sesgos, si es completa, si está expresada en términos sencillos para el usuario, si es relevante y de interés.

- Actualización de los contenidos: existencia de fecha de edición y actualización de los contenidos.

- Calidad: existencia de sello de calidad reconocido, y de apartado de calidad asistencial en la atención a sus pacientes.

- Información para el profesional: existencia o no de un apartado para el profesional del centro.

Actualmente, la calidad de los contenidos de las páginas de salud accesibles en Internet es deficiente o mejorable (Eusenbach et al., 2012). En este sentido, algunos colectivos y la administración pública han realizado intentos para mejorar la calidad de estos contenidos: Health on the Nets, Web Médica Acreditada, Hi-Ethics, Asociacion Iberoamericana de Webmaster en Salud, entre otros.

En un análisis realizado en los portales web de los hospitales españoles se observaron aspectos positivos como que por ejemplo, el 
$75 \%$ de las web estudiadas permitía el contacto con el hospital mediante correo electrónico con el servicio de información o con el de admisión, y en el $25 \%$ se podía contactar a través de Internet con los servicios del hospital. Incluso en 7 de los hospitales estudiados era posible pedir cita a través de la página web. Sin embargo, el estudio destacó numerosas áreas de mejora en estos portales web de hospitales españoles (Arencibia-Jiménez, 2007). Pocos portales presentan una información útil para el paciente o usuario, pobre usabilidad y escasa actualización de sus contenidos.

Un análisis realizado en los portales Webs de los hospitales españoles por el Laboratorio de Cibermetría del Instituto de Estudios Documentales sobre Ciencia y Tecnología del CSIC indicó que la rapidez y difusión de la información es una de las cuestiones más valoradas por los usuarios, que buscan en estos portales acceder de forma rápida a información actualizada (Utrilla-Ramírez et al., 2010). Este mismo estudio también reveló la desventajosa presencia de los centros hospitalarios españoles en la Red, en comparación con los portales de otros países occidentales.

\section{Experiencia y usabilidad de los usuarios de la web de un hospital}

Un estudio realizado en Dinamarca (Cerdán et al., 2014) en el que se recogieron las experiencias y usabilidad de los usuarios de una web de un hospital mostraron los siguientes aspectos que deben ser tenidos en cuenta para mejorar la comunicación:

- La motivación de los pacientes para seguir los consejos recibidos por la web. La recepción de consejos de salud de forma online tiene menor impacto que de forma presencial. Por ejemplo, los usuarios se sienten más motivados acudiendo al centro sanitario a realizar ejercicios para su recuperación en un grupo con otros usuarios, que haciéndolos solos en casa. Además, el contacto físico con los profesionales de la salud hace que el usuario se sienta más seguro. Al mismo tiempo, los usuarios interpretan que el uso de las tecnologías supone un mayor esfuerzo, quizás debido a la poca experiencia que muchos de ellos puedan tener. Todos estos 
aspectos afectan a la motivación del paciente en realizar los consejos saludables recibidos de manera online.

- La experiencia usando aplicaciones online sobre salud. El uso de estas aplicaciones es interpretado como algo complicado por los usuarios. Por ejemplo, el acceso a estas aplicaciones es, en ocasiones, difícil debido a los requerimientos técnicos necesarios para su buen funcionamiento. El acceso mediante cuentas de usuarios y claves de acceso es también complejo debido a que las olvidan o no las recuerdan con facilidad.

- Diseño, gráficos y sonido. En relación a los aspectos audiovisuales, los usuarios de las páginas de centros hospitalarios tienen frecuentemente algunos niveles de discapacidad auditiva o visual, lo que les puede dificultar la recepción de la información. Por otro lado, numerosos usuarios reflejan que el diseño de estas páginas web podría ser mejorable para facilitar la búsqueda y acceso a la información relevante. Además, en ocasiones encuentran términos de difícil comprensión o información que puede crear confusión sobre su estado de salud.

- Objetivos de la comunicación online de los hospitales. Muchos centros han sustituido servicios que antes proporcionaban de manera física por un formato online. Por ejemplo la solicitud de citas con un profesional de la salud. A este respecto, los usuarios reflejan que la comunicación online debería ser complementaria al sistema tradicional, para que aquellas personas con analfabetismo tecnológico puedan seguir accediendo a los servicios sanitarios con total normalidad.

Se puede observar en los resultados expuestos anteriormente, que aún existen aspectos que deben ser considerados en cuanto a la comunicación online con los usuarios de un hospital. El cambio de un sistema de comunicación interpersonal a otra online supone un proceso que requiere tiempo para que tanto usuarios como profesionales puedan adaptarse de una manera natural. La integración de sistemas de comunicación online por los centros sanitarios debe, por consiguiente, seguir un cronograma de implementación progresivo para evitar posibles problemas en la comunicación con los usuarios. 


\section{Reflexiones finales}

La comunicación online está adquiriendo cada vez un mayor protagonismo en los centros sanitarios para relacionarse con sus usuarios, ofrecer servicios telemáticos y realizar una mejor gestión del sistema de salud. Sin embargo, tal y como se ha reflejado en este capítulo, aún quedan aspectos que deben ser considerados tales como los aspectos éticos, la confidencialidad de los datos de los usuarios, la calidad de la información publicada, los servicios ofrecidos, y la usabilidad por los usuarios.

Es necesaria la realización de evaluaciones económicas de estos nuevos procesos de comunicación online con los usuarios para determinar si existe una buena relación costo-efectiva que apoye la implementación de estas nuevas formas de comunicación.

Sin duda, la mejora de la comunicación online de los hospitales facilitará la comunicación con los usuarios, para dar a conocer los servicios que presta un hospital, ofrecer un mayor acceso a esta información y servicios de índole virtual encaminados a mejorar y facilitar el acceso a la salud por los usuarios.

\section{Referencias bibliográficas}

Arencibia-Jiménez, M., Aibar-Remón, C. (2007): "Páginas web de hospitales. Realidad virtual o... ¿son realmente un medio útil para la difusión de información para sus usuarios?" Revista Calidad Asistencial, 22(3), 118-27.

Cerdán, J., Catalán-Matamoros, D., Warny-Berg, S. (2014): Patient's communication and experiences using a web portal in a rehabilitation department. A qualitative study. Disability and Rehabilitation, in press.

El Gobierno aprueba el Plan Avanza [en prensa]. elmundo.es Navegante [diario electrónico] 2005, noviembre 5 [consultado 26-02-2008]: Disponible en:

<http://www.elmundo.es/navegante/2005/11/04/esociedad/ 1131109447.html> 
Eysenbach, G., Powell, J., Kuss, O., Sa, E.R. (2012): Empirical studies assessing the quality of health information for consumers on the World Wide Web. JAMA, 287, 2691-700.

Ley General de Sanidad, ley 14/1986, de 25 de abril.

Nebot, M., Fontanet, G., Díez, E. (2003): "Educación sanitaria e Internet". FMC, 10, 243-8.

Pfizer. (2010): Encuesta Pfizer: "El rol de Internet en el proceso de consulta de información sobre salud". Recuperado el 10 de noviembre de 2013, de

$<$ http://www.pfizer.es/docs/pdf/noticias/Resultados encuest a Pfizer.pdf $>$

Plan Avanza. Recuperado el 26 de octubre de 2013, de $<\underline{\text { http://www.planavanza.es }>}$

Utrilla-Ramírez, A.M., Fernández, M., Ortega, J.L., Isidro, F. (2010): "Clasificación web de hospitales del mundo: situación de los hospitales en la web". Laboratorio de Cibermetría, Instituto de Estudios Documentales sobre Ciencia y Tecnología (IEDCYT), Consejo Superior de Investigaciones Científicas (CSIC). Ciencias Sociales [Internet], 171.

Sanz-Valero, J., Castiel, L. D., Wanden-Berghe, C., y Juan Quilis, V. (2006): "Internet y la búsqueda de información en salud pública: desde la relevancia hacia la «revelancia»". Gaceta Sanitaria, 20(2), 159-160.

Soto Álvarez, J. (2006, March): "Valoración de los resultados en salud percibidos y comunicados por los pacientes:¿ necesidad o lujo?" En Anales de medicina interna (Vol. 23, No. 3, pp. 136-138). Arán Ediciones, SL.

Torrente, E., Escarrabill, J., y Martí, T. (2010): “Impacto de las redes sociales de pacientes en la práctica asistencial". Revista de Innovación Sanitaria y Atención Integrada, 2(1), 1. 


\section{6 \\ Gestión de la comunicación interna en hospitales}

Pablo Medina Aguerrebere (Universitat Internacional de Catalunya) [ORCID]

\section{Resumen}

La promoción de la comunicación institucional se ha convertido en una prioridad para aquellas organizaciones hospitalarias que desean mejorar el servicio médico ofrecido al paciente y de este modo fijar una ventaja comparativa respecto a sus competidores. El contexto hospitalario y el tipo de servicio ofrecido al paciente convierten a la comunicación interna en la iniciativa comunicativa más importante en un hospital. La creación de un Departamento de Comunicación Interna que establezca los objetivos y estrategias de esta función profesional, así como las implicaciones de la misma para los empleados, pacientes y el hospital en su conjunto constituye un paso previo a la implantación de las acciones concretas de comunicación interna.

Palabras clave: Hospital, comunicación institucional, comunicación interna, estrategias, empleados, pacientes.

\section{Introducción}

T OS HOSPITALES, las compañías de seguros, los laboratorios $\perp$ farmacéuticos, las autoridades sanitarias y las asociaciones de pacientes son las organizaciones principales del sector sanitario. Sin embargo, el contexto de cada una de ellas varía considerablemente. 
En el caso de los hospitales, destaca el número elevado de personas que trabajan en estas organizaciones. Los hospitales emplean muchos profesionales (personal médico, personal de enfermería, administrativos, personal de mantenimiento, etc.). Todos ellos tienen perfiles profesionales muy diferentes, pero deben trabajar de un modo coordinado para poder ofrecer al paciente una atención integral y personalizada.

Otro de los aspectos propios del contexto hospitalario es el valor atribuido a los intangibles, como por ejemplo los valores transmitidos por los empleados: respeto, empatía, cordialidad, etc. Este aspecto resulta especialmente importante si se considera que, como indica Errasti Goenaga (1997), el hospital es el tipo de empresa de servicios donde un mayor porcentaje de las personas que trabajan tienen una relación directa con el cliente. Un tercer aspecto propio del contexto hospitalario es la connotación vital que tiene el servicio ofrecido al paciente. El hospital tiene por misión controlar y mejorar el estado de salud de todos y cada uno de los ciudadanos.

En cuarto lugar, hay que destacar el marco legal que se aplica en las organizaciones hospitalarias. Sin duda, se trata de una organización que está muy sometida a la normativa regional, nacional e internacional, lo cual delimita mucho su margen de acción. $\mathrm{Y}$ en quinto lugar, se puede destacar la importancia creciente concedida a las labores de gestión. El desarrollo de la sanidad privada y el endeudamiento de algunos hospitales públicos han llevado a los responsables hospitalarios a optimizar al máximo sus procesos internos de trabajo así como sus sistemas de racionalización de costes.

Es en este contexto en el que cada vez más profesionales de la comunicación desarrollan su trabajo. Los hospitales son organizaciones que se caracterizan por su escasa tradición comunicativa. Es decir, si se compara a estas organizaciones con otras empresas del sector sanitario, como por ejemplo los laboratorios farmacéuticos o las compañías de seguros, se puede observar que la gestión profesional de la comunicación institucional es algo reciente en la mayor parte de los hospitales, especialmente en los públicos. En estos últimos 15-20 años, cada vez más hospitales en España han implementado departamentos de comunicación que asumen 
diferentes funciones como por ejemplo la comunicación interna, la comunicación externa, la relación con los medios de comunicación, la organización de eventos, etc. Junto con estas acciones, algunos hospitales han implementado también iniciativas de marketing.

El concepto de marketing es el menos aceptado en el ámbito hospitalario debido a que las connotaciones de venta y producto que tiene dicho concepto parecen no encajar bien en el entorno hospitalario. Sin embargo, según Thomas y Calhoun (2007), los hospitales deben superar este "rechazo" hacia el marketing y apostar por esta herramienta comunicativa, ya que gracias a ella la organización puede obtener numerosos beneficios: a) construir reconocimiento de marca, b) mejorar la visibilidad de la imagen del hospital, c) aumentar la penetración de mercado y conseguir nuevos clientes, d) constituirse en recurso de información para la sociedad como es el caso de la educación del ciudadano en los hábitos de vida saludables, e) influir en la toma de decisiones del consumidor especialmente cuando éste decide a qué hospital privado desea acudir, f) desarrollar un posicionamiento de marketing competitivo que le permita al hospital diferenciarse del resto de competidores, g) crear una fuerza de ventas interna y h) atraer personal médico y distintos empleados a la organización.

\section{Comunicación interpersonal}

La comunicación interpersonal está en la base de todas las acciones de comunicación que emprende un hospital. El gran valor atribuido a esta actividad no sólo viene dado por el hecho de que es la más común y practicada en el entorno hospitalario, sino también porque, según Duterme (2007) la comunicación interpersonal influye en el desempeño profesional de los integrantes de una organización.

En el caso de los hospitales, como ya se ha señalado, trabajan un gran número de personas, todos ellos con perfiles profesionales muy distintos entre sí. Y, sin embargo, para que el hospital funcione de un modo cohesionado, es necesario que todos estos profesionales se comuniquen eficazmente $y$ orienten sus esfuerzos hacia la consecución de los objetivos globales fijados por el hospital. Con el objetivo de analizar el impacto de la comunicación interpersonal en un hospital, se estudia a continuación a los principales protagonistas 
de esta actividad en un hospital: a) personal médico y de enfermería, b) pacientes, c) ejecutivos de salud, d) empleados de administración y de mantenimiento.

Personal médico y de enfermería. La relación que establece el profesional de la salud con los pacientes está determinada por las habilidades de comunicación interpersonal de las que dispone cada uno (Wright, Sparks y O'Hair, 2008). La principal responsabilidad de este profesional consiste en restablecer la salud de sus pacientes, y para ello necesita disponer de los conocimientos científicos necesarios. Sin embargo, para poder satisfacer las necesidades clínicas y emocionales de los pacientes, no es suficiente con disponer de estas habilidades profesionales, sino que también debe poseer habilidades de comunicación interpersonal que le permitan gestionar eficazmente el caso de cada paciente. Habilidades como saber escuchar, gestionar el silencio, hacer preguntas, relacionar información, etc. son muy valoradas en este tipo de profesionales. Las habilidades de comunicación interpersonal se han convertido en una herramienta indispensable para el profesional de la salud.

Tanto el personal médico como el personal de enfermería se han convertido en los principales comunicadores de un hospital. Es cierto que estas organizaciones disponen de Departamentos de Comunicación que asumen la responsabilidad de gestionar profesionalmente la comunicación institucional -interna y externa- del hospital. Sin embargo, en la práctica, el profesional de la salud es el interlocutor que más interactúa con el paciente y con sus familiares. Desde un punto de vista comunicativo, la asistencia médica es un proceso a través del cual el profesional de la salud recopila el máximo de información posible sobre el paciente para así reducir al mínimo el riesgo que implica tomar una decisión relativa al tratamiento médico a seguir. Hay una parte de esta información que resulta relativamente fácil obtener a través de la consulta de la historia clínica del paciente, los informes de resultados, etc. Sin embargo, otra parte de la información, la relativa al estado actual del paciente, sus preocupaciones, sus expectativas, etc. es más difícil de obtener y exige que entre el profesional de la salud y el paciente se establezca un clima de confianza en el que fluya eficazmente la comunicación interpersonal. 
Los profesionales de la salud deben disponer de habilidades de comunicación interpersonal que les faciliten la realización de su trabajo. De hecho, el paciente cada vez es más exigente con este tema y se queja cuando el personal médico o de enfermería no gestiona bien la información relativa a su caso. Una de las principales razones que justifican la importancia concedida a las habilidades de comunicación interpersonal es que gracias a ellas, el profesional de la salud puede conocer mejor a sus pacientes, lo cual es especialmente necesario cuando se considera la variedad de pacientes con las que interactúa este profesional. Berry (2007) identifica hasta siete grupos de pacientes, según sus diferentes comportamientos.

En primer lugar, las personas mayores. Se trata de uno de los colectivos de pacientes más importantes por el número que representan y por la frecuencia con la que acuden a los hospitales. El profesional de la salud debe dedicarles el tiempo necesario para que entiendan los conceptos médicos relativos a su tratamiento o patología.

En segundo lugar, los pacientes menores de edad que acuden a la consulta con sus padres. En este caso, es importante que el profesional de la salud no sólo se dirija a sus padres: también debe explicar el problema de salud al menor de edad.

En tercer lugar, los adolescentes. El personal médico y de enfermería debe intentar ganarse su confianza, lo cual no es fácil ya que muchas veces estos pacientes acuden a la consulta "sesgados" por diferentes informaciones que han consultado en Internet, con sus amigos, etc.

En cuarto lugar, los pacientes que provienen de culturas distintas a la practicada por el profesional de la salud. La gestión de la diferencia cultural debe ser vista como una oportunidad para acercarse al paciente, y no como una barrera comunicativa.

En quinto lugar, las personas con dificultades para leer, escribir $y$ comprender. Con este público, el profesional de la salud debe ser especialmente paciente y presentarle la información del modo más divulgativo posible. En sexto lugar, los pacientes tímidos o reservados, con quienes el personal médico y de enfermería debe intentar establecer unas relaciones comunicativas bidireccionales, lo cual es siempre un reto. 
Y, en séptimo lugar, los pacientes agresivos. El profesional de la salud debe identificarlos lo antes posible para así adelantarse a la situación e intentar reaccionar de la forma más apropiada.

Pacientes. Cuando un paciente acude a un centro hospitalario, se activa un proceso de atención médica cuyo objetivo es restablecer la salud de dicho paciente. Y para ello, la gestión de la comunicación interpersonal establecida entre el paciente y el personal médico y de enfermería es fundamental. La actitud comunicativa del paciente influye directamente en el tipo de trabajo realizado por el profesional de la salud.

Dicho de otro modo, las habilidades y actitudes comunicativas de un paciente repercuten en el grado de perfección con el que el profesional de la salud lleva a cabo su trabajo. Según los estudios de Sharf, Haidet y Kroll (2005), el simple hecho de que el profesional de la salud anime al paciente a plantear preguntas sobre su salud patología, tratamiento, etc.- puede influir positivamente en la satisfacción de este último así como en su decisión de seguir el tratamiento médico establecido. La relación comunicativa médicopaciente debe evolucionar de la comunicación unidireccional en la que el primero transmite información al segundo, hacia la comunicación bidireccional en la que el médico y el paciente comparten información y buscan conjuntamente una solución al problema de salud del segundo.

La comunicación es una herramienta fundamental para el paciente antes, durante y después de la consulta. Antes de la consulta, el paciente utiliza diferentes fuentes de información, como por ejemplo la página web del hospital, las páginas web sobre salud, los medios de comunicación especializados en salud, etc. Entre todas estas fuentes informativas, destaca el caso de Internet, que se ha convertido en un soporte cada vez más utilizado por todas aquellas personas que desean informarse sobre temas relativos a la salud.

Si bien es cierto que Internet aporta varias ventajas (acceso inmediato a la información, posibilidad de consultar la información en texto, vídeo o imagen, contacto directo con profesionales de la salud, etc.), también representa varias amenazas. Así, según Fostier (2005), cada vez es más frecuente que los pacientes que dudan de la opinión del personal médico acudan a Internet para buscar una 
información que les convenga más y, en algunos casos, incluso prefieren seguir los consejos de dicha información online en lugar de la aportada por el médico. Esta situación representa una verdadera amenaza a la confianza que el paciente deposita en la relación terapéutica establecida con el personal médico. Durante la consulta médica con el profesional de la salud, el paciente recurre a la comunicación interpersonal para intentar comprender todos los aspectos que conciernen a su problema de salud.

Uno de los retos comunicativos que deben superar los hospitales es la asimetría informativa que existe entre el profesional de la salud y algunos pacientes. Es decir, a menudo, estos últimos no poseen la misma formación ni capacidad de comprensión que el profesional de la salud, lo cual dificulta enormemente el establecimiento de una relación comunicativa fluida. Una vez que se ha acabado la consulta médica, el paciente sigue utilizando la comunicación para comprender su problema de salud y solucionar dudas. Algunas de las iniciativas que emprende el paciente es el envío de emails a los doctores que le trataron para solucionar dudas relativas al tratamiento o la patología, la búsqueda de nuevos elementos informativos en Internet, etc.

Ejecutivos de salud. Se trata de aquellos profesionales, con formación científica o no, que asumen responsabilidades de gestión dentro del hospital, como por ejemplo el Director de Admisión, el Director de Administración, etc. Las habilidades de comunicación son fundamentales para el correcto desempeño de sus responsabilidades profesionales. Los gestores de hospitales deben tener la capacidad de establecer y mantener relaciones comunicativas satisfactorias con los empleados de la organización, así como con los periodistas, los medios de comunicación, las autoridades públicas, las asociaciones de pacientes y, por supuesto, los propios pacientes.

Parsons (2001) considera que las habilidades de comunicación son fundamentales para que un ejecutivo de salud tenga éxito en su ámbito profesional. No hay que olvidar que, en muchos casos, una gran parte del tiempo de trabajo de estos profesionales está destinada a comunicar diferentes informaciones al resto de empleados. Las habilidades de comunicación interpersonal se han convertido en una de las habilidades profesionales más importantes de los ejecutivos de salud. Una parte importante de las acciones de dirección de los 
ejecutivos de salud se enmarca en el ámbito de la comunicación interna, en la que la transmisión de valores, motivación y confianza es, a menudo, igual o más importante que la mera información en sí. Dicho de otro modo, los ejecutivos de salud deben conseguir sus objetivos profesionales (gestión, administración, etc.) pero la consecución de dichos objetivos debe ser coherente con la promoción de valores que influyan positivamente en la motivación del resto de empleados. Y para alcanzar este nivel de desempeño profesional, el hospital debe disponer de un Departamento de Comunicación Interna capaz de formar a los ejecutivos de salud en las habilidades de comunicación interpersonal que exigen sus respectivos puestos profesionales.

Empleados de administración y de mantenimiento. Un hospital emplea a un gran número de personas que realizan diferentes funciones profesionales relacionadas con la administración y el mantenimiento. Desde los electricistas hasta los vigilantes, pasando por los administrativos o los cocineros, se pueden identificar numerosos puestos de trabajo realizados por personas que no participan directamente en el trabajo del profesional de la salud, pero que sí contribuyen a mejorar el servicio integral recibido por el paciente.

Para este colectivo profesional, como sucede con el resto de empleados del hospital, el uso de la comunicación interpersonal resulta decisivo. No hay que olvidar que el mismo nivel de especialización que hay en el ámbito de las profesiones médicas también existe en otros ámbitos profesionales. Por ello, para que todos los profesionales cualificados especializados en un ámbito puedan interactuar eficientemente es necesario el recurso a una herramienta de trabajo común: la comunicación interpersonal. Como señalan Van Riel y Fombrun (2007), la comunicación está en el corazón de la competitividad de cualquier organización.

\section{Comunicación institucional}

La importancia creciente de la comunicación interpersonal en el funcionamiento organizacional del hospital justifica la decisión de esta organización de crear un Departamento de Comunicación Institucional que se encargue de gestionar profesionalmente, y de manera autónoma y protocolizada, todas y cada una de las iniciativas 
relacionadas con la comunicación interna, comunicación interpersonal, comunicación externa, relaciones públicas, eventos, marketing, etc. Una de las primeras responsabilidades que asume este departamento consiste en definir la arquitectura de marca del hospital, es decir, aquellos elementos corporativos que permiten definir a la marca hospitalaria: identidad, valores, misión, visión, cultura e imagen. En un contexto hospitalario caracterizado por el desarrollo de la medicina privada y la creación de grupos hospitalarios internacionales, resulta cada vez más necesario que los hospitales fijen de un modo preciso su arquitectura de marca para así poder diferenciarse estratégicamente de la competencia.

El primer elemento corporativo hace referencia a la identidad. Según Alfonso Nieto (2008), la identidad es el conjunto de notas que tipifican y diferencian a la institución de otras concurrentes en los mismos mercados, es decir, la identidad manifiesta públicamente la razón de ser de la institución, su fundamento intelectual, qué es y por qué es de una determinada manera. Dicho de otro modo, la identidad corporativa del hospital es el conjunto de manifestaciones (culturales, simbólicas, etc.) que ilustran la esencia del hospital, que se transmiten a través de la comunicación institucional -interna y externa- y que permiten generar cohesión interna así como diferenciar al hospital del resto de organizaciones hospitalarias competidoras.

La definición de la identidad corporativa resulta especialmente importante en el caso de los hospitales ya que en estas organizaciones el paciente participa activamente en la preparación de su tratamiento (consulta, pruebas diagnósticas, etc.), lo que implica que éste está en contacto directo con varios empleados del hospital. Y precisamente dichos empleados son los encargados de transmitir, a través de sus comportamientos y actitudes, la identidad corporativa del hospital. Según Quirke (2000), los momentos de contacto entre un cliente y una marca son cruciales ya que es en ese momento cuando dicho cliente evalúa si la promesa de la organización es verdadera o no.

Esta situación implica que el hospital debe realizar una labor de divulgación de su identidad a nivel interno de tal modo que todos y cada uno de los empleados interiorice dicha identidad y puedan transmitirla al paciente así como a los familiares del paciente. Una de las funciones de la identidad corporativa consiste en facilitar el 
establecimiento de un nexo común entre todas las acciones de comunicación que emprende el hospital, lo cual aporta una coherencia comunicativa a la organización.

El segundo elemento corporativo son los valores. Según Richard Barret (2003), los valores corporativos son aquellos que son compartidos por los empleados de una organización, que contribuyen a construir la confianza y que permiten crear una comunidad dentro de la organización. Los valores corporativos recogen la esencia de la identidad del hospital y tienen como misión ayudar al empleado a aplicar, en su día a día, una serie de ideas que le permitan orientar su esfuerzo hacia la meta final perseguida por el hospital. Todas las acciones de comunicación que emprende un hospital se basan en dichos valores. De este modo, el hospital consigue generar credibilidad ante sus diferentes stakeholders (pacientes, periodistas, autoridades públicas, etc.).

El tercer elemento corporativo es la misión. Siguiendo al experto en comunicación corporativa Alfonso Nieto (2008), se puede afirmar que las instituciones nacen para alcanzar una meta, unos objetivos que son su misión en la sociedad, los cuales pueden ser exclusivamente económicos, sociales o comunitarios. Dicho de otro modo, la misión es el objetivo que persigue un hospital, lo cual no sólo incluye los aspectos financieros, sino también los relacionados con el paciente, el hospital o la sociedad en su conjunto. Por su parte, Parsons (2001) afirma que la definición de la misión ayuda a la organización de tres maneras diferentes.

En primer lugar, definir la misión ayuda a la organización a conocer mejor a sus públicos. Los hospitales interactúan con numerosos públicos (pacientes, familiares, periodistas, autoridades públicas, etc.). Este mapa de públicos tan amplio puede complicar, en ciertos momentos, las decisiones de comunicación que debe asumir el hospital. Por ello, la definición de la misión constituye una base a partir de la cual el hospital puede decidir qué públicos son prioritarios y cuáles no. En segundo lugar, la misión indica las prioridades de comunicación de una organización. Un hospital puede emprender numerosas acciones de comunicación (prensa, eventos, marketing, etc.) ya que el hospital tiene distintos públicos, a quienes envía mensajes diferentes sobre sus distintos tratamientos y servicios 
médicos. La misión actúa como filtro para seleccionar las acciones de comunicación que realmente son prioritarias. Y en tercer lugar, la misión señala el tono de comunicación institucional que debe utilizar el hospital, es decir, ayuda a decidir si el tono debe ser más o menos institucional, si hay que usar un vocabulario más o menos divulgativo, etc. El fin último de la misión del hospital es conseguir que los empleados la interioricen y la apliquen en su día a día.

El cuarto elemento que constituye la arquitectura de marca es la visión. La principal diferencia entre la misión y la visión es el carácter de largo plazo que tiene este último concepto. Según Barret (2003), la visión representa un nivel de motivación superior al de la misión ya que, mientras la misión describe los medios, la visión describe el objetivo y establece una declaración emocionante de lo que la organización intenta conseguir. Por su parte, Nieto (2008) afirma que la visión tiene un carácter más de largo plazo que la misión puesto que indica los objetivos económicos, sociales o comunitarios que tiene la institución en el plazo de cinco o más años.

Gracias a la visión, el hospital puede decidir qué acciones de comunicación son prioritarias así como establecer guías concretas que permitan orientar el trabajo de todos y cada uno de los empleados de la organización. Al igual que sucede con los otros elementos corporativos (identidad, valores, misión, cultura e imagen), el hospital debe emprender las acciones de comunicación interna necesarias para difundir ante sus empleados cuál es la visión de la organización, así como explicar cuáles son las consecuencias prácticas de dicha visión en el día a día de todos y cada uno de los trabajadores del hospital.

En quinto lugar, el hospital debe definir su cultura corporativa. La cultura corporativa está formada por el conjunto de formas de trabajar y de ser que tiene el empleado. Siguiendo a Nieto (2008), la cultura es el conjunto de valores, actitudes, comportamientos, formas de ser y de relacionarse de una institución con las personas directamente vinculadas a ella y con los públicos a los que dirigen sus productos o servicios, es decir, es un estado de sentimientos y valores compartidos en libertad. En cierto modo, se puede decir que la cultura corporativa es la parte más visible de la arquitectura de marca del hospital ya que todos los conceptos intangibles anteriormente definidos (identidad, valores, misión y visión) se plasman en 
realidades prácticas que constituyen la cultura (la forma de ser y de trabajar de los empleados del hospital). La cultura corporativa se relaciona con los valores así como con el resto de elementos de la arquitectura de marca, lo cual permite aumentar la coherencia institucional del hospital. Para lograr que todos los empleados pongan en práctica eficientemente la cultura corporativa, el hospital debe apoyarse en las acciones de comunicación interna. Gracias a ellas, puede explicar de un modo detallado a todos los empleados cuál es la arquitectura de marca de la organización.

El sexto elemento corporativo que conforma la arquitectura de marca de un hospital es la imagen de marca. Según Van Riel (1998: 55), "las impresiones personales, la comunicación interpersonal y la comunicación de los medios masivos de comunicación se combinan para producir una mezcla de impresiones reales y paralelas cuya totalidad forma la imagen". Es decir, la imagen de marca es, en cierto modo, la opinión que sobre una organización tienen cada uno de sus stakeholders. Por tanto, se puede afirmar que del mismo modo que la definición de los elementos corporativos anteriores (identidad, valores, misión, visión y cultura) depende de la organización, la imagen es un elemento que se "escapa" al control del hospital. No obstante, el hospital debe medir el estado de su imagen de marca con el objetivo de solucionar posibles incoherencias entre lo que propugna el hospital y lo que sus stakeholders piensan de él.

La proyección social a la que están expuestos los hospitales hace muy necesaria la medición constante de las opiniones que sobre el hospital tienen sus diferentes stakeholders.

Buckley (2008) considera que los hospitales pueden utilizar tres modelos a la hora de gestionar su imagen de marca: a) modelo monolítico (se da todo el peso a la marca de la organización y pasan a un segundo plano las marcas de departamentos y de organizaciones adheridas al hospital -facultades de medicina, centros de investigación, etc.-); b) modelo refrendo (en este modelo se da más importancia a las marcas de las organizaciones adheridas que a la marca madre del hospital) y c) modelo híbrido (se establece un equilibrio entre la marca madre y el resto de marcas del hospital). Por su parte, Costa (2001) defiende que la imagen de marca de una empresa tiene quince funciones: destacar la identidad, definir la 
cultura, construir la personalidad, reforzar el "espíritu de cuerpo", atraer a los trabajadores, motivar a los inversores, evitar las crisis, impulsar los nuevos productos, relanzar a la empresa, generar una opinión pública favorable, reducir los mensajes involuntarios, optimizar las inversiones en comunicación, acumular reputación, atraer a los clientes e inventar el futuro.

Una vez que el hospital ha definido su arquitectura de marca, se fija la política global de comunicación corporativa. Van Riel y Fombrun (2007: 25) aportan la siguiente definición de comunicación corporativa: "el conjunto de actividades incluidas en la gestión y en la organización de todas las comunicaciones internas y externas cuyo objetivo es crear puntos de partida favorables respecto a los grupos de interés de los que depende la compañía. La comunicación corporativa consiste en la difusión de información sobre una organización a través de una variedad de especialistas y generalistas con el objetivo común de mejorar la habilidad de la organización a la hora de conservar su licencia para actuar". La política global de comunicación corporativa constituye una base a partir de la cual el hospital define todas sus acciones de comunicación -internas, externas, eventos, etc.-, las cuales deben quedar recogidas en un Plan Oficial de Comunicación. El Departamento de Comunicación Institucional de un hospital trabaja de un modo autónomo y protocolizado, y colabora con el resto de departamentos del hospital así como con empresas externas (agencias de comunicación, imprentas, etc.).

\section{Comunicación interna hospitalaria}

La comunicación interna se ha convertido en una de las iniciativas con mayor peso estratégico dentro de un hospital, de ahí la importancia de estas organizaciones dispongan de un Departamento de Comunicación Interna que se encargue de gestionar esta función profesional de un modo autónomo y protocolizado. Una de las labores asumidas por este departamento consiste en explicar a todos los empleados de la organización en qué consiste esta actividad, qué implicaciones tiene, que objetivos persigue y qué estrategias se pueden implantar para alcanzar dichos objetivos. 
Diversos autores han definido el concepto de comunicación interna. La importancia creciente concedida a esta actividad ha hecho que dichas definiciones sean cada vez más completas. En la actualidad, se puede afirmar que el concepto de comunicación interna está caracterizado por cuatro elementos. En primer lugar, se trata de una actividad decisiva para que la organización establezca buenas relaciones comunicativas con sus empleados, lo cual es especialmente importante si se considera el número elevado de empleados que en un hospital tienen contacto directo con el paciente. En segundo lugar, esta actividad se basa en la bidireccionalidad, es decir, la necesidad de que exista un retorno comunicativo.

Según Del Pozo Lite (2000), el concepto de comunicación interna en el ámbito empresarial está determinado por el retorno necesario del mensaje transmitido. En tercer lugar, la comunicación interna permite potenciar el servicio de base de algunas organizaciones, como por ejemplo los hospitales, ya que en estas organizaciones los pacientes exigen un servicio de calidad que, además del diagnóstico médico, incluya otros aspectos como la capacidad relacional del personal médico o sus habilidades de comunicación interpersonal. En cuarto lugar, la comunicación interna tiene un carácter financiero, es decir, intenta alcanzar objetivos precisos que se plasmen en distintas realidades tangibles, como el aumento del número de pacientes de un departamento, la mejora del conocimiento que los empleados tienen sobre la organización, etc.

Después de haber analizado estos cuatro elementos que caracterizan a la comunicación interna, se puede ofrecer una definición de esta actividad que se adapte especialmente bien al contexto hospitalario: "tipo de comunicación que favorece o promueve relaciones eficientes entre las personas que configuran los públicos internos de una organización, y que genera la confianza necesaria para coordinar adecuada y responsablemente todos los recursos disponibles en la consecución de la misión compartida. Su objetivo es mejorar la calidad del trabajo de la organización y llevar a cabo con mayor perfección la realización de su misión" (La Porte, 2001: 43).

Una vez analizado el concepto de comunicación interna, hay que estudiar cuáles son las implicaciones que esta actividad tiene para los 
empleados, para los pacientes y para el hospital en su conjunto. En lo que concierne al empleado, una de las principales implicaciones de la comunicación interna es el conocimiento generado. Es decir, gracias a esta actividad los empleados conocen mejor a la organización hospitalaria (funcionamiento interno, funciones de los departamentos, etc.) así como a los pacientes y al resto de empleados. Uno de los elementos informativos más importantes que debe conocer el empleado es la arquitectura de marca de la organización (identidad, valores, misión, visión, cultura e imagen). El conocimiento de la arquitectura de marca repercute directamente en el día a día del trabajador hospitalario y le hace ser más competitivo ya que éste entiende cuáles son los objetivos que persigue la organización y se implica de un modo sincero en la consecución de los mismos. El hospital, además, debe informar a los empleados sobre la estrategia empresarial.

Según Quirke (2000), el conocimiento de la estrategia por parte de los trabajadores es una condición necesaria para que ésta pueda llevarse a cabo. Por eso, el Departamento de Comunicación Interna personaliza el mensaje y los medios usados de tal modo que todos los empleados del hospital, independientemente de su perfil profesional, puedan comprender la estrategia organizacional. Además de aportar conocimiento sobre distintos temas (arquitectura de marca, estrategias del hospital, objetivos, etc.), la comunicación interna tiene otra implicación importante para los empleados: influye positivamente en el ambiente de trabajo.

Esta actividad intenta crear en el hospital una cultura de diálogo gracias a la cual todos los empleados puedan relacionarse de forma satisfactoria. Por último, hay que señalar que gracias a la comunicación interna, la organización puede emprender procesos de cambio y lograr que los empleados acepten dichos cambios. Los hospitales están sometidos al cambio constante (adquisición de nuevos equipos tecnológicos, creación de nuevos departamentos o puesta en marcha de tratamientos diagnósticos innovadores, contratación de empleados, etc.), por eso es importante que la comunicación interna asuma como responsabilidad facilitar dichos procesos de cambio. 
La comunicación interna también tiene varias implicaciones para los pacientes. Los pacientes son los receptores de muchas de las acciones de comunicación interna que emprende el hospital. Cuando acuden al centro hospitalario, no sólo lo hacen para solucionar su problema de salud, sino también para recibir un apoyo emocional. Por eso, es importante que una de las labores del Departamento de Comunicación Interna de un hospital consista en formar a los profesionales de la salud en habilidades de comunicación interpersonal. La comunicación se ha convertido en un elemento clave del servicio sanitario ofrecido por los hospitales ya que dicho servicio está determinado por valores intangibles (confianza, empatía, tranquilidad, etc.), los cuales son transmitidos a través de la comunicación interpersonal médico-paciente.

El tipo de comunicación que se establece entre el personal médico y el paciente influye en el funcionamiento del hospital; así, una comunicación fluida entre ambos facilita el trabajo de los distintos departamentos médicos implicados en el caso de cada paciente. Las relaciones comunicativas establecidas entre el profesional de la salud y el paciente determinan la satisfacción de este último, no sólo con el tratamiento, sino también con la institución hospitalaria en su conjunto (Wright, Sparks, O’Hair, 2008).

Las habilidades de comunicación interpersonal que tiene un profesional de la salud son muy valoradas por el paciente, el cual desea que dicho profesional sepa comunicarse de un modo correcto, transmita la información de manera comprensible, sepa escuchar, gestione los silencios, etc. Para satisfacer las necesidades comunicativas del paciente, el hospital recurre a diferentes herramientas de comunicación interna (dípticos, revista corporativa, etc.), aunque, en la práctica, la herramienta más valorada es la comunicación interpersonal establecida con el personal médico y de enfermería. La comunicación interna actúa como un elemento socializador que ayuda a la organización hospitalaria a establecer y a mantener relaciones satisfactorias y duraderas con los pacientes.

La comunicación interna también tiene varias implicaciones para el hospital en su conjunto. Entre ellas, se puede señalar que gracias a la comunicación interna, el hospital conoce mejor a sus pacientes, a sus empleados y consigue dinamizar la organización. El conocimiento del 
paciente no se reduce únicamente al ámbito clínico, sino que incluye también otros aspectos como los sociales, personales o emocionales. Según Halley (2007), el hospital necesita conocer las necesidades clínicas del paciente, pero también las necesidades no clínicas ya que de este modo puede ofrecer un servicio personalizado y lograr una diferenciación competitiva. Los profesionales de la salud se convierten en la principal fuente de información de la que dispone el hospital para conocer a sus pacientes, ya que tienen un contacto directo con ellos y pueden observar al detalle sus reacciones, opiniones, etc.

Los profesionales de la salud comparten la información que recopilan sobre los pacientes con el objetivo de ayudar a la organización a mejorar el servicio médico ofrecido al paciente. Esta información, además, es de vital importancia para las futuras acciones de comunicación que emprenda el hospital. Además de dar información sobre el paciente, la comunicación interna también permite a la organización conocer mejor a sus empleados.

El empleado, especialmente aquel que tiene contacto directo con el paciente, se convierte en el "representante del hospital", de ahí la importancia de que la organización conozca bien el carácter de sus empleados, preocupaciones, comportamientos, etc. Por último, la comunicación interna ayuda a dinamizar y rejuvenecer la organización hospitalaria. La promoción del diálogo y del trabajo en equipo, la transformación de la estrategia en acciones concretas que facilitan el trabajo del empleado y el intercambio de información entre los trabajadores son algunos de los beneficios que la comunicación interna aporta al hospital y que permiten a éste ser más dinámico.

Una vez analizado el concepto de comunicación interna así como sus implicaciones para empleados, pacientes y hospital, resulta necesario analizar cuáles son los objetivos que persigue el Departamento de Comunicación Interna de un hospital. En muchas organizaciones hospitalarias, la delimitación de objetivos es algo más teórico que práctico, sin embargo, es necesario que cada vez que el hospital realiza su Plan de Comunicación Interna, establezca unos objetivos precisos, realistas y medibles. Para ello, es necesario, en primer lugar, conocer la realidad institucional del hospital y, en segundo lugar, las implicaciones comunicativas que tiene cada 
objetivo. Según Libaert (2008), para que los objetivos sean eficaces, deben ser realistas, observables, jerarquizables, flexibles, moldeables, basados en las metas de la empresa, deben recibir apoyo (presupuesto, plazos temporales, personal que los dirija, etc.) y no deben reducirse a los medios que se van a emplear.

Según D'Almeida (2008), los objetivos principales de la comunicación interna son cuatro: a) apoyar el proyecto global de acción que emprende la empresa y explicar sus objetivos; b) ayudar a los gestores a crear un clima de diálogo y de escucha con los empleados; c) generar unión entre los trabajadores y fomentar la cohesión del grupo; y d) difundir de vez en cuando algunas políticas que hace falta dar a conocer, como por ejemplo un evento, una dificultad que afecta a la organización, o el lanzamiento de un nuevo producto. A la hora de definir los objetivos, los profesionales de la comunicación interna deben tener presentes cuáles son los objetivos de comunicación externa, así como los objetivos globales perseguidos por la organización hospitalaria.

Una vez definidos los objetivos, el hospital define las estrategias de comunicación interna que va a adoptar para intentar alcanzar dichos objetivos. Según Mora (2009), para que la comunicación institucional alcance su máximo nivel de rendimiento es necesario basar esta actividad en un planteamiento estratégico previo. Según los objetivos marcados, el Departamento de Comunicación Interna fija una u otra estrategia.

Elías y Mascaray (1998) identifican 10 estrategias de comunicación interna:

a) apalancamiento -ordenar las decisiones para detectar las causas de los problemas y actuar sobre ellas-; b) franquiciamiento -delegar la gestión de la comunicación interna a un coordinador, lo que lleva al departamento de comunicación interna a realizar únicamente labores de consultoría interna-; c) adelantamiento -elaborar los medios, procedimientos y acciones necesarios para lograr que la comunicación interna vaya por delante de los acontecimientos-; d) nominamiento emprender las acciones necesarias para que la comunicación interna siempre tenga lugar entre personas plenamente identificadas y que se conocen mutuamente-; e) acercamiento -mejorar la fluidez de la información dentro de la organización-; f) acompañamiento -la 
organización pone a disposición un experto en un tema que apoya el proceso de cambio al que está sometida la organización-; g) ritualizamiento -la organización pone en funcionamiento actos que permitan transmitir la comunicación interna por sí mismos, como por ejemplo reuniones, celebraciones de cumpleaños, etc.-; h) facilitamiento -identifica los obstáculos que dificultan el proceso de comunicación interna e intenta mitigarlos-; i) diseñamiento -utiliza las técnicas de diseño para captar la atención de los destinatarios de la información-; y j) anclamiento -centra su actividad en ordenar los procesos y los recursos destinados a la consolidación del cambio-.

\section{Conclusión}

La gestión profesional de la comunicación interna se ha convertido en una prioridad estratégica para todos aquellos hospitales que desean mejorar el servicio médico ofrecido al paciente y de este modo crear una ventaja competitiva que les permita diferenciarse como institución.

La comunicación interna permite una construcción de la marca desde dentro hacia fuera. Sin embargo, para que esto sea posible es necesario que el hospital disponga de un Departamento de Comunicación Interna, que dependa directamente de la Dirección General, que gobierne sobre el resto de áreas comunicativas del hospital (comunicación externa, marketing, eventos, etc.), que trabaje de un modo autónomo y exclusivo y que base su funcionamiento en el uso de protocolos y planes ofíciales de comunicación interna. Los hospitales que disponen de este tipo de estructura consiguen que la comunicación pase a formar parte del servicio médico ofrecido al paciente, lo cual impacta positivamente en la reputación interna y externa de la organización hospitalaria.

\section{Referencias bibliográficas}

Barret, R. (2003) : Libérer l'âme de l'entreprise. Bâtir une organisation visionnaire guidée par les valeurs. Bruxelles; París: De Boeck.

Berry, D. (2007): Health communication: theory and practice. Maidenhead: Open University Press. 
Buckley, P. T. (2007): The complete guide to hospital marketing (1 ${ }^{\mathrm{a}} \mathrm{Ed}$.). Marblehead: HCPro Inc.

D'Almeida, N. (2008): «Le plan de communication interne». En: Libaert, T. (Coord.). Le plan de communication: définir et organiser votre stratégie de communication ( ${ }^{\mathrm{ème}} \mathrm{Ed}$.) (pp. 189-194). Paris: Dunos, Cop.

Del Pozo Lite, M. (2000): Gestión de la comunicación interna en las organizaciones: casos de empresa. Pamplona: Eunsa.

Duterme, C. (2007) : La communication interne en entreprise: l'approche de Palo Alto et l'analyse des organisations $\left(1^{\mathrm{a}} \mathrm{Ed}\right.$.). Bruxelles: De Boeck Université.

Elías, J. y Mascaray, J. (1998): Más allá de la comunicación interna: diez. estrategias para la implantación de valores y la conquista del comportamiento espontáneo de los empleados. Barcelona: Gestión 2000.

Errasti Goenaga, F. (1997): Principios de gestión sanitaria. Madrid: Díaz de Santos.

La Porte, J. M. (2001): Entusiasmar a la propia institución: gestión y comunicación interna en las organizaciones sin ánimo de lucro. Madrid: Ediciones Internacionales Universitarias.

Libaert, T. (2008) : Le plan de communication: définir et organiser votre stratégie de communication ( $3^{\mathrm{a}}$ Ed.). París: Dunos, Cop.

Mora, J.M. (2009a): (Ed.). Nuevos desafíos para una profesión centenaria. En: 10 ensayos de comunicación institucional (pp. 13-27). Pamplona: Eunsa.

Nieto, A. (2008, 10 de marzo): Comunicación institucional: bases para la evaluación. Ideas tomadas en el curso de doctorado impartido por don Alfonso Nieto en la Facultad de Comunicación de la Universidad de Navarra.

Parsons, P. J. (2001): Beyond persuasion: the healthcare manager's guide to strategic communication ( $1^{\text {st }}$ Ed.). Chicago: Health Administration Press.

Quirke, B. (2000): Making the connections: using internal communication to turn strategy into action. Aldershot: Gower. 
Sharf, B.F., Haidet, P. y Kroll, T.L. (2005): I want you to put me in the grave with all my limbs: the meaning of active health participation. En: Berlin Ray, E. (Ed.), Health communication in practice. A case study approach (pp. 39-51). Mahwah, New Jersey: Lawrence Erlbaum Associates, Inc., Publishers.

Thomas, R.K. y Calhoun, M. (2007): Marketing matters. A guide for healthcare executives. Chicago: Health Administration Press. 



\section{Comunicación en el ámbito sanitario}

Elena López Parra (Médico de Familia, Madrid)

[O ORCID] [ GGS]

Concepción Álvarez Herrero (Médico de Familia, Madrid)

[O ORCID] [GGS]

Paloma Elviro García (Médico Internista, Madrid)

[D $\underline{\mathrm{ORCID}}]$ [GS]

\section{Resumen}

Dentro de las relaciones interpersonales (interacción recíproca entre dos o más personas), la relación entre el profesional de la salud y el paciente, constituye un tipo especial en el que la base de la misma es una relación de ayuda. Esta relación ha ido evolucionando desde el comienzo de la historia hasta la actualidad.

Como en toda relación interpersonal, la comunicación constituye el eje central de la misma, de tal forma que la puesta en marcha de habilidades de comunicación del profesional de la salud condiciona el éxito de dicha relación traducible en el logro de entrevistas más efectivas, mejora de la satisfacción del paciente y del profesional, reducción de conflictos con los usuarios, mejora en el conocimiento sobre la salud, aumento de la observancia terapéutica y optimización de los resultados clínicos.

Palabras clave: Comunicación interpersonal, Relación médicopaciente, Entrevista clínica. 


\section{Introducción}

$\mathrm{U}$

NA ADECUADA relación sanitario-paciente constituye la base del entendimiento clínico y condiciona múltiples aspectos en relación a la confianza, seguimiento de pautas terapéuticas y éxito en los cambios de conducta que condicionan la enfermedad.

Uno de los aspectos fundamentales que sustenta la base de esta relación es la capacidad comunicativa del sanitario.

\section{Escenario: estructura y condicionantes del Sistema Nacional de Salud en España}

El Sistema Nacional de Salud español se encuentra organizado en dos niveles asistenciales: Atención Primaria (AP) y Atención Especializada (AE). Ambos niveles presentan características diferenciales de tal forma que la accesibilidad espontánea de los usuarios y la complejidad técnica se hallan en relación inversa en uno y en otro (Tabla 1).

El nivel de AP es el nivel básico e inicial de atención, dando respuesta a la mayoría de los problemas de salud planteados por los ciudadanos. Su actividad se realiza en los Centros de Salud donde desarrollan su función equipos multidisciplinares de profesionales (médicos de familia, pediatras, profesionales de enfermería, profesionales administrativos y en algunos casos odontólogos, matronas, fisioterapeutas y trabajadores sociales) proveyendo servicios cercanos y accesibles al ciudadano y una atención longitudinal que condiciona una relación permanente y a lo largo de la vida del individuo. En el Centro de Salud se realizan actividades asistenciales en enfermedades agudas y crónicas, curativas y rehabilitadoras así como tareas de promoción de la salud, educación sanitaria y de prevención de la enfermedad. Además, el equipo de AP, desarrolla la atención tanto en el Centro de Salud como en el domicilio del paciente cuando es preciso por inmovilización del paciente o por dificultad en el desplazamiento. 
El nivel de AE presta sus servicios en los centros periféricos de especialidades (CEP) y en los Hospitales, de manera ambulatoria o durante el ingreso del paciente.

Tabla 1: Características de los niveles asistenciales de atención sanitaria

\begin{tabular}{|c|c|c|}
\hline & $\begin{array}{l}\text { ATENCIÓN } \\
\text { PRIMARIA }\end{array}$ & $\begin{array}{l}\text { ATENCIÓN } \\
\text { ESPECIALIZADA }\end{array}$ \\
\hline Características & Accesibilidad & Complejidad técnica \\
\hline Actividades & $\begin{array}{l}\text { Promoción de la } \\
\text { salud y de } \\
\text { prevención de la } \\
\text { enfermedad con } \\
\text { capacidad de } \\
\text { resolución técnica } \\
\text { para abordar de } \\
\text { forma completa los } \\
\text { problemas de salud } \\
\text { más frecuentes }\end{array}$ & $\begin{array}{l}\text { Cuenta con los } \\
\text { medios diagnósticos } \\
\text { y terapéuticos de } \\
\text { mayor complejidad } \\
\text { y coste cuya } \\
\text { eficiencia aumenta si } \\
\text { se } \\
\text { concentran }\end{array}$ \\
\hline Acceso & Espontáneo & $\begin{array}{l}\text { Por indicación de los } \\
\text { facultativos de } \\
\text { atención primaria }\end{array}$ \\
\hline $\begin{array}{l}\text { Dispositivo } \\
\text { asistencial }\end{array}$ & $\begin{array}{l}\text { Centros de salud y } \\
\text { consultorios } \\
\text { locales }\end{array}$ & $\begin{array}{l}\text { Centros de } \\
\text { especialidades y } \\
\text { hospitales }\end{array}$ \\
\hline $\begin{array}{l}\text { Régimen de } \\
\text { atención }\end{array}$ & $\begin{array}{l}\text { En el centro y en el } \\
\text { domicilio } \\
\text { del ciudadano }\end{array}$ & $\begin{array}{l}\text { De manera } \\
\text { ambulatoria } \\
\text { o con internamiento }\end{array}$ \\
\hline
\end{tabular}

Fuente: Sistema Nacional de Salud. España 2012. Ministerio de Sanidad, Servicios Sociales e Igualdad. 
Una vez concluido el proceso asistencial en AE, el paciente es nuevamente integrado en el ámbito de la AP junto con su información clínica, garantizando una visión global del paciente, una visión integral e integrada y la continuidad de la atención a lo largo de la vida del mismo.

El paciente en su recorrido en este sistema establece una serie de relaciones con otros seres humanos, los profesionales, interacciones especialmente frecuentes y continuadas con los profesionales de Atención Primaria.

\section{Aspectos básicos en la interacción entre el procesional de la salud y el usuario del sistema sanitario}

\subsection{Encuentro clínico}

Denominamos encuentro clínico a la interacción entre los pacientes, personas necesitadas de ayuda específica relacionada con la salud (enfermedad, deseo de prevención, alivio, curación,...) y los profesionales sanitarios, personas que ofrecen ayuda habiendo sido educadas académica, cultural y socialmente para brindar alivio.

La relación entre el profesional de la salud y el usuario del sistema sanitario se construye con múltiples encuentros clínicos, que son la base de la labor como médicos y enfermeras. Es lo que Pellegrino denominó "el principio arquitectónico" de la práctica clínica, de la interacción con el paciente. Se trata de la herramienta más útil de la que disponen los profesionales sanitarios.

Durante su formación académica en la Universidad, las Ciencias Básicas ayudan al profesional de la salud a entender la realidad del cuerpo humano. Es esta la base fundamental del estudio a lo largo de la formación universitaria de un médico o enfermera, pero no se puede cometer el error de reducir lo humano a lo biológico, lo estructural y lo funcional. Tanto la medicina como la enfermería, no son por lo tanto exclusivamente ciencia, sino práctica centrada en el Encuentro Clínico con el paciente, encuentro interpretativo a través del diálogo y la comprensión. 
La diferencia fundamental entre las carreras sanitarias y las ciencias en las que se sustentan, radica en la perspectiva integradora, así como en las concepciones de ayuda y curación, conceptos específicos de la Sanidad. Por otra parte las carreras sanitarias también incluyen conocimientos de Humanidades, pero se distingue de las disciplinas humanísticas en su fin práctico al que sirve, desde la ayuda y la mitigación del sufrimiento causado por perturbaciones biopsicosociales.

Cuando una persona padece una dolencia, según su intensidad, va a sufrir una disminución de libertad en relación a su cuerpo, pero también respecto a sus sentimientos y emociones. El grado de pérdida condiciona la mayor o menor limitación de su autonomía como persona tanto a nivel físico como psíquico. La enfermedad condiciona que esta persona se convierta a la vez en "paciente" y que acuda al profesional de la salud en busca de ayuda con el fin de eliminar o minimizar dicha dolencia.

El profesional sanitario, formado en la Universidad, necesita de formación en aspectos científicos, pero también, y no menos importante, en habilidades humanísticas, ya que la persona es mucho más que un cuerpo, que un conjunto de órganos y sistemas. Estas habilidades son de gran importancia para poder afrontar la ayuda que precisa una persona que presenta sufrimiento.

Estos elementos, físicos y psíquicos, científicos y humanísticos interactúan en cada encuentro profesional-paciente.

Lo que caracteriza al Encuentro Clínico, por tanto, no es la asunción biológica del paciente como objeto de estudio, sino el deseo de compartir una misma comprensión de la enfermedad con el paciente.

La relación que se establece entre el paciente y el médico es asimétrica (implica desde la perspectiva del paciente sentimientos de desamparo, abandono, temor y minusvalía y desde la del médico, conocimiento, experiencia y compromiso moral de ayuda). Por ello, es fundamental el acercamiento entre las expectativas del paciente y el abordaje de la situación por el médico, este acercamiento se realiza a través del diálogo, la escucha activa y la creación de un clima de confianza en cada encuentro clínico que sustente la comprensión de 
la dolencia que plantea el paciente y conduzca a la decisión clínica más acertada por parte del médico.

Cada una de las interacciones profesional-paciente constituye un Encuentro Clínico y la sucesión de diferentes Encuentros Clínicos construyen la Relación Clínica.

\subsection{Relación clínica}

La relación entre el profesional de la salud y el usuario del sistema sanitario ha sido denominada relación médico-paciente, relación sanitario-paciente, relación sanitario-usuario y de un modo más amplio Relación Clínica.

Esta relación ha ido evolucionando a lo largo de los siglos, pudiendo definir varios modelos de la misma.

Diferenciamos cinco tipos básicos de relación entre médicos y pacientes, según el grado de control de unos u otros en la interacción:

Modelo Paternalista - Es el modelo hipocrático por excelencia. El médico es el único agente activo de la consulta, pues es quien toma todas las decisiones, ya que el paciente no está capacitado y le transfiere toda la responsabilidad de las mismas.

Modelo Tecnológico - Se ve al paciente exclusivamente como un ente biológico, como si fuera un conjunto de órganos y no una persona. Se confía todo el poder a la técnica y se deja a un lado a la persona. En general los médicos estamos más entrenados para hacer preguntas que para escuchar al paciente. Por otra parte en este modelo al médico, escuchar y hacerle la historia al paciente le resulta irrelevante, mientras que los datos obtenidos por la tecnología médica le resultan más claros y objetivos.

Modelo Consumista - La base de este modelo es que el paciente presenta total autonomía para auto - prescribirse pruebas diagnósticas y auto - prescribirse fármacos. El médico es exclusivamente un elemento pasivo de la relación que aporta el título de Medicina para "legalizar la situación".

Modelo legal - En este modelo el médico y el paciente firman un "contrato de común acuerdo", que limita la naturaleza de la relación a un ámbito estrictamente jurídico. La falta de confianza mutua -por el 
médico porque cree que en cualquier momento se puede ver denunciado, y por el paciente que considera que si no se cumple el contrato debe demandarlo-, hace que se trate de una relación completamente deshumanizada, marcada por los miedos y la desconfianza.

Modelo de Alianza o Mutual o Centrada en el paciente - La clave de este modelo es la mutua confianza que existe entre las dos partes de la relación clínica. No se trata de una relación de igual a igual, el médico recaba la información que aporta el paciente y una vez decide las posibilidades del camino a seguir, tanto diagnósticas como terapéuticas, se las oferta al paciente, que es quien finalmente decide.

Una Relación Clínica eficaz conlleva:

- Mejoría en el nivel de satisfacción con la asistencia por parte del paciente, lo que influye directamente en la comprensión de los problemas, en la capacidad de afrontamiento y en la evolución clínica de los mismos.

- Facilita al médico la detección del problema del paciente, y su manejo posterior, da lugar a un uso más eficiente de los recursos, disminuye el desgaste profesional y reduce la exposición a problemas médico-legales.

En la actualidad los modelos de relación clínica considerados más eficaces contemplan el abordaje psicosocial de los problemas de salud, considerando no sólo aspectos dependientes del profesional o del paciente, sino que integran factores psicológicos y sociofamiliares.

El paradigma de estos modelos de relación clínica es el modelo "Centrado en el paciente".

Este modelo se sustenta en seis pilares:

1.- Exploración de la enfermedad y de las vivencias del paciente. El modelo se basa en la distinción entre enfermedad (disease) y dolencia (illness). Es decir, indaga por un lado la alteración real existente en el organismo y, por otro, el impacto que esa enfermedad produce en el individuo y la vivencia que hace de la misma el sujeto enfermo. 
2.- Comprender a la persona completa: el abordaje del paciente no sólo trata al paciente como tal, sino a su contexto, familiar, social o laboral ("Yo soy yo y mi circunstancia...")

3.- Establecimiento de acuerdos: marca un importante cambio frente a modelos preexistentes (modelo paternalista $\mathrm{y} / \mathrm{o}$ autoritario). El paciente participa en la toma de decisiones en relación al diagnóstico mediante el acercamiento al modelo explicativo de la dolencia-enfermedad del paciente por parte del médico y también en relación al tratamiento, estableciendo las metas y objetivos del mismo, clarificando las tareas y logrando objetivos comunes. Como ejemplos podemos mencionar la realización de una endoscopia u otra exploración diagnóstica molesta, y en cuanto al tratamiento, a la decisión de pautar insulina en un paciente diabético o de perder peso en un paciente obeso.

4.- Incorporar tareas de prevención de la enfermedad y de promoción de la salud.

5.- Potenciar la relación profesional-paciente en cada Encuentro Clínico, manteniendo el propósito de esta relación que no es otro que ayudar al paciente y afianzar la confianza.

6.- Ser realistas: todo ello debe hacerse en el contexto en el que se desarrolla el encuentro (recursos limitados, tiempo escaso, problemas de los pacientes cada vez más complejos y con más necesidades sentidas, demandas burocráticas excesivas,...). Debemos ser realistas y conocer estas limitaciones para no caer en el desgaste emocional. Tengamos en cuenta que, como comentábamos al principio, la atención longitudinal del paciente que se desarrolla en Atención Primaria nos va a permitir explorar problemas múltiples y complejos a lo largo del tiempo, en diferentes visitas.

Se ha comprobado que una relación clínica centrada en el paciente tiene las siguientes consecuencias:

\footnotetext{
${ }^{31}$ ("Yo soy yo y mi circunstancia, y si no la salvo a ella no me salvo yo" J. Ortega y Gasset (Meditaciones del Quijote, 1914).
} 
-Mayor calidad de la información clínica obtenida.

-Mejor comprensión del mensaje que ofrece el profesional.

-Mayor satisfacción del paciente.

-Un mejor cumplimiento de los tratamientos.

-Mejor utilización de los recursos sanitarios.

-Mejora de algunos resultados de salud.

En las últimas décadas muchos trabajos de investigación han demostrado la utilidad práctica de este modelo y las consecuencias favorable antes descritas, no obstante, el modelo puede no ser el idóneo para todos los pacientes. La clave del día a día para el médico práctico es ser flexible para poder ofrecer al paciente la mejor respuesta posible a sus necesidades clínicas y, a la vez mantener la capacidad adaptativa al contexto en que desarrolla su actividad siendo fiel y honesto con sus valores como profesional.

\subsection{Comunicación. Habilidades}

La comunicación entre el médico y el paciente constituye un elemento clave de la práctica clínica, considerándose en la actualidad una competencia clínica fundamental junto con los conocimientos médicos, el manejo de las técnicas exploratorias y la habilidad para tomar decisiones.

Para realizar una consulta realmente eficaz, el médico ha de ser capaz de integrar estos cuatro aspectos que, en conjunto, determinan su competencia clínica global. El hecho de estar en posesión de unos extensos conocimientos médicos no otorga la competencia necesaria para un adecuado abordaje del paciente si existen problemas de comunicación que impiden al médico averiguar el motivo de consulta, que el paciente comprenda el tratamiento pautado o que imposibiliten lograr el clima de confianza necesario. Sin las apropiadas habilidades de comunicación, todos los conocimientos y esfuerzos intelectuales del profesional pueden ser fácilmente desaprovechados.

Las habilidades de comunicación son actitudes y comportamientos específicos que utilizados en la actividad médica diaria (realización de una historia clínica, información al paciente de un diagnóstico o 
propuesta de un plan terapéutico) mejoran la comprensión y satisfacción del paciente, favorecen la adherencia terapéutica, elevan la precisión diagnóstica y consecuentemente aumentan la calidad de la atención al paciente.

Por todo ello consideramos que el aprendizaje de habilidades de comunicación es una necesidad básica en la formación tanto de pre como de postgrado en las carreras sanitarias.

Kurtz y Silverman han sintetizado en la guía de observación de Calgary Cambrige (Guía CC) aquellas habilidades específicas que sostienen una comunicación efectiva. Cada uno de sus 70 ítems está basado en la evidencia y constituye una guía dinámica que evoluciona según avanza la investigación en el campo de la comunicación médico-paciente.

Aunque la guía cuenta con una larga lista de habilidades, las tareas se pueden agrupar en los siguientes grandes apartados:

1. Iniciar la sesión

2. Obtener información

3. Construir la relación

4. Explicar y planificar

5. Cerrar la sesión

Para realizar de forma efectiva cada una de las tareas se precisan utilizar una serie de habilidades que se resumen en la tabla 2.

En cada encuentro clínico no es necesario desarrollar todas las habilidades sino aquellas que se consideren oportunas según la situación concreta y el objetivo marcado por el médico y el paciente. Ocurre algo similar a cuando un mecánico precisa reparar un coche, requerirá de una o de múltiples herramientas según el problema a solucionar. 
Tabla 2: Algunas habilidades especificas para cada tarea de la entrevista (adaptada de las Guias Calgary Cambridge)

\begin{tabular}{|c|c|c|}
\hline $\begin{array}{l}\text { Proporcionar } \\
\text { estructura }\end{array}$ & Etapas de la entrevista & $\begin{array}{c}\text { Construcción de la } \\
\text { relación }\end{array}$ \\
\hline $\begin{array}{l}\text { Progresar de } \\
\text { una sección a } \\
\text { otra, utilizando } \\
\text { enunciados } \\
\text { que señalicen } \\
\text { cambios o } \\
\text { transición }\end{array}$ & $\begin{array}{l}\text { Iniciar la sesión } \\
\text { Establecer el contacto inicial } \\
\text { Saludar al paciente y llamarle por } \\
\text { su nombre } \\
\text { Presentarse, aclarar el rol y la } \\
\text { naturaleza de la entrevista: } \\
\text { obtener consentimiento si fuera } \\
\text { necesario } \\
\text { Identificar lo(s) motivo(s) de } \\
\text { consulta } \\
\text { Identificar los problemas del } \\
\text { paciente con preguntas abiertas } \\
\text { Escuchar atentamente el } \\
\text { planteamiento inicial del paciente, } \\
\text { sin interrumpirlo ni guiar su } \\
\text { respuesta }\end{array}$ & $\begin{array}{l}\text { Mostrar } \\
\text { comportamiento } \\
\text { no verbal } \\
\text { apropiado: } \\
\text { contacto visual, } \\
\text { postura... } \\
\text { Si se lee o se } \\
\text { toman notas, } \\
\text { hacerlo de } \\
\text { manera que no } \\
\text { interfiera con el } \\
\text { diálogo o con la } \\
\text { relación }\end{array}$ \\
\hline $\begin{array}{l}\text { Estar atento a } \\
\text { los tiempos y a } \\
\text { mantener el } \\
\text { foco de la } \\
\text { entrevista }\end{array}$ & $\begin{array}{l}\text { Obtener información } \\
\text { Utilizar preguntas abiertas y } \\
\text { cerradas en forma equilibrada } \\
\text { Facilitar en forma verbal o no } \\
\text { verbal las respuestas del paciente } \\
\text { Clarifica los enunciados del } \\
\text { paciente que no resultan claros o } \\
\text { que necesitan ampliación } \\
\text { Resumir periódicamente para } \\
\text { verificar la comprensión } \\
\text { Explorar la perspectiva del } \\
\text { paciente (expectativas, miedos } \\
\text { etc.) }\end{array}$ & $\begin{array}{l}\text { Aceptar la } \\
\text { legitimidad del } \\
\text { punto de vista y } \\
\text { los sentimientos } \\
\text { del paciente; no } \\
\text { juzgar }\end{array}$ \\
\hline
\end{tabular}




\begin{tabular}{|l|l|l|}
\hline $\begin{array}{l}\text { Durante la } \\
\text { exploración } \\
\text { física, explicar } \\
\text { el proceso, } \\
\text { pedir permiso }\end{array}$ & $\begin{array}{l}\text { Explicar y planificar } \\
\text { Proporcionar la cantidad y tipo de } \\
\text { información correcta }\end{array}$ & $\begin{array}{l}\text { Contribuir a que el paciente } \\
\text { recuerde y comprenda de manera } \\
\text { precisa } \\
\text { verbalizar las } \\
\text { emociones } \\
\text { evidentes en el } \\
\text { paciente }\end{array}$ \\
$\begin{array}{l}\text { Estructurar la } \\
\text { entrevista } \\
\text { siguiendo una } \\
\text { secuencia } \\
\text { lógica }\end{array}$ & $\begin{array}{l}\text { preguntas al paciente a formular } \\
\text { Lograr un entendimiento y } \\
\text { planificación en común: } \\
\text { incorporar la perspectiva del } \\
\text { paciente }\end{array}$ & $\begin{array}{l}\text { Brindar apoyo; } \\
\text { expresar interés, } \\
\text { comprensión y } \\
\text { predisposición } \\
\text { para ayudar }\end{array}$ \\
\hline & $\begin{array}{l}\text { Cerrar la sesión } \\
\text { Establecer junto con el paciente } \\
\text { los pasos a seguir por el paciente y y } \\
\text { el médico } \\
\text { Resumir el encuentro brevemente } \\
\text { y clarificar el plan de cuidados } \\
\text { Verificación final: comprobar que } \\
\text { el paciente esté de acuerdo y } \\
\text { cómodo con el plan }\end{array}$ & $\begin{array}{l}\text { Hacer participar } \\
\text { al paciente: } \\
\text { pompartir su }\end{array}$ \\
\hline
\end{tabular}

Fuente: "La comunicación médico-paciente: ¿Cuáles son las habilidades efectivas?" Moore P., Gómez G., Kurtz S., Vargas A. Rev Med Chile 2010; 138: $1047-1054$

\subsection{Características de un buen entrevistador en el ámbito sanitario}

Dentro del marco general de la comunicación médico-paciente, podemos definir una serie de características que definen a un buen entrevistador (Tabla 3):

- Cordialidad: hace referencia a la proximidad afectiva, dando a entender al consultante que es bienvenido y que deseamos 
comunicarnos con él. Existe un contacto visual facial adecuado, un recibimiento personalizado o una sonrisa oportuna.

- Baja reactividad: la reactividad es el tiempo que transcurre desde que el paciente termina de hablar hasta que el profesional lo hace. La baja reactividad suele ir acompañada de capacidad de escucha, cualidad especialmente valorada por nuestros pacientes.

- Empatía: es la capacidad del entrevistador para comprender las emociones del paciente dándole a entender esta comprensión y para conectar con el sufrimiento o alegría del paciente. El entrevistador se solidariza con sus emociones. Puede ser verbal o no verbal, como, por ejemplo, un gesto.

- Asertividad: es la capacidad para cumplir de forma plena y segura los derechos y deberes correspondientes a nuestro rol profesional, trasmitiendo seguridad y credibilidad a la hora de tomar decisiones, haciéndole ver al paciente que se encuentra en buenas manos.

Tabla 3: Habilidades de un buen entrevistador

HABILIDADES DE UN BUEN ENTREVISTADOR

- CORDIALIDAD (profesional amable)

- EMPATIA (profesional humano)

- ASERTIVIDAD (seguridad, “estar en buenas manos”)

- ORDEN (plan de entrevista )

- RESPETUOSO (no es juez ni moralista)

- FLEXIBLE (capaz de adaptarse y cambiar)

Fuente: Grupo Comunicación y Salud SoMaMFyC 


\section{La entrevista clínica}

La entrevista clínica es el procedimiento que posibilita la interacción entre el profesional sanitario y el paciente y puede ser definida como el conjunto de recursos que facilitan la relación humana e interpersonal que se establece entre dos o más personas (sanitariopaciente-familiar,...), por medio de la cual el profesional de la salud, procede a realizar una acción técnica para evaluar diagnóstica y terapéuticamente los problemas biológicos, psicológicos y sociales de los usuarios que demandan su servicio.

\subsection{Objetivos de la entrevista clínica}

- Conocer el motivo por el que acude el paciente y obtener la información necesaria para llegar a un diagnóstico.

- Prescribir un tratamiento o recomendar una pauta de conducta.

- Establecer una relación asistencial eficaz y satisfactoria.

\subsection{Tipos de entrevista clínica}

Diferenciamos distintos tipos de entrevista según los objetivos, el método, el receptor de los cuidados de salud o el canal de comunicación.

Según los objetivos:

- Operativa, es decir, con objetivos acordados previamente

- De diagnóstico o de escucha, en la que la finalidad no se ha acordado previamente.

Según el método:

- Entrevista libre, con libertad total del entrevistado para escoger los contenidos a explicar.

- Entrevista dirigida o estructurada, los contenidos están predeterminados por el sanitario.

- Entrevista semiestructurada o semidirigida, cuyos contenidos están parcialmente determinados por el sanitario, con espacio para la libre narración del paciente. 
Según el receptor de los cuidados de salud:

- Dual, en la que el profesional de salud entrevista a un solo paciente, por ejemplo, cuando acude un adolescente sin acompañante o bien un familiar a consultar algo sobre el paciente.

- Múltiple, cuando se realizan en una misma consulta diferentes visitas a varios miembros de una familia.

Según el canal de comunicación:

- Consulta cara a cara, en la que el profesional y paciente están uno frente al otro.

- Consulta telefónica, en la que la consulta evidentemente se produce mediante este medio.

Vamos a centrarnos en el análisis de la entrevista semiestructurada, que es la que mejor se adapta la atención clínica en general (a excepción de la entrevista psiquiátrica), tanto por el tiempo como por los contenidos que se pueden aplicar.

\subsection{La entrevista semiestructurada}

Una entrevista eficaz sigue un orden establecido que persigue la consecución de los objetivos reflejados en el punto 1.

Podemos distinguir cuatro partes en una entrevista clínica eficaz:

\section{a. Antes de empezar la entrevista}

En esta fase se deben cuidar los elementos no verbales del entorno (orden en la mesa, bata limpia, expresión relajada, ...), valorar la carga asistencial de la jornada para equilibrar el tiempo que dedicamos a cada paciente, habilitar actuaciones para evitar interrupciones (teléfono, interrupciones de otros profesionales o de pacientes,...), intentar lograr un clima de concentración superando las emociones negativas que podrían interferir en la escucha o la toma de decisiones y repasar la historia clínica de cada paciente antes de que entre en la consulta.

b. Parte exploratoria, en la que el médico intenta delimitar el motivo o motivos de consulta. Se produce un vaciado de la información preelaborada por el paciente mediante apoyo a su narrativa, búsqueda 
de datos específicos necesarios para nuestra toma de decisiones y acompañamiento de la exploración física o las técnicas instrumentales.

- Recibimiento cordial

La forma habitual de iniciar una relación clínica en la consulta es mediante el recibimiento. Durante éste y en los primeros momentos de la consulta, tienen lugar reajustes conductuales que determinan el resto de la consulta y de la relación. Mediante métodos de análisis conversacional, algunos autores han llamado la atención sobre cómo determinadas secuencias de apertura y reglas usadas en el recibimiento pueden también determinar la concordancia entre profesional sanitario - paciente, y el grado en el que ambos van a compartir las decisiones durante el resto de la consulta. Algunas habilidades a aplicar en esta fase son el saludo, llamar al paciente por su nombre, el contacto físico (p.e. estrechar la mano), el contacto visual o la sonrisa.

- Pregunta abierta

Una vez se ha recibido al paciente la entrevista debería seguir con una pregunta abierta. Es una pregunta sencilla, que no permite la contestación en forma de monosílabo, sí o no.

“¿Qué le pasa?”, “¿Qué tal?”, “Cuénteme”, “Usted dirá”.

Un error frecuente es el de presuponer el motivo de consulta haciendo una pregunta cerrada.

- Técnicas de apoyo narrativo

Son técnicas que crean un clima de confianza: empatía, silencios adecuados y facilitaciones.

La empatía es una capacidad que conlleva el poner en juego una serie de conductas que están encaminadas a descifrar los sentimientos y las preocupaciones del paciente y darles una respuesta, de manera que el profesional le demuestre que los ha entendido y aceptado. La empatía supone, por lo tanto, el reconocimiento y reflejo del estado emocional del paciente. Según Rogers y otros autores, la empatía constituye una de las más importantes habilidades para construir y mantener una relación terapéutica. Una comunicación basada en la 
empatía contribuye a mitigar los sentimientos negativos tales como la ansiedad, la tristeza, el miedo o la ira, y, por ello, es terapéutica.

Los silencios funcionales, según la definición de Francesc Borrel, consisten en la ausencia de palabras o mensajes no verbales cuyo efecto tiene un contenido claro para ambas partes: facilitar un espacio para meditar una determinada respuesta, o trasladar al consultante la responsabilidad de proseguir el diálogo.

Las facilitaciones, son conductas, verbales o no verbales, que ayudan a iniciar o proseguir un relato. No se indican ni sugieren contenidos; por ejemplo, Continúe... sí... mmmm...., cabeceos. A su vez existen facilitadores verbales que favorecen la elaboración de percepciones, ideas o emociones como las frases por repetición (repetición de una palabra o frase que orienta la atención del paciente hacia un determinado contenido), la clarificación (conducta verbal o no verbal que obliga a explicar el sentido de un término o idea) o el señalamiento (ayuda al paciente a clarificar emociones o ideas, evidencia conflictos o áreas de estrés psicosocial, profundiza en las motivaciones del paciente y le muestra sus emociones o conductas).

- Técnicas para obtener información específica

En general, la información se debe recoger empezando por preguntas abiertas, continuando por menú de sugerencias y terminando con preguntas cerradas.

La pregunta abierta es aquella que obliga a responder con una frase y no encierra en sí misma sugerencias. Permiten obtener una gran cantidad de información, a la vez que dejan al paciente libertad para responder como crea más conveniente sobre el tema en cuestión; por ejemplo, ¿Cómo es el dolor? Estas preguntas abiertas se deben hacer fundamentalmente al comienzo de la entrevista.

El menú de sugerencias: el entrevistador ofrece en su formulación al menos dos opciones para orientar el sentido de la respuesta del paciente. Un ejemplo de menú de sugerencias sería: el dolor, ¿es opresivo, punzante o quemante?

Las preguntas cerradas son aquellas que se pueden responder con un monosílabo, como ¿el dolor es punzante? Cuando hacemos preguntas cerradas, el paciente cuenta con pocas opciones de respuesta y generalmente responde con un sí o con un no. Conviene evitar el 
basar la entrevista en este tipo de preguntas y complementar la exploración con técnicas de apoyo narrativo y después de probar preguntas abiertas y menús de sugerencias. Estas preguntas son de mayor utilidad cuando se trata de perfilar los últimos detalles de una determinada información.

- La delimitación de la demanda

“¿Algo más?" Conviene hacer esta pregunta tras la narrativa inicial del paciente, y siempre antes de la exploración física. Cuando esta pregunta se realiza al final, con el cierre de la entrevista, o no se realiza, pueden dar lugar a nuevas demandas (demandas aditivas) que producen distorsiones para el entrevistador. Se ha demostrado que las consultas en las que el sanitario ha redirigido precozmente el discurso del paciente mediante preguntas cerradas, la aparición de nuevos problemas en el cierre fue significativamente más alta frente a aquellas en las que no se redirigía el discurso.

- Otras tareas a realizar a continuación y antes de la siguiente fase de la entrevista son:

- Comprobación e integración de la información, realizando escucha activa, sumarios y el abordaje bio-psico-social (fundamental en algunas patologías como por ejemplo las psicosomáticas).

- Actualización de problemas anteriores, si existe algún problema reciente pendiente de valorar evolución.

- Exploración física, pidiendo permiso y explicando lo que vamos a hacer respetando la intimidad.

c. Parte resolutiva, en la que se enuncian y explican los problemas encontrados, y se acuerda con el paciente la individualización de las medidas preventivas, terapéuticas o diagnósticas propuestas.

La parte resolutiva de la entrevista clínica se inicia cuando el profesional toma una decisión acerca de la mejor conducta a seguir. En este momento el profesional explica, aconseja o informa al paciente en relación a la demanda del mismo y es el elemento informativo el principal protagonista. Informar no es exactamente lo mismo que educar. La educación es un proceso más global, un 
proceso en el cual tratamos de modificar conductas y creencias del paciente.

La información por sí sola puede conducir a cambios importantes en el estilo de vida, pero no forzosamente. La característica básica de la información es que la damos en tiempo y lugar concretos, mientras que el proceso educativo es un proceso que se da en una relación humana en la que los procesos de imitación, identificación y persuasión tienen tanta o más importancia que la simple información en el logro de cambios saludables en el estilo de vida.

La información emitida debe adaptarse al paciente de tal forma que sea comprensible y sea capaz de mantener su atención.

Pero ¿qué grado de eficacia tiene la información? Es conveniente conocer que una correcta información no asegura el seguimiento del tratamiento. Una persona no modifica sus hábitos de vida simplemente porque le informemos de que sus hábitos son tóxicos o perjudiciales. $Y$ un paciente que no hace caso de nuestras recomendaciones no tiene por qué ser una persona que no nos ha comprendido o que ha sido mal informada. Muchas personas a las que se les informa correctamente declararán que no han recibido ningún tipo de información sobre su proceso. A estas personas les hace falta motivación y no sólo información.

Las habilidades y técnicas que aumentan la memorización y comprensión de los mensajes informativos emitidos por el profesional comprenden habilidades formales como utilizar frases cortas, una dicción clara y entonada, información bidireccional y emplear vocabulario neutro evitando tecnicismos y palabras de alto contenido emocional y habilidades conceptuales tales como enunciar la enfermedad y la medida terapéutica (decirle al paciente de qué vamos a hablar), poner ejemplos, racionalidad de la medida terapéutica (explicación de cómo actúa el medicamento o el cambio de conducta), detallar los cambios y comprobar la asimilación de la información emitida.

Durante esta fase se debe constatar que la propuesta de acuerdo es aceptada por el paciente bien de forma implícita o bien explícita (¿Está usted de acuerdo con...?). En caso de que esto no sea así es preciso entrar en la fase de negociación en la cual, tras advertir que el paciente no acepta la información y da muestras de que no le satisface 
el plan diagnostico, terapéutico o preventivo que se le está ofreciendo, el profesional precisa de influir, persuadir, negociar o motivar.

No hay que olvidar que se debe aceptar el derecho que tiene el paciente a participar y opinar sobre su proceso asistencial; por ello, el profesional debe ser capaz de desarrollar técnicas de negociación y persuasión (incluso en situaciones en que creamos poco justificadas las opiniones del paciente), capacitándose para ejercitar una respuesta evaluativa frente a las opiniones del paciente, aunque estas opiniones se digan de manera agresiva o recelosa. Ello se contrapone con la respuesta justificativa, que es la más habitual cuando a cualquier profesional se nos pone en entredicho. Por tanto, en este punto, la respuesta evaluativa es de enorme importancia y es la clave de toda la negociación. Requiere por parte del entrevistador una actitud reflexiva equivalente a decir: “¿Y si efectivamente tuviera razón?” "¿Y si lo que desea decirme fuera de interés?". Desde luego que la respuesta evaluativa mediante la cual realizamos la exploración de creencias debe hacerse en un clima empático, pues en caso contrario se propiciarán un aumento de las resistencias del paciente. Es necesaria una escucha que intente encontrar los aspectos positivos, hallando las ideas o sugerencias aprovechables del paciente o su familia. Adaptar las preferencias del paciente a su plan terapéutico es indudablemente una virtud del entrevistador.

\section{d. Cierre de la entrevista y toma de precauciones}

El cierre del encuentro clínico engloba las siguientes tareas:

- Avisar sobre el cierre

- Resumir la sesión y el plan de actuación

- Revisar los objetivos

- Planificar próximas visitas y pasos

- Establecer planes de contingencia o toma de precauciones, esto es, tener en mente las siguientes cuestiones:

1. Si estoy en lo cierto ¿Qué debo esperar que ocurra?

2. ¿Cómo voy a saber si estoy equivocado? 
3. ¿Qué voy a hacer posteriormente?

- Preguntar si el paciente tiene otros temas

- Animar y apoyar al paciente

- Despedirse de manera cordial: fórmulas de cortesía, acompañar a la puerta,...

Las técnicas anteriormente descritas son muy sencillas de entender y comprender aunque algo más difíciles de practicar. Es importante que los profesionales de la salud vayan introduciéndolas en su práctica habitual con el fin de mejorar sus entrevistas clínicas y así lograr una mejor conexión emocional con el paciente, favorecer la exploración de la enfermedad y del impacto que ésta tiene en el mismo, aumentar la adherencia terapéutica y mejorar la satisfacción de los usuarios y de los propios profesionales.

\section{Referencias bibliográficas}

Borrell i Carrió, F. (2011): Práctica clínica centrada en el paciente.

Triacastela, Madrid.

Borrell I Carrió, F. (1989): Manual de entrevista clínica. Doyma, $2^{\mathrm{a}}$ Ed. Barcelona.

Epstein RM, Street RL Jr. (2007): Patient-Centered Communication in

Cancer Care: Promoting Healing and Reducing Suffering. National

Cancer Institute, NIH Publication N. 07-6225. Bethesda, MD.

Martínez-Betancur, O. (2008): “Opiniones, Debates y Controversias.

El encuentro clínico dialógico, comprensivo y ético como

fundamentos de la práctica médica". Rev. Fac. Med. Vol.56 No.3.

Universidad Nacional de Colombia. Bogotá.

Pellegrino, E.D. (1993): The virtues in medical practice. Oxford University Press US.

Silverman, J; Kurtz, S; Draper J. (2005): Skills for Communicating with Patients. Radcliffe Publishing ( $2^{a}$ edition). Oxon, UK.

Vinuesa Sebastián, M.; Alfaro Latorre, M., Esteban Gonzalo, S. (2012): Sistema Nacional de Salud. España 2012 [monografía en 
Internet]. Ministerio de Sanidad, Servicios Sociales e Igualdad. Madrid. Disponible en: www.msssi.gob.es

\section{Otras lecturas recomendadas}

Borrel i Carrió, F. (2004): Entrevista clínica. Manual de estrategias Prácticas. semFYC. Ed. Barcelona.

Elviro, P; Serrano, R. (2005): Cómo entender al paciente y que él nos entienda. Sankyo Pharma, Madrid.

Ruiz Moral, R. (2004): Relación clínica, guía para aprender, enseñar e investigar. semFYC. Ed. Barcelona. 


\section{Metodología para el análisis de las webs de salud dirigidas a jóvenes}

\section{Lázaro Echegaray Eizaguirre [-ORCID] [ GGS] (Escuela}

Universitaria de la Cámara de Comercio de Bilbao, EUCCB)

Milagros Ronco López [@ORCID][CGS] (Universidad del País Vasco/EuskalHerrikoUnibertsitatea, UPV/EHU)

Idoia Camacho Markina [ORCID] [ GGS] (Universidad del País Vasco/EuskalHerrikoUnibertsitatea, UPV/EHU)

\section{Resumen}

Los jóvenes de hoy en día se enfrentan diariamente a situaciones de riesgo para su salud. Situaciones que pueden estar relacionadas con el consumo de drogas o que pueden ser resultado de prácticas sexuales poco seguras. No es de extrañar, por tanto, que otorguen una considerable importancia a la adquisición de hábitos de vida saludable, ni la preocupación que muestran por la aparición de las nuevas enfermedades que observan a su alrededor y que pueden afectarles. La duda y la curiosidad preceden a la búsqueda de información. Siendo estos jóvenes nativos digitales, Internet se consolida como el medio preferido para satisfacer la búsqueda de información acorde a sus necesidades; es accesible, rápido, completo y proporciona cierta privacidad. Por tanto, no es de extrañar la proliferación que los contenidos de salud han experimentado en las páginas web dirigidas a jóvenes, ni el crecimiento de éstos de forma exponencial. La aparición de un nuevo entorno destinado a la difusión de información, significa la aparición de nuevos hábitos y 
formas de búsqueda y recopilación de la misma. La comunicación, entendida como un proceso a través del cual las personas dan sentido a su realidad, resulta trascendental para la actividad y el comportamiento del consumidor de salud ${ }^{32}$.

Palabras clave: Salud y comunicación, salud de la adolescencia y juventud, metodología de recursos web, webs de salud.

\section{Marco interpretativo}

- L HECHO de que los jóvenes actuales pertenezcan a la generación que se ha denominado de los 'nativos digitales', significa que poseen una elevada capacitación para el uso de las tecnologías digitales puesto que se han educado en su proximidad y en relación íntima con ellas; forman parte de su vida cotidiana. Este colectivo desarrolla así un conocimiento más amplio y completo del leguaje audiovisual y comprende de forma adecuada el proceso de interacción comunicativa propio de las nuevas tecnologías de la comunicación y de la información. Como fuente de información relativa a la salud y al bienestar, Internet constituye un área de conocimiento amplia y en expansión, lo que le hace ganar protagonismo y notoriedad como herramienta de búsqueda. Añadido a lo anterior, hay que recordar que el mundo digital actúa como una extensión del mundo real y la información que ofrece es susceptible de generar pautas de conducta en un ámbito social que accede con mayor frecuencia y facilidad a los contenidos difundidos por los medios en general, sobre todo si tenemos en cuenta la convergencia mediática que existe en Internet. La consecuencia de estas características propias de la red, es un cambio de paradigma en la forma en que los distintos actores del sistema sanitario, no sólo los jóvenes sino también otros pacientes e incluso los facultativos, buscan, encuentran y difunden información médica.

\footnotetext{
${ }^{32}$ Esta investigación está subvenciona por la Universidad del País Vasco/Euskal Herriko Unibertsitatea (código EHU 12/12) dirigida por Carmen Peñafiel (IP) y en la que colabora el equipo constituido por: Idoia Camacho, Milagros Ronco, Lázaro Echegaray y José Mari Pastor, profesores y profesoras de la UPV/EHU y de la Escuela Universitaria de la Cámara de Comercio de Bilbao.
} 
El objetivo de este trabajo es, por una parte, analizar los recursos web sobre salud dirigidos a adolescentes y jóvenes, con edades comprendidas entre 12 y 24 años, en español y en euskera, para determinar qué tipo de contenidos informativos recogen esos sitios web. Por la otra, determinar cuál es el tratamiento que reciben dichos contenidos y los efectos que pretenden crear en sus receptores.

Teniendo en cuenta los problemas con los que suelen encontrarse los jóvenes a la hora de acceder a la información de salud en los medios tradicionales, resulta adecuada la investigación para la mejora de los procesos de comunicación que les caracterizan, sin olvidar aspectos propios de las nuevas tecnologías como la interacción social y el aprendizaje resultante tanto a partir de programas de educación como de información de salud.

Aprovechando las ventajas que ofrecen las nuevas tecnologías y la facilidad de acceso y uso que demuestra tener el colectivo joven hacia ellas, Internet debería convertirse en un soporte sólido que integre y aplique las directrices que la Organización Mundial de la Salud (OMS) recomienda a los sistemas de información de salud dirigidos a los adolescentes y jóvenes. No siendo tratadas con rigor y calidad, las noticias de salud pueden generar efectos negativos sobre la población (Ayestaran et al., 2012).

En lo que se refiere a los contenidos de salud que se ofrecen en Internet, a la hora de analizarlos, es importante asegurar su veracidad, su origen, la profesionalidad de los responsables que los crean y difunden y la forma en que se transmite esa información a la población en general y a la juventud en particular.

Los estudios realizados indican que son los jóvenes de entre $15 \mathrm{y}$ 24 años quienes hacen un mayor uso de Internet para informarse sobre aspectos sanitarios (Baker et al., 2003). Se percibe, por tanto, la necesidad de educar a los más jóvenes, tanto en el buen uso de Internet como en su uso específico para la búsqueda de información sobre salud y para la transmisión del conocimiento adquirido sobre el tema. Borzekowski y Rickert (2001) exponen las diversas razones por las que Internet puede ser una herramienta importante para los jóvenes en la búsqueda de información de salud: facilidad de acceso, confidencialidad y personalización. El modo de conocer, pensar, sentir y relacionarse con los jóvenes, cuestiona la función social y 
educativa de los agentes sociosanitarios y educativos (Gabelas, 2009) que podrían ser calificados como servicios rígidos y autoritarios. Lascoste y Cols (1999) defienden que los programas de prevención con formato de páginas web aportan información, datos o pautas de actuación, e introducen una serie de ventajas de cara al usuario que los hacen diferentes frente al formato tradicional.

Estas ventajas son: la información ilimitada, tanto en formato de texto como en imágenes; posibilidad de acceso a los datos requeridos en un momento determinado, pudiendo seleccionar aquellos que sean de su interés; existencia de disponibilidad total de acceso: sin días festivos, ni noches, ni vacaciones; la exigencia de un esfuerzo mínimo de accesibilidad al ofrecer directamente al interesado, en el ordenador de su casa, la información requerida; es un medio interactivo, siendo el destinatario final del mensaje también el coautor, pues puede colaborar activamente aportando y/o modificando los contenidos; es el canal de comunicación que usan los jóvenes de hoy y será la forma de comunicación de las próximas generaciones.

Aunque la literatura sobre Internet y salud es cada vez más extensa, en España se han hecho muy pocos estudios para conocer los patrones de búsqueda de información sobre salud en Internet y la percepción sobre la calidad de estos recursos que tienen los diferentes grupos de población.

El objetivo de este trabajo que ahora se narra es el de diseñar una base metodológica válida y eficaz para alcanzar esas pautas de conocimiento necesarias para conocer aquellos aspectos relacionados con la calidad de los contenidos de Internet y los usos que se hacen del soporte en la búsqueda de información de salud.

\section{Objetivos de investigación}

Según los expertos, los medios de comunicación tradicionales mostraron cierta incapacidad para generar el empoderamiento necesario de sus usuarios hacia los temas de salud. En contraposición, los medios de comunicación digitales se han conformado como una herramienta importante para la difusión de contenidos de salud dirigidos a todos los públicos. Las características de la digitalización, como la interactividad o el hipertexto, suponen una nueva forma de 
acercarse a la información en los dos sentidos del proceso comunicativo.

Sin embargo, estas características, no suponen por sí mismas la calidad de la información que se difunde, ni de los contenidos que albergan. En este sentido, y desde una perspectiva que tiene su inicio en los años sesenta del siglo pasado, la calidad de la información que ofrecen los medios de comunicación ha significado un campo de estudio común en los estudios de los investigadores sociales.

En la medida en que Internet también ofrece contenidos susceptibles de generar significados que ayudan a construir realidades sociales, también la calidad de éstos ha significado un campo de preocupación para los investigadores. A este respecto, tanto las instituciones públicas como los equipos de investigadores de ámbito académico, han realizado aportaciones importantes en cuanto a los parámetros y los indicadores que deben conformar la calidad online.

Los efectos que los contenidos de salud pueden tener para el público en general, y para los jóvenes en particular, hacen de la investigación sobre la calidad de los mismos un motivo importante de análisis. No obstante, el objetivo de este trabajo que ahora se presenta pretende ir más allá del análisis de calidad de aquellos recursos web que presentan contenidos de salud dirigidos a los jóvenes de entre los 12 y los 24 años de la Comunidad Autónoma del País Vasco y de la Comunidad Foral de Navarra, en páginas escritas en euskera y castellano. Busca también el análisis del modo en que éstos jóvenes consumen e interactúan con esa información.

Siendo ese el objetivo general de la investigación, el objetivo del presente artículo es el de exponer la base metodológica que el equipo de investigación ha desarrollado para alcanzar el objetivo marcado.

\section{Metodología utilizada para la investigación}

La investigación desarrollada para estudiar los recursos web de información de salud dirigidas a jóvenes de entre 12 y 24 años de la Comunidad Autónoma Vasca y de la Comunidad Foral de Navarra, escritas en euskera y en castellano, se está desarrollando mediante el uso de una metodología mixta, que incluye tanto técnicas de tipo cualitativo como de tipo cuantitativo. Se trata de un proceso 
establecido en dos direcciones, de acuerdo con las características del proyecto, con los objetivos planteados y con el universo que conforma el objeto de estudio: 1) En lo que respecta a la creación y al uso de los recursos web se trabaja desde un punto de vista jerárquico que empieza en el nivel institucional y termina en el usuario receptor de contenidos.

El objetivo de este esquema es adquirir conocimiento sobre el proceso de creación de los recursos web, la composición de su estructura jerárquica y creativa, la razón de ser de los contenidos seleccionados y la oportunidad o no de los mismos en relación con el público objetivo al que se dirigen 2) En lo que respecta a lo grupal y a lo individual, se aspira a establecer las relaciones de correspondencia que existen entre ambos niveles, partiendo de la idea de que todo aquello que afecta, de manera general, a un grupo afecta, de manera particular, a un individuo. En este aspecto, nos sentimos identificados con la frase de Jesús Ibáñez (1976) que dice: "Cuando un individuo habla conscientemente en un grupo de discusión es inconscientemente hablado por la sociedad".

Pasaremos posteriormente al análisis de las generalizaciones en cuanto a uso, costumbres, percepciones, opiniones y los niveles de repetición de experiencias, en función del refuerzo o recompensa adquiridos en la navegación. Para ello, se procederá al uso de la investigación cualitativa y de la investigación cuantitativa.

Una base metodológica parecida, estructurada en varias fases relacionadas directa y jerárquicamente entre sí, fue utilizada por el mismo equipo de investigación en la realización del primer proyecto de análisis sobre medios y noticias de salud (Echegaray y Ayestaran, 2012; Ayestaran et al., 2012; Camacho et al., 2012)). De una forma similar, se han establecido los procesos encaminados a la búsqueda de las respuestas de investigación.

\subsection{El análisis de contenidos en los sitios web y las fases en que se divide el trabajo de investigación}

A continuación se detallarán las diferentes fases por las que ha pasado la investigación una vez que ha sido explorada la bibliografía existente. Estas fases quedan estructuradas de la siguiente manera: En 
los aspectos referentes a las características y a la calidad de los recursos web se establece: 1) Análisis del universo y diseño de la muestra 2) Aproximación exploratoria 3) Diseño y desarrollo de plantilla para recogida de información. En lo que respecta al análisis de los grupos e individuos usuarios y de las formas de acceso y uso que hacen de la información de salud, se establecerán las siguientes fases consecutivas: 4) Análisis con grupos de discusión 5) Entrevistas en profundidad con desarrollo etnográfico 6) Análisis cuantitativo mediante sondeo.

\subsubsection{Estructura del universo y diseño de la muestra}

Uno de los problemas importantes con los que se ha encontrado la investigación es el del desarrollo de una metodología que sea capaz de contabilizar todas las unidades que componen el universo de páginas web dedicadas a salud. La extensión y amplitud de la red en todos los campos, materias y temáticas, hace de este trabajo una tarea casi inabarcable. En este sentido, no se debe olvidar que el objetivo de investigación es analizar páginas web con contenidos de salud, a nivel nacional e internacional, escritas en español y en euskera y que sean utilizadas por jóvenes de la Comunidad Autónoma del País Vasco y de la Comunidad Foral de Navarra.

Como una primera condición de acercamiento a la realidad a la que la investigación pretende acercarse, se ha determinado crear una definición clara de lo que significa un 'recurso web'. Esto supondrá una clara ayuda al análisis, permitiendo una mayor comprensión del objeto de estudio. Para ello, se ha tomado la definición de página web ofrecida por Codina y que posee las mismas características que la ofrecida por la IFLA (Internacional Federation Of Library Association and Institutions) esto es: "Una acción unitaria de un sitio o lugar web" (Codina, 2000: 179). Un recurso digital, dice el autor, es sinónimo de recurso electrónico y éste queda definido como: "Material codificado para ser manipulado por ordenador. Incluye materiales que requieren utilización de un periférico conectado a un ordenador y los servicios en línea" (ISBD - ER: 1997). Por tanto es un término abstracto para referirse a cualquier documento o servicio de información en formato digital (Codina, ídem). 
De cara a la obtención de una muestra representativa sobre la que realizar el análisis de contenido, se ha partido del análisis y estudio del universo a partir de las opciones ofrecidas por los motores de búsqueda. La revisión de fuentes documentales señala que un alto porcentaje de población joven recurre a estos motores para acceder a páginas web de salud al no tener otras referencias en ese sentido. Su uso ofrece la posibilidad de encontrar la heterogeneidad del universo en cuanto a niveles de calidad.

De acuerdo con Polledo (2010), se estima que "mediante los buscadores se accede a mucha información y a páginas seguras y recomendables pero también a otras que no cumplen con los mínimos requisitos exigidos y que pueden llegar a desinformar o confundir" (Polledo, 2010). La navegación desde motores de búsqueda ofrece al investigador no solo la posibilidad de utilizar el mismo método que el usuario a la hora de seleccionar páginas, sino también el acceso a un amplio abanico de recursos web en los que por probabilidad deben encontrarse todas las tipologías que se han definido dentro del universo.

Además, los recursos ofrecidos tendrán variedad en cuanto a la calidad de los mismos. Esto contribuye a crear un campo de estudio completo a la hora de tener referencias para concretar la muestra. Por otra parte, se considera que estos buscadores forman parte de la web como complemento (García del Castillo et al., 2008).

Tras el análisis y conocimiento de las características estructurales del universo, ha sido posible determinar aquellas diferentes categorías que diferencian los recursos web analizados. Las distintas tipologías de sitios web están organizadas en función de su autoría o pertenencia, aspectos especialmente relacionados con la oficialidad o no del sitio o con su objetivo comercial. Así, los denominados portales 'oficiales' son aquellos que han sido creados bajo la tutela de la administración pública.

Los portales 'no oficiales', son los creados por instituciones desvinculadas de la administración. Entre estos últimos se encuentran aquellos recursos que pertenecen a organizaciones como pueden ser

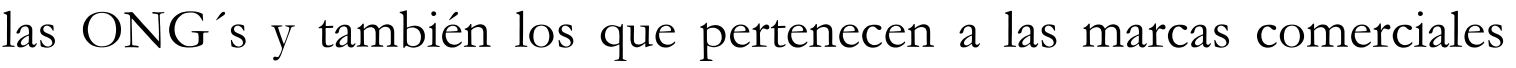
que, conocedoras de la relevancia del tema y del impacto que pude tener su difusión, cumpliendo al mismo tiempo con su lógico 
objetivo de comercial y con el de ofrecer responsabilidad social, han introducido el asesoramiento sobre salud en su misión empresarial. Además de éstos, existen también las webs pertenecientes a la prensa estatal, que también dedican amplia información a la prevención y al asesoramiento en temas de salud. No obstante, la configuración del universo no termina ahí: a estas categorías les siguen subcategorías que se desarrollan en función de las temáticas de las páginas encontradas: Salud en General, Adicciones, Sida, Sexualidad, Nutrición, Diversos.

Partiendo de los datos resultantes de la búsqueda, la investigación ha contado con un universo compuesto por 235 páginas web, según los datos de los buscadores web mejor posicionados y más utilizados por los internautas, el de Google y el de Yahoo.

Una vez definida la muestra y determinado el coeficiente de elevación de la misma según las categorías, la distribución del universo queda de la siguiente manera: 135 corresponden a webs de tipo nacional e internacional y 100 a las Comunidades Autónomas de País Vasco y Navarra. Aplicando la fórmula de muestra para universos finitos sobre el universo definido, se ha considerado que una muestra de 57 unidades, siempre distribuidas en función de las categorías y subcategorías que se han explicado anteriormente, es un tamaño de muestra representativo para un nivel de confianza del $95,5 \%$ y un margen de error del $4 \%$.

La gran diversidad que posee el universo genera también ciertas dificultades a la hora de emprender la acción de muestro. Aunque sí ha sido posible encontrar páginas web que cumplan con las características propias de cada categoría, no todas esas webs cuentan con las subcategorías que se han establecido. No obstante, se ha procedido a muestrear teniendo en cuenta parámetros de representatividad, realizando la selección siempre con atención a las condiciones muestrales. Esto requería establecer dos fases de muestreo para llegar al resultado final. Así, en la primera fase se ha procedido a la utilización del método de muestreo aleatorio simple, para pasar después a una segunda selección que se ha desarrollado según criterio del investigador, método también denominado de 'muestras intencionadas': "con un buen juicio y una estrategia 
adecuada se pueden definir finalmente los casos incluidos en la muestra" (García Ferrando, 2006: 150).

El diseño del muestreo parte de una combinación de los métodos probabilísticos, en los que influye el azar y métodos no probabilísticos, en los que no influye el azar y que en este caso será aquel por el cual se determinen en última estancia los elementos finales de la muestra. La utilización de métodos no probabilísticos en la segunda fase de la investigación, evita los problemas que surgen usando muestras al azar (García Ferrando, 2006: 149) y que en este caso tiene que ver con la aparición en el universo de unidades que no son apropiadas para el estudio aunque los buscadores las ofrezcan como unidades relacionadas con juventud y salud.

Es importante indicar que la eliminación de determinadas unidades de la muestra ha respondido siempre a criterios relacionados con la adecuación o no del recurso al objeto de investigación y nunca en relación a la calidad o no del recurso, entendiendo, como ha quedado comentado con anterioridad, que esos aspectos de calidad forman parte de la heterogeneidad del mismo, que es el objeto de estudio en este momento.

Entendemos que de esta manera el universo total adquiere representatividad y que los resultados de la muestra serán, por tanto, extrapolables. Hay que advertir una característica del muestreo: se determina que aquellos recursos web que han sido analizados, mediante entrevista con los responsables, en la fase exploratoria formen parte de la muestra final.

\subsubsection{Características de la investigación exploratoria}

Pretendiendo alcanzar un primer conocimiento válido para el desarrollo de las próximas etapas de investigación, se procede al diseño de una investigación exploratoria que ayudará a obtener una primera aproximación empírica al problema de estudio desde la utilización de técnicas de investigación cualitativa (Grande et al., 2007). Se trata de alcanzar un conocimiento concluyente, partiendo del conocimiento más elemental.

En esta fase se ha establecido el contacto con los responsables de 5 webs de contenidos de salud para jóvenes. El objetivo ha sido 
conocer los criterios empleados a la hora de evaluar y seleccionar los contenidos expuestos en ellas. Las webs seleccionadas, partiendo de la base estructural de universo, han sido las siguientes: web del Gobierno de Navarra y del Gobierno Vasco en representación de los sitios web de tipo institucional; web del periódico El País, de la asociación EDEX y de Teinteresa, en representación de los sitios web no institucionales.

La técnica utilizada en esta aproximación o investigación exploratoria ha sido la entrevista en profundidad. La información ha sido obtenida mediante la distribución de cuestionarios autoadministrados distribuidos por correo electrónico previo acuerdo con los entrevistados. Este tipo de investigación permite que los participantes ofrezcan respuestas precisas al tener tiempo para recapacitar sobre ellas (Poynter, 2010). El guión realizado para las entrevistas en profundidad consta de cuatro bloques diferenciados:

- La estructura jerárquica que se sigue antes de la edición de los contenidos

- Los patrones de calidad comunicativa

- Los patrones de diseño exigidos y practicados

- La fuente que en origen los determina.

\subsubsection{Información resultante del análisis de contenido. Método de recogida de datos}

Una vez que se ha realizado una primera aproximación al objeto de estudio, mediante entrevista en profundidad con cuestionario autoadministrado online y una vez definido el universo y la muestra sobre la que trabajar, se impone el desarrollo de un método sistemático y organizado de recogida de información. Para ello se ha rediseñado una plantilla en la que se incluyen aquellos parámetros e indicadores que ayudan a determinar la calidad de los recursos web. Al decir que se ha procedido al rediseño de la plantilla nos referimos a que ésta ya había sido creada para una investigación similar a la expuesta en este trabajo. Sin embargo, y debido a las características de fondo de cada una de las investigaciones, la plantilla original precisaba la adaptación a los objetivos de la presente. 
En una investigación precedente a esta ${ }^{33}$, el equipo de investigación desarrolló un proceso de entrevista en profundidad con una muestra de profesionales de la salud en la Comunidad Autónoma Vasca en Navarra. Esta entrevista se orientaba a la generación de discurso por parte de los expertos sobre los criterios de calidad que debían tener las noticias de salud. Se buscaba también que expresaran su opinión sobre conceptos imprescindibles para la investigación, conceptos como rigor, calidad de las noticias de salud así como sobre la profesionalización de los redactores de este tipo de información. El colectivo entrevistado coincidía en señalar que la calidad de las noticias y de las informaciones de salud pasaba por el conocimiento que de las fuentes debían tener los redactores sin dejar de lado la necesidad de referenciarlas mediante citación. A esto se añadía el contraste de la información y, sobre todo, la colaboración entre profesionales de la salud y de la comunicación en la redacción de los contenidos de salud (Echegaray et al, 2013; Peñafiel et al., 2013).

La aproximación a las definiciones sobre el concepto de calidad en las noticias periodísticas es un tema que ha sido tratado ampliamente por los investigadores de la comunicación. Sin embargo, los criterios de calidad que deben prevalecer en los recursos web se encuentran en una fase que podríamos llamar de desarrollo pero no de consolidación, si bien muchos de esos criterios han estado fundamentados en los criterios de calidad que deben encontrarse en los medios de comunicación escritos. El Consejo Europeo (CCE) respaldó una iniciativa en 2002 propuesta para la creación de una serie de requisitos de calidad de los sitios web de salud (CCE, 2002). Estos requisitos fueron afianzados por la misma institución en 2005 (eEurope, 2005) y en 2010 (eEurope, 2010). Las especificaciones de ambos documentos apenas varían sobre el redactado en 2002, incidiendo en la importancia de unificar los criterios de calidad de los recursos web, empezando por el ámbito comercial. Entre los criterios principales se destacan:

\footnotetext{
${ }^{33}$ La información de salud en la prensa diaria vasca (2000-2010). Estudio realizado con subvención UPV/EHU. EHU 10/47 entre los años 2010 y 2012. Miembros del equipo. Idoia Camacho Markina (IP), Carmen Peñafiel, Alazne Ayestarán, Milagros Ronco, profesoras del Departamento de Periodismo de UPV/EHU y Lázaro Echegaray, profesor de la Escuela Universitaria de la Cámara de Comercio de Bilbao.
} 
- Transparencia y honradez

- Autoridad

- Intimidad y protección de datos

- Actualización de la información

- Rendición de cuentas

- Accesibilidad

En su tesis doctoral, González Pacanowski ofrecía una plantilla de recogida de información en formato Excel, que ha servido como base para la creación de la ya mencionada plantilla adaptada a las necesidades particulares de la presente investigación. La plantilla de González Pacanowski, ofrecía valores en forma de indicadores para tres parámetros principales de análisis en las páginas web con contenidos de salud: Funcionalidad, Credibilidad y Acreditación. Son parámetros que coinciden con aquellos que recomendados en esas otras fuentes ya mencionadas. No obstante, este equipo de investigación decidió hacer una adaptación de los mismos a fin de amoldarlos a sus necesidades particulares.

La plantilla para recogida de información que desarrolla este equipo respeta el criterio de funcionalidad de la plantilla de González Pacanowski pero elimina el criterio Credibilidad al considerar que los indicadores que conforman dicho criterio no son aplicables a un estudio enfocado al análisis de recursos web para jóvenes y adolescentes. El rediseño de la plantilla se realiza, por tanto, sobre los criterios de Funcionalidad y Acreditación.

En lo referente al criterio de Acreditación, de acuerdo con González Pacanowski, éste certifica si el recurso asume algunas de las declaraciones vigentes relativas al carácter deontológico y legal, declaraciones que obligan a adoptar un criterio más responsable con la información que se difunde (González Pacanowski, 2005).

Los principales parámetros se han configurado de la siguiente forma:

Respecto a los principios de Acreditación (Si el recurso declara asumir o no estar controlado y/o evaluado por algún organismo de control de calidad del contenido): 1.- Suscripción de los principios legales vigentes en el Estado 2.- Garantía de cualificación profesional 
en los consejos médicos 3.- Responsabilidad profesional 4.Adscripción a normativa deontológica 5.- Presentación de certificado de calidad y acreditación por parte de alguna Institución 6.Presentación de etiqueta de calidad autoaplicada 7.- Ofrecimiento de alguna guía de comprobación al usuario 8.- Protección de datos.

Respecto a los principios de Funcionalidad: 1.- Autoría/fuente: identificación y solvencia de la fuente 2.- Contenido: calidad de la información 3.- Acceso a la información: navegación y recuperación 4.- Ergonomía: comodidad y facilidad de utilización 5.- Luminosidad 6.- Usabilidad: procesos 7.- Usabilidad: errores 8.- Usabilidad: adaptación.

También se ha establecido una cabecera en la que recoger la información de inicio en cuanto a: 1) La tipología del recurso. 2) El público al que se dirige 3) La temática 4) El carácter del recurso 5) El idioma 6) La introducción de normas deontológicas y/o de acreditación de instituciones 7) Protección de datos 8) Dirección web 9) Conexión con redes sociales.

Existe una diferencia entre la información que se recoge en la plantilla, que se codifica mediante la respuesta Sí ó No, y la información que se encuentra en la cabecera, que obtendrá respuestas de tipo explicativas.

\subsection{Fase de investigación sobre percepción y formas de uso del usuario de páginas web de salud}

Hasta este momento se ha desarrollado un proceso de investigación enfocado a analizar las características de la naturaleza de las páginas y la calidad de los contenidos que se ofrecen en ellas. No obstante, y como ya ha quedado comentado, la investigación pretende abordar también aquellos aspectos relacionados con la recepción y los receptores de esos contenidos, tanto a nivel de usuario como a nivel grupal.

Esta fase busca profundizar en las formas de uso, las costumbres, la percepción y las opiniones resultantes así como en los niveles de repetición de experiencias, entendiendo que cuando esto se produce es porque los contenidos han generado satisfacción en el usuario. Para alcanzar los objetivos de esta fase, que podríamos denominar 
orientada al individuo, se procede al uso de una metodología mixta o triangular que alterna técnicas cualitativas y cuantitativas (Grande et al., 2007). Las siguientes estrategias de investigación están orientadas al logro de esos objetivos.

En lo que se refiere al universo de investigación compuesto por el público objetivo, este ha quedado ya definido como los jóvenes de entre 12 y 24 años, que usan el idioma castellano y/o el euskera en sus procesos de búsqueda de información y que realizan o han realizado búsquedas sobre temas de salud en Internet, con residencia en ciudades y sus áreas periféricas, que serán divididas en zonas residenciales y zonas trabajadoras, de las áreas metropolitanas del País Vasco y de Navarra. La confección del universo de trabajo termina dividiendo al público en dos segmentos diferenciados por la edad y sexo: 1) Jóvenes entre 12 y 17 años 2) Jóvenes entre 18 y 24 años.

\subsubsection{Acercamiento al público objetivo mediante grupos de discusión}

La realización de grupos de discusión tiene una orientación doble: 1) Descubrir la percepción social que producen las páginas consultadas y los contenidos difundidos en las mismas, conociendo la perspectiva de usuario. En este punto cobran importancia aspectos como la inquietud, la duda, el desarrollo del proceso de búsqueda, la experiencia, la prevención o la solución, la adquisición de hábitos, el proceso educativo y el constructo comunicativo 2) Conocer aquellos motivos que llevan a los usuarios a la utilización de estas páginas como fuentes de información sobre salud y el conocimiento de los sitios web que existen, y más concretamente aquellos que han servido para el análisis establecido en la primera fase: notoriedad y protagonismo de los sitios, circunstancias de acceso, frecuencia. También es importante llegar a conocer aquellos sitios utilizados por el público que no han sido tenidos en cuenta por el equipo investigador, dada la amplitud del universo al que nos enfrentamos.

En busca de analizar cómo se produce la construcción del discurso sobre los aspectos comentados, la investigación recurre al grupo de discusión como técnica que permite comprobar el comportamiento colectivo (Gordo et al., 2008). La estructura de investigación se basa en un diseño que viaja de lo grupal a lo individual, alcanzando al 
grupo como primer nivel y produciendo la información necesaria para descender hasta el nivel individual. La distribución de los grupos se hará confeccionando un grupo de discusión por cada uno de los territorios históricos que componen el universo. Serán grupos formados por 8 jóvenes de entre 12 y 18 años, distribuidos por edad y sexo, residentes en zonas céntricas y periféricas.

La confección de los guiones de investigación adquiere en este momento una importancia extrema. Se ha seleccionado para el caso el uso del denominado 'guión conversacional' en el que se distinguen las siguientes partes: A) Presentación B) Formas de suscitar conversación en el grupo C) Concreción de un orden lógico en el tratamiento de las cuestiones de investigación (Gordo et al, 2008).

\subsubsection{Investigación del comportamiento mediante técnicas etnográficas}

La etnografía es una técnica apropiada para el trabajo que se plantea ya que combina la entrevista en profundidad con la observación, pasiva, no participante, de la actuación física del entrevistado ante el objeto de estudio. En el caso que nos ocupa será utilizada para observar las características básicas de navegación de los jóvenes que componen el universo, a la vez que se les pregunta sobre los pasos dados y las acciones realizadas. Se pretende conocer su experiencia de navegación. La técnica contribuye a captar la idea del proceso de investigación que en este apartado se desplaza desde la fase grupal que se desarrollaba en el apartado anterior, hasta la individual.

Este apartado arrojará valoraciones referentes a la navegación, acceso, interacción, atención, nivel de respuesta y otras características que pueden estar ocultas y que saldrán a la luz en el desarrollo del proceso.

Para el desarrollo de este momento de investigación se selecciona una muestra en la que se incluirán, mediante proceso de muestreo no probabilístico de bola de nieve, dos unidades de cada una de las tipologías determinadas.

Las sesiones etnográficas serán grabadas en formato de vídeo y audio. El guión de investigación se fortalecerá con las notas que se tomen en un 'cuaderno de notas', a modo de 'cuaderno de campo'. 


\subsubsection{Aspectos fundamentales de la fase cuantitativa}

Los resultados de todas las fases anteriores, desembocan en esta última fase de la investigación. Los datos que se han conseguido hasta ahora son datos de tipo cualitativo: tanto los que provienen del análisis de contenido de páginas web de salud, como los que lo hacen desde el análisis de usabilidad y acceso del grupo y de los individuos que los componen. La investigación busca en este momento la generalización de la información obtenida en el proceso. Para ello se aplicará la metodología cuantitativa.

Las técnicas cuantitativas de investigación confirmarán si las pautas de navegación, los aspectos comunicaciones que han resultado, los motivos y formas de uso de las diferentes webs en los diferentes segmentos de clasificación a los que ha sido sometida la muestra, se cumplen a nivel global. Interesa ahora descubrir y entender los hábitos y las costumbres de los usuarios en sus búsquedas de información sobre salud y el grado de implantación social de cada uno de ellos.

El universo con el que se trabaja en esta fase es el mismo que ha sido utilizado en las fases anteriores. El proceso de investigación que se había generado en lo concerniente al usuario encuentra ahora, mediante la aplicación cuantitativa el encaje holístico que cierra el círculo de la investigación.

Los resultados obtenidos en las fases anteriores de investigación ofrecerán la información necesaria para completar los cuestionarios estructurados que van a ser utilizados en este momento. Se aplicarán a una muestra de 250 unidades, distribuida en función de las características del universo: edad, género, zona de residencia y seleccionada entre los centros educativos de los tres territorios históricos seleccionados a partir de las características de representatividad, los niveles educativos y las áreas geográficas señaladas.

\section{Conclusiones}

El proceso metodológico que se ha presentado en este trabajo ha adoptado diferentes metodologías y técnicas de investigación de 
acuerdo al logro de los objetivos mercados. La idea de la investigación es el análisis de los distintos factores que puedan existir en el entorno de consumo de información de salud en páginas web. Esto implica el análisis de la calidad de los recursos web, por una parte, y en análisis de la usabilidad de los mismos, por otra. Así, además de la citada calidad que es resultado del proceso de diseño y redacción, nos interesa conocer el uso que de esos recursos se hace, la capacidad de influencia que puedan tener y los efectos que puedan generar en el colectivo.

La determinación del universo ha sido problemática en tanto en cuanto es complicado poder determinar la totalidad de unidades que lo componen debido a la amplitud que significa Intenet. Para solucionarlo se ha recurrido a las aportaciones dadas por otros equipos de investigación que han encontrado problemas similares a la hora de determinar sus universos de trabajo. Son metodologías existentes en fuentes documentales y que han establecido el universo atendiendo a las acciones de búsqueda que realiza el propio colectivo estudiado. Esto, es: la navegación desde motores de búsqueda como Google o Yahoo. Se ha considerado, por tanto, que el universo estará compuesto por todas esas unidades que aparecen en los buscadores. Esto ofrece garantía pues se usan los mismos buscadores que utilizan los jóvenes, a la sazón los más populares. Si bien este método dejará fuera muchos de los recursos existentes, sí es verdad que genera un universo suficientemente amplio y sólido y veraz como para extraer de él una muestra heterogénea.

La idea de desarrollar un proceso de investigación holístico conlleva el proceso de investigación mixto. Se parte de un todo, para descender al nivel de grupo y al individuo mediante la investigación cualitativa y regresar al todo mediante la investigación cuantitativa. Es el modo de Triangulación de Técnicas que surge al recurrir al contraste de diferentes técnicas dentro de un mismo método (Ruiz Olabuenaga, 1996: 113).

\section{Referencias bibliográficas}

Ayestaran Yarza, A., Camacho Marquina, I, Ronco López, M. (2012): "La salud en la prensa vasca. Análisis de contenido de la década 2001-2010”. Ponencia presentada en el IV Congreso Internacional 
Latina de Comunicación Social "Comunicación, control y resistencias". Actas del Congreso. Tenerife.

Baker, L; Wagner, TH; Singer, S. and Bundorf, MK (2003): "Use of the Internet \& E-mail for Health Care Information Results Froma National Survey". JAMA, Vol. 289, no 18.

Borzekowski, DLG \& Rickert, VI (2001). “Adolescent cybersurfing for health information". Archives of Pediatric Adolescence Medicine 155, p. 813-817.

Camacho Marquina, I.; Peñafiel Saiz, C.; Ronco López, M. (2012): "Necesidad de una información sanitaria de calidad: análisis de las noticias sobre salud en la prensa vasca". Ponencia presentada en el III Congreso Internacional de la Asociación Española de Investigación de la Comunicación AE-IC "Comunicación y Riesgo". Actas del Congreso. Tarragona

Carnicero, J; Louro, A; González Guitián, C (2007) "Internet como puerta de información". En El medicamento. La información médica y farmacéutica en España. Puede verse en $<$ http://www.masterline.es/libro-medicamento-informacionmedica-farmaceutica/pages/04.htm $>$

CCE (2002). Comunicación de la Comisión del Consejo al Parlamento Europeo, al Comité Económico y Social y al Comité de las Regiones. eEurope (2002): Criterios de calidad para los sitios web relacionados con la salud. Bruselas, 29 del 11 de 2002. COM (2002) 667 Final. Accesible en:

<http://enfermeriacomunitaria.org/web/attachments/article/49 7/eEurope2002.\%20Criterios \%20de $\% 20$ calidad $\% 20$ para $\% 20 l o s$ $\% 20$ sitios $\% 20$ web $\% 20$ de $\% 20$ salud.pdf>

Codina, L. (2000): El libro digital y la www. Taurus. Madrid.

Dader, J. L. (1992): El periodista en el espacio público. Bosch. Barcelona.

Del Pozo, J y Nuez, (2012): "Las tecnologías comunicación y de la salud pública”. En Pérez, Lura; Nuez, Cristina; Del Pozo, Juan (Coord.) Tecnologías de la comunicación, jóvenes y promoción de la salud. Gobierno de la Rioja, 2012.

Durkheim, E. (1895): Las reglas del método sociológico. En edición 1982 Ediciones Morata. 
Echegaray, L. y Ayestaran, A. (2012): "Base metodológica para el estudio y análisis sobre la información de salud en la prensa diaria vasca y navarra (2001-2010)". III Congreso Internacional de la Asociación Española de Investigación de la Comunicación AE-IC “Comunicación y Riesgo". Actas del Congreso. Tarragona.

eEurope 2005 "Plan de acción eEurope (2005): una sociedad de la información para todos" $<$ http://europa.eu/legislation_summaries/information_society/ strategies/124226_es.htm>

eEurope i2010 "Estrategia Digital, Estrategia i2010. Plan de Acción eEurope". La Agenda Digital es parte de la Estrategia Europa $\underline{2020}$

$<$ http://europa.eu/legislation_summaries/information_society/ strategies $/>$

Gabelas Barroso, J.A. (2009): "Pantallas y jóvenes en el área del nuevo milenio”. En Del Pozo, J.; Pérez, L.; Ferreras, M. 2009. Adicciones y nuevas tecnologías de la información y de la comunicación. Perspectivas de su uso para la prevención y el tratamiento. Ed. Consejería de Salud, Gobierno de La Rioja. Logroño.

IFLA (1997): ISBD (ER) International Standard Bibliographic Description for Electronic Resources. München: K.G. Saur

García Castillo, J. A; Segura, M.C (2009): "Prevención de drogas online. Análisis y propuestas de actuación" en Del Pozo, J.; Pérez, L.; Ferreras, M. 2009. Adicciones y nuevas tecnologías de la información y de la comunicación.

García Ferrando, M. (2006): Socioestadística. Introducción a la estadística en sociología. Alianza. Madrid.

Giner, S.; Lamo de Espinosa, E.; Torres, C. (2006): Diccionario de Sociología. Alianza Editorial. Madrid.

González Pacanowski, A. (2005): La información digital en línea en medicina y salud. Conceptos, métodos y evaluación. Tesis Doctoral. Universidad Pompeu Fabra. Barcelona.

Grande, I. y Abascal, E. (2007): Fundamentos y técnicas de investigación comercial. ESIC. Madrid. 
Gordo, Á. J. y Serrano, A (2008): Estrategias y prácticas cualitativas de investigación social. Pearsons. Madrid.

Ibáñez, J. (1976): Más allá de la sociología. El grupo de discusión: técnica y práctica. Madrid. Siglo XXI.

Lacoste, J.A; Megías, E; Tascón, C y García-Camba, E (1999): “La atención-prevención en drogodependencias a través de Internet. Beneficios y perjuicios". Encuentros nacionales sobre drogodependencias y su enfoque comunitario. CPD de Cádiz.

Martín-Barbero, J. (2010): De los medios a las mediciones. Comunicación, cultura y hegemonia. Anthropos. Barcelona.

Peñafiel, C y Echegaray, L. (2012): "La perspectiva del colectivo sanitario sobre los contenidos de salud en la prensa vasca". Ponencia presentada en el IV Congreso Int. Latina de Comunicación Social. Actas del Congreso. Tenerife.

Peñafiel, C., Camacho, I., Ayestaran, A., Ronco, M., Echegaray, L. (2014): "La divulgación de la información de salud: un reto de confianza entre sectores implicados/Disclosure of Health Information: a challenge of truts between the various sdectors envolved." Revista Latina de Comunicación Social, 69, pp. 135 a 151. http://www.revistalaintacs.org/069/paper/1005UPV/08c.html

Polledo, J. J. (2010): "El rol de Internet en el proceso de consulta de información sobre salud". Estudio presentado por Pfizer en IV Foro de diálogo 'La información al paciente: una cuestión del siglo XXI'. Madrid, 22 de septiembre de 2010.

Poynter, R. (2010): The handbook of online and social media research. Tools and techniques for market researchers. Wiley. West Sussex.

Ruiz Olabuenaga, J.I (1996): Metodología de la investigación cualitativa. Deusto. Bilbao. 



\section{La información de salud en el universo web dirigida a la juventud: entre profiláctica y educativa}

Carmen Peñafiel Saiz (Universidad del País Vasco/Euskal Herriko Unibertsitatea) [OORCID] [GGS]

José Mari Pastor González [@ORCID] [CGS] (Universidad del País Vasco/Euskal Herriko Unibertsitatea)

Idoia Camacho Markina (Universidad del País Vasco/Euskal Herriko Unibertsitatea) [ORCID] [GGS]

\section{Resumen}

Este artículo presenta los resultados de una investigación financiada sobre las webs de información de salud dirigida a jóvenes y adolescentes. Internet es el principal canal de comunicación que usan los jóvenes y adolescentes, de ahí la importancia de analizar y conocer cómo se presenta la información de salud en los sitios web, su estructura y el uso que la población juvenil hace de ella en busca de información. Se han desarrollado técnicas cualitativas y cuantitativas. Se han realizado entrevistas en profundidad durante 2013 a personas responsables de webs con información de salud, tanto institucionales como privadas. Se ha realizado un análisis de las webs en el primer trimestre de 2014 con información de salud en español y euskera, dirigidas a jóvenes y adolescentes; seguidamente, se han realizado Focus Group a jóvenes de 12 a 24 años en la Comunidad Autónoma Vasca y Comunidad Foral de Navarra; y, finalmente, se pasará un 
cuestionario a una muestra representativa de 250 jóvenes de ambas Comunidades para conocer el acceso y uso de Internet como fuente de información en salud. Entre las conclusiones obtenidas se detecta que el tema de salud ha ganado importancia en los medios convencionales y, sobre todo, en Internet en los últimos años. El volumen de contenidos y la calidad de la información han mejorado notablemente poniendo mayor énfasis en un esfuerzo divulgativo. La información de salud en las webs dirigidas a la población más joven cumple una función profiláctica-educativa huyendo de mensajes moralizantes. La formación y la información son los objetivos fundamentales para los responsables de los sitios web con información de salud sin caer en la 'infoxicación'.

Palabras clave: Salud, información, recursos digitales, Internet, juventud, educomunicación, prevención.

\section{Introducción}

$\mathrm{E}$ STE ARTÍCULO forma parte del trabajo que viene realizando un grupo de investigación de la Facultad de Ciencias Sociales y de la Comunicación de la Universidad del País Vasco/Euskal Herriko Unibertsitatea con una línea abierta hacia los temas de Comunicación y Salud ${ }^{34}$.

Una primera investigación analizó durante 2011 y 2012 la información de salud y la responsabilidad de los diferentes sectores implicados en el ejercicio de esta divulgación. Los objetivos fueron descubrir si se conseguía una información educativa, de rigor y de calidad en la prensa vasca; analizar las informaciones de salud; y reflexionar sobre el trabajo que realizan los periodistas en el ámbito de la salud y su relación con el colectivo facultativo. Se desarrollaron

\footnotetext{
${ }^{34}$ Esta investigación está subvencionada por la Universidad del País Vasco/Euskal Herriko Unibertsitatea (código EHU 12/12) dirigida por Carmen Peñafiel y en la que colabora el equipo constituido por: Idoia Camacho, Milagros Ronco, Lázaro Echegaray y José Mari Pastor, profesores y profesoras de la UPV/EHU y de la Escuela Universitaria de la Cámara de Comercio de Bilbao.
} 
técnicas cuantitativas y cualitativas. Se realizó un análisis de contenido de la prensa vasca entre los años 2001-2010: El Correo, Noticias de Gipuqkoa, Noticias de Álava, Diario de Navarra y Berria. Un total de 30.311 periódicos que se habían editado en las dos comunidades autónomas en esos diez años. Se procedió a la recolección de datos desde la técnica de la 'semana compuesta'. El estudio cualitativo se realizó a través de entrevistas en profundidad durante 2012 a periodistas, que habitualmente publicaban informaciones de salud en los diarios señalados y a directores/as de centros sanitarios del País Vasco y Navarra. Entre los resultados más destacados se observó que la información de salud carecía de perspectiva educativa; que se necesitaba una especialización profesional; y que médicos y periodistas tenían que fortalecer una mejor relación minimizando las diferencias que les separaban.

La segunda investigación se desarrolla desde hace más de un año (2012-2014) y se centra en conocer la información de salud dirigida a jóvenes y adolescentes en español y en euskera, que se aloja en los sitios web de Internet.

Es evidente que el uso de las nuevas tecnologías de la comunicación (TIC) está cambiando actitudes y comportamientos de las personas y muchos usuarios hacen uso de plataformas distintas para buscar informaciones relacionadas con la salud, la medicina y el bienestar saludable. En este sentido, es importante educar a los más jóvenes tanto en el buen uso de Internet como en su uso específico para la búsqueda de información sobre salud y para la transmisión del conocimiento en salud. Son los jóvenes entre 15 y 24 años quienes hacen mayor uso de Internet para informarse sobre aspectos sanitarios (Baker et al., 2003). El modo de conocer, pensar, sentir y relacionarse de los jóvenes, cuestiona la función social y educativa de los agentes socio-sanitarios y educativos (Gabelas, 2009). Borzekowski y Rickert (2001) señalan distintas cualidades del uso de Internet por las que los jóvenes acuden a la web 2.0 para buscar información de salud, tales como facilidad de acceso, confidencialidad y personalización.

También observamos que las páginas web aportan una serie de ventajas frente a los medios de información convencionales o frente a los formatos tradicionales para muchos temas $y$, especialmente, para 
temas de salud porque nos ofrecen información, datos o pautas de actuación de manera ilimitada y gracias a un lenguaje hipertextual encontramos una mayor riqueza en el tratamiento informativo; además, el usuario puede consultar los datos o la información que desea en cualquier momento y en cualquier lugar gracias a los dispositivos móviles como iPad, smartphone $\mathrm{u}$ ordenadores portátiles; y también puede tener una participación más directa a la hora de recibir los mensajes o interactuar a través de chats o foros de consulta. Se trata de un medio interactivo posibilitando incorporar nuevas informaciones o facilitando un feedback con el emisor de contenidos. Internet es el canal de comunicación que usan actualmente los jóvenes y adolescentes con un mínimo esfuerzo y será la forma de comunicación de las próximas generaciones (Lacoste et al., 1999).

\section{Antecedentes y estado actual del tema}

Cada vez hay más líneas de investigación que hablan de cómo los medios digitales multiplican las posibilidades de la participación activa y cómo han ido apareciendo en Internet diferentes tipos de iniciativas para el desarrollo de programas de prevención de enfermedades, promoción de hábitos saludables, información sobre temas de salud, comunicación entre médicos y pacientes, etc.

Según la consultora digital de Saatchi \& Saatchi Health, los jóvenes sí se preocupan de temas relacionados con su Salud, y el principal canal de consulta es Internet. Mónica Egui, responsable de la consultora, indica que hasta un $46 \%$ de los jóvenes utiliza Internet para buscar información sobre salud. Estos datos fueron presentados durante la pasada edición de los premios ASPID de Publicidad de Salud y Farmacia en 2013. Ella considera que "para las nuevas generaciones lo digital 'es la norma', no 'lo nuevo' puesto que no han conocido otra cosa; consumen salud a través del ordenador y los smartphones".

Mónica Egui señala que entre las principales preocupaciones de los jóvenes y que tienen mayor cantidad de búsquedas por Internet, están los temas relacionados con el VIH/sida, embarazos o partos prematuros y también lo referente a la seguridad vial, el alcohol y el tabaquismo. En este sentido, Mónica Egui coincide con un grupo de 
investigación de la Escuela Andaluza de Salud Pública (EASP) que ha trabajado el binomio 'salud y juventud' por considerar que los accidentes de tráfico, el sida, los problemas de salud ligados al sexo, el consumo y abuso de drogas y la conducta alimentaria son los asuntos de especial interés para la población juvenil. La susceptibilidad de la juventud al impacto de los cambios sociales y culturales y a factores de riesgo para la salud, les convierte en un punto focal en salud pública (Hernán, Ramos y Fernández, 2010).

La Escuela Andaluza de Salud Pública investiga desde 2003 sobre las tendencias de uso de Internet como fuente de información de salud en varios grupos poblacionales y los factores que favorecen el acceso a estos recursos, estudiando los códigos de conducta para mejorar la calidad de las webs de salud mientras que otros acercamientos se concentran en destacar aquellas páginas que cumplen con requisitos definidos (Jiménez-Pernett et al., 2010).

El debate sobre la fiabilidad de los sitios web relacionados con la salud ha generado que diversos organismos se planteen criterios de evaluación para definir la calidad de la información, su estructura y su acceso (Roqué, 2007).

Otros estudios ofrecen también datos de interés sobre los hábitos de la juventud a la hora de buscar información sobre salud. El proyecto de investigación «Adolescentes en red. Uso de Internet y las redes sociales para la prevención de problemas de salud mental en adolescentes» dirigido por la investigadora Noemí Guillamón, tiene como objetivo estudiar los usos que los estudiantes de Cataluña, de entre 12 y 18 años, hacen de Internet y las redes sociales en temas de salud. El estudio también analiza la percepción de los jóvenes con relación a su salud y la necesidad de ayuda en este ámbito y explora cómo Internet puede resultar un recurso de información y asesoramiento para ellos.

El grupo PSINET de Barcelona, después de una primera fase de investigación llevada a cabo en 2011, ha publicado recientemente los resultados del segundo estudio realizado en la ciudad de Girona entre enero y marzo de 2013. Sus aportaciones son muy interesantes puesto que contribuyen a ampliar y completar lo conocido hasta ahora. En ese estudio se indica que el $100 \%$ de los adolescentes usa Internet de forma frecuente mediante el ordenador (92,1\%) o el móvil (75,6\%). 
El 96,2\% son usuarios de una o más redes sociales y casi el 30\% las usa para compartir con los demás cómo se sienten. El 73,6\% de los estudiantes ha usado Internet para buscar información sobre salud, principalmente sobre el aspecto físico. Otros aspectos que les siguen son los relacionados con las enfermedades (38,2\%), sexualidad $(20,7 \%)$, salud mental $(15,7 \%)$ y sustancias adictivas, como las drogas $(14,9 \%)$, el alcohol $(13,8)$ y el tabaco $(11,1 \%)$. Las vías más utilizadas para pedir ayuda son el cara a cara $(79,9 \%)$, el teléfono/móvil $(43,5 \%)$ e Internet $(29,3 \%)$. En la red, Google $(69,9 \%)$ y Wikipedia $(46,3 \%)$ son los lugares de referencia para la búsqueda de información sobre temas de salud, seguidos de las webs especializadas (29,3\%), los blogs donde la gente comparte experiencias (18,1\%) y las redes sociales (11,6\%). Otros aspectos clave en el uso de Internet para buscar información de salud son el anonimato de su identidad (47\%), la confidencialidad con que se tratan sus problemas $(40 \%)$ y la gratuidad del servicio $(39,7 \%)$.

Según la mayoría de los estudiantes, las principales características que debe reunir un servicio de salud online son privacidad (anonimato de la identidad y confidencialidad de los casos tratados), orientación al público joven, que sea fácil de usar, interactiva (con foros de participación), fiable y seria, respetuosa, con información resumida, que contenga fotos, vídeos, aplicaciones móviles y juegos, y consultable desde el móvil.

Otros estudios nos aproximan a una teoría de la e-health y la prevención. Un grupo de investigadores ha trabajado sobre la implicación del uso de los medios sociales en el desarrollo de programas de educación para la salud dirigidos a jóvenes, donde exponen un programa de educación para la salud desarrollado en el entorno escolar para prevenir el consumo de cocaína mediante el uso de Internet (Cuesta, Méndez y Ugarte, 2010).

El ámbito de la prevención ha experimentado una fuerte evolución en los últimos años, no sólo en España, sino en toda la comunidad sanitaria occidental. Esta evolución obedece a razones sociopolíticas y científicas (Del Pozo, Ferreras y Pérez, 2008; García y Segura, 2009).

El uso de Internet y dispositivos portátiles de comunicación, para dejar de fumar, para retrasar el inicio del consumo de drogas, o para reducir riesgos y daños por consumo de drogas, es el propósito de 
diversos proyectos que se están realizando para profundizar en esta cuestión (Del Pozo, Ferreras y Pérez, 2008; García y Segura, 2009). Este grupo de investigación analiza las herramientas que nos ofrece Internet al servicio de la prevención del consumo de drogas y se establecen algunas propuestas de futuro, principalmente para regular y acreditar la calidad y pertinencia de los contenidos que nos ofrece la red en el ámbito de las adicciones.

\section{Metodología de trabajo, objetivos y preguntas de investigación}

Tal y como hemos indicado, en nuestra investigación analizamos la información de salud dirigida a jóvenes y adolescentes, en español y euskera, en el segmento de edad entre 12 y 24 años, que se aloja en los sitios web. Con este análisis pretendemos determinar qué tipo de contenidos informativos se recogen en esos recursos digitales, qué tratamiento reciben esos contenidos y los efectos que pretenden crear en sus receptores. Es el punto de partida para reflexionar sobre el papel de Internet como herramienta de educación para la salud de la población adolescente y joven.

\subsection{Hipótesis}

Se parte de las siguientes hipótesis: H1) La mayor parte de páginas web sobre salud dirigidas a jóvenes y adolescentes centran sus contenidos en aspectos relacionados con la prevención de adicciones y enfermedades. Por esto, su objetivo es cumplir un papel fundamental en la educación sobre salud de los jóvenes H2) Como consecuencia de la expansión del uso de Internet como medio hegemónico para buscar información sobre salud entre los jóvenes, los agentes socio-sanitarios y educativos quedan en un segundo plano como educadores en salud e Internet se configura como la principal fuente de información sobre prevención H3) El paradigma comunicativo de la información sobre salud ha evolucionado de un modelo unidireccional, en el que los profesionales sanitarios emitían información a los pacientes, a una comunicación bidireccional e interactiva. 


\subsection{Objetivos}

Nos planteamos los siguientes objetivos específicos:

1. Realizar un mapeado de webs de salud que pueden ser utilizadas por la población más joven.

2. Analizar los criterios de calidad de los recursos digitales para saber si los contenidos y la orientación que difunden estas webs sobre salud para jóvenes y adolescentes cumplen una función como educadores.

3. Determinar el grado de implicación profesional y la estructura jerárquica, desde el punto de vista institucional y de otros actores, en la toma de decisión sobre la creación de contenidos de salud en las páginas web, la relación que se crea entre el usuario final y los profesionales de la atención sanitaria y el proceso educativo que surge tras las experiencias de navegación y búsqueda de información.

4. Analizar la experiencia de navegación de los jóvenes y adolescentes, las posibles relaciones e interacciones entre pares existentes en ella, así como la existencia de complicidades en el plano de la confidencialidad durante el proceso de navegación y búsqueda de información.

\subsection{Metodología aplicada al objeto de investigación}

Para dar respuesta a las hipótesis y objetivos planteados, la investigación en su conjunto se desarrolla sobre el siguiente universo $\mathrm{y}$ en seis fases bien diferenciadas, aunque claramente complementarias.

La población sobre la que se realiza la investigación se compone de jóvenes de entre 12 y 24 años, residentes en ciudades y áreas periféricas del País Vasco y Navarra, que usan el idioma castellano y/o el euskera en sus procesos de búsqueda de información. Dividimos la muestra en dos grupos de edad comprendidos entre los 12-17 años y los 18-24, a su vez divididos por sexo.

El universo de sitios web es abierto, conformado por todos aquellos escritos en español y en euskera, lo que elimina una delimitación geográfica peninsular. 
Fase 1. Desde la metodología cualitativa se realiza el rastreo de fuentes documentales. La revisión de la literatura y de la utilización de la estadística existente son tareas siempre presentes en los estudios cualitativos y cuantitativos. En esta fase se debe adquirir un conocimiento de aquellas situaciones en las que se encuentran los jóvenes en cuestiones relacionadas con la salud. Uniendo esta información a la de otros equipos de investigación y fuentes secundarias, se establece un marco de referencia e interpretativo de estudio. Esta información inicial funciona como un eje transversal en la investigación.

Fase 2. Entrevistas en profundidad, buscan la obtención de información mediante la conversación focalizada en el problema con una serie de expertos en la materia. La existencia de un guión marca los temas a tratar. Se realizan entrevistas en profundidad con expertos para alcanzar conocimiento sobre el estado actual del tema y sobre el proceso de creación y desarrollo de las webs y de los contenidos de las mismas. Esta fase es un pilar fundamental en el proceso de investigación para emprender las siguientes fases.

Fase 3. Se realiza un análisis de contenido y comunicacional de las webs que se han ofrecido en una check list atendiendo a los criterios comunicativos, de acceso, de navegación, interacción y atención, nivel de respuesta ante las solicitudes y de diseño y frecuencia de actualización, así como los ítems de acreditación y calidad.

Fase 4. A partir de los datos obtenidos se han elaborado los guiones de investigación de los grupos de discusión con los dos segmentos de edad de jóvenes y adolescentes. La realización de estos ha generado conocimiento de la situación desde la perspectiva de usuario, atendiendo a aspectos relacionados con la inquietud, la duda, el proceso de búsqueda, la experiencia, la prevención o la solución, la adquisición de hábitos, el proceso educativo y el constructo comunicativo. Las webs se han sometido también a la testación por parte de los participantes. Se han realizado dos grupos de 
discusión (12-17 años y 18-24 años) por cada uno de los territorios históricos que componen el universo de las dos Comunidades Autónomas: Comunicad Autónoma Vasca (Araba, Bizkaia, y Gipuzkoa) y la Comunidad Foral Navarra.

Fase 5. Los resultados de los grupos de discusión se complementan con un estudio de tipo etnográfico en el que se observa la experiencia de navegación de diferentes usuarios, dos de cada tipología segmentados por sexo y edad. La recogida de información en esta técnica se realiza mediante grabación audiovisual de la actividad de navegación a la que se agregan preguntas confeccionadas en un guión de observación mientras la persona observada desarrolla su experiencia de navegación. El guión de observación se soporta en un cuaderno de campo en el que se encuentran las preguntas de investigación y en el que se toma nota de todas aquellas acciones interesantes y espontáneas.

Fase 6. Como resultado de todas las fases anteriores se realiza un estudio cuantitativo basado en la encuestación a una muestra representativa del universo de investigación. Se genera una muestra representativa de 250 entrevistas realizadas mediante cuestionario estructurado. Las preguntas que conforman el cuestionario son las resultantes de las fases de investigación anteriores. Las 250 entrevistas se distribuyen según las características del universo: edad, género, zona de residencia. La labor de encuestación se realiza en los centros escolares y universitarios del País Vasco y Navarra, generando la muestra de centros a partir de las características de representatividad relacionadas, además de con los niveles educativos, con las áreas geográficas definidas como residenciales o trabajadoras. Se obtienen datos generales en los que son valorados los hábitos y costumbres y se descubre en cada uno de ellos su implantación social y los niveles de su impacto.

En este capítulo nos centramos en la parte exploratoria indicada como 'Fase 2' de la investigación que ha sido realizada para obtener una primera aproximación empírica al problema de estudio desde la utilización de técnicas de investigación cualitativa (Grande y Abascal, 
2007). En esta fase se ha establecido el contacto con los responsables de seis webs de contenidos de salud para jóvenes. El objetivo ha sido conocer los criterios empleados a la hora de evaluar y seleccionar los contenidos expuestos en ellas. Las webs seleccionadas, partiendo de la base estructural de universo, han sido las siguientes: web del Gobierno de Navarra y del Gobierno Vasco en representación de los sitios web de tipo institucional; web del periódico El País; de la Asociación EDEX; de SEMA (Sociedad Española de Medicina de la Adolescencia) y de teinteresa.es, en representación de los sitios web no institucionales.

La técnica utilizada en esta primera aproximación de la investigación ha sido la entrevista en profundidad. La información ha sido obtenida mediante la distribución de cuestionarios autoadministrados distribuidos por correo electrónico previo acuerdo con los entrevistados. Este tipo de investigación permite que los participantes ofrezcan respuestas precisas al tener tiempo para recapacitar sobre ellas (Poynter, 2010). El guión realizado para las entrevistas en profundidad consta de cuatro bloques diferenciados: la estructura jerárquica que se sigue antes de la edición de los contenidos; los patrones de calidad comunicativa; los patrones de diseño exigidos y practicados; y la fuente que en origen los determina.

Las entrevistas en profundidad se han realizado en el segundo semestre de 2013 y han sido dirigidas a los y las siguientes profesionales que coordinan webs de salud:

1) Emilio Navarro, Coordinador de Secciones: www.teinteresa.es

2) Emilio de Benito, Responsable de la información de salud: www.elpais.com

3) Juan Carlos Melero, Coordinador del sitio web: www.edex.es

4) Antonio Redondo, pediatra y director del sitio web:

http://www.adolescenciasema.org/ SEMA, Sociedad Española de Medicina de la Adolescencia, asociación miembro de CODAJIC (Confederación de Adolescencia y Juventud de Iberoamérica y el Caribe)

5) Alejandro Palacios Elizalde, Jefatura Sección de Planificación y Observatorio Joven del Gobierno de Navarra: www.juventud.navarra.es 
6) Arantza Urizar, Responsable de la web; Nerea Antia, Área de Drogodependencias; Arantxa Arrillaga, Programa Sida; Aitziber Benito, Dirección de Salud Pública del Gobierno Vasco ${ }^{35}$ : http://www.gazteaukera.euskadi.net/r58-19024/es/

\section{Algunos resultados}

\section{1 ¿Cómo debe ser la información de salud dirigida a jóvenes y adolescentes?}

La salud es igual de importante en todos los ámbitos de la vida y los jóvenes y adolescentes ya han demostrado que se sienten interesados por mantener una vida saludable y por conocer la información relacionada con temas de salud. Algunas páginas web con información de salud están claramente dirigidas a un público determinado o a un segmento de edad muy definido (niños/as; adolescentes; jóvenes; y adultos), es el caso del sitio web de SEMA ${ }^{36}$, Sociedad Española de Medicina de la Adolescencia, Antonio Redondo, pediatra y director del sitio web, señala que en la web de SEMA trabaja un equipo humano inquieto e interesado en la atención al adolescente, "donde el centro es el adolescente y su atención sanitaria desde la multiprofesionalidad que es tan necesaria en este grupo etario".

Los recursos provienen exclusivamente de la gestión privada. La web tiene un total de cinco apartados bien diferenciados y cuenta con Facebook. De su mantenimiento se encargan tres técnicos y su director, el propio doctor Redondo. Los técnicos son profesionales universitarios y los sanitarios, "casi todos" médicos y pediatras formados en el área de la adolescencia: "Un grupo estable de profesionales sanitarios coordina el contenido, y cuenta con un amplio abanico de colaboradores, que van participando en función de

\footnotetext{
${ }^{35}$ Los contenidos sobre la web para la juventud del Gobierno Vasco se han recabado de las cuatro entrevistas realizadas a las personas arriba indicadas. La información está, en principio, fragmentada, si bien su núcleo gira alrededor de las respuestas ofrecidas por Arantza Urizar, que es la responsable de la gestión de la web. Las otras personas complementan -a nivel más específico- esa información, cada una desde su ámbito de actuación.

${ }^{36}$ La web nació en el año 2002, por iniciativa de la junta directiva de la Sociedad Española de Medicina del Adolescente. El sitio dispone de una base técnica de profesionales informáticos y de diseño gráfico.
} 
las necesidades que se vayan creando o vayan surgiendo. El plantel es totalmente abierto". SEMA pretende ofrecer información de salud que sea de interés, fácil de comprender, y que sirva para tomar decisiones sobre sus hábitos y conductas. La asociación cree que hay que dar a los adolescentes "suficientes argumentos sólidos" para modificar aquellos aspectos de su vida que supongan un riesgo para su salud. La formación es "fundamental", y la información, importante, pero siempre sin caer en la "infoxicación".

Otro sitio web que tiene un público joven al que dirigirse específicamente es la web de la Subdirección de Juventud del Instituto Navarro de Deporte y Juventud del Gobierno de Navarra ${ }^{37}$ que ofrece información diversa para los jóvenes, sea de tipo institucional o práctico (programas de formación, movilidad juvenil...).

La jerarquía de los contenidos fue decidida por el especialista que creó la web. Las secciones ya mencionadas relacionadas con la salud las llevaba una sola persona, hasta el 1 de noviembre de 2012. Esa persona era sexóloga y socióloga, y se encargaba del mantenimiento diario de la web. En la actualidad la información sobre salud se gestiona desde el departamento de Salud.

El Gobierno Vasco también tiene una web específica dentro del organigrama general dedicado a salud y a jóvenes llamada Gazteaukera $^{38}$. La información relativa a salud es una parte de los

${ }^{37}$ La web se creó en primavera de 2011 y nació por iniciativa del entonces llamado Instituto Navarro de Juventud (hoy Subdirección de Juventud del Instituto Navarro de Deporte y Juventud) del Gobierno de Navarra. El soporte no es independiente, ya que se encuentra dentro del sitio web institucional del gobierno navarro. Su diseño ha sido realizado por la institución pública: "Nos hemos basado en la experiencia del personal de la red corporativa del Gobierno de Navarra". Sus recursos, claro está, provienen del ámbito institucional.

${ }^{38}$ Gazteankera es el nombre de la web del Gobierno Vasco dedicada a la juventud (http:/ / www.gazteaukera.euskadi.net/r58-19024/es/). Tal y como informa Arantza Urizar, responsable de la web, se ofrece información relativa a salud y, además, se dan a conocer los servicios donde los y las jóvenes pueden recibir atención y/o asesoramiento en Euskadi: "El criterio general es seccionar y citar información de interés para el público objetivo (jóvenes de Euskadi de 14 a 30 años). En algunos casos concretos también elaborar contenidos propios". 
contenidos del portal. La web se nutre de información que toma de otros sitios incluidos en el web general del Gobierno Vasco, como pueden ser aquellos dedicados al sida, a las drogodependencias y a la salud en general, eligiendo siempre la información que pueda interesar a los jóvenes o adolescentes. Además, Gazteaukera ha elaborado contenidos propios para dar a conocer los servicios existentes para los jóvenes en la Comunidad Autónoma Vasca.

Los responsables de salud hacen suya la declaración de la OMS a la hora de definir este concepto: "Es el logro del máximo nivel de bienestar físico, mental y social y de la capacidad de funcionamiento que permiten los factores sociales en los que viven inmersos los individuos y la colectividad". En principio, el concepto de salud para los jóvenes y adolescentes tendría la misma base, "siempre teniendo en cuenta que muchos de los modelos de comportamiento adquiridos durante la adolescencia (tales como los de las relaciones entre sexos, el comportamiento sexual, el consumo de tabaco, alcohol y otras drogas, los hábitos alimentarios y la forma de hacer frente a conflictos y riesgos) durará toda la vida".

Desde Gazteaukera apuntan que esos comportamientos y tendencias "afectarán a la salud y al bienestar de los niños y niñas del futuro". Por ello, la adolescencia es una época de la vida que presenta "la oportunidad de prevenir el comienzo de comportamientos nocivos para la salud y sus repercusiones futuras". Los ámbitos más específicos que se incluyen en el área de salud de la juventud son la salud mental (trastornos del comportamiento, ansiedad, depresión), nutrición, ejercicio, salud sexual y reproductiva, traumatismos involuntarios, violencia y consumo de sustancias.

Sin embargo, hay otros sitios web que no hacen distinciones o bien no disponen de apartados específicos en la web para la población más joven. Así lo indica Emilio Navarro, coordinador de secciones del sitio web Teinteresa.es", "no hacemos distinciones entre edades ni

\footnotetext{
39 Teinteresa.es se trata de una web de información general con sede social en Madrid y que fue creada en el año 2011 por un grupo de profesionales del sector de la comunicación. En la actualidad, cuenta con una plantilla de unas 30 personas entre periodistas, técnicos y personal administrativo. La web dispone de 29 secciones principales de información, dentro de las cuales se desarrollan diversas subsecciones. Se trabaja durante 24 horas los 365 días del año.
} 
sexos". La información para los jóvenes no debe ser enfocada desde un punto de vista paternalista, sino con "objetividad", asegura Navarro: "Son los propios profesionales de la Medicina los que transmiten el mensaje a los jóvenes que previamente han mandado sus preguntas a través de las redes sociales y foros". Teinteresa parte de la premisa de que a los jóvenes también les interesa la salud. Aunque no cuente con un apartado concreto para ellos, pretende enfocar esa información de una manera global, pese a que pueda ser discutible si lo consigue o no. Valga como ejemplo el hecho de que en el apartado de Pregunta al médico haya un total de 20 subsecciones correspondientes a diversas especialidades médicas, y ninguna de ellas informe de temas relacionados con la sexualidad, ni siquiera de manera indirecta - no hay sección de ginecología ni urología, y si las hay acerca de microbiología, por ejemplo-.

En la web de El País tampoco hay un apartado especial para la información de salud dirigida a jóvenes y adolescentes. El Pais ${ }^{40}$ tiene claro cuáles son los temas de información propias de la juventud: "Algunos tumores (linfomas), la salud reproductiva, traumatología y, sobre todo, es el momento de educar en salud". Las áreas de la salud más importantes para este segmento de la población serían tres: "La salud reproductiva, la salud emocional y la adquisición de hábitos".

Según Emilio de Benito, responsable de la información de salud del diario El País, la información para los adolescentes y jóvenes debe difundirse mediante un "proceso gradual", teniendo en cuenta el desarrollo físico, psicológico y emocional de los adolescentes: "Debe empezar a los 11-12 años como tarde, porque luego empiezan las relaciones sexuales (a los 14) o el consumo de drogas (también a esa edad, más o menos)". Entre los más jóvenes la información debería tener una función preventiva: “A los 13-15 años empezaría a tratarse

\footnotetext{
${ }^{40}$ La web del diario El País fue creada hace diez años. En ella se repiten las secciones de la edición impresa del periódico. Dentro de una de ellas, Sociedad, se incluye la subsección de salud, que no cuenta con un apartado específico para jóvenes. En el área de salud trabajan un responsable y tres o cuatro colaboradores, "algunos con formación científica", según De Benito. La web cuenta con una red de expertos para consultar temas de salud. Suelen ser profesionales sanitarios o miembros de ONG's y asociaciones de pacientes.
} 
de solucionar problemas (desmitificar, exponer con naturalidad...). A partir de los 16-17 años la información debería estar dada”.

Los responsables del apartado de salud actúan con cautela a la hora de difundir determinadas informaciones, como pueden ser aquellas relacionadas con nuevos tipos de drogas. No quieren 'dar pistas' y facilitar así el acceso a ellas por parte de los usuarios.

Según Juan Carlos Melero, coordinador de la web Edex.com ${ }^{41}$, los temas de salud dirigidos a jóvenes y adolescentes se basan en aquellas situaciones que resultan "más problemáticas para los adolescentes y jóvenes". En general, estos temas tienen relación con los consumos de drogas, legales o no, los problemas de alimentación (bulimia, anorexia, obesidad, etc...) y los riesgos asociados a una sexualidad no protegida (enfermedades de transmisión sexual, etc...).

Esos tres ámbitos deberían trabajarse, en opinión del responsable de Edex, a partir de la entrada en la adolescencia, "en torno a los catorce años". Edex se dirige al sector de la educación, no directamente a los jóvenes, sino a los agentes socioeducativos que trabajan con este segmento de la población. La asociación está en contacto con gente de otras webs creadas con el mismo objetivo: "Una experiencia interesante es www.kolokon.com, con cuyos responsables institucionales mantenemos relación". En opinión de Edex, tanto las webs oficiales como las no oficiales son "demasiado rígidas para los jóvenes, cuando no también para los propios adultos". Ellos se han basado en criterios de "atractivo y dinamismo", siempre apoyándose en personal especializado.

La comunicación que establecen este tipo de webs debe partir del respeto y reconocimiento respecto a que las decisiones que toman (los jóvenes), aunque para la sociedad adulta puedan resultar a veces equivocadas, responden a unas expectativas.

\footnotetext{
${ }^{41}$ La fundación Edex ha creado webs para promocionar la salud entre jóvenes y adolescentes durante los últimos quince años. Estos sitios han tenido sucesivas actualizaciones hasta el día de hoy. Para cada ocasión han contratado especialistas en diseño, con quienes mantienen una relación constante, "para lograr los objetivos de cada web, tanto desde el punto de vista de contenidos y posicionamiento, como gráfico". La web incluye contenidos generales y redes sociales (blog, twitter) y cuenta con ayuda institucional para su mantenimiento.
} 
La información para la salud debería tener una función preventiva a partir de la infancia, y reforzarla, posteriormente, en las sucesivas etapas evolutivas. Para ello, habría de primar el enfoque educativo, entendiéndolo como la difusión o divulgación de una información veraz fomentando los hábitos saludables y el desarrollo de habilidades que ayuden a comportarse de manera saludable. Para el responsable de Edex, Juan Carlos Melero, es conveniente huir de los mensajes moralizantes, partir de una base educativa, "ya que de otro modo se desentenderán de los mensajes".

De Benito - responsable de la web de El País- considera que, en general, la función de una web de salud para jóvenes debe ser la de informar, para que a partir de los 14 años los adolescentes extraigan sus propias conclusiones: "Yo soy partidario de la información. La decisión posterior depende de ellos". El tipo de comunicación ha de ser "fría y científica", basada en una información "validada científicamente, sin alarmismos". En algunos casos se dirige esa información a un sexo determinado. En temas de violencia de género o salud reproductiva se incide en la mujer.

\subsection{Enfoque profiláctico y educativo en la información de salud dirigida a jóvenes y adolescentes}

Las informaciones que nos encontramos en las webs de salud tienen unos objetivos claros que cumplir, así lo han manifestado las personas entrevistadas -responsables de los contenidos y las secciones de salud-. En opinión de Emilio Navarro la información de salud dirigida a los jóvenes debe marcarse los siguientes objetivos: "Que tengan buena información sobre hábitos saludables, sobre los riesgos de una mala alimentación, enfermedades nuevas y sobre la importancia del deporte para la salud".

Para Antonio Redondo, el objetivo sería "la adquisición de habilidades para una etapa adulta plena", según Redondo, siempre teniendo bien en cuenta el segmento de la población a la que se dirige: "Los consejos moralizantes son poco efectivos". En este sentido, la asociación distingue tres ámbitos de trabajo: los relacionados con la salud física, los relacionados con la salud mental y las situaciones de riesgos a las que los y las jóvenes pueden exponerse. 
Temas como identidad sexual, depresión, ideas suicidas, trastornos del comportamiento alimentario, bullying y demás entran en el área de la salud mental. Las situaciones de riesgo incluyen accidentes, consumo de drogas legales e ilegales, violencia en sus diferentes modalidades, incluida la informática, infecciones de transmisión sexual, embarazo...

Alejandro Palacios, responsable de la web de salud del Gobierno de Navarra, indica que los objetivos a conseguir en el terreno de la información de salud para jóvenes en la web no se diferencian demasiado de los apuntados por las otras webs cuyos responsables han sido entrevistados en este estudio. Informar sobre "hábitos saludables, buena alimentación, buen estado físico, relación sana con el entorno y el tiempo libre, sexualidad, drogas y estrés". Se trata, sobre todo, de información preventiva, pero, junto a ello, también se ofrece información para la solución de casos - contactar con centros de atención sobre consumo de drogas o salud mental, por ejemplo-.

Desde Gazteankera, la sección de salud de la web general del Gobierno Vasco - euskadi.net- apuntan la importancia de educar en salud a la población más joven ya que los comportamientos y tendencias sociales "afectarán a la salud y al bienestar de los niños y niñas del futuro". Por ello, la adolescencia es una época de la vida que presenta "la oportunidad de prevenir el comienzo de comportamientos nocivos para la salud y sus repercusiones futuras". Los ámbitos más específicos que se incluyen en el área de salud de la juventud son la salud mental (trastornos del comportamiento, ansiedad, depresión), nutrición, ejercicio, salud sexual y reproductiva, traumatismos involuntarios, violencia y consumo de sustancias.

La importancia del factor profiláctico también queda en evidencia en el tema del consumo de drogas entre los jóvenes: "La mayoría de los jóvenes y adolescentes, la mayoría de la población escolar en definitiva, en algún momento experimenta con alguna droga o con varias (especialmente el tabaco el alcohol o el cannabis). También es cierto que, en su mayoría, los jóvenes no las siguen consumiendo de forma periódica a lo largo del tiempo".

Los responsables de la web piensan que hay que diferenciar entre "consumos esporádicos, habituales o de grave riesgo, así como estados de dependencia". Para hacer frente a ello hay que establecer 
programas que permitan dar una respuesta adecuada a cada situación, "teniendo en cuenta factores como la edad, la situación socioeconómica, la vulnerabilidad...". Todo ello, sin olvidar "los niveles de permisividad, el sistema de valores y los factores psicológicos" relacionados con cada tipo de consumo ente la juventud. No es lo mismo el consumo de ciertas sustancias ilegales, que pueden estar demonizadas socialmente y el consumo de una droga como el alcohol, especialmente en menores, debido a su "arraigo y aceptación social".

Por ejemplo, Redondo, de SEMA, piensa que la división clásica entre drogas legales e ilegales es caduca en cuanto a los efectos de ese tipo de substancias "pero no en cuanto a la posibilidad de adquisición de unas u otras, y de la normalización de su uso". El especialista alerta acerca del crecimiento de las adicciones: "Crece de forma imparable la dependencia, sea patológica o no. Falta mucha formación en estos aspectos: la prevención de la cyberadicciones". Esta misma perspectiva es compartida por Juan Carlos Melero, quien considera que el tema de las drogas merece especial atención en la educación para la salud de los jóvenes y adolescentes. Afirma que "la distinción entre drogas legales e ilegales no es la más idónea desde un punto de vista educativo. Tiene más sentido clasificar las drogas por su grado de nocividad que no necesariamente tiene que ver con su estatus legal. Ahí está el caso del tabaco para demostrarlo".

Para todos los entrevistados la educación sigue siendo la clave. Es necesario educar con mayor precocidad en habilidades que ayuden a construir estilos de vida en los que el recurso sistemático al alcohol no sea la única clave para divertirse. En este sentido, Juan Carlos Melero, de Edex, cree que "también hay que poner límites a la promoción y publicidad que realiza la industria alcoholera".

El responsable de la subsección de Salud de El País considera que no hay que hacer distinciones entre drogas legales e ilegales, división un tanto caduca. Tanto con unas como con otras hay que exponer los riesgos del consumo y sus consecuencias.

Desde el ejecutivo navarro, nos indican que la web de salud no tiene un perfil determinado de su visitante. Trabaja para los jóvenes de 14 a 30 años, pero no son sólo ellos los que la utilizan, ya que también la consultan profesionales del ámbito de la juventud. En 
opinión de Alejandro Palacios, hay que informar a los jóvenes de su problemática específica "desde la edad escolar, desde que uno empieza a entender". La información que se facilite ha de ser "directa y clara", dirigida a los jóvenes: "Lenguaje llano, de tú a tú, y siempre respetuoso". Se impone el sentido práctico: "No creemos conveniente incluir consejos moralizantes. Creemos que ha de primar la función profiláctica-educativa".

La web de SEMA enfoca el tema de la información sobre sexualidad de una manera gradual: "Cuando se empieza la educación sexual en edades más tempranas se puede empezar por destacar sobre todo valores y afectividad, incluso sin hablar de sexualidad y mucho menos de genitalidad. Cuando va dirigido a etapas superiores se amplía la información". El proceso, pues, iría por etapas: "Sería como una larga escalera que se han de subir peldaños de uno en uno y el paso al siguiente no se da hasta que el anterior se haya consolidado".

Según Navarro, la información dirigida a la juventud en el terreno sexual debería combinar el aspecto profiláctico-educativo y el "moralizante". Por lo que respecta al tema de las drogas, la web no hace distinción entre drogas legales e ilegales, y aboga por la prevención, la información sobre los riesgos que ellas conllevan también en el caso del alcohol- y hacer una apuesta por la promoción del deporte, ya que la salud física y la psicológica tienen la misma importancia en el desarrollo del individuo.

En el tema de salud sexual y reproductiva se considera que para que la información divulgada por la web tenga algún efecto positivo entre los jóvenes debe existir una formación previa. "La información sola no es suficiente. Lo deseable es que los jóvenes hayan recibido a lo largo de su vida formación en habilidades y competencias personales, para que con la llegada de la adolescencia sepan gestionar los riesgos y retos a los que se van a enfrentar" (Arantza Urizar, responsable de la web de salud de Gobierno Vasco). Para los responsables de salud del ejecutivo vasco el momento adecuado para informar específicamente de los "riesgos" de la sexualidad serían "los primeros años de la adolescencia, es decir, un poco antes de que empiecen a tener relaciones sexuales".

La violencia de género es enfocada como un problema social, pero que también incide en la salud física y psicología de las mujeres que 
las padecen: "A los 14-15 años empiezan los noviazgos, las relaciones y hay que prevenirlo desde el principio", afirma Emilio de Benito de El Pais.com.

La salud mental de los jóvenes tiene un lugar "muy importante" en el sitio web de SEMA: "El suicidio es la segunda o tercera causa de muerte en adolescentes de países desarrollados. La depresión existe, igual que la hiperactividad, los trastornos del comportamiento alimentario, los duelos que les toca vivir, los fracasos escolares, la consecuencia de las separaciones de sus padres...". En opinión del entrevistado, Antonio Redondo, para promover la salud entre los jóvenes es conveniente ir poniendo la base a edades tempranas. Esto ayudará a la creación de hábitos saludables: "La prevención de los trastornos de alimentación debe comenzar sobre los 8 años, aunque siempre hay que cuidar su desarrollo personal, así como los hábitos que viva en casa (familias con dietas de adelgazamiento, sobrealimentación, sedentarismo, etc.). Para el resto de los temas se debe comenzar a los 10 años de forma progresiva y adecuada a cada tramo de edad y a su madurez".

Al igual que la asociación SEMA, el Gobierno de Navarra señala que también la salud mental de los jóvenes debe ser un objetivo prioritario: "La salud mental debería tener su sitio. Los datos recogidos para la Estrategia Foral y Plan de Juventud de Navarra así lo demuestran. La Encuesta Nacional de Salud Navarra 2006 cifraba en un $11,2 \%$ los jóvenes de entre 16 y 24 años que mostraban signos de probables trastornos mentales". La población joven con algún tipo de trastorno y que ha recibido asistencia sanitaria en Navarra casi se ha duplicado en 10 años: "La atención a la población infanto-juvenil es la que más ha aumentado en los centros de salud mental, ya que mientras que en el año 2000 representaba el 7\%, en el 2011 representaba el 13,5\% de los pacientes atendidos".

Respecto a la salud mental del adolescente, Edex subraya que desarrolla su trabajo educativo "desde la óptica de la promoción de la salud emocional", para dar así más importancia al bienestar psicológico del joven y evitar problemas en el futuro. La fundación subraya que hay tres líneas claras en el área de la salud para jóvenes y adolescentes: "Educación para la salud, prevención de las drogodependencias y fomento de la cultura ciudadana". También 
destaca el papel de los padres, con los cuales se mantienen en contacto: "Realizamos actuaciones específicamente dirigidas a la familia, convencidos de que son un agente educativo de primer orden y difícilmente sustituible".

En general, los responsables entrevistados de los sitios web señalados, dan mucho valor a la información preventiva, pero, junto a ello, también quieren ofrecer información para la solución de casos, tales como contactar con centros de atención sobre consumo de drogas o salud mental, por ejemplo.

\subsection{La interactividad con los jóvenes: papel fundamental en el desarrollo de la información de salud en Internet}

Las nuevas tecnologías son fundamentales en las webs de información de salud dirigidas a jóvenes y adolescentes. Todos los responsables de las secciones de salud cuidan mucho los perfiles en Twitter y Facebook, donde se nutren de nuevas informaciones cada pocos minutos.

Emilio Navarro, de teinteresa.es, indica que "la interactividad con los usuarios juega un papel fundamental en nuestro desarrollo". El periodismo, según el responsable de la web de salud de El País.com, advierte del peligro de los pseudo-informantes en Internet y la "competencia terrible" que existe en la red. En ese sentido su web solo difunde información verificada correctamente: "Nosotros sólo publicamos información verificada con rigor científico, nada de homeopatía, flores de Bach, Feng Shui y cosas de esas. No se conoce ningún ensayo doble ciego que haya probado científicamente la eficacia de eso". En la web de teinteresa.es, salud es una de las 29 secciones del sitio web y la más visitada por los usuarios. Este apartado de salud cuenta con diversas subsecciones que se renuevan cada día. Es el caso de Pregunta al médico, que se actualiza con la colaboración de profesionales de la medicina y el director científico de Teinteresa, el doctor Antonio López Farré. Los periodistas también escriben sobre temas de salud, pero siempre con el asesoramiento de profesionales. Todos los médicos que colaboran en la web son expertos en sus diferentes campos. El doctor López Farré escribe sobre salud una vez a la semana. 
En el sitio web de El País dedicado a salud, la información es volcada con una periodicidad diaria. Los usuarios pueden comunicarse con el diario por Twitter, "pero no hay compromiso de respuesta". Emilio de Benito se define como 'emisor', pero no suele polemizar con los usuarios: "Pocas veces entro en el debate, porque al final solo es discutir, pero nadie convence a nadie. Eso sí, acepto correcciones, sugerencias o alguna crítica de médicos".

En Edex el contacto con los usuarios y la interactividad también se manifiesta de una manera preponderante a través de los perfiles en redes sociales, aunque las secciones de la web son "variables", si bien responden a un menú similar: Quiénes somos - Qué es este programa - Cuáles son las herramientas - Contacto - Redes sociales. "Siempre se mantiene una sección fija, que cambia poco, y secciones más variables cuyos contenidos tratamos de recoger en los blogs". Los contenidos de la web se deciden "internamente" (Juan Carlos Melero).

Antonio Redondo, de SEMA, enumera las ventajas del soporte digital "facilidad, rapidez y comodidad", pero también es consciente de sus puntos flacos: "La debilidad radica en que puede existir información no contrastada y la posibilidad de tener mala interpretación de la información que reciben".

La web del Gobierno de Navarra utiliza las nuevas tecnologías para establecer interactividad con los jóvenes. "La comunicación multidireccional la hacemos a través de las redes sociales. Nos han servido para romper con el esquema que se venía utilizando". Su papel es "muy importante", según señala Alejandro Palacios: "Utilizamos las redes sociales Twitter y Facebook para ofrecer información, atender preguntas... Y redirigimos el tráfico siempre a nuestra web".

La web de salud de Gobierno Vasco es parte del portal Gazteankera (sitio digital dedicado a la juventud) que está integrado en Euskadi.net (la web institucional del ejecutivo vasco) http://www.euskadi.net/r33-2220/es/. La webmaster lleva a cabo las tareas del portal Gazteaukera desde su creación (2003). La web está gestionada por una persona a tiempo completo. Su perfil es de Técnica de Juventud que ha realizado diversos cursos de formación relativos a gestión de la información, gestión de redes sociales, etc. Además, esa persona cuenta con la asistencia de varias personas con 
'perfil de editor', que actualizan los contenidos de su área de trabajo. Se trata de personal con experiencia en el mundo de la información. En el momento de la creación de la web (2003) y en su posterior mantenimiento se sigue de cerca la actividad de otras entidades, asociaciones, etc.

En el área de salud, cuando se creó el portal de salud de Gobierno Vasco (<http://www.osasun.ejgv.euskadi.net/r52-ghhome00/es/>) se enlazaron los contenidos de dicho portal más adecuados para el público joven. La información se actualiza prácticamente cada día. Eso en lo referente al sitio en general. De todas formas, desde una perspectiva más específica, cabe señalar que esa periodicidad no se da en el área de Salud de la web, como asegura la responsable de esta: "En lo relativo al apartado de salud, la actualización de contenidos es escasa y se limita a revisar los enlaces periódicamente y comprobar las direcciones y teléfonos que se facilitan en sus contenidos". "La sencillez y la claridad" han sido las características que han priorizado a la hora de diseñar el sitio de Gazteaukera. Para fomentar el contacto con los jóvenes, la web abrió en el año 2009 los canales Facebook, Twitter y Tuenti. En Facebook cuentan con más de 5.000 seguidores. "Son principalmente jóvenes y el número de chicas duplica al de chicos".

\section{A modo de conclusiones}

Nos encontramos con sitios web que están destinados exclusivamente a jóvenes y/o adolescentes pero también hay webs que se dirigen a públicos diversos sin hacer distinción entre edades ni sexos.

Los y las webmaster de salud forman parte de equipos humanos interesados/as en la atención al adolescente y al joven y su atención sanitaria desde la multiprofesionalidad con una clara voluntad de transmitir calidad informativa. Consideran que la información de calidad en salud es aquella que permite a las personas tomar decisiones adecuadas sobre su salud y en la que las distintas fuentes (periodistas, médicos, expertos/as) proporcionan a los destinatarios una información fiable y rigurosa. 
Son conscientes de que la función que deben cumplir estas webs es la de formación e información, pero sin caer en la 'infoxicación'. Su objetivo es ofrecer información de salud que sea de interés, fácil de comprender y que sirva para tomar decisiones sobre sus hábitos y conductas.

La mayoría de los entrevistados coincide en que la información para los jóvenes no debe ser enfocada desde un punto de vista paternalista, sino con objetividad, fría y científica (sin alarmismos) y mediante un proceso gradual, teniendo en cuenta el desarrollo físico, psicológico y emocional de este grupo etario.

Los temas más presentes en las páginas web son aquellos relacionados con las problemáticas de los adolescentes y jóvenes y que tienen relación con los consumos de drogas, legales o no, los problemas de alimentación (bulimia, anorexia, obesidad, etc.) y los riesgos asociados a una sexualidad no protegida (enfermedades de transmisión sexual, etc.), así como salud mental (trastornos del comportamiento, ansiedad, depresión). En algunos casos se dirige esa información a un sexo determinado. En temas de violencia de género o salud reproductiva se incide en la mujer.

Consideran que la información entre los más jóvenes debe tener una función preventiva a partir de la infancia, y reforzarla, posteriormente, en las sucesivas etapas evolutivas. Para ello, hay que primar el enfoque educativo, entendiéndolo como la difusión o divulgación de una información veraz fomentando los hábitos saludables y el desarrollo de habilidades que ayuden a comportarse de manera saludable. En general, los responsables entrevistados de los sitios webs señalados dan mucho valor a la información preventiva, pero, junto a ello, también quieren ofrecer información para la solución de casos, tales como contactar con centros de atención sobre consumo de drogas o salud mental, por ejemplo.

Para todos los entrevistados la educación sigue siendo la clave. Es necesario educar con mayor precocidad en habilidades que ayuden a construir estilos de vida. Es necesario educar en salud con el fin de exponer los riesgos y sus consecuencias.

Las personas responsables de las secciones de salud de las webs dirigidas a jóvenes y adolescentes cuidan mucho los perfiles en Twitter y Facebook, donde se nutren de nuevas informaciones cada 
pocos minutos. La interactividad con los usuarios juega un papel fundamental y advierten del peligro de los pseudo-informantes en Internet que existe en la red.

Actualmente, la comunicación en Internet es multidireccional y la hacen a través de las redes sociales. Estas redes han servido para romper con el esquema que se venía utilizando y su papel es muy importante para ofrecer información, atender preguntas, etc. y redirigir el tráfico siempre a la web.

\section{Referencias bibliográficas}

Ayestaran, A. Camacho, I. y Ronco, M. (2012): "La salud en la prensa vasca. Análisis de contenido de la década 2001-2010”. Actas del IV Congreso Internacional Latina de Comunicación Social, Tenerife.

Baker, L.; Wagner, TH., Singer S. \& Bundorf, MK. (2003): "Use of the Internet and e-mail for health care information: results from a national survey". En revista $J A M A$. Vol. 289, 18.

Berrios y Buxarrais (2005): "Las tecnologías de información y comunicación (TIC) y los adolescentes". 2005 <http://www.campus\&\#8211;oei.org/valores/monografias/mon ografia05/reflexion05.htm>

Borzekowski, D. L. G., \& Rickert, V. I. (2001): “Adolescents, the Internet, and health: Issues of access and content". Journal of Applied Developmental Psychology, 22, 49-59.

Camacho, I., Peñafiel, C. y Ronco, M. (2012): "Necesidad de una información sanitaria de calidad: análisis de las noticias sobre salud en la prensa vasca". Actas del III Congreso Internacional de la Asociación Española de Investigación de la Comunicación AE-IC "Comunicación y Riesgo". Tarragona

Camacho I. (2010): "Noticias sobre salud y medicina: mucho más que información”. En Camacho Markina, Idoia (ed.): La especialización en el periodismo. Formarse para informar. Comunicación Social, Zamora.

Cuesta y Menéndez (2009): Adicciones y nuevas tecnologías de la información y de la comunicación. Perspectivas de uso para la prevención y el tratamiento. Gobierno de La Rioja. 
Cuesta, Ugarte y Menéndez (2008): Comunicación y salud. Avances en modelos y estrategias de intervención Editorial Complutense, Madrid.

Del Pozo, Ferreras y Pérez (2008): Proyecto DROJNET. Cooperación Interregional Transfronteriza para desarrollo de Servicio de Información sobre las drogas interactivo y adaptado al público joven. Gobierno de La Rioja.

Del Pozo, Pérez y Ferreras (Coord., 2009): Adicciones y nuevas tecnologías de información y de comunicación. Perspectivas de uso para la prevención y el tratamiento. Gobierno de La Rioja, Logroño.

Del Pozo Irribarria (2009): "La utilización de las nuevas tecnologías de comunicación e información para la adopción de comportamientos saludables: el consumo de drogas" en Del Pozo, Pérez y Ferreras (Coords): Adicciones y nuevas tecnologías de información y de comunicación. Perspectivas de uso para la prevención y el tratamiento. Gobierno de La Rioja, Logroño.

Demiris (2006): "The diffusion of virtual communities in health care: concepts and challenges" en Revista Patient Educ Couns. Vol 62, 2.

Echegaray, L. y Ayestaran, A. (2012): "Base metodológica de la información de salud en la prensa escrita vasca (2001-2010)". Contribución en Comunicación y riesgo. AE-IC 2012, Universitat Rovira i Virgili, Tarragona.

Gabelas Barroso (2009): "Pantallas y jóvenes en el ágora del nuevo milenio" en Del Pozo, Pérez y Ferreras (Coords): Adicciones y nuevas tecnologías de información y de comunicación. Perspectivas de uso para la prevención y el tratamiento. Gobierno de La Rioja, Logroño.

Grande, I. y Abascal, E. (2007): Fundamentos y técnicas de investigación comercial. ESIC. Madrid.

Instituto de Información Sanitaria (2011): Barómetro Sanitario, 2010. Ed. Ministerio de Sanidad, Política Social e Igualdad, Madrid.

Janz y Becker (1984): “The health belief model: A decade later". En revista Health Education Quarterly, 11

Jiménez et al (2007): "Tendencias en el uso de Internet como fuente de información sobre salud” en Hernández, E. y Gómez- Zúñiga, B. (coord). Intervención en salud en la Red. UOC Papers [artículo en línea]. No 4 UOC.

< $\underline{\text { http://www.uoc.edu/uocpapers/4/dt/esp/jimenez.pdf }>}$ 
Jiménez y García (2006): "Health information seeking on the Internet in Spain: evolution or revolution?" in $11^{\text {th }}$ World Congress on Internet in Medicine. Toronto, Canadá. En Hernández y B. Gómez- Zúñiga (coord). Intervención en salud en la Red. UOC Papers [artículo en línea]. $\mathrm{N}^{\circ}$ 4. UOC. <http://www.uoc.edu/uocpapers/4/dt/esp/jimenez.pdf $>$

Lacoste, J.A., Megías, E., Tascón, C. y García-Camba E. (1999): La atención-prevención en drogodependencias a través de Internet. Beneficios y perjuicios. Encuentros Nacionales sobre Drogodependencias y su Enfoque Comunitario. CPD de Cádiz.

Mayer, M. A.; Leis, A. (2008): "La calidad de la información sanitaria en Internet, presente y futuro en Europa. Especial: La informática de la salud en Europa”. Revista I+S (abril 2008), núm. 68. Madrid, SEIS.

Mayer, M.A., Leis A., Lupiáñez, F., Terrón, J.L y García, L. (2008): "Elaboración de guías prácticas para el uso responsable de la información obtenida en Internet con fines sanitarios" en Informed2008, Actas del XII Congreso Nacional de Informática Médica.

Nafría (2007): Web 2.0. El usuario, el nuevo rey de Internet. Barcelona, Gestión 2000.

Organización Mundial de la Salud (OMS)(1995-2012): Informes sobre la salud en el mundo. Disponible en:

$<\underline{\text { http://www.who.int/whr/es/index.html }}>$

Peñafiel, C., Camacho, I., Ayestaran, A., Ronco, M. y Echegaray, L. (2014): "La divulgación de la información de salud: entre sectores implicados / Disclosure of Health Information: a challenge of trust between the various sectors envolved". Revista Latina de Comunicación Social, 69, pp. 135 a 151.

http://www.revistalatinacs.org/069/paper/1005 UPV/08c.html

Peñafiel, C. y Echegaray, L. (2014): "Periodistas y médicos, una simbiosis necesaria en el espacio mediático de la información de salud". Actas del IV Congreso de la Asociación Española de la Investigación en Comunicación Komunikazioak Eremuak / Espacios de Comunicación. AE-IC, Bilbao.

Peñafiel, C. y Echegaray, L. (2012): “La perspectiva del colectivo 
sanitario sobre los contenidos de salud en la prensa vasca". Actas IV Congreso Internacional Latina de la Comunicación Social, Universidad de La Laguna (diciembre 2012):

< http://www.revistalatinacs.org/12SLCS/2012 actas.html>

Poynter, R. (2010): The handbook of online and social media research. Tools and techniques for market researchers. Wiley. West Sussex.

Quart (2005): Marcados. La explotación comercial de los adolescentes. Debate. Barcelona.

Rice (2006): "Influences, usage, and outcomes of Internet health information searching: multivariate results from the Pew surveys". En revista International Journal of Medical Informatics. Vol. 75, 1.

Rojas y Cols (2007): Web 2.0. Manual (no oficial) de uso. Madrid: ESIC.

Ruiz Olabuénaga, J.I. (2006): Metodología de la investigación cualitativa. Bilbao: Deusto.

Thackeray, Neiger, Hanson \& Mckenzie (2008): "Enhancing promotional strategies within social marketing programs: Use of Web 2.0 social media". En Revista Health Promotion Practice Journal, Vol. 8, no 4 .

Tirado Pérez y Aguaded, J.I. (2004): El proyecto StopDrog@s: La teleformación como espacio intercultural para la prevención del consumo problemático de drogas en los entornos universitarios. Barcelona, EDUTEC.

Valles, M.S. (2007): Técnicas cualitativas de investigación social. Reflexión metodológica y práctica profesional. Síntesis Sociología, Madrid.

Van Riel, C.B.M. (1998): Comunicación corporativa (Trad. E. Cerdá) (2a Reimp.). Madrid: Prentice Hall.

Van Riel, C.B.M. y Fombrun, C. J. (2007): Essentials of corporate communication: implementing practices for effective reputation gestion. Abingdon, Oxon: Routledge.

Wright, K. B., Sparks, L. y O'Hair, D. (2008): Health communication in the $21^{\text {st }}$ century. Malden: Blackwell Pub. 



\section{Los autores}

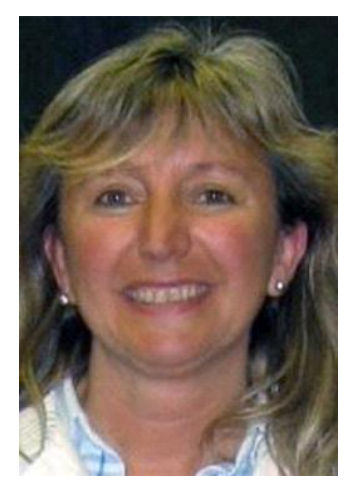

Carmen Peñafiel Saiz. Doctora en Periodismo (1992), Profesora Titular (1994), Acreditada Catedrática desde 2012. Ha trabajado en la Cadena SER, Radio Popular de Bilbao y Radio EuskadiEITB. Es experta en medios audiovisuales y ha participado en 18 proyectos de investigación siendo investigadora principal en 10, entre los que destaca un Proyecto Europeo de cuatro años de duración, siendo la Responsable de la UPV/EHU.

En su actividad investigadora se puede hablar de una creciente proyección internacional habiendo presentado resultados de las investigaciones en Bélgica, Francia, Inglaterra, Italia, Polonia, EE.UU, México y Chipre.

Ha sido miembro fundador del Grupo International Radio Research Network-IREN; miembro del Comité Científico del Grupo francés de Estudios de Radiodifusión-GRER; miembro de ECREA; es miembro de la Junta Directiva de la Asociación Española de Investigación de la Comunicación (AE-IC); forma parte del Institut de la Comunicació de la Universitat Autónoma de Barcelona (InCom$\mathrm{UAB}$ ); es miembro del grupo cmc-incom-uab con quien trabaja en una investigación $\mathrm{I}+\mathrm{D}+\mathrm{i}$ sobre las relaciones sociales de los jóvenes migrantes en Internet desde la perspectiva de la interculturalid; igualmente, forma parte del Grupo de Investigación COMAndalucía; actualmente dirige un proyecto de investigación subvencionado por la UPV/EHU sobre la información de salud dirigida a jóvenes y adolescentes en Internet.

Ha realizado estancias de investigación y de docencia en University of California-San Diego (USA); University of Nevada (USA); Basque Studies Center-Reno (USA); Institut for Informasjons og Medievitenskap University of Bergen (Noruega); TEC de Monterrey Campus de Toluca (México); University of New York (USA); The Freedom Forum Media Studies Center of Columbia University (USA). Actualmente, es la Responsable del Master Oficial en Comunicación Social de la UPV/EHU. 


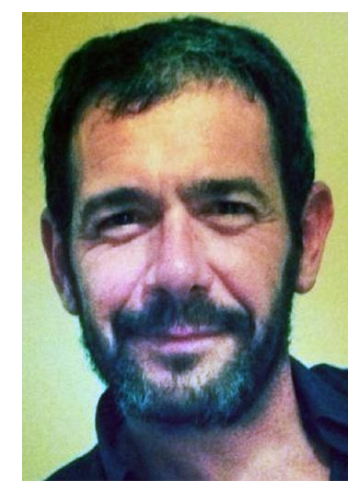

Lázaro Echegaray Eizaguirre. (Madrid 1971). Doctor por la Universidad del País Vasco/ Euskal Herriko Univertsitatea (2012) y Licenciado en Sociología por la Universidad de Granada (1998). Profesor en el área de Sociología e Investigación de Mercados en la Escuela Universitaria de la Cámara de Comercio de Bilbao.

Ha trabajado diferentes aspectos en el campo de la investigación de medios de comunicación y en la relación de éstos con la educación, la accesibilidad, las audiencias y los contenidos. También investiga aspectos relacionados con la comunicación en medios tradicionales e interactivos en temas de salud.

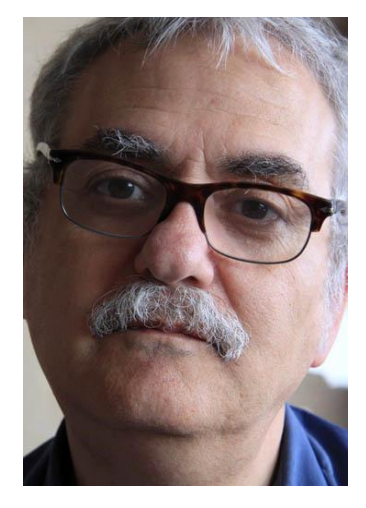

José Luis Terrón Blanco. Profesor Titular del Departament Comunicació Audiovisual i Publicitat de la Universitat Autònoma de Barcelona.

En la actualidad es director del Instituto de Comunicación (Incom-UAB) y Director del Observatorio de Comunicación y Salud (también integrado en el InCom-UAB), del que es fundador (marzo de 1996).

Forma parte del Consejo Editor de Cuadernos de Comunicación y Salud; de Revista Española de Salud Publica; y del Comité Científico de Communication Papers. $\mathrm{Ha}$ sido miembro del $\mathrm{I}+\mathrm{D}+\mathrm{i}$ " $\mathrm{La}$ publicidad de TV entre otros factores socioculturales influyentes en los TCA"; del FIS "Elaboración de guías prácticas para el uso responsable de la información obtenida en Internet y del correo electrónico con fines sanitarios" y Codirector de "Estrategias de evaluación de las campañas de salud. El caso de las campañas sobre el ictus" financiada por el Plan de Calidad para el Sistema Nacional de Salud.

Desde 2006 y hasta la fecha, es IP de una serie de investigaciones sobre el tratamiento del VIH/sida en los medios escritos españoles; desde 2012 estas investigaciones también se desarrollan en República Dominicana y México. Es autor de artículos y comunicaciones en publicaciones y congresos españoles e internacionales en torno a la comunicación y la salud. 


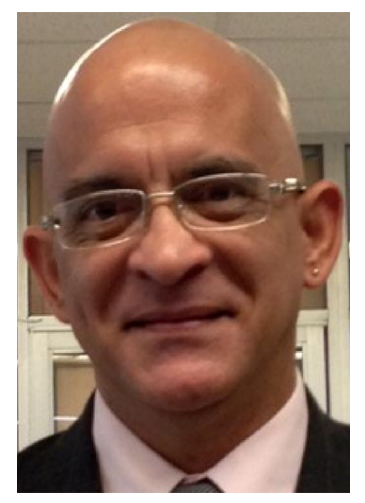

Carlos David Santamaría Ochoa, México, D.F. (1957), Licenciado en Relaciones Públicas, maestro en Trabajo Social con especialidad en Orientación Familiar, Maestro en Comunicación con énfasis en medios masivos (Universidad Autónoma de Tamaulipas); Doctor en Comunicación y Periodismo (Universidad de Santiago de Compostela, Galicia, España). Profesor investigador de tiempo completo en la Unidad Académica de Derecho y Ciencias Sociales (U.A.T.) Catedrático desde el año 2001.

Integrante del Cuerpo Académico "Comunicación Estratégica" de la UADCS.

Miembro de la Asociación Española de Investigación en la Comunicación desde 2014.

Periodista desde el año de 1979, fotógrafo, promotor de educación en diabetes.

Presidente de la Asociación Mexicana de Diabetes en Ciudad Victoria en dos ocasiones, presidente del Task Force de Consumidores de la región SACA (Sudamérica-Centroamérica) de la IDF (International Diabetes Federation, 1999), presidente de la Federación Mexicana de Diabetes A.C. período 2000-2002.

Editorialista en diversos periódicos, revistas y portales de circulación nacional y extranjera, investigador en comunicación.

Ha sido jefe de prensa en el Hospital General de Ciudad Victoria y en el Instituto Electoral de Tamaulipas, fotógrafo de prensa desde 1979 a la fecha, foto documentalista desde el año 1980.

Autor de libros como: Historia Gráfica de Tamaulipas (ITCA, 1989) y Diario del Camino (U.A.T., 2007), así como colaborador en diversas revistas de información diversa.

Como miembro de la Federación Mexicana de Diabetes se ha desempeñado como promotor de la educación sobre este padecimiento durante dos décadas. Fundador de la asociación "Vive con Diabetes A.C." 


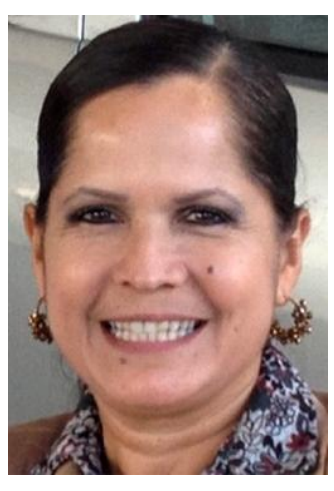

Blanca Guadalupe Cid de León Bujanos (Matamoros, México, 1959). Profesora investigadora, Unidad Académica de Trabajo Social y Ciencias para el Desarrollo Humano, Universidad Autónoma de Tamaulipas, México.

Licenciada en Trabajo Social, Maestra en Salud Pública, egresada de la Universidad Autónoma de Tamaulipas. Profesora de tiempo completo e investigadora en la Unidad Académica de Trabajo Social y Ciencias para el Desarrollo Humano de la Universidad Autónoma de Tamaulipas desde 1995.

Integrante del Grupo Disciplinar "Vulnerabilidad Social" de la misma Institución Universitaria. Jefe del departamento de Relaciones Públicas del Hospital General de Ciudad Victoria; jefe del departamento de Trabajo Social en el mismo hospital. Jefa del Departamento de Trabajo Social de la Secretaría de Salud en Tamaulipas. Cuenta con la Especialidad en Terapia Familiar, Diplomado en Gerencia Hospitalaria, Psicoterapia Gestáltica, en SICALIDAD, entre otros.

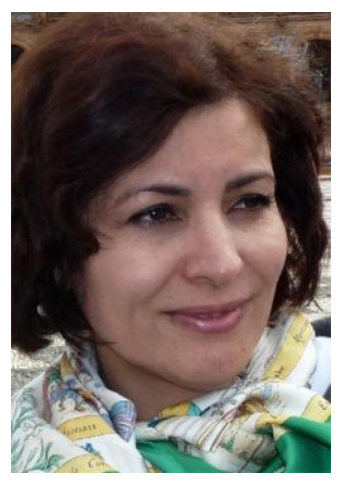

Flor Micaela Ramírez Leyva. Profesora Titular adscrita al Departamento de Psicología Centro Universitario de la Costa de la Universidad de Guadalajara. Licenciada en Medios Masivos de Comunicación y Maestra en Sociología de la Cultura, por la Universidad Autónoma de Aguascalientes.

Aspirante al Doctorado de Nuevos Modelos Periodísticos de la Universidad Miguel Hernández, de Elche, Alicante. Realizó una estancia de investigación sobre Comunicación y Salud en la Universidad de la Frontera, Chile.

Trabajó en la elaboración y difusión de contenidos en radio, televisión y revistas de Aguascalientes y Jalisco.

Es coautora del libro Voces regionales. Construcción de identidades a partir del mito, leyenda y relato popular en la Costa de Jalisco. UdG CUC Cuerpo Académico de Análisis Regional y Turismo. México, 2010.

Sus líneas de investigación son medios de comunicación y salud; poder, exclusión e inclusión social en Psicología Clínica; representaciones sociales y salud sexual de adolescentes; sobre estos 
tópicos cuenta con diversas publicaciones y conferencias. Pertenece al comité editorial de revistas de Temuco (Chile), Madrid y Cartagena de Indias (Colombia).

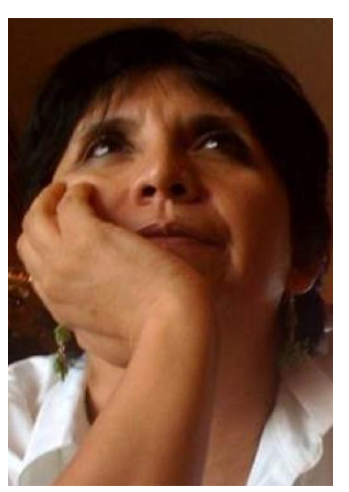

Leticia Castillo Quiñónez. Profesora investigadora en el Departamento de Ciencias Sociales de la Universidad Autónoma de Ciudad Juárez, en Ciudad Juárez, Chihuahua, México.

Fue periodista de medios impresos. Socióloga y maestra en Ciencias Sociales para el Diseño de Políticas Públicas en la terminal de Estudios Culturales. Estudiante del Doctorado en Investigación en El Colegio de Chihuahua.

Es autora de artículos académicos relativos a los siguientes temas: participación de audiencias en los medios, medios de comunicación y elecciones, mujeres en el periodismo chihuahuense, medios de comunicación y violencia social en Ciudad Juárez. Coordinó el testimonial Rostros y Voces de Victimas de Violencia en Ciudad Juárez. (2010).

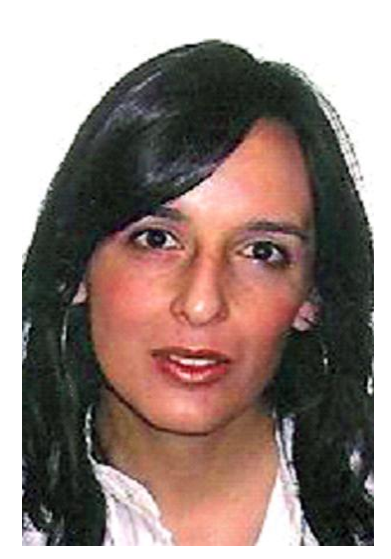

Paloma López Villafranca. Licenciada en Comunicación Audiovisual y Periodismo por la Universidad de Málaga. Máster en Gestión Estratégica e Innovación en Comunicación y doctoranda cuya línea de investigación versa sobre la comunicación sanitaria. Desde 2009 es profesora en la Universidad de Málaga en el Departamento de Comunicación Audiovisual y Publicidad.

Lleva dedicándose a la docencia en ámbito público y privado desde 1999. Profesional en los medios de comunicación desde 1998 a 2009. Ha trabajado como periodista para el Grupo Prisa, Recoletos, empresa privada y entidades municipales, además de colaborar en el año 1998 en RNE. En la actualidad está investigando sobre la comunicación de las asociaciones de pacientes que padecen enfermedades raras. 


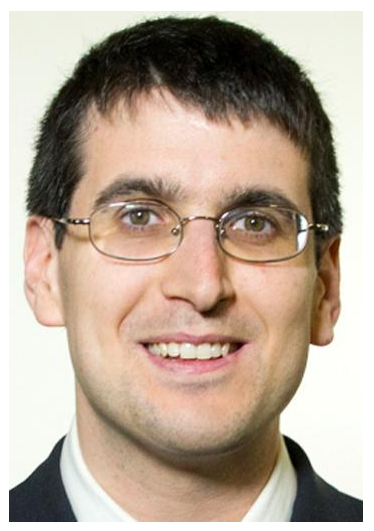

Pablo Medina Aguerrebere. Doctor en Comunicación Institucional (Universidad de Navarra, 2011). Ha publicado diferentes artículos científicos, libros y comunicaciones de congresos sobre el ámbito de la comunicación institucional en salud, y ha realizado estancias de investigación relacionadas con este tema en Suiza y Francia.

En la actualidad es profesor contratado doctor en la Facultad de Ciencias de la Comunicación de la Universitat Internacional de Catalunya, donde investiga sobre comunicación corporativa en organizaciones hospitalarias.

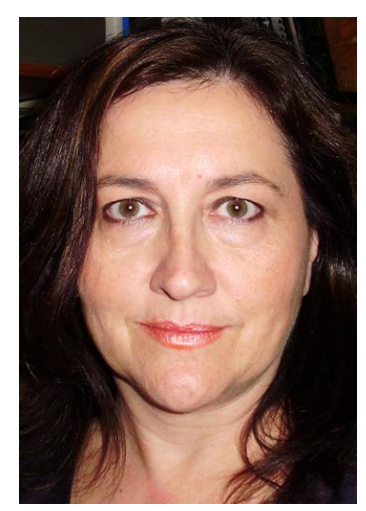

Elena López Parra. Médico Especialista en Medicina de Familia y Comunitaria.

Médico de Atención Primaria en el CS Universitario Cerro Almodóvar. Directora del Centro.

Coordinadora y Docente del Grupo Comunicación y Salud de la SoMaMFyC.

Profesora de Comunicación Asistencial y Entrevista Clínica.

Tutora de Médicos Internos Residentes de la especialidad de MFyC (Unidad Multiprofesional de Atención Familiar y Comunitaria de la Dirección Asistencial Sureste de Madrid).

Profesora en el Plan de Formación Transversal Común de residentes adscritos a las Unidades Docentes Multiprofesionales de Atención Familiar y Comunitaria de Madrid.

Médico Colaborador en Docencia Práctica Externa en la Facultad de Medicina de la Universidad Complutense de Madrid (UCM).

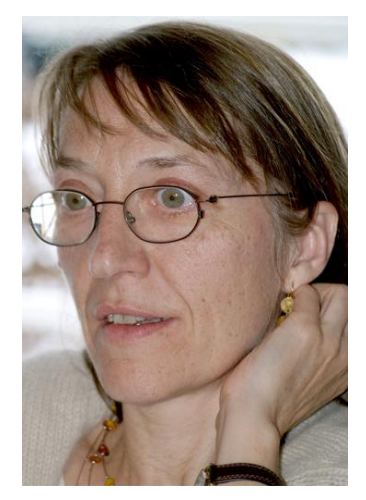

$\mathbf{M}^{\mathbf{a}}$ Concepción Álvarez Herrero. Especialista en

Medicina Familiar y Comunitaria.

Médico de Familia del Centro de Salud Universitario "V Centenario" (San Sebastián de los Reyes. Madrid).

Coordinadora y Docente del Grupo Comunicación y Salud de la Sociedad Madrileña de Medicina Familiar y Comunitaria de Madrid (GCyS de la SomamFYC). 
Profesora Asociada de Ciencias de la Salud en la Facultad de Medicina de la UAM (Universidad Autónoma de Madrid).

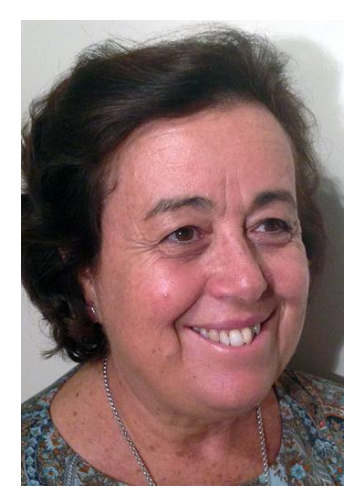

Paloma Elviro García. Trabaja en el Centro de Salud Ciudad de los Periodistas de Madrid, como médico de Atención Primaria y tutora de Residentes de Medicina Familiar y Comunitaria y de estudiantes de medicina.

Pertenece al Grupo-Programa de Comunicación y Salud de la Sociedad Española de Medicina Familiar y Comunitaria, del cual es miembro desde 1992. Especialista en Medicina Interna, imparte cursos de habilidades de comunicación en el ámbito clínico a estudiantes, residentes y distintos profesionales sanitarios tanto a nivel de atención primaria como hospitalaria.

Colaboradora docente de la Facultad de Medicina Autónoma de Madrid en la asignatura de Introducción a la Práctica Clínica y de la Universidad Complutense en la asignatura de Comunicación Clínica.

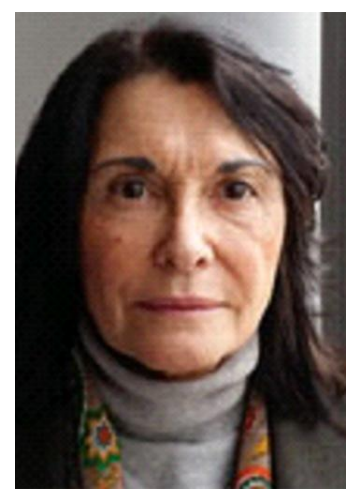

Milagros Ronco. Profesora Titular y experta en Documentación desde 1982. Es miembro de la Comisión Española de la UNESCO como Vocal del Grupo de Comunicación, desde 2000. Ha dirigido durante 8 años el Proyecto financiado por UNESCO Análisis de la relación existente a través de los medios de comunicación de la CAV con el País Vasco-Francés y Unión Europea (2000-08).

Ha participado en varios Proyectos de Investigación financiados por la UPV-EHU, siendo los más recientes Información de Salud en la Prensa Diaria Vasca (2000-2010) realizado en el bienio 2010-12 y Estudio de las webs de información de salud en español y euskera, dirigidas a jóvenes y adolescentes, proyecto que se encuentra en fase de realización durante el bienio 2012-14.

Es miembro fundador de la Asociación Vasca de Bibliotecarios, Archiveros y Documentalistas (ALDEE) integrada en la Federación de Asociaciones Nacionales de Archiveros, Bibliotecarios y Documentalistas (FESABID) 


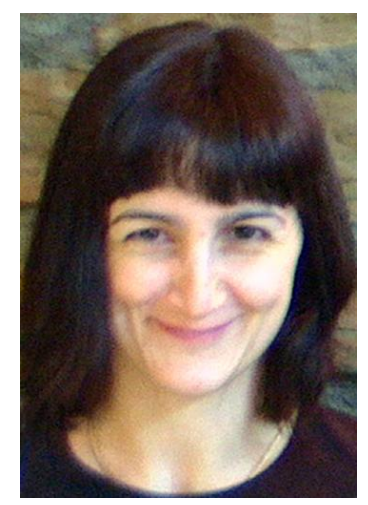

Idoia Camacho. Experta en Periodismo especializado con una vinculación UPV/EHU 2003 y en investigación 1998.

Destacan las contribuciones: Noticias sobre salud y medicina: mucho más que información in La especialización en el periodismo: Formarse para informar. Comunicación Social 2010; La gripe A en la prensa española, Revista Latina CS, 2009; El virus informativo de la gripe A: Análisis de la prensa española. Ponencia A Gripea: Honetatik ikasi duguna / Gripe A Lecciones aprendidas. Eusko Jaurlaritza/Dpto Sanidad y Consumo Bilbao, 2010; Pánico infundado. Tratamiento del brote de gripe A en la prensa española. I Congreso Internacional Latina de Comunicación Social, Universidad de La Laguna, 2009; El papel de los medios de comunicación como educadores en salud en XIII Jornadas Internacionales de Jóvenes Investigadores en Comunicación, Nuevos Retos de la Comunicación: Economía, Empresa y Sociedad, Universidad San Jorge, 2006.

Ha sido IP del Proyecto UPVEHU10/ 47 para el bienio 2011-12.

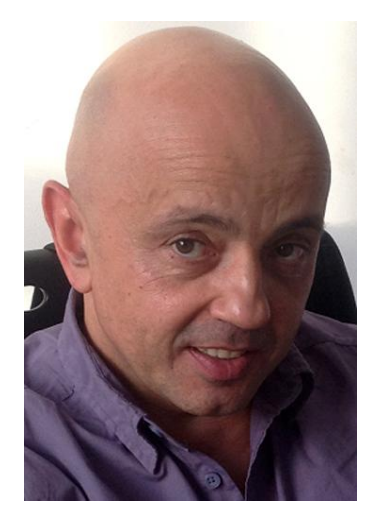

José Mari Pastor González (Barakaldo, 1961). Profesor del Departamento de Periodismo de la Universidad del País Vasco y doctor en Ciencias Sociales y de la Comunicación por la misma universidad. Ha trabajado durante más de 30 años en medios de comunicación tanto en lengua vasca como en castellano. Dio sus primeros pasos en el mundo de la información en el semanario

\section{Anaitasuna.}

Desde entonces ha desarrollado su actividad periodística en otros medios, entre los que destacan la ETB, televisión pública vasca, y el diario Euskaldunon Egunkaria. Su experiencia y conocimiento del medio audiovisual y de la programación de informativos del mismo le sirvieron como base para realizar su tesis doctoral sobre la información política del noticiero Gaur Egun.

Participa en proyectos de investigación reconocidos y financiados por la Universidad del País Vasco. Galardonado con el Premio de Periodismo Rikardo Arregi, el Premio de Periodismo Joan Cendrós y el Premio de Periodismo Argia (galardón colectivo a los periodistas 
de Internacional, cuya sección dirigía en el diario Berria), en la actualidad compagina la docencia con su labor de columnista en ese periódico y de tertuliano en el programa informativo Egun On Euskadi de la ETB.

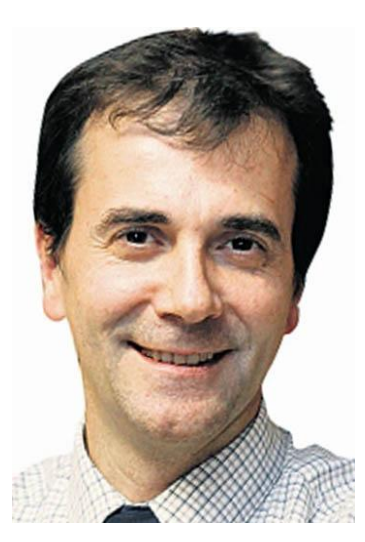

Fermín Apezteguia (Amorebieta, 1965). es licenciado en Periodismo por la Facultad de Ciencias Sociales y de la Comunicación de la Universidad del País Vasco (UPV-EHU) y está especializado en Salud.

En los años 80 contribuyó a impulsar la primera radio municipal de Euskadi, Zornotzako Udal Irratia, en Amorebieta (Bizkaia), aunque su carrera profesional se ha desarrollado de manera prácticamente íntegra en el diario El Correo (Bilbao) desde 1986. Ocupó el puesto de director de Comunicación del Departamento de Sanidad del Gobierno Vasco entre 2009 y 2010.

Es autor del libro Ahora que te tengo (sida en España 1997-2006) y colaborador del informe La noche de las víctimas (2009), del grupo Isavic, sobre las consecuencias para la salud de la violencia colectiva en Euskadi.

Impulsor y coordinador del programa Encuentros con la Salud de El Correo para la prevención, formación y divulgación del conocimiento científico, que cuenta con la asesoría de la Academia de Ciencias Médicas de Bilbao - a la que pertenece como miembro honorífico- y de la Facultad de Medicina y Odontología de la UPV-EHU.

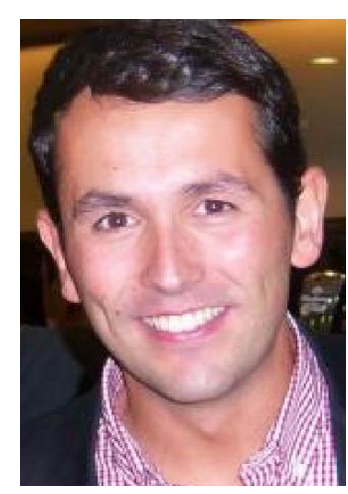

Daniel Catalán Matamoros. Licenciado en Publicidad y Relaciones Públicas, y Doctor Europeo por la Universidad de Málaga, MBA y Máster en Salud Pública por la Escuela Nórdica de Salud Pública. Autor y revisor de artículos en revistas científicas de comunicación y salud como Patient Education and Counselling, Gaceta Sanitaria y Revista Española de Salud Pública.

Ha participado como profesor y ponente en diversas Universidades y Congresos nacionales e internacionales. Ha trabajado en diversas organizaciones nacionales e internacionales, como la Comisión 
Europea, el Ministerio de Sanidad, Servicios Sociales e Igualdad de España, y en la Organización Mundial de la Salud.

Es socio-fundador y vicepresidente de la Asociación Española de Comunicación en Salud, así como Editor-Jefe de la Revista Española de Comunicación en Salud.

Actualmente, es profesor del Departamento de Periodismo y Comunicación Audiovisual de la Universidad Carlos III de Madrid.

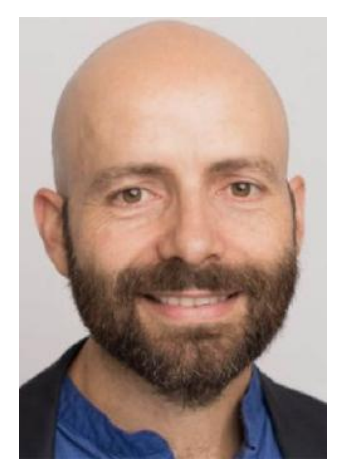

José Cerdán de las Heras. Licenciado en tecnologías de la información y E-business por la ITU de Copenaguen, Dinamarca.

Master y Bachelor en fisioterapia por la Universidad de Gotemburgo, Suecia.

Creador del portal web para pacientes crónicos del hospital Hvidovre de Copenhagen (Dinamarca) www.patientpjecen.dk y de la herramienta de telemedicina www.optimov.com

Ha trabajado como fisioterapeuta en distintos centros de rehabilitación, clínicas y hospitales, tanto privados como públicos en 5 países de Europa.

Actualmente reside en Copenhague, donde trabaja como director científico de la herramienta Optimov. 


\section{Comunicación y Sociedad}
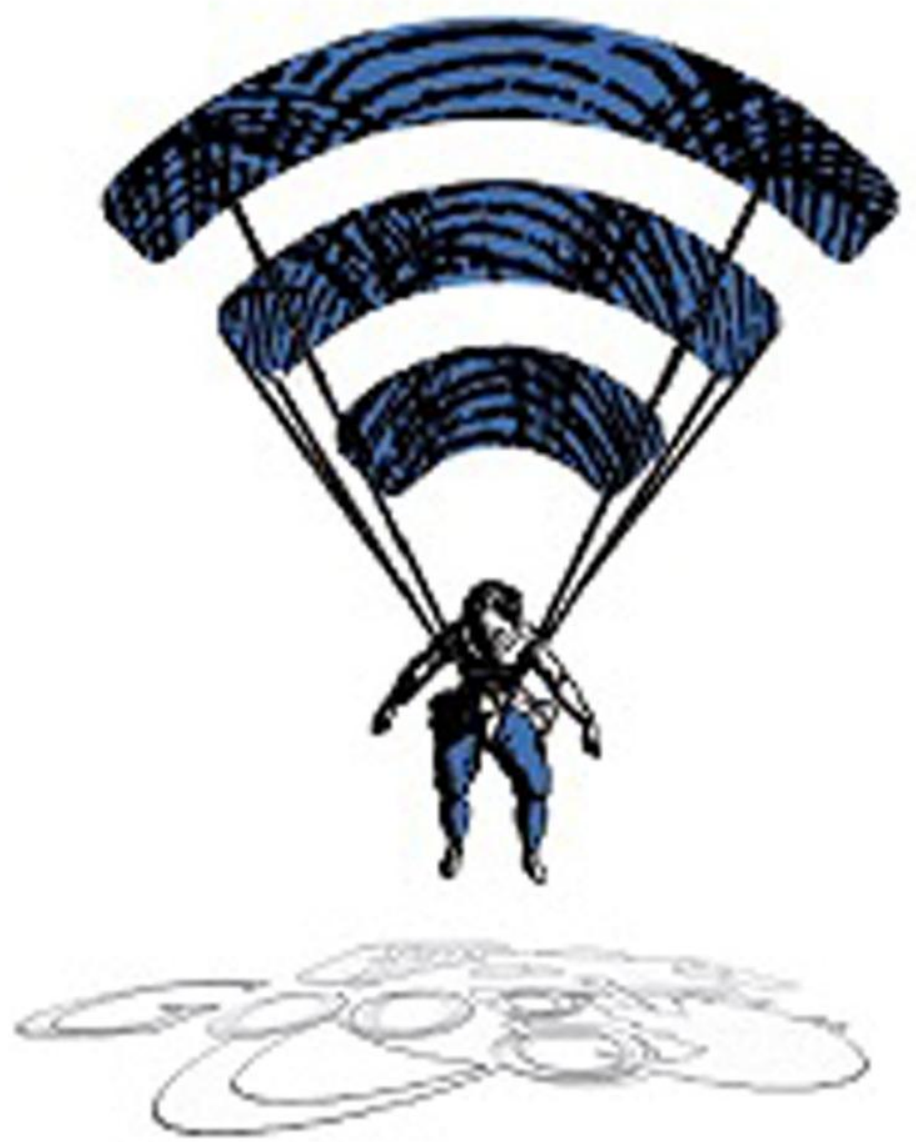

Degartamenco de Esnubixs de la Comunicación Social Universidad de Guadalajara

Revista Comunicación y Sociedad (Universidad de Guadalajara, México), número 22 (nueva época) enero-junio de 2014, http://www.comunicacionysociedad.cucsh.udg.mx 